\title{
Effort related energy expenditure in patients with chronic obstructive pulmonary disease
}

Citation for published version (APA):

Baarends, E. M. (1997). Effort related energy expenditure in patients with chronic obstructive pulmonary disease. [Doctoral Thesis, Maastricht University]. Maastricht University.

https://doi.org/10.26481/dis.19971106eb

Document status and date:

Published: 01/01/1997

DOI:

10.26481/dis.19971106eb

Document Version:

Publisher's PDF, also known as Version of record

\section{Please check the document version of this publication:}

- A submitted manuscript is the version of the article upon submission and before peer-review. There can be important differences between the submitted version and the official published version of record.

People interested in the research are advised to contact the author for the final version of the publication, or visit the DOI to the publisher's website.

- The final author version and the galley proof are versions of the publication after peer review.

- The final published version features the final layout of the paper including the volume, issue and page numbers.

Link to publication

\footnotetext{
General rights rights.

- You may freely distribute the URL identifying the publication in the public portal. please follow below link for the End User Agreement:

www.umlib.nl/taverne-license

Take down policy

If you believe that this document breaches copyright please contact us at:

repository@maastrichtuniversity.nl

providing details and we will investigate your claim.
}

Copyright and moral rights for the publications made accessible in the public portal are retained by the authors and/or other copyright owners and it is a condition of accessing publications that users recognise and abide by the legal requirements associated with these

- Users may download and print one copy of any publication from the public portal for the purpose of private study or research.

- You may not further distribute the material or use it for any profit-making activity or commercial gain

If the publication is distributed under the terms of Article $25 \mathrm{fa}$ of the Dutch Copyright Act, indicated by the "Taverne" license above, 
EFFORT RELATED ENERGY EXPENDITURE IN PATIENTS WITH

CHRONIC OBSTRUCTIVE PULMONARY DISEASE 
Onslag: Hendrikje van Dijk

Druk: Ponsen en Looijen b.v.

ISBN nr: $90-9010986-2$

EErica Baarends

Het beschreven onderzoek werd gesubsidieerd door het Nederlands Astma Fonds (project 91.38)

De publicatie van dit proefschrift werd gesponsord door Nutricia Nederland b.v. 


\section{CHRONIC OBSTRUCTIVE PULMONARY DISEASE}

\section{PROEFSCHRIFT}

ter verkrijging van de graad van doctor aan de Universiteit Maastricht, op gezag van de Rector Magnificus, Prof. Mr. M.J. Cohen, volgens het besluit van het College van Decanen in het openbaar te verdedigen op donderdag 6 november 1997 om 14.00 uur

$$
\text { door }
$$

Erica Maria Barends 


\section{Promotor}

Prof. Dr. E.F.M. Wouters

\section{Co-promotor}

Dr. Ir. A.M.W.J. Schols

\section{Beoordelingscommissie}

Prof. Dr. G.J. van der Vusse (voorzitter)

Prof. Dr. M. Decramer (Katholieke Universiteit Leuven, België)

Dr. J.W. Fitting (Université Vaudois, Zwitserland)

Prof. Dr. W.H.M. Saris

Prof. Dr. P. B. Soeters 
CHAPTER 1: GENERAL INTRODUCTION

CHAPTER 2: ANALYSIS OF BODY WATER COMPARTMENTS IN RELATION TO TISSUE DEPLETION IN CLINICALLY STABLE PATIENTS With Chronic Obstructive Pulmonary Disease.

CHAPTER 3: BODY-WATER COMPARTMENTS MEASURED BY BIOELECTRICAL IMPEDANCE SPECTROSCOPY IN PATIENTS WITH Chronic Obstructive Pulmonary Disease.

CHAPTER 4: TOTAL FREE LIVING ENERGY EXPENDITURE IN PATIENTS WITH SEVERE CHRONIC OBSTRUCTIVE PULMONARY Disease.

CHAPTER 5: TOTAL DALY ENERGY EXPENDITURE RELATIVE TO RESTING ENERGY EXPENDITURE IN CLINICALLY STABLE PATIENTS With Chronic Obstructive Pulmonary Disease.

CHAPTER 6: ANALYSIS OF THE METABOLIC AND VENTILATORY RESPONSE TO SELF-PACED 12 MINUTE TREADMILL WALKING IN PATIENTS WITH SEVERE CHRONIC OBSTRUCTIVE PULMONARY DISEASE.

CHAPTER 7: PEAK EXERCISE RESPONSE IN RELATION TO TISSUE DEPLETION IN PATHENTS WITH CHRONIC OBSTRUCTIVE PULMONARY DISEASE.

CHAPTER 8: DECREASED MECHANICAL EFFICIENCY IN CLINICALLY STABLE PATIENTS WITH CHRONIC OBSTRUCTIVE Pulmonary DISEASE. 
CHAPTER 9: METABOLIC AND VENTLLATORY RESPONSE PATTERN TO ARM

ELEVATION IN PATIENTS WITH CHRONIC OBSTRUCTIVE

PULMONARY DISEASE AND hEALTHY AGE-MATCHED

SUBJECTS.

CHAPTER 10: BREATHING EFFICIENCY DURING INSPIRATORY THRESHOLD

LOADING IN PATIENTS WITH CHRONIC OBSTRUCTIVE

PULMONARY DISEASE.

CHAPTER 11: GenERAL Discussion.

ABBREVIATIONS

SUMMARY

SAMENVATTING

DANKWOORD

Publicaties

Curriculum VitaE 
GENERAL NTRODUCTION 


\section{Chronic Obstructive Pulmonary Disease}

Chronic obstructive pulmonary disease (COPD) represents an important health care problem. In general practice roughly 73 per 1000 persons are diagnosed as having COPD, but studies performed in random populations in the Netherlands indicate that the actual prevalence is higher'. It is furthermore estimated that the prevalence will increase up to $33 \%$ from 1990 until $2010^{\prime}$. In addition, COPD represents at present the fourth cause of death in the Netherlands ${ }^{2}$, and will be the third leading cause of death worldwide in 2020 , with an expected mortality of 4.7 million persons each year ${ }^{3}$.

The American Thoracic Society and the European Respiratory Society (ERS) define COPD as a disorder indicated by tests of abnormal expiratory airflow, that do not change markedly over periods of several months. This definition refers to the chronic nature of the disease, thus to the fact that the disease cannot be cured. In the presence of a limited farmacotherapeutic outcome, it is important to focus not only on prevention of further deterioration of lung function, but also on other determining factors contributing to the experienced morbidity in patients suffering from this chronic disorder. The World Health Organization has developed a model to structure the various aspects of chronic disorders. Using this model, not only the impaiment (anatomical, physiological or psychological abnomalities) associated with the disease is described. but also the impact of the disease on the ability to perform activities (disablement), which ultimately affects the patients sociall life (handicap) ${ }^{6}$.

\section{Impaiment in COPD}

COPD is characterized by a number of structural changes in the respiratory system. Traditionally, a division is made between the chronic bronchitis and emphysema subtypes of COPD. In short, chronic bronchitis is predominantly characterized by chronic or recurrent excessive mucus production and emphysema is a condition of the lung characterized by permanent, abnormal enlargement of airspaces?. However, combinations of the characteristics ascribed to either chronic bronchitis or emphysema frequently occurt.

According to the ERS concensus statement ${ }^{3}$ both disorders are characterized by reduced maximum expiratory flow and slow forced emptying of the lungs. The expiratory airflow is limited by varying combinations of pathologies such as a diminished driving 
pressure by loss of the elastic recoil of the lung tissue and narrowing of the large and small airways ${ }^{7}$. The limitation of expiratory airflow is usually irreversible and shows an abnormal rapid progressive deterioration with age.

In addition to the decreased expiratory airflow, particularly the structural changes of the lung parenchyma result in a decreased diffusing capacity of the lung, and thereby an impaired gas exchange. The efficiency of gas exchange is dependent on the balance between alveolar ventilation and pulmonary blood flow (perfusion). An impaired oxygenation of the blood especially occurs in emphysema, due to the destruction of gasexchange units, but it is also present in chronic bronchitis, due to regions of appreciable ventilation to perfusion mis-match.

Airflow limitation in COPD is an expiratory phenomenon and is resistive in nature. Paradoxically, there is growing evidence that the functional consequences are encountered in inspiration and are primarily restrictive in nature, due to dysfunctioning of the ventilatory pump ${ }^{8.9}$. In patients with COPD, the inspiratory muscles need to generate more force than normal in order to move air into the lungs, due to increased airflow resistance and reduced dynamic pulmonary compliance ${ }^{x}$. Furthermore, due to an inefficient gas exchange, minute ventilation at rest is in general slightly greater in patients with COPD than in healthy subjects ${ }^{8}$. In addition, changes in the elastic properties of the lungs and chest wall can lead to an increase in the relaxation volume of the respiratory system. This increase in functional residual capacity (FRC) is defined as chronic hyperinflation". It has been suggested that the inspiratory muscles operate at shorter than normal length resulting from the increased FRC and therefore have a reduced ability to lower intrathoracic pressure ${ }^{*}$. Recent experimental research indicates, however, that diaphragm muscle length can be shortened, and that possibly also other adaptations to a chronic overload of the muscle occur, which preserve the ability to reach a maximal tension". This linding was confirmed by a recent study of Similowski ${ }^{10}$, showing that patients with COPD express a higher transdiaphragmatic pressure than expected on the basis of an increased lung volume. The reported decreased zone of apposition in patients with COPD probably represents a more important mechanical disadvantage, particularly for the diaphragm*. Taken together, the force-generating capacity of the respiratory system as a whole is decreased". Furthermore, respiratory muscle endurance is decreased in these patients ${ }^{13}$. In severe COPD, the chronic hyperinflation can be further accentuated by a variable degree of dynamic pulmonary hyperinflation. In the setting of increased ventilatory demand, such as during exercise, when expiratory flow is reduced and expiratory time is 
prolonged, inspiration begins before lung volume has declined to the level normally dictated by the balance of static recoil of the lung and chest wall, resulting in an increased end-expiratory lung volume ${ }^{13.14}$. Dynamic hyperinflation results in a blunted tidal volume response to exercise and increases the elastic load against which the inspiratory muscles must operate, while at the same time it reduces the efficacy of these muscles as pressure generators ${ }^{13.14}$.

In addition to this local impairment, during the last decade increasing attention is given to metabolic disturbances associated with COPD. A substantial part of patients with COPD suffers from weight loss. The prevalence of a decreased body weight depends on the population studied, but varies between $25-48 \%$ in clinically stable patients with COPD eligible for pulmonary rehabilitation ${ }^{15}$ and $20 \%$ in stable out-patients ${ }^{16}$. Furthermore, patients with COPD can suffer from a decreased fat-free mass (FFM), even when body weight is normal ${ }^{15}$. A disturbed body composition affects the clinical condition in COPD, as shown from the significantly reduced respiratory and peripheral muscle weakness ${ }^{17}$, especially in those patients with a disturbed body composition ${ }^{15.16}$. Furthermore, a low body weight is found to have an adverse effect on survival ${ }^{18-21}$.

In general, a decrease in body weight occurs when an individual is in a negative energy balance, i.e. when energy expenditure exceeds energy intake. Several studies have shown that energy intake in patients with COPD is comparable to the intake of healthy age-matched subjects ${ }^{22.23}$. During the past years the attention has therefore primarily been focused on the energy expenditure of patients with COPD. An increased resting energy expenditure (REE) has been found in a marked part of patients with COPD $^{23-28}$. These findings have lead to the hypothesis that the energy intake in weight-losing patients with COPD is probably insufficient for the increased energy expenditure, based on the assumption that REE is representative for total daily energy expenditure in sedentary subjects.

\section{Disablement in COPD}

The most prominent symptom experienced by patients with COPD is dyspnea, which mostly occurs during activities, but also at rest. Studies concerning physiological mechanisms leading to dyspnea in patients with COPD have demonstrated that airflow limitation is not strongly related to dyspnea, since a great inter-subject variation exists in the relationship between dyspnea and the proportion ventilatory demand to ventilatory capacity $^{43}$. Increasing evidence suggests that dynamic hyperinflation represents an 
important intrinsic mechanical loading resulting in the sensation of dyspnea ${ }^{14}$. Following a theoretical concept, described by $O^{\prime}$ Domell ${ }^{13}$, the sensation of dyspnea may has its physiologic origin in a neuroventilatory dissociation of the respiratory pump. In healthy subjects, a harmonious relationship exists between the level of inspiratory muscle activity, or perceived effort, and the anticipated ventilatory consequence. In patients with COPD, the relationship between inspiratory effort and the anticipated ventilatory consequence is seriously disrupted, as a consequence of impeded inspiratory muscle action and respiratory weakness due to dynamic hyperinflation ${ }^{13}$.

Furthermore, the impairment associated with COPD leads to a markedly decreased exercise capacity. Approximately 10 years ago, Wasserman introduced a model in order to explain the observed impaired exercise tolerance. This model visualized the functional coupling of the rates of ventilation and circulation to the metabolic activity of the muscle ceil $^{29}$. In patients with COPD the ventilatory capacity is reduced due to airflow obstruction and the ventilatory requirement is increased due to ventilation-perfusion mis-matching. During exercise this may pose a serious problem, since the "external respiration" must keep pace with the increased respiration of the muscle cell during exercise, in order to allow venous blood to be oxygenated and to maintain arterial carbon dioxide and hydrogen ion homeostasis. These limiting factors for exercise, which are related to the pulmonary (local) impairment, are mostly irreversible and prone to further deterioration.

Recent research provides evidence for a direct role of muscle disfunctioning in exercise limitation in patients with COPD. It has been shown by Killian et al. ${ }^{30}$ that most. patients with COPD experience not only dyspnea but also muscular fatigue as symptoms limiting exercise. In addition, Hamilton et al. ${ }^{17}$ showed a decreased peripheral muscle strength in patients with pulmonary diseases, which was related to a decreased work capacity and an increased sensation of discomfort'"

In addition, recent studies ${ }^{31-34}$ demonstrated a reduced oxidative capacity of the skeletal muscle of patients with COPD, due to a reduced activity of oxidative enzymes, accompanied by an augmented anaerobic glycolysis. Maltais et al. ${ }^{34}$ demonstrated that patients with COPD expressed a steeper increase in lactic acid during exercise compared to healthy subjects, which was significantly related to the reduced activity of oxidative enzymes. Combined with preliminary results that blood flow and the oxygen extraction rates of peripheral muscle are not decreased in COPD ${ }^{35}$, it is suggested that not oxygen delivery to the muscle cells, but oxygen utilization in these cells is a determining factor of exercise limitation in patients with COPD. 
Muscle metabolism and muscle function are closely related to body composin$\mathrm{on}^{36,37}$. As mentioned earlier, a disturbed body composition is a common feature in patients with COPD. The relationship between body composition and muscle function or exercise capacity in patients with COPD is indicated by an earlier study by Schols et al., showing that FFM was an independent determinant of the 12 minute walking distance in patients with $\mathrm{COPD}^{38}$ :

Other factors that might contribute to muscle weakness or decreased exercise capacity are the frequently administered steroid medication ${ }^{39}$ and deconditioning. In contrast to the local impairment that limits exercise tolerance in COPD, it has been demonstrated that the disturbed body composition and the deconditioned state in patients with COPD are reversible by means of a controlled nutritional intervention, exercise training or other anabolic stimuli, resulting in an increase in exercise capacity or muscle strengtot ${ }^{40-43}$.

\section{Handicap in COPD and goals of pulmonary rehabilitation}

It is important to determine to which extent the impairment and disablement associated with COPD ultimately affect the patient's life. The progressive and debilitating physical illness can lead to profound psychosocial problems. One of the most commonly reported psychological consequences of COPD is depression ${ }^{44-46}$. Sources of depression range from negative self-assessment to decreased social contacts. Anxiety manifested in various ways is another commonly reported consequence of $\mathrm{COPD}^{47}$. In addition to these symptoms, several other emotional consequences have been described including irritability, somatic preoccupation, frustration ${ }^{44}$ as well as a sense of embarrassment ${ }^{48}$.

Quantification of the impact of disease on daily life and well being can be obtained by health-related quality of life (HRQL) questionnaires. Studies evaluating disease-specific HRQL generally report a severely decreased quality of life in COPD ${ }^{49.50}$. The perceived quality of life cannot be predicted by the degree of lung function impairment ${ }^{5 i}$. In contrast, several studies have shown a significant correlation between exercise performance and (specific aspects of) quality of life $\mathrm{f}^{50}$.

From the summarized characteristics of COPD it is clear that it represents a complex disease, involving local as well as systemic disturbances, accompanied by dyspnea and a decreased exercise capacity, ultimately leading to a decreased quality of life. In general, the primary treatment for patients with COPD is directed at improving 
airflow obstruction by bronchodilators and anti-inflammatory agents. However, medical treatment has only partial success in alleviating symptoms and improving functional capacity.

Pulmonary rehabilitation addresses to the functional deficit with a comprehensive multidisciplinary programme. The most important goal in the rehabilitation of patients with COPD is the achievenent of an optimal daily functioning and health related quality of life of individual patients. The components of a pulmonary rehabilitation programme should therefore include an optimal medical treatment, snoking cessation programmes, chest physiotherapy, education, psychological support, nutritional therapy, nursing care,

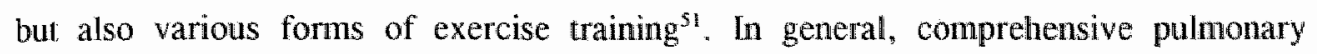
rehabilitation programmes benefit patients with COPD by an improvement of exercise endurance, a reduction of dyspnea, and an increase in quality of life $e^{52,53}$.

\section{Aim of the study}

In order to conduct an individually tailored rehabilitation program, aimed to improve the daily functioning and quality of life of patients with COPD, characterization of patients with COPD is important, since it is likely that the summarized impairments and disablements will vary between individuals, which leads to the need for different treatment strategies. In addition, in order to provide a foundation for potential treatment strategies, knowledge of the underlying mechanisms associated with the disablements in COPD is important. In this respect the previously reported alterations in energy expenditure, body composition and exercise physiology of patients with COPD need further investigation.

The aim of the research reported in this thesis was to analyze clanges in body composition and energy expenditure of patients with COPD in more detail, and to investigate the relationship between these changes and exercise performance. Therefore, actually three sub-aims can be defined:

1 to obtain a more detailed characterization of patients with COPD concerning body composition

2 to obtain a comprehensive analysis of total daily energy expenditure in patients with COPD

3 to obtain an analysis of the metabolic and ventillatory response to activities or exercise, taken a potential relationship with body composition into account. 
Insight in the metabolic consequences of activities and exercise might be translated into grounded treatment tools or goals in the rehabilitation of COPD.

\section{Outline of the thesiss}

Firstly, in chapter 2 and chapter 3 the impairment in body composition is studied in more detail. Body weight can be divided into FFM and fat mass. FFM can be further subdivided into two components: the intracellular part, which is also defined as the "metabolic active tissue mass" , and the extracellular part. It is examined whether depletion of FFM in patients with COPD is accompanied by shifts between the intracellular- and extracellular compartment. In addition, it is studied if these bodycompartments can be measured accurately by means of a recently introduced clinically applicable method: bioelectrical impedance spectroscopy.

Secondly, total free living daily energy expenditure (TDE) is studied in patients with COPD and healthy elderly persons (chapter 4). The effect of an increased REE on TDE is reported in chapter 5 .

The third part of this thesis is focused on exercise performance. In Chapter 6 the metabolic and ventilatory stress of a generally assumed submaximal exercise performance test, the 12 minute walking test, is investigated. Furthermore, the contribution of lung function and body-composition to the variation in peak metabolic capacity in patients witl COPD is studied comprehensively in chapter 7.

In the final part three studies, investigating the physiological response to activities are reported, in order to examine the efficiency of converting energy into activities in patients with COPD. In chapter 8 and 9 the mechanical efficiency and the physiological response pattern to cycle ergometry and a simple static arm-activity respectively are analyzed in patients with COPD. Finally, in chapter 10 breathing efficiancy is investigated in order to discuss its potentiall role in the energy expenditure at rest and during activities.

\section{References}

I Rijksinstituut voor volksgezondheid en milleuhygiene (National institute of public health and enviromental protection). Volksgezondheid toekomst werkenning. De gezondheidstoestand van de Nederlands hevolking in che periode 1950-2010 (Public health status and torecasts. The hezlth status of the Dutch population over the period 1950-2010.) Part II. Ruward D, Kramer PGN, eds. Sdu Uitgeverij Plantijnsiraat, The Hague, 1993.

2 Central bureau voor de staistiek. Sterfe nar belangrijkste doodsoorzaken $1970-1990$ (M ortality. hy importani causios od death 1970-1990). Sdu Uitgeverij Plantijnstrant, The Hague, 1992. 
WHO personal conmunication

American Thoracic Society. Standards for the diagnoses and cart of patients with chronic obstructive pulnonary disease (COPD) and asthina. Am. 2. Respir. Crit. Care Med. 1995: 152: $877-120$.

European Respiratory Society. Optimal assessment and management of chronic obstrnctive pulimouaty disease. Eur. Respir. J. 1995; 8: 1398-1420.

World Health Organisation. International classification of impaiments, disabilities and handicaps. Geneva: WHO, 1980.

Thurlbeck WM. Pathophysiology of Chronic Obstructive Pulmonary Disease. Clin. Cliest Med. 1990: 1.1: 389-404.

Troyer de A. Effeci of hyperinflation on the diaphragm. Eur. Respir. J. 1997: 10: 708-713.

Gibson GJ. Pulmonary hyperinthation a clinical overview. Eur. Respir. J. 1996: 9: 2640-2649.

Similowski T, Yan S. Gauthier AP, Macklem PT, Bellenkare F. Contractile properties of the human diaphragm during chronic hyperinflation. N. Eng. J. Med. 1991; 325:917-923.

Decramer M, Demed ts M. Rochete F. Billiet L. Maximal transrespiratory pressures in obstructive lung disease. Bull. Eur. Physiopathol, Respir. 1980; 16: 479-90.

Morrison NJ, Richardson J, Dunn L. Pardy RL. Respiratory muscle perfomance in nomall elderly subjects and patients with COPD. Chest 1989; 95: 90-94.

$\mathrm{O}^{\prime}$ Donnell $\mathrm{DE}$. Breathlessness in patients with chronic airflow limitations. Mechanisns and management. Chest 1994; 106: 901-912.

O'Donnell DE. Webb KA. Exertional breathlessness in patients with chronic airflow limitation. The role of lung hyperinflation. Am. Rew. Respir. Dis. 1993; 148: 1351-7.

Schols AMWJ, Soeters PB. Dingemans ANC. Mostert R, Frantzen PJ, Wouters EFM: Prevalence and characteristics of nutritional depletion in patients with COPD egligble for pulmonary rehabilitation. Am. Rev. of Resp. Dis. 1993; 147; 1151-1156.

Engelen MPKJ, Schols AMWJ. Baken WC, Wesseling GJ, Wouters EFM. Nutritional depletion in relation to respiratory and peripheral skeletal muscle function in out-patients with COPD. Eur. Respir. J. 1994; 7: 1793-1797.

7 Hamilton AL. Killian KJ, Summers E, Jones NL. Muscle strength, symptom intensity, and exercise Capacity in patients with cardiorespiratory disorders. Am. J. Respir. Crit. Care Med. 1995: 152: 202131.

Vandenbergh $\mathrm{E}$, an de Woestijne $K$, Gyselen $\mathrm{A}$. Weight changes in the terminal stages of chronic obstructive lung disease. Am. Rev. Respir. Dis. 1967: 95: 556-66.

Wilson DO, Rogers RM, Wright E, Anthonisen NR. Body weight in chronic obstructive pulmonary disease. Am. Rev. Respir. Dis. 1989; 139: 1435-8.

Gray-donald K, Gibbons L, Shapiro SH, Macklem PT, Martin JG. Nutritional status and mortality in cluronic obstructive pulmonary disease. Am. J. Respir. Crit. Care Med. 1996: 153: 1961-6.

Chailleux E. Fauroux B, Binet F., Danczenherg B, Polu $\mathrm{d}$. Predictors of survival in patients receiving domiciliary oxygen therapy or mechanical ventilation. A 10 -year analysis of ANTADIR observatory. Chest 1996: 109: $74: 49$.

Hunter AMB, Carey MA, Larsh HW. The nutritional stans of patiens with chronic obstructive pulmonary disease. Am. Rev. Respir. Dis. 1981: 124: 376-81.

Schols AMWJ, Soeters PB. Saris WHM, Wouters EFM. Energy balance id patients with chitonic obstructive pulmonary disease. Am. Rev. Respir. Dis. 1991: 143: 1248-1252.

Schols AMWI. Fredrix WWHM. Soeters PB. Westerterp KR. Wouters EFM. Resting energy expenditure in patients with chronic obstructive pulnonary disease. Ant. J. Clin. Nutr, 1991: 54: 983-7.

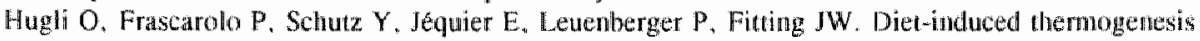
in cluronic obstructive pulmonary disease. Am. Rev. Respir. Dis. 1993: 148: 1479-83.

Fining JW, Fiacarolo P. Jequier E. Leuenberger P. Energy expenditure and rib cage-abdonimal motion In chronic obstructive pulmonary discase. Eur. Respir. J. 1989; 2: 840-45.

Donahoe M. Rogers RM. Wilson DO, Pennock BE. Oxygen consumption of the respiratory muscles in nomal and in malnourished pattenis with chronic obstructive pulmonary disease. Am. Rev. Respir. Dis. 1989; 140: 385-91.

Green JH, Muers MF. The themic effects of food in underweight patients with emphysemausus cluronic ohstructive pulmonary disease. Eur. Respir. J. 1991:4: 813-9. 
Brown $H V$, Wasseman $\mathbb{K}$. Exercise performance in chronic obstructive pulfnonary duseases. Med. Cin. North Anerica. 1981:65: 525-547.

KJilian KJ. LeBlanc P. Martin DH. Summers E. Jones NH. Campbell EJM. Exercise capacity and ventilatory, circulatory, and symptom limitation in patients with chronic airflow limitation. An. Rev. Respir. Dis. 1992: 146: 935-940.

31 Piaccadori E, Canale Del S, Vitali P, Coffrini E, Ronda N, Guariglia A. Skeletal muscle energetics. acid-base equilibrium and lactae metabolism in patients with severe hypercapua and hypoxemia. Chest 1987: 92: $883-887$.

Geriz 1 , Hedenstierna $G$, Hellers $G$, Wallen J. Muscle netabolism in patiens with chronic obstructive lung disease and acute respiratory failure. Cli. Sci.\& Mol. Med. 1977; 52: 395-403.

Jakobsson P. Jorfetdt L, Henriksson J. Metabolic enzyme activity in the quadriceps femoris muscle in patients widh severe chronic obstructiwe pulmonary disease. Am. J. Respir. Crit. Care Med. 1995: 151 : 374-377.

Maltais F, Simard A, Simard C. Jobin J. Descagnés P, LeBlanc P. Oxidative capacity of the skeletal muscle and lactic acid kinetics during exercise in normal subjects and in patients with COPD. Am. J. Respir. Cril. Care Med. 1996; 153: 288-293.

Maltais F, Jobin J. Sullivan MJ. Bernard $S$. Whittom F, Killian KJ. Desmeules $M$, Belanger $M$, LeBlanc P. Lower limb metabollic and hemodynamic responses during exercise in nomal subjects and in COPD. Am. J. Respir. Crit. Care Med. 1997; 155: A913.

MCRussel DM, Walker PM. Leiter LA, Sima AAF, Tanmer WK, Mickle DAG. Whitwell J. Marliss EG. Metabolic and structural changes in skeletal nuscle during hypocaloric dieting. An. J. C:in. Nutr. 1984; 39: 503-513.

Lopes JM, Russel DMcR, Whitwell J, Jeejeebhoy KN. Skeletal muscle funcion in mallnutrition. Am. J. Clin. Nutr. 1982; 36: 602-610.

Schols AMWJ, Mostert R. Soeters PB, Wouters EFM. Bodly composition and exercise performance in patienus with cluronic obstructive pulmonary disease. Thorax 1991: 46: 695-699.

Decramer M, Lacquet LM. Fagard R, Rogiers P. Corticosteroids contribute 10 muscle weakness in

chronic ainflow obstruction. Am. J. Respir. Crit. Care Med. 1994; 150: 11-16.
Schols AMWJ, Soeters PB, Mostert R. Pluymers RJ Wouters EFM. Physiological support and anabolic steroids in COPD patients, a placebo controlled randomized trial. Am. I. Respir. and Cri. Care Med. 1995; 152: 1268-1274.

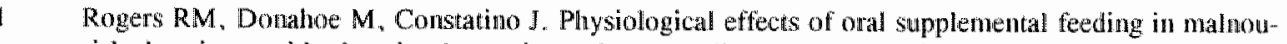
rished patients with chronic obstructive pulmonary disease, a randonized control study. Am. Rev. Respir. Dis. 1992: 146: 1511-1517.

42. Toshima MT, Kaplan RM, Ries AL. Experimental evaluation of reluabilitation in chronic obstructive pulmonary disease: short term effects on exercise endurance and health status. Healh Physiol. 1990: 9: 237-52.

Cockroft AE, Berry $G$. Randomised controlled trial of rellabilitation in chronic respiratory disability. Thortix 1981:36:200-3.

McSweeny A L. Labulnn KT. Chronic obstructive pulmonary disease, In: B. Spilker, eds. Quality of life assessment in clinical trials. Raven Press. Lid. New York 1990: p341-417.

Dudley DL, Glaser EM, Jorgenson BN, Logan DL. Psychosocial consonitans to retuabilitation in chronie obstructive pulnwonary disease, part II: psychosocial treatment. Chest 1980; 77: 544-551.

Greenberg GD, Ryan JI, Bourlier PE. Psychological and neuropsychological aspects of COPD. Psyclnssomatics. 1985; 26:29-33.

Kinsman RA, Yaroush RA. Fernandez E, et al. Symptoms and experiences in chronic bronchitis and emphysema. Chest 1983: 755-761.

Dudley $D L$. Sitzmatu J. Psychobiological evaluation and treatment of COPD. In: AJ MeSweeney and I Grants (eds). Chronic obstructive pulmonary diseas. A behanvioral perspective. New York. 1988.

Ketelars CAI. Schlosse: MAG, Mostert R. Huijer Abu-Saad H, Halfens RIG. Wouters EFM. Determinants of health related quality of life in patiens with chronic obstructive pulmonary disedse. Thorax 1996:51:39-43.

Curtis. JR, Deyo RA. Hudson LD. Health-related cquality of life among patients with chronic obstruene pulnomary distase. Thorax 1994: 49: 162-70. 
51 Donner CF. Mair JF, Rehabilitation and clironic care scientific group of the European Respiratory Society. Selection criteria and progranmes for pulmonary relahiliation in COPD patients. Eur. Respir. J. 1997; 10: 744-757.

52 Ferguson GT. Cherniack RM: Management of chronic obstructive puinonary disease. The New. Eng. J. Med. 1993; $328: 1017-1022$.

53 Celli BR. Is pulmonary rehabilitation an effective treatment for chronc obstructive pulmonary disease? Yes. Am. J. Respir. Crit. Care Med. 1997; 135: 781-783. 


\title{
ANALYSIS OF BODY WATER COMPARTMENTS \\ IN RELATION TO TISSUE DEPLETION \\ IN CLINICALLY STABLE PATIENTS WITH \\ CHRONIC OBSTRUCTIVE PULMONARY DISEASE
}

Erica M. Baarends', Annemie M.W.J. Schols.3. Wouter D. wan Marken Lichtenbelt". Emiel F.M. Wouters" 'Departments of Pulmonology and "Human Biology, Maastricht University. Maastricht, Asthma Center Hornerheide, Horn, The Netherlands.

\begin{abstract}
Tissue depletion often occurs in patients with Chronic Obstructive Pulmonary Disease (COPD), even in those that are weight-stable. Limited data are available, however, about changes in body water compartments in chronic wasting diseases such as COPD. The purpose of this study was to measure body composition in severe COPD patients with special attention to fat-free mass (FFM) depletion and the distribution of body-water compartments. Total body water (TBW) and extracellular water (ECW) were measured by deuterium and sodium bromide dilution techniques, respectively, in 38 COPD patients (Age: $65 \pm 9 \mathrm{y}$, forced expiratory volume in $1 \mathrm{~s}: 38 \pm 14 \%$ of predicted) in a stable clinical condition. FFM was calculated by assuming a hydration coefficient of $73 \%$. Underweight patients (body mass index (BMI;in $\mathrm{kg} / \mathrm{m}^{2}<21$ ) were characterized by a significantly lower percentage fat mass than normal-weiglt patients, but no significant difference was found in the ratio ECW/ICW (BMI $<21 \mathrm{~kg} / \mathrm{m}^{2}: 0.72$ $\left.\pm 0.12, \mathrm{BMI}>21 \mathrm{~kg} / \mathrm{m}^{2}: 0.71 \pm 0.16 ; \mathrm{NS}\right)$. When the study population was divided into depleted patients (FFM/height ${ }^{2} \leq 15 \mathrm{~kg} / \mathrm{m}^{2}$ ) and non-depleted patients (FFM/height ${ }^{2}>15 \mathrm{~kg} / \mathrm{m}^{2}$ ) there was no significant difference in the percentage fat mass, but the $\mathrm{ECW} / \mathrm{ICW}$-ratio was significantly higher in the depleted patients $(0.78 \pm$ $0.16)$ than in the nondepleted patients $(0.66 \pm 0.12 ; p<0.05)$, this was most pronounced in women. In conclusion, it was found that COPD patients with extreme FFM wasting are characterized by an increased $\mathrm{ECW} / \mathrm{ICW}$ ratio, despite a relatively spared fat mass.
\end{abstract}




\section{Introduction}

Weight loss and a low body weight often occur in patients with Chronic Obstructive Pulmonary Disease (COPD) ${ }^{12}$. We showed earlier that weight loss in COPD patients comprises both loss of fat mass (FM) and fat-free mass (FFM). Loss of FFM has even been shown in weight-stable patients ${ }^{2}$. The particular relevance of wasting of FFM for the clinical condition of COPD patients was shown in an adverse effect on physical performance $e^{3-7}$, on respiratory muscle function ${ }^{8.9}$ and even on survival ${ }^{10.11}$.

Body composition can be presented by a simple two-compartment model: FM and FFM. FFM can be measured accurately with deuterium dilution under the assumption of a constant hydration factor of $73 \%^{12}$. FFM can however be further subdivided into two compartments: the intracellular compartment (also known as body cell mass; BCM) which represents the energy exchanging part, and the extracellular compartment which represent substances outside the cells (such as collagen, fascia, plasma and interstitial fluid) and mainly functions as a support and transport tissue. It is not currently possible to measure the intracellular compartment directly ${ }^{13.14}$. Indirect methods to determine BCM by total-body potassium or total-body nitrogen are not readily applicable in clinical practice or require sophisticated equipment. The greatesit part of BCM is intracellular water (ICW) and this compartment can be calculated indirectly from total body water (TBW) and extracellular water (ECW). This assessment of ECW and TBW by deuterium and sodium bromide dilution is relativelly casy to perform.

A description of body composition by a three-compartment model is especially important in acute wasting diseases ${ }^{14.13}$ or after a catabolic stress such as extreme weight loss ${ }^{16.17}$ or severe trauma. Under these circumstances, the BCM can be decreased, whereas the ECW is absolutely or relatively expanded. Therefore, in cases of fluid shifts, measurement of FFM is an inappropriate measure of the metabolically active tissue mass. Limited data are available about changes in body water compartments in chronic wasting diseases such as COPD, cardiac failure, acquired immunodeficiency syndrome (AIDS) and cystic fibrosis.

The purpose of this study was to measure bodly composition in severe COPD patients with special attention to FFM depletion and the distribution of the body water conpartments. 


\section{Methods}

\section{Patiens}

Thirty nine patients $\left(24 \delta^{*}, 15\right.$ \%) with moderate to severe COPD ${ }^{18}$, who were participating in a pulmonary rehabilitation program, were studied just after entering the program. All patients were referred by a pulmonary physician to the rehabilitation center in a stable clinical condition. None of the patients had a respiratory tract infection or clinically visible signs of severe edema at the time of the study. Patients exhibiting an increase in forced expiratory volume in $1 \mathrm{~s}\left(\mathrm{FEV}_{1}\right)>10 \%$ of baseline after inhalation of a $B_{2}$-agonust or patients suffering from cancer, unstable pulmonary or cardiac conditions, active gastrointestinal abnormalities, recent surgery, or severe endocrine disorders were excluded from the study. The study was approved by the local ethical committee. Procedures followed were in accord with the Helsinki declaration from 1977 as revised in 1983 .

\section{Body composition}

Body height was determined to the nearest $0.5 \mathrm{~cm}$ (Lameris, WM 715, Breukelen, The Netherlands) with subjects standing barefoot. Body weight was measured with a beam scale to the nearest $0.1 \mathrm{~kg}$ (SECA, Hamburg. Germany) with subjects barefoot and in light clothing.

To measure TBW each patient received a weighed oral dose of deuterium labelled water (99.84 atom percentage excess) of $1 \mathrm{~g} / \mathrm{L}$ predicted TBW (based on height, weight, age and $\operatorname{sex}^{19}$ ) mixed into $\approx 70 \mathrm{~mL}$ water. For the estimation of $\mathrm{ECW}$ $60 \mathrm{mg}$ sodium bromide/L predicted TBW (based on height, weight, age and sex) was added to the deuterium dose. Patients received this "cocktail" in the late evening around 10 p.m. Just before and approximately 10 hours later venous blood and urine samples were obtained. Urine was analyzed for deuterium with an isotope ratio-mass spectrometer according to the standard Maastricht protocol ${ }^{12}$. Deuterium dilution space was calculated from the quantity of administered deuterium and the urine deuterium concentrations after complete equilibration. TBW was calculated from these values by applying a conversion factor of 1.04. This correction accounts for the exchange of labile hydrogen that occurs in humans during the equilibration period ${ }^{2}$. FFM was 
calculated by assuming a hydration factor of 0.73 . Bromide (Br) concentration in serum ultrafiltrate was determined by HPLC according to the anion-exchange chromatographic method $^{21}$. ECW was estimated by the corrected bromide space (CBS) and calculated according to the following formula:

$\mathrm{CBS}=\frac{\mathrm{Br}_{- \text {dose }}(\mathrm{mmol})}{\left(\mathrm{Br}_{-\mathrm{i}}-\mathrm{Br}_{\mathrm{r} / 2}\right)(\mathrm{mmol} / \mathrm{L}) * 0.90 * 0.95}$

Where $\mathrm{Br}_{\mathrm{f}}$ is the final bromide concentration in the serum ultrafiltrate (after 10 hours of equilibrium), $\mathrm{Br}_{\text {br }}$ is the background bromide concentration from the initial blood sample, 0.90 is the correction factor for the bromide in the nonextracellular sites, and 0.95 is the correction factor for the Donnan equilibrium.

\section{Blood analysis}

From the blood drawn for the analysis of CBS, concentrations of albumin and chloride were also determined by an automated system (Cobas Mira; Hoffmann-Ia Roche, Basel, Switzerland). Serum sodium and potassium concentration were determined by a flame photometer (243, Instrumentation Laboratory, Ysselstein, The Netherlands). Hematocrit was determined after separation of the whole blood.

\section{Pulnonary function}

Lung function tests consisted of flow volume measurements: (FEV, and forced vital capacity (FVC)), The highest walue of at least three measurements was used and expressed as a percentage of the reference value ${ }^{22}$.

\section{Data analysis}

Results are given as means \pm SDs. Differences between groups were analyzed with an unpaired Student's t-test, or in the case of small group sizes the Mann-Whitney $U$ test. The level of significance was determined as a $\mathrm{p}$ value $\leq 0.05$. The SPSS/PC + (SPSS Inc, Chicago) computer software program was used for statistical analyses. A body mass index (BMI: in $\mathrm{kg} / \mathrm{m}^{2}$ ) of 21 was used to divide the patient population into 
underweight and normal-weight groups. In addition, on the basis of the total patient group median FFM-index ( $=$ FFM/height ${ }^{2}$ an analog to BMD), 15 , the patients were divided in a depleted and a non-depleted group.

\section{Results}

There was one patient with a significantly disproportionately high ECW/TBWratio of $64.5 \%$ (analyzed with the Bonferroni-corrected outlier test). This patiant was excluded from further statistical analysis. Of the remaining 38 patients mean age was $65 \pm 10 \mathrm{y}$ for women and $65 \pm 8 \mathrm{y}$ for men (NS). Mean FEV, was $40.3 \pm 11.6 \%$ of predicted for women and $36.2 \pm 14.7 \%$ of predicted for men. The BMI ranged widely from 13.6 to 31.0, mean BMI was $22.1 \pm 5.1$ for women and $22.6 \pm 3.7$ for men (NS). The mean $\mathrm{ECW} / \mathrm{ICW}$-ratio was significantly different for men $(0.67 \pm$ $0.15)$ and for women $(0.78 \pm 0.12, p<0.05)$.

In Figure 1 the mean body composition of underweight $(n=12)$ and nomall weight $(\mathrm{n}=26)$ men and women are shown. Underweight women $(\mathrm{n}=5)$ were characterized by a significantly lower FM $(8.9 \pm 5.6 \mathrm{~kg}$ or $21.0 \pm 11.4 \%$ of weight compared with $25.4 \pm 9.8 \mathrm{~kg}$ or $38.8 \pm 8.8 \%$ of weight; $p<0.01$ ), a tendency towards a lower TBW $(23.6 \pm 3.6 \mathrm{~L}$ compared with $27.9 \pm 2.9 \mathrm{~L} \mathrm{p}=0.05)$ and a similar ECW (10.4 $\pm 1.8 \mathrm{~L}$ compared with $12.1 \pm 1.1 \mathrm{~L}$, NS) than the normal-weight women $(\mathrm{n}=9)$. No significant difference was found in the $\mathrm{ECW} / \mathrm{ICW}$-ratio between underweight women $(0.79 \pm 0.09)$ and normal weight women $(0.78 \pm 0.14)$.

Compared with normal-weight man $(n=17)$ underweight men $(n=7)$ were also characterized by a significantly lower FM $(8.5 \pm 3.1 \mathrm{~kg}$ or $16.7 \pm 6.5 \%$ of weight compared with $23 . \mathrm{l} \pm 5.1 \mathrm{~kg}$ or $32.9 \pm 5.8 \%$ of weight; $\mathrm{p}<0.001$ ), a non significantly lower TBW $(3 \Perp .2 \pm 3.5 \mathrm{~L}$ compared with $34.1 \pm 3.8 \mathrm{~L}$. NS) and a similar ECW $(12.4 \pm 1.2 \mathrm{~L}$ versus $13.5 \pm 2.4 \mathrm{~L}$, NS). The ECW/ICW-ratio was also not significantly different between underweight men $(0.68 \pm 0.13)$ and normal-weight $\operatorname{men}(0.67 \pm 0.16)$ 


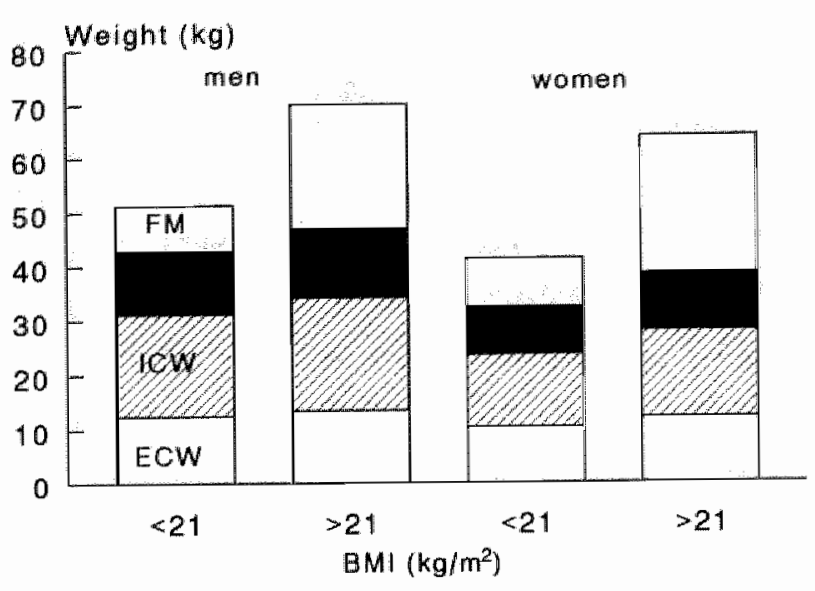

Figure 1: Body

composition of

patients with a low $(\leq$

$\left.21 \mathrm{~kg} / \mathrm{m}^{2}\right)$ or normal

$\left(>2 I \mathrm{~kg} / \mathrm{ml}^{2}\right)$ BMI, $n$

$=24$ men, 14 women.

FM, fat mass; ICW,

intracellular water;

ECW, extracellular

water.

On the basis of FFM, the body composition of the study population was divided into depleted patients (FFM-index $\leq 15 \mathrm{~kg} / \mathrm{m}^{2}$ ) and non-depleted patients (FFM-index $>15 \mathrm{~kg} / \mathrm{m}^{2}$ ); the results are presented in Table 1 .

Patients with wasting of FFM did not have a lower BMI or a significantly different FM (depleted: $18.4 \pm 9.2 \mathrm{~kg}$, non-depleted: $19.7 \pm 9.8 \mathrm{~kg}$, NS) or percentage FM (depleted: $31.5 \pm 11.3 \%$, non-depleted: $28.3 \pm 10.6 \%$ ). TBW was significantly lower in the depleted patients (TBW: $26.9 \pm 3.7 \mathrm{~L}$ ) than in the nondepleted patients (TBW: $33.9 \pm 3.61$; $p<0.001$ ). However, ECW was not significantly lower in depleted patients, men $(12.1 \pm 1.8 \mathrm{~L})$ or women $(11.1 \pm 1.52$

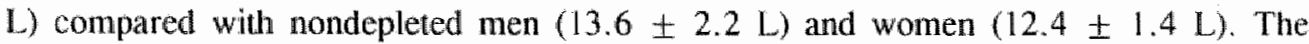
ECW/ICW-ratio was significantly higher in depleted women $(0.82 \pm 0.12$ than in nondepleted women: $0.70 \pm 0.08 p<0.05$ ). In men the depleted patients also had a higher ECW/ICW-ratio (0.72 \pm 0.20$)$ than the non-depleted men $(0.65 \pm 0.13)$ but the difference was not significant. Serum hematocrit values and concentrations of sodium, potassium and chloride were not significantly different between depleted and nondepleted patients. 
Table 1: Characteristics of patients with chronic obstructive pulwonary disease and fat free indexes (FWMindex; $\left.\mathrm{kg} / \mathrm{m}^{2}\right) \leq$ and $>15$

Duta are prewented as means $\pm S D$;

BMI: body mass index; FM: fat mass; TBW: total body water; ECW: exrocellular water estimatad by corrected bromide space; ECWTBW: extracellular water as percentage of total body water; Na: serum rodum concentration: $K$ : seram potassium concentration; $C l$ : serum clibride concenmation.

Significantly different from group ar subgroup with FFM-inder $\leq 15$ (Mam-Whimey U for men and wonten separately, men and women together: paired t-test): $p<0.05, * p<0.01, * * 0.001$

\begin{tabular}{|c|c|c|c|c|c|c|c|}
\hline \multirow[b]{2}{*}{ Variable } & & \multicolumn{3}{|c|}{ FFM-index $\leq 15$} & \multicolumn{3}{|c|}{ FFM-index $>15$} \\
\hline & & $\begin{array}{c}\text { All } \\
(n=17)\end{array}$ & $\begin{array}{c}\text { Men } \\
(n=7)\end{array}$ & $\begin{array}{l}\text { Women } \\
(n=10)\end{array}$ & $\begin{array}{c}\text { All } \\
(n=21)\end{array}$ & $\begin{array}{c}\text { Men } \\
(n=17)\end{array}$ & $\begin{array}{l}\text { Wonnen } \\
(n=4)\end{array}$ \\
\hline BMI & $\left(\mathrm{kg} / \mathrm{m}^{2}\right)$ & $21.0 \pm 4.2$ & $21.2 \pm 2.3$ & $20.9 \pm 5.2$ & $23.5 \pm 3.9$ & $23.2 \pm 4.0$ & $25.11+3.7$ \\
\hline FFMI & $\left(\mathrm{kg} / \mathrm{m}^{2}\right)$ & $13.9 \pm 0.9$ & $14.3 \pm 0.8$ & $13.7 \pm 0.9$ & $16.5 \pm 1.3^{\text {w* }}$ & $16.7 \pm 1.3^{* * * * 3}$ & $15.9 \pm 0.9^{*}$ \\
\hline FM & $(\mathrm{kg})$ & $18.4 \pm 9.2$ & $19.4 \pm 5.8$ & $17.7 \pm 11.3$ & $19.7 \pm 9.8$ & $18.6 \pm 9.1$ & $24.3 \pm 12.9$ \\
\hline FM & (\% weight) & $31.5 \pm 11.4$ & $31.8 \pm 9.1$ & $31.4 \pm 1.4 .2$ & $28.3 \pm 10.6$ & $26.6 \pm 10.3$ & $35.2 \pm 10.2$ \\
\hline TBW & (L) & $26.9 \pm 3.7$ & $29.7 \pm 2.7$ & $24.9 \pm 3.0$ & 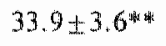 & $34,7 \pm 3,3^{\text {th }}$ & $30.3 \pm 2.4$ \\
\hline ECW & (L) & $11.5 \pm 1.7$ & $12.1 \pm 1.8$ & $11.1 \pm 1.5$ & $13.2 \pm 2.1 *$ & $13.6 \pm 2.2$ & $12.4+1.4$ \\
\hline ECW/TBW & $(\%)$ & $43.2 \pm 5.4$ & $41.1 \pm 7.2$ & $44.7 \pm 3.3$ & $39.5 \pm 4.4 H$ & $39.1 \pm 4.7$ & $40.9 \pm 2.94$ \\
\hline ECW/ICW & & $0.78 \pm 0.16$ & $0.72 \pm 0.2$ & $0.82 \pm 0.12$ & $0.66 \pm 0.12$ & $0.65 \pm 0.1$ & $0.69 \pm 0.08 *$ \\
\hline Albunin & $(\mathrm{g} / 1)$ & $36.7 \pm 1.6$ & $35.8 \pm 1.2$ & $37.4 \pm 1.6$ & $37.3 \pm 2.1$ & $37.5 \pm 1.9$ & $36.7 \pm 2.9$ \\
\hline Henatocrit & $(\%)$ & $41.2 \pm 3.3$ & $41.3 \pm 4.6$ & $41.1 \pm 2.3$ & $41.8 \pm 2.8$ & $41.7 \pm 2.8$ & $42.3 \pm 2.9$ \\
\hline $\mathrm{Na}$ & $(\mathrm{m} E q)$ & $138.1 \pm 2.3$ & $139.3 \pm 1.7$ & $137.3 \pm 2.3$ & $139.0 \pm 3.9$ & $1139.6 \pm 3.6$ & $136.5 \pm 5.2$ \\
\hline K & $(\mathrm{mEq})$ & $4.3 \pm 0.5$ & $4.1 \pm 0.5$ & $4.5 \pm 0.5$ & $4.3 \pm 0.5$ & $4.2 \pm 0.4$ & $4.6 \pm 0.8$ \\
\hline $\mathrm{Cl}$ & $(\mathrm{mEq})$ & $101.2 \pm 4.5$ & $102.3 \pm 2.9$ & $100.5+5.3$ & $101.1 \pm 5.1$ & $101.7 \pm 5.1$ & $98.5=5.1$ \\
\hline
\end{tabular}

Although there was no relation between ECW/ICW ratio and BMI (Figure 2a), a weak but significant linear relationship was found between ECW/ICW and the FFMindex $\left(r^{2}=0.14 \mathrm{p}<0.05\right)$ (Figure $\left.2 b\right)$. Figure $2 b$ also shows that all patients with $a$ FFM-index below $14 \mathrm{~kg} / \mathrm{m}^{2}$, and nearly all patients with a FFM-index below $15 \mathrm{~kg} / \mathrm{m}^{2}$ had an elevated ECW/ICW-ratio. 


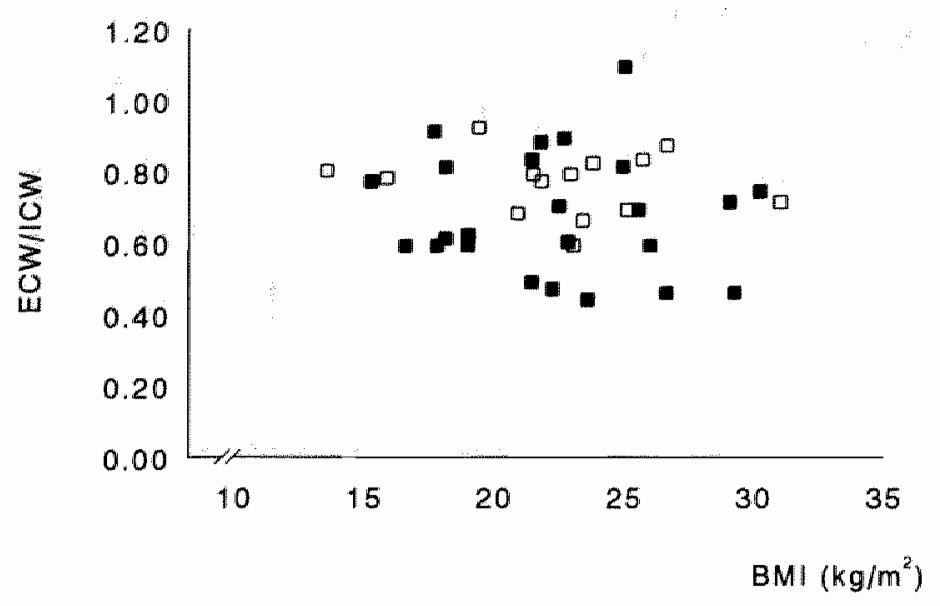

Figure 2a: Relations-

hip between the extracellular (ECW) intracellular ( $\mathrm{ICW}$ ) ratio and BMI for men (black square) and women (open square). Linear association: $r^{2}=0.0 I$ NS $(n=38)$

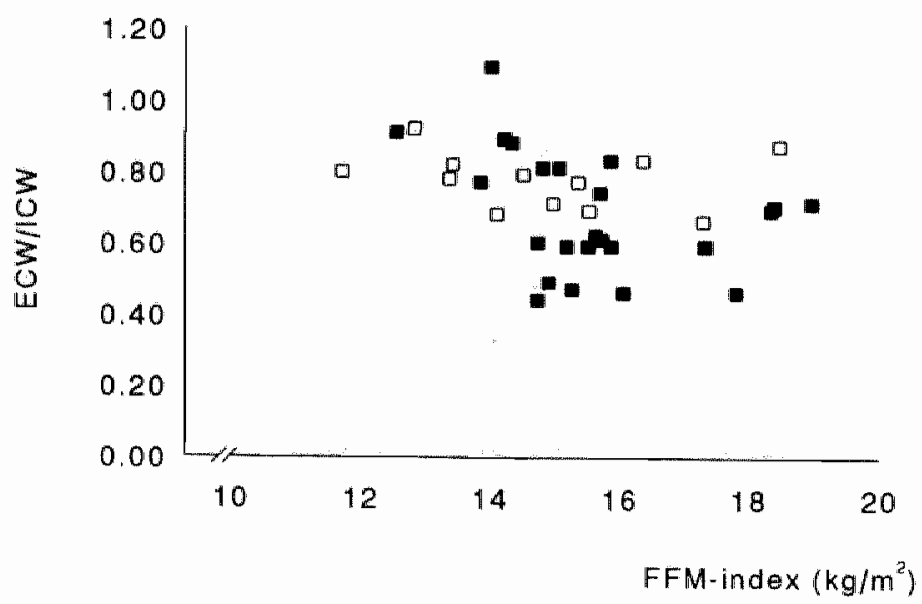

Figure $2 b$ :

Relationship between the extracellular (ECW)/iniracellular (ICW) ratio and FFMindex for men (black square) and women (open square). Linear assaciation: $r^{2}=0.14 p$ $<0.05(n=38)$ 
No significant correlation was found between the FFM-index and FM/height ${ }^{2}$ (Figure 3).

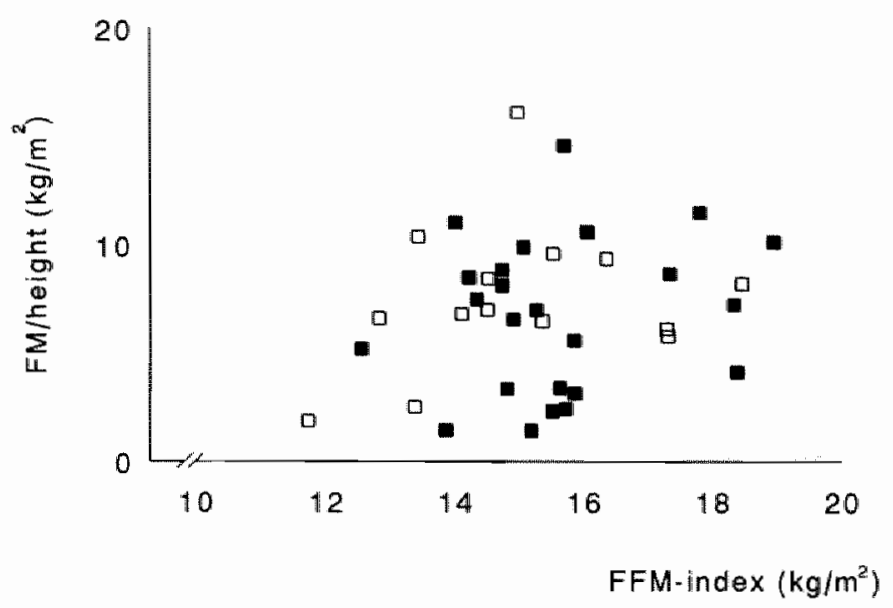

Figure 3: Relationship between fat mass (FM)/height and fat free mass index (FFM-index) for men (black square) and women (open square). Linear association: $r^{2}=0.04$ NS $(n=38)$

\section{Discussion}

This study shows that tissue wasting occurred despite a relative sparing of FM in patients with clinically stable COPD. Fluid shifts manifested as a relative increase in ECW can occur in COPD patients with extreme FPM wasting. It is suggested that generally below a FFM-index of $15 \mathrm{~kg} / \mathrm{m}^{2}$, bady composition is characterized by a relatively increased $\mathrm{ECW}$.

Measurement of body composition is important in the clinical evaluation of (chronic) wasting disease and acute metabolic stress. Assessment of the magnitude of the energy exchanging part of the body is important for the interpretation of metabolic rate $^{23}$, the prediction and/or interpretation of functional capacity, and the evaluation of nutritional, pharmacologic, and training interventions ${ }^{24}$.

Weight loss and tissue wasting may be due to a decreased food intake, diseaserelated metabolic stress, or a combination of these two. A catabolic state is generally defined as "malnutrition" or "undernutrition", which may be confusing because these 
terms only refer to the nutritional cause of weight loss. Earlier we mentioned that, especially in wasting disease, it would be more appropriate to call patients depleted instead of malnourished ${ }^{2}$. Kinney and Weissman ${ }^{25}$ also made a distinction between depletion after a reduced intake ("unstressed" depletion) or associated with a disease condition ("stressed" depletion), in view of different body-composition changes in these conditions $^{25}$. Recent studies, however, suggest that body-composition changes also vary between different (acute or chronic) diseases ${ }^{26-30}$.

The effects of total starvation on body composition and body water compartments have rarely been studied. In a case report of total starvation associated with acute and rapid weight loss in a normal-weight subject, clinical edema was not observed ${ }^{31}$. Several studies of total starvation have been performed in obese subjects ${ }^{32}$. 34, and they all reported a reduction of FM as well as lean tissue loss, but unfortunately, no measurements of ECW were made. One study in seven obese subjects with an extremely long fasting period (20-48 weeks) reported a 25 to $67 \mathrm{~kg}$ loss of weight, 8 to $20 \mathrm{~L}$ loss of TBW resulting from a loss of ICW (5-15 L) as well as a loss of "sodium space" (or ECW) of $0-7 \mathrm{~L}^{35}$. On the contrary, the effects of chronic partial starvation (50-60\% of normal dietary intake) on body composition were thoroughy studied in the historical studies by Keys et all ${ }^{17}$ and more recently by Barac-Nieto et al $^{16}$ The changes described included a large decrease in FM, a decrease in BCM, no changes in absolute $\mathrm{ECW}$, but because of the reduced body weight a relative increase in ECW. Partial (relatively short) starvation in obese subjects, however, resulted in an increase in $\mathrm{ICW}$ (instead of a decreased BCM), and no change or a decrease in relative $\mathrm{ECW}^{36}$.

The effects of stressed depletion on body composition have been studied in great detail by Moore et $\mathrm{a}^{15}$ and by Schizgal ${ }^{14}$ in hospitalized patients using isotope dilution methods. They described a depleted state after acute metabolic stress that was associated with a decreased FM, a decreased BCM, but an absolutely as well as relatively increased $\mathrm{ECW}^{25}$.

Recently more studies have been performed of body (water)-composition changes in chronic wasting diseases. Schizgal ${ }^{37}$ found in a subgroup of depleted cancer patients a decrease in BCM, an (absolute and relative) increase in $\mathbb{E C W}$ and a massive reduction of $\mathrm{FM}$. Several studies in lung cancer patients found mainly a reduction of FM instead of FFM in patients losing weight ${ }^{38.39}$, but measurements of ECW were not made in these studies. Another recent study in cancer patients (cancer of the stomach, 
esophagus or pancreas) found a decrease in body weight and BCM (measured with ${ }^{4} \mathrm{~K}$ ), but no reduction of BCM as a percentage of body weight, indicating that only in patients with dramatic fat loss would ECW be increased ${ }^{40}$. In AIDS, a chronic wasting disease, two sudies by Kotler et al. ${ }^{29.30}$ showed that there was no evidence for an increased ECW (measured with dilution methods and measurements of $B C M$ with ${ }^{40} \mathrm{~K}$ ). The authors stated that the wasting observed in AIDS was similar to historical reports of semistarvation. These recent studies show different patterns of body composition in chronic diseases that can deviate from body composition changes assumed to be associated with acute metabolic stress. This was also found in patients with myelomeningocele, or spina bifida (depletion of $\mathrm{BCM}$, absolute/relative increase in ECW, but increased relative $\mathrm{FM}^{41}$, spinal cord injury (body weight and TBW reduction, but only a relative increase in ECW) ${ }^{42}$, and liver cirrhosis (heterogenous presentation of body-composition changes $)^{26,27.43}$.

Why is COPD an interesting chronic wasting disease with respect to metabolism? On the one hand COPD patients represent a homogeneous population with a normal dietary intake $e^{44.45}$ and no gastrointestinal abnormalities. On the other hand, a substantial percentage of depleted COPD patients do not manifest the natural metabolic adaptation to weight loss, but have an increased resting energy expenditure ${ }^{46,47}$. Furthermore, total daily energy expenditure can be increased in COPD patients, even independently of an increased resting energy expenditure ${ }^{48}$. Factors contributing to the elevated resting energy expenditure in these patients can be a chronic inflammatory state $^{49}$, medication such as theophylline and $B_{2}$ agonists ${ }^{50}$, and the oxygen cost of breathing $^{51.52}$. Furthermore, COPD is associated with periods of acule disease exarcebations during which energy expenditure is further elevated ${ }^{53}$, possibly associated with catabolism.

In an earlier study we observed that body composition in depleted COPD patients was different from the body composition of patients with acute metabolic stress". Wasting of FFM appeared to occur also in stable normal weight COPD patients. This observation was confirmed in the present study because the FFM-index was not significantly correlated with percentage FM (or FM/height ${ }^{2}$ ). Therefore, the patients with severe wasting of FFM still had a percentage FM similar to that of the patients with a normal FFM. Patients with COPD usually are relatively inactive because of their dyspnea and ventilatory and metabolic limitations. Inactivity may affect FFM more than FM, independently of an impaired energy balance. Comparable results 
were found in patients with myelomeningocelet:. These patients had a depletion of $\mathrm{BCM}$, an absolute as well as relative increase in $\mathrm{ECW}$, but a relatively high percentage FM. The latter was especially evident in the non-ambulatory group of patients. FFM in COPD can also be affected by a disturbed intermediate muscle (exercise) metabolism (lower intracellular pH and ATP depletion), which has been observed in recent studies by using ${ }^{3} \mathrm{P}$ nuclear magnetic resonance measurements ${ }^{54.55}$. It has been hypothesized that factors like hypoxemia, hypercapnia and/or medication (corticosteroids) could contribute to the disturbed intermediate muscle metabolism and atrophy of type IIb muscle fibers in COPD patients. Another explanation for the relatively high percentage fat may be the use of corticosteroids prescribed as maintenance medication or during exacerbations. In animal studies corticosteroids were shown to stimulate food intake and the maintenance of body fat despite a reduced body weight ${ }^{56}$.

Another deviation in the body composition of depleted COPD patients compared with the general observations associated with acute depletion is the fact that fluid shifts could not be detected by stratification of the group by body weight. BMI was not correlated with the ECW/ICW-ratio. Stratification of patients by the FFM-index, however, demonstrated that the $\mathrm{ECW} / \mathrm{ICW}$-ratio was significantly higher in the depleted women. In men, the ECW/ICW-ratio was not significantly higher in patients with depletion of FFM, but wasting of FFM in men was associated with a significant lower TBW without a decreased ECW. Indications of a relative increased ECW in COPD patients were found earlier ${ }^{57}$. "This observation results in two interesting issues, which, to our knowledge, have not been discussed previously for chronic wasting diseases. Because FM/height ${ }^{*}$ was not correlated with the FFM-index, the patients with FIM-depletion who had a significantly higher ECW/ICW-ratio, had a relatively spared FM. Second, the results of this study suggest that below a certain critical point of FFM wasting a relative increase in $\mathrm{ECW}$ is more likely to occur. However, note that the variance of the ECW/ICW-ratio was high in the patients with a higher FFM-index and that in men the relation between depletion and fluid shitis was not as clear as it was in women.

The difference berween men and women is difficult to explain, and to our knowledge was not observed and discussed earlier. The increased ECW/ICW in depleted patients might be explained by the theories of Flear \& Singh ${ }^{58}$. They suggested that the cell membrame function is probably altered in disease ("sick cells"), especially the function regulating osmolarity (causing fluid shifts). This could also mean that the 
changes in the cell membrane caused bromide-leakage to the ICW and ECW in fact was not increased, but. Flear and Sing said that the ECW is likely to increase in the case of "sick cells". Hảussinger et al $\left.\right|^{59}$ also posited interesting theories concerning cellular hydration state in catabolism and stated that factors like inflammatory state, amino acid starvation, and stress conditions that result in hormonal alterations (low insulin, high glucagon and catecholamines) could favor cell shrinkage (water flow out of the cell). Cell shrinkage would act as a catabolic signal. The chronic inflammatory state in COPD patients, especially in depleted patients or those losing weight ${ }^{49.60}$, could be important with respect to the theories of Häussinger et al. Furthermore, pharmacologic treatment in many COPD patients includes $B_{2}$-sympathicomimetics, which can influence the $\mathrm{NA}^{+} / \mathrm{K}^{+}$-ATPase activity ${ }^{61}$. In the study by Hofford et al ${ }^{62}$ increased norepinephrine concentrations were observed in COPD patients. With respect to the theories of Häussinger et a $^{59}$ these factors might also be important for fluid shifts.

A relative increase in $\mathrm{ECW}$ implies that $\mathrm{BCM}$ is overestimated in these patients (by 13 to $30 \%$ ) by the measurement of FFM. As a consequence, the increased resting energy expenditure found earlier ${ }^{48}$ or total daily energy expenditure ${ }^{48}$ despite a low FFM in COPD patients may therefore have even underestimated the metabolic derangements in COPD.

Finally, is the use of a theoretical constant hydration factor to calculate FFM valid in depleted patients? In a study of Beddoe et $\mathrm{al}^{63}$, the hydration of FFM was studied in protein-depleted patients. The 95 patients who were studied had undergone surgery and were selected for intravenous nutrition. The mean hydration of these patients was 0.719 , which was significantly lower than that of the control group (0.741). However, there were still 48 patients with a normal hydration factor despite a $15 \%$ loss of body protein. A recent study by Royall et al ${ }^{64}$ showed that in mainourished patients (mean BMI $<21$ ) with Crohn disease the hydration of FFM (measured by dual energy $X$-ray absorptionetry and isotope dilution) was $71.1 \%$ which was not significantly different from the theoretical value of hydration, $73 \%$, as well as the hydration in healthy humans, $71.9 \%$, studied by Streat et al ${ }^{65}$. Furthermore, Streat also reported that depleted patients (who underwent surgery) had a hydration of FFM comparable with that of the normal volunteers.

In summary, we found that COPD patients with FFM wasting showed an increased $\mathrm{ECW} / \mathrm{ICW}$-ratio. This was especially evident in those with extreme FFM wasting, many of whom had a relatively spared FM. This study showed that in a 
chronic disease such as COPD, which is associated with weight loss and for tissue wasting, body-composition changes may deviate from the usually ascribed (acute) disease-related changes, or those after reduced energy intake.

This study stresses the importance of a detailed measurement of body composition in chronic wasting diseases to investigate further the prevallence of body-water compartment fluid shifts and the possible causes for this phenomenon.

\section{References}

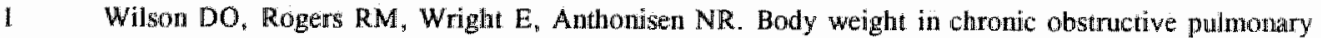
disease. An. Rev. Respir. Dis. 1989; 139: 1435-1438.

2 Schols AMWI, Soeters PB, Dingemans AMC, Mostert R, Frantzen PJ, Wouters EFM. Prevalence and characteristics of nutritional depletion in patients with stable COPD eligible for pulmonary reluabilitation. Am, Rev, Respir. Dis. 1993; 147: 1151-1156.

3 Openbrier DR, Irwin MM, Rogers RM, Gottlieb GP. Dauber $\mathrm{JH}_{\text {" }}$ Van Thied DH, et all. Nutritional status and lung function in patients with emphysema and chronic bronchitis. Clest. 1983; 83: 17-22. Schols AMWJ, Mostert R, Soeters PB, Wouters EFM. Body composition and exercise performance in patients with chronic obstructive pulmonary disease. Thorax. 1991: 46: 695-699.

5 Renzi GD, Renzi PM, Feustel PJ, Dutton RE. The influence of weight on exercise limitation in chronic obstructive lung disease. Am. Rev. Respir. Dis. 1985; 131 (suppl):A353(abstr.). Cotes JE, Zedja J, King B. Lung function impairment as at guide to exercise limitation in workvelated lung disorders. An. Rev. Respir. Dis. 1988; 137: 1089-1093.

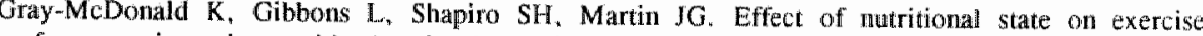
performance in patients with chronic obstructive pulmonary disease. Am. Rev "Respir. Dis. 1989; 140: 1544-1548,

Arora NS, Rochester DF. Effect of body weight and muscularity on human diaphragm muscle mass. dhickness and area. 1. Appl. Physiol. 1982; 52: 64-70. disease. Am. Rev. Respir. Dis. 1986; 134: 646-648. Schols $A M W J$, De Vries G, Slangen J. Wouters EFM. The predictive value of a low body nass index on survival in COPD patients. Eur. Respir. J. 1995;8:166s (abstr.).

11 Wilson DO, Rogers RM, Wright E, Anthonisen NR. Body weight in chronic obstructive pulmonary diserse. Am. Rev. Respir. Dis. 1989: 139: 1435-1438.

12 Westerterp KR. Wouters L, Marken Lichtenbelt WD. The Mastricht Protocol for the measurenvent of body composition and energy expenditure with labelled water. Obesity Research. 1995; 3 (suppl.11): 49-57. Hiil GL, Beddoe AH. Dimensions of the human compartments. In: Kinney IM, Jeejeebhoy KN, Hill GL. Owen OE, eds. Nutrition and metabolism in patient care. Philadelphia: WB Saunders, 1988:89-
118 Schizgal HM. Body composition. Un: Fischer JE, ed. Surgical Nutrition. Boston: Little, Brown and
Company, 1983: 3m17 its suppotting environment. Philadletplia: WB Saunders, 1963. Barac-Nieto m, Spurr GB. Lotero H. Maksud MG. Body composition in chronic undernutrition. Am. J. Clin. Nutr. 1978; 31: 23-40. Keys A. Brozek J, Henschel A, et al. The biology of human starvation. Volume 1. Minneapolis, American thoracic saciety. pulmonary disease (COPD) and astlon for thagnosis and care of patients with chronic obstructive Deurenberg P. Westrate JA, Seidell JC. Am. Rev. Respir. Dis. 1987; 137:225-228. specific prediction formulas. Br. J. Nurr. 1991;65:105-114. 
Schoelter DA. Isotope dilurion methods. Im: Bjontröp P. Brodoff BN, eds. Obesiny. Philladelphia: J.B. Lippecott Company, 1992; $80-88$.

Miller ME, Cosgriff JM. Forbes GB. Bromide space detemination using anuon-exchange chromatography for measurement with bronide. Am. J. Clin. Nurr. 1989; 50: 168-171.

Quanjer Ph, Tamneling GJ, Cotes JE, Pedersen OF, Pesin R, Yernault J-C. Standardized lung function testing. Eur. Resp. J. 1993; 6 (suppl 16): 5-40.

Weissman C. Assessing hypernetabolism and hypometabolism in the postoperative critically ill patien. Chest 1992;102:1566-71.

Vantallie TB, Yang MU, Heymstield SB, Funk RC. Boileau RA. Height-nomalized indices of body's fat-free mass and tat mass: potentially useful indicators of nutritional status. Am. I. Clin. Nutr. 1990; 52: 953-959.

Kimey JM. Weissman C. Forms of malnutrition in stressed and unstressed pattents. Clin. Chesi Med. 1986;7: 19-28.

Shepherd RW, Chin SE, Gleghorn GI, Patrick M. Ong TH, Lynch SV. Balderson G. Strong R. Malnutrition and children with chronic liver transplantation: clinical profile and effect on outcome. J. Peadiatr. Child Health. 1991: 27: 295-299.

Lauz HU. Selberg 0 . Körber J, Bürger M, Müller MJ. Protein - calorie malnutrition in liver cirthosis. Clin. Investing. 1992; 70: 478-486.

McMillan DC. Preston T, Watson WS, Simpson IM, Fearon KCH, Shenkin A, Burns HJG, McArdle CS. Relationship between weighr loss, reduction of body cell nass and intlammatory response in patients with cancer. Brit. J. Surg. 1994; 81: 1011-1014.

Kotler DP. Tierney AR. Wang J, Pierson RN. Magnitude of body-cell-mass depletion and the timing of death from wasting in AIDS. Am. J. Clin. Nutr. 1989; 50: 444-447.

Kotter DP. Tiemey AR. Brenner SK. Couture S. Wang J, Pierson RN. Preservation of shon - term energy balance in clinically stable patients with AIDS. Am. J. Clin. Nutr. 1990;51:7-13.

Sunderman FW.: Studies in senum electrolytes: XIV. Changes in blood and body fluids in prolonged fasting. Am. J. Clin. Pathol. 1947;17:169-180.

Benoit FL. Martin RL. Watten RH. Changes in body composition during weight reduction in obesity. Balance studies comparing effects of fasting and a ketogenic diet. Amm. Lntern. Med. $1965 ; 63: 604-612$

Bolinger RE, Lukert BP, Brown RW, Guevara L, Steinberg R. Metabolic balance of obese subjects during fasting. Arch. intern. med. 1966:118:3.

Ball MF, Canary J]. Kyle LH. Comparative effects of caloric restriction and total starvation on body

composition in obesity. Ann. Intern. Med. 1967:67:60-67

Barmard DL. Ford J, Garnett ES, Mardell RJ, Whymatn AE. Changes in body composition produced by prolonged total starvation and refeeding. Metabolism 1969: 18:564-569.

Pierson RN. Wang f. Yang MU, Hashim SA, Vanltallie TB. The assessment of human body composition during weight reduction: evaluation of a new model for clinical studies. Nit. Nutr. 1976:106:1694-1701.

Schizgal HM. Body composition of patients with malnutrition and cancer. Cancer. 1985:55 (suppl.): 250-253.

Staal-vd Brekel AI, Schols AMWI, Ten Velde GPM, Butman WA, Wouners EFM. Analysis of the energy balance in lung cancer patients. Cancer research 1994:54:6430-6433.

Simons JPFHA, Schols AMWJ. Hoefnagels JMI, Westenterp KR, Hillen HFP. Ten Velde GPM. Wouters EFM. The effects of medroxyprogesterone acetate (MPA) on energy intake and body composition in patients with advanced cancer. Proc ASCO 1995;14:430 (abstr).

Moley JF. Aanodi R. Rumble W. Kaye W. Norton JA. Body cell mass in cancerbearing and anorexic paticnts ]. Parent. Ent. Nutr. 1987:11:219-222.

Shepherd K. Roherts D, Golding S, Thomas BJ. Sheplerd RW. Body composinion in myelomeningrocele. Am. J. Clin. Nutr. 1991;53:1-6.

Cardus D. Wesley G. MeTagger BS. Total body water and its distribution in men with spinal curd injury. Arch. Phys. Med. Rehabil. 1984;65:509-512.

McCullough AJ. Mullen KD. Kalhan SC. Body cell mass and leucine metabolism in cirriosils. Gatroenterology 1992:102:1325-1373. 


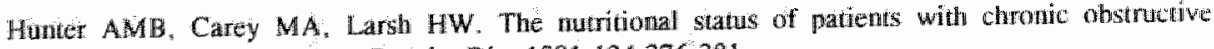
pulmonary distase. Am. Rev. Respir. Dis. 1981;124:376-381.

Braun SR, Kem NL, Dixom RM, Clagnaz P. Anderegg A, Shrago ES, The prewalenve and deterininants of nutrional changes in chronic obstructive pulmonary diseast. Chest 1984;86:558-563.

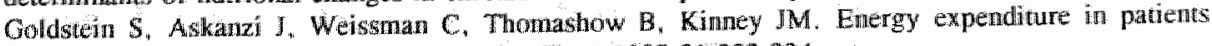
with chronic obstructive pulmonary disease. Chest $1987: 91,222-224$. Shol AMWJ Fredrix EWHM Saters PB Westerterp KR Wouters EFM: Resting energy expendiure in patients with chronic obsmuctive pulmonary disease. Am. J. Clin. Natr. 1991;54:983-987. Barends EM, Schols AMWI, Pannenans DLE, Westerterp KR, Wouters EFM. Total daily thergy expenditure in clinically stable patients with sewere COPD and age-natched healthy subjects using the doubly labelled water method. Am. J. Respir. Crit. Care Med 1995:141:A206 (abstr.).

Schols AMWI, Butrman WA. Wouters EFM. Is an impared emergy metabolisn associated with chromic inflammation in patients with severe COPD? Am J. Respir. Crit. Care Med. 1994" 149:

Alo13 (absir.).

Creutzberg EC, Schols AMWJ. Wesseling GJ, Wouters EFM. Acute effects of inhalled salbutamol on lung function and energy merabolism in COPD patients and nomal subjects. Eur. Respir. J. $1994 ; 7$ (suppl. 18$) \div 4665$ (abstr.).

Cherniack RM. The oxygen consumption and efficiency of the respiratory muscles in health and disease. J. Clin. linvest. 1959:38:494-499.

Donahoe $M$, Rogers RM, Wilson DO, Pennock BE. Oxygen consumption of the respiratory muscles in normal and malnowrished patients chronic obstructive pulmonary disease. Am. Rev. Respir. Dis. $1989 ; 140: 385-391$.

Vermeenen MAP, Schols AMWI, Quadwiteg FCM, Wouters EFM. The influence of acute disease exarcebation on the metabolic profile of parients with chronic obstructive pulmonary discase. Chin. Nuur. 1994; 13 (suppl):P28 (abstr.).

Kutsuzawa T, Shioya S, Kurita D, Haida M, Ohta Y, Yambayashi. 31P. NMR study of skeltat muscle metabolism in patients with chronic respiratory impaiment. Am. Rev. Respir. Dis. 1992:146:1019-1024.

Payen JF, Wuyani B, Levy $P_{4}$, Reutenater $H$, Stieglitz $P$, Paramelle B, Le Bas Jf: Muscular metabolism in COPD during oxygen supplenentation in patients with chronic hypoxemia. Am. Rev. Respir. Dis, 1993: 147: 592-598.

Sankana P. Akana SF, Hanson ES, Strack AM, Sebastian RJ, Dallman MF. Aldosterone and dexamethasone both stimulate energy acquisition whereas only the glucocorticoid alters energy storage Endlocrinology 1995; 136:2214-2222.

Telter N, Bawer FK, Mickey MR, Herbst HH. Body composition in chronic obstructive pulmonary disease. Am. Rev. Respir, Dis. 1968;98:640 645.

Flear CTG and Singh CM. Hyponatramia and sick cells. Brit. J. Anatsth. 1973: 45: 976994. HAissinger D, Roth $\mathbb{E}_{\text {, Lang }} F^{-}$, Gerok W. Cellular hydration state: an important deterninam of protein catabolism in health and disetse. The Lancet 1993:341:1331-1332.

60 Frincia $M$ di, Barbier D, Mege $\mathrm{L}$. Orehek. Turnor necrosis factor-alpha levels and weight loss in chronic obstmcive pulmonary disease. An. J. Respir. Crit Care Med. 1994: 150: 1453-1455. Asthma: Basic mechanics and clinical management. London: London Academic Press, 1988: 563590 .

Hofford JM: Milakofsky L, Vogel WH, Sacher RS. Savage GJ, Pell S. The nutritional status in advanced emphysema associated with clironic bronchitis. Am. Rev. Respir. Dis, 1990; 141:902-908. Beddoe AH, Sireat SI. Hill GL. Hydration of fat-free body in protein deplewed patients. Am. I. Physiol. 1985: 249: E227-E233.

64 Royal D, Grenberg GR, Allard JP, Baker JP, Harrison IE, Jeejeebhoy KN. Critical assessmant of body composition neasurements in malnourished subjects with Crohn's disease: the rolc of bioelectric impedance analysis. Am. J. Clin. Nutr. 1994; 59:325-330.

Streat SH. Beddoe AH. Hill GL. Measurement of body fat and hydration of fat-free bodly in liealdh and disiotse. Metabolism 1985; $34: 509-518$. 


\section{BODY-WATER COMPARTMENTS MEASURED \\ BY BIO-ELECTRICAL IMPEDANCE SPECTROSCOPY \\ IN PATIENTS WITH \\ CHRONIC OBSTRUCTIVE PULMONARY DISEASE}

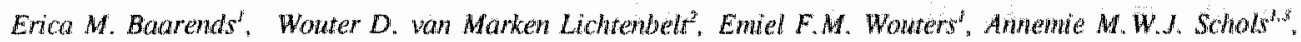

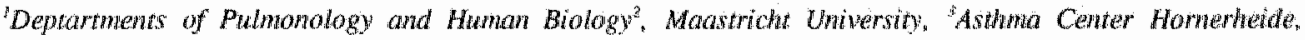
Horn, The Netherlawds

\section{Abstract}

It was demonstrated previously that single frequency bio-electrical impedance (BIA) measurement at $50 \mathrm{kHz}$ is a useful method to assess total body water (TBW) in patients with Chronic Obstructive Pulmonary Disease (COPD). In the present study it was examined whether bioelectrical impedance spectrospcopy (BIS) could predict extracellular water (ECW) and improve the prediction of TBW in these patients. TBW and ECW (corrected bromide space) were measured by deuterium and bromide dilution. In 37 COPD patients prediction equations were obtained using BIS (5-500 $\mathrm{KHz}$ ) measurements, and these were crossvalidated in a second group of $40 \mathrm{COPD}$ patients. All patients were in a clinically stable condition. TBW predicted by BIS was not significantly different from actual TBW and demonstrated a comparable SEE as found previously in healthy subjects ( $\delta$ correlation coefficient: $r=0.88$, standard error of estimate: SEE: $2.3 \mathrm{~L}, q \mathrm{r}=0.85$, SEE: $2.9 \mathrm{~L})$. Predicted ECW using BISmeasurements was not significantly different from measured ECW ( $\& \mathrm{r}=0.75, \mathrm{SEE}$ : $1.4 \mathrm{~L}, \mathrm{P}=0.73 . \mathrm{SEE}: 1.2 \mathrm{~L}$ ), but the error in the prediction was relatively large and the correlation between predicted and actual ECW relatively low compared to most studies in healthy persons. Predicted TBW using BIS was comparable to actuall TBW, but presented no improvement of the prediction of TBW using BIA at $50 \mathrm{kHz}$ and a patient specific regression equation. The error of the prediction of ECW by BIS limits the ability to predict fluid shifts in individual patients with clinically stable COPD. 


\section{Introduction}

Several chronic and acute disease states are accompanied by marked changes in body compartments. The estimation of the body compartments is not only of importance in research, but also in the clinical situation. Numerous body composition methods are presently available, but most of these are either too sophisticated, too inconvenient (especially for bed-ridden subjects), time consuming or require large and stationary equipment, often at high cost, which make these methods not suitable for clinical practice.

Therefore, the estimation of body composition by bio-electrical impedance (BIA) represents a simple, practical and convenient method. Since the 1980 s numerous studies have been performed to predict total body water (TBW) using BIA at $50 \mathrm{kH} z_{\text {, }}$ but it appears that this technique involves several drawbacks. The sitandard error of estimate of BIA is usually $1-3$ liters?, which limits the ability to measure small effects of intervention on body composition ${ }^{2.3}$. Furthermore, the use of BIA at $50 \mathrm{kHz}$ to measure the resistance of TBW has been questioned ${ }^{4.5}$, since the frequency at which the current flows through both extracellular water (ECW) and intracellular water (ICW) may differ between individuals, and is probably higher than $50 \mathrm{kHz}$. Finally, TBW measurements may be misleading in case of a deviating $\mathrm{ECW} / \mathrm{ICW}$ distribution following disease or Severe starvation ${ }^{6,7.8}$.

Theoretically, the resistance of intracellular and extracellular water can be obtained by bio-electrical impedance spectroscopy (BIS). Using BIS the resistance of the body can be measured at a spectrum of frequencies. At low frequencies the current flows primarily through ECW because the capacitance of cell membranes is minimized. whereas at high frequencies the current passes also through ICW $\mathrm{I}^{\circ}$. It is hypothesized that, in order to predict TBW, it is more accurate to use the resistance of TBW obtained by BIS than the resistance at $50 \mathrm{kHz}$, because theoretically the latter is a suboptimal representative of the resistance of TBW. Until now, the BIS has been predominantly evaluated in healthy subjects ${ }^{10-15}$, but the accuracy to measure bodywater compartments should particularly be tested in wasting conditions associated with subtle to marked fluid shifts stuch as in patients with Chronic Obstructive Pulmonary Disease (COPD).

The purpose of this study was to examine whether body water compartments using BIS-measurements (ranging from 5 to $500 \mathrm{kHz}$ ) are accurately predicted in 
patients with severe COPD, using (isotope) dilution methods as a reference. In a first patient group, prediction equations based on BIS measurements were built, and these were subsequently crossvalidated in a second COPD study group.

\section{Methods}

\section{Patients}

Firstly, thirty seven patients (230) with moderate to severe COPD $^{16}$ were studied. The body mass index (BMI: weight/height ${ }^{2}$ ) ranged widely from 13.6 to 31.0 $\mathrm{kg} / \mathrm{m}^{2}$ (Table 1A). Prediction equations derived from this study-population were tested in a second group of $40(32 \delta, 8$ 9) COPD patients (Table 1B).

All patients were referred by a pulmonary physician to a rehabilitation center in a stable clinical condition. None of the patients had a respiratory tract infection or clinically visible signs of oedema at the time of the study. When measurements were performed patients did not receive any diuretic medication. Patients exhibiting an increase in forced expiratory volume in one second $\left(\mathrm{FEV}_{1}\right)>10 \%$ of baseline after inhalation of a $B_{2}$-agonist or patients suffering from cancer, unstable pulmonary or cardiac conditions, active gastrointestinal abnormalities, recent surgery, or severe endocrine disorders were excluded from the study. The study was approved by the local ethical committee. Procedures followed were in accord with the Helsinki declaration from 1977 as revised in 1983.

\section{Body composition}

Body height was determined to the nearest $0.5 \mathrm{~cm}$ (Lameris, WM 715 , Breukelen, The Netherlands) with subjects standing barefoot. Body weight was measured with a beam scale to the nearest $0.1 \mathrm{~kg}$ (SECA, FRG) with subjects barefoot and in light clothing.

To measure total body water each patient received a weighted $1 \mathrm{gram} / \mathrm{L}$ estimated TBW $^{15}$ oral dose of deuterium labelled water $\left(\mathrm{D}_{2} \mathrm{O}: 99.84\right.$ atom percentage excess) mixed into $\approx 50 \mathrm{~mL}$ water. For the estimation of extracellular water $60 \mathrm{mg}$ sodiumbromide $(\mathrm{NaBr})$ per liter estimated TBW was added to the deuterium dose. 
Pallents received this "cocktail" in the late evening around 10 p.m. Just before and approximately 10 hours later a venous blood sample and an urine sample (from second voiding) were obtained ${ }^{18.19}$. Urine was analyzed for deuterium with an isotope ratio mass spectrometer according to the standard Maastricht protocol ${ }^{19}$. Deuterium dilution space was calculated from the quantity of administered $\mathrm{D}_{2} \mathrm{O}$ and the urine $\mathrm{D}_{2} \mathrm{O}$ concentrations following complete distribution. TBW was calculated from these values by applying a conversion factor of 1.04 . This correction accounts for exchange of labile bydrogen which occurs in humans during the equilibrium period ${ }^{20}$.

Bromide concentration in serum ultrafiltrate was determined with HPLC, and ECW was estimated by the corrected bromide space (CBS) which was calculated from the quantity of administered bromide and the concentration of bromide in the background blood sample and the blood sample after complete equilibrium as described by Lichtenbelt et al ${ }^{1 *}$. CBS was calculated correcting for the bromide in the nonextracellular sites $(0.90)$, and the Donnan equilibrium $(0.95)$.

Bio-electrical impedance spectroscopy measurements (BIS)

Bio-electrical measurements were taken using a four-surface-clectrode technique in the early morning at standardized time, the same day isotope dilution was performed. Measurements were made while the patients were lying comfortably on a polystyrene mattress, with the legs separated, and the arms relaxed aside, not touching the trunk. The electrodes (Tracets MP3000, LecTec Corporation, Minnetonka MN) were placed at the right side on the hand and the foot as described by Lukaski et al ${ }^{2 !}$. Impedance was measured using a bio-electrical impedance spectrometer (Xitron 4000 , Xitron technologies, San Diego, California) at a spectrum of 48 frequencies ranging from $510500 \mathrm{kHz}$.

\section{Pulmonary function}

Lung function tests consisted of flow volume measurements (Forced expiratory volume in one second: $\mathrm{FEV}_{1}$, forced vital capacity: FVC). The highest value of at least. three measurements was used and expressed as a percentage of the reference value ${ }^{2 *}$. 


\section{Theoretical considerations}

The electrical impedance of the body is measured by introducing a small alternating current through the body and measuring the difference in potentiall. An alternating electrical current flows through the body by different physicall mechanisms. The current flows through physiological fluids by the movement of ions. "This movement is opposed by viscosity and other effects, which can be modeled electrically as a resistance. In addition, the applied current will charge cell membranes and other interfaces, which can be modeled electrically as capacitors. Thus, the impedance $(Z)$ of the body can be modelled by an equivalent electrical circuit with a parallel combination of capacitive (resulting in the reactance: $X$ ) and resistive elements (resistance: $R$ ), where the absolute value of $Z=\left(X^{2}+R^{2}\right)^{0.5}$ and arctan $(X / R)$ is its phase angle $e^{23}$.

The impedance is strongly dependent on the frequency of the alternating current. At low frequencies, the bioelectrical current flows primarily through extracellular fluids and reactance is minimized since the capacitant aspects of body cells (cell membranes, tissue interfaces) are thought to be bypassed. As frequency increases the capacitant properties start to retard the current, producing an increase in reactance. The capacitant effects reach a peak with a maximum reactance value, but as the frequency of the current increases the current penetrates all body tissues completely, since at high frequency the rate of charge and discharge becomes such, that the effect of the capacitance is diminished to insignificant properties ${ }^{23.24}$. With increasing frequency, the resistance will decrease, because the amount of conducting volume is increasing.

A plot of the resistance versus the reactance of tissue, as a function of frequency, characteristically forms a semicircular arc, the center of which is depressed below the real axis. This frequency dependence of the complex $Z$ can be modlelled empirically by the Cole-Cole equation. From this equation the resistance of ECW (Recw) and of TBW (Rtbw) at respectively zero and infinity frequency can be obtained. Considering that in the electrical model used, the Recw and Ricw are linked parallel, the Ricw can be calculated from the Recw and Rtbw (Rtbw = (Ricw Recw) / $(\text { Ricw + Recw) })^{23}$.

In the present study Recw and Ricw were obtained using the software provided by the manufacturer previously described in detail ${ }^{24}$ which models the impedance and phase angle spectra data into the Cole-Cole model, using nonlinear curve-finting, and 
adjusting for the time delay caused by the speed at which electrical information is transferred through a conductor.

The prediction of ECW and TBW using Recw and Ricw depends on the underlying theory. The theory most frequently used is based on the principle that the complex impedance (reactance and resistance) of a conducting cylinder is related to its length (L), cross-sectional area (A), the frequency of the signal and the resistivity of the material $(\rho)$. At a specific fixed frequency therefore: $Z=\rho^{*}(\mathrm{~L} / \mathrm{A})$, by multiplying this equation by $L / L$, the equation of the volume of a conducting cylinder becomes $\rho^{*}\left(L^{2} / Z\right)^{23}$. If the contribution of the reactance is neglected (because it is usually small) the volume of a conducting cylinder is related to $\rho^{*}\left(\mathrm{~L}^{2} / \mathrm{R}\right)^{1.23}$, where $\mathrm{L}$ is estimated by height. The ratio height ${ }^{2} /$ resistance is usually referred to as the resistivity index (RI).

In the second theory based on emulsion sciences the apparent resistivity of a conducting material is thought to be also dependent of the restricting concentration of non-conductive material in the suspension: $\rho=\rho_{0} /(1-\mathrm{C})^{3 / 2}$, where $\rho$ is the apparant resistivity of the conductive material; $\rho_{0}$ is the actual resistivity of a conductive marterial; and $\mathrm{C}$ is the volumetric concentration of the nonconductive marterial contained in the mixture ${ }^{24}$. An extensive explanation of this theory is described by Hanai as well as by De Lorenzo et al $^{24.25}$. Since untill now there is no uniformity concerning the theory used to obtain the prediction of body water compartments, we tested both the theory using the RI and the theory based on emulsion sciences.

Based on the above mentioned theories the following equations were tested:

1 The relationship between height ${ }^{2} /$ Rtbw and TBW, height ${ }^{2} /$ Recw and ECW were determined from the first group of patients and subsequently used to predict TBW and ECW in the second group of patients.

2 The prediction formulas for TBW and ECW based on the theory of Hanai. The equations have been described in detail previously ${ }^{24}$. There are several constants used in these equations, which are based on assumptions, as described by De Lorenzo et al $^{24}$. These equations are build on an assumption concerning the volumetric concentration of non-conductive elements in the body at low and high frequencies, an assumption concerning the calculation of total body volume "the assumption that the constants used in the equation are not variable, and that the Hanai equation can be applied at high frequencies and low frequencies to mixtures found in the human body. The constants involved in the prediction equation are a correction factor $\left(\mathrm{K}_{1 \mathrm{~B}}\right)$ for a whole body measurement between 
wrist and ankle and a constant for body density. Furthermore, the equations are built on the assumption that the total volume of a body fluid can be described as: $\mathrm{K}_{\mathrm{B}}{ }^{*} \rho_{\mathrm{F}} *\left(\mathrm{~L}^{2} / \mathrm{R}\right)$, where $\rho_{\mathrm{F}}$ represents the resistivity of the water. Therefore, in these formulas ECW and ICW resistivity constants are used. However, these coefficients were derived by the manufacturer using other reference methods than our own. Therefore, the standard resistivity coefficients were replaced by resistivity coefficients calculated from our first patient group. TBW and ECW were subsequently predicted from the formulas provided by the manufacturer and the patient-specific resistivity coefficients.

\section{Data analysis}

Results are given as mean \pm SD. Correlation coefficient analysis was performed to test the linear relationship between variables. Multiple regression analysis was performed in order to obtain partial correlations and prediction equations. Differences between group 1 and 2, men and women were tested with a Mann-Whitney $U$ test. Differences between actual and predicted body water compartments were analyzed with a paired t-test and following the procedures suggested by Bland and Altmann ${ }^{26}$. To compare two methods, the mean difference or the mean underestimation or overestimation from 0 (=bias) was calculated. In addition, the SD of the mean difference between actual and predicted body-water compartment was calculated, which indicates the error of an individual prediction (="error"). Level of significance was determined as a $\mathrm{p}$ value $<0.05$.

\section{Results}

There was no significant difference in pulmonary function between the first group in which the prediction equations were built (group 1) and the group in which crossvalidation was performed (group 2), but body composition was different between the groups. TBW and ECW were significantly higher in group 2, but ratio ECW/TBW was comparable between the groups (Table 1). 
Table 1: Characteristics of patients whith chronic obstructive pulmonary disease

Table IA: Characteristics of the first patient group

Data are presented as meants I SDs: FEV : forced expiratory volume in 1 second; FUC: forced vital capaciry. BMI: body mass index; TBW: tonal body water; ECW: extracellular water.

- Signiffcandy difference between males ffemales (Main-Whiney U Test)

\begin{tabular}{|c|c|c|c|c|c|}
\hline$n=$ & & $\begin{array}{c}\text { Total } \\
37\end{array}$ & $\begin{array}{c}\text { Male: } \\
23\end{array}$ & $\begin{array}{c}\text { Females } \\
14\end{array}$ & p valué \\
\hline $\mathrm{FEV}_{\|}$ & (\% pred) & $37.6+13.8$ & $36.0 \pm 15.0$ & $40.0 \pm 11.6$ & $\mathrm{NS}$ \\
\hline FVV & $(\%$ pred $)$ & $82.0 \pm 15.8$ & $79.4 \pm 17.6$ & $86.3 \pm 11.5$ & NS \\
\hline Age & $(y x)$ & $65 \pm 9$ & $65 \pm 8$ & $65+10$ & $N S$ \\
\hline $\mathrm{BMI}$ & $\left(\mathrm{kg} / \mathrm{nm}^{2}\right)$ & $22.4 \pm 4.2$ & $22.6 \pm 3.7$ & $22.1 \pm 5.1$ & $\mathrm{NS}$ \\
\hline TBW & (L) & $30.8 \pm 5.1$ & $33.4 \pm 3.9$ & $26.4 \pm 3.8$ & $p<0.001$ \\
\hline $\mathrm{ECW}$ & (L) & $13.2 \pm 2.1$ & $13.9 \pm 2.2$ & $12.2 \pm 1.6$ & $p=0.05$ \\
\hline $\mathrm{ECW}$ & $(\% \mathrm{TBW})$ & $43.5 \pm 5.3$ & $41.6 \pm 5.4$ & $46.5 \pm 3.7$ & $p<0.05$ \\
\hline
\end{tabular}

Table IB: Characteristics of the second patient group

Data are presented as meaws $\pm S D, F E V_{1}$ forced expiratory volume in I second; FVC: forced wital capacity: BMI: body mass index; TBW: total body water; ECW: extracellular water.

* Significantly difference between males females (Mann-Whitney U test)

\# Significantly difference berween growp $I$ and 2 (Mann-Whitney $U$ text)

\begin{tabular}{|c|c|c|c|c|c|c|}
\hline $\mathrm{n}=$ & & $\begin{array}{c}\text { Total } \\
40\end{array}$ & $\begin{array}{c}\text { Males } \\
32\end{array}$ & $\begin{array}{c}\text { Females } \\
8\end{array}$ & p value & p value \\
\hline $\mathrm{PEV}_{1}$ & (㨐 pred) & $40.3 \pm 16.8$ & $37.9 \pm 15.6$ & $49.9+17.8$ & $p=0.05$ & NS \\
\hline FVC & (\% pred) & $87.9 \pm 16.2$ & $86.7 \pm 16.2$ & $87.9 \pm 16.2$ & NS & NS \\
\hline Age & $(y a)$ & $65 \pm 9$ & $67 \pm 8$ & $60 \pm 9$ & $p=0.05$ & NS \\
\hline BMI & $\left(\mathrm{kg} / \mathrm{m}^{2} \mathrm{l}\right)$ & $23.9 \pm 4.4$ & $24.0 \pm 3.9$ & $23.6 \pm 6.3$ & NS & NS \\
\hline TBW & (L) & $34.3 \pm 5.1$ & $35.6 \pm 4.6$ & $29.3 \pm 4.2$ & $p<0,001$ & $p<0.01$ \\
\hline $\mathrm{ECW}$ & (L.) & $15.1 \pm 2.3$ & $13.8 \pm 1.9$ & $12.6 \pm 1.6$ & $p<0.001$ & $p<0.01$ \\
\hline ECW & $(\% \mathrm{TBW})$ & $44,2 \pm 4$ & $44.5 \pm 4.0$ & $43.2 \pm 4.6$ & $N S$ & NS \\
\hline
\end{tabular}


The regression equations for the prediction of TBW and ECW using the RI are demonstrated in Table 2. With respect to the prediction of TBW, the regression equations were significantly different for men and women, but this was not the case for the prediction of ECW. The partial correlation between the RI (height/Rtbw) and TBW (adjusted for the correlation with ECW) was still statistically significant in men, but not

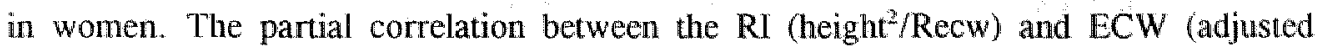
for the correlation with TBW) was not statistically significant.

Table 2: Prediction equations using the resistivity index (height'/resistance) in BIS.

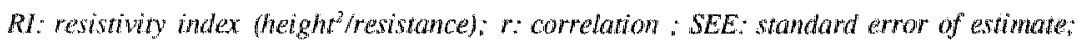

* partial $r=$ the correlation adjusting for the correlation between $\mathrm{TBW}$ and $\mathrm{ECW}$.

\begin{tabular}{lcccccccc}
\hline & RI with & intercept & slope & r & SEE & p-value & partial * $^{*}$ & p-value \\
\hline$d$ & Ribw & 10.7882 & 0.3653 & 0.82 & 2.21 & $<0.001$ & 0.72 & $<0.001$ \\
9 & Rtbw & 12.1960 & 0.2910 & 0.73 & 2.69 & $<0.01$ & 0.38 & 0.19 \\
$8+9$ & Recw & 6.8641 & 0.1668 & 0.65 & 1.60 & $<0.001$ & 0.22 & 0.21 \\
\hline
\end{tabular}

The patient specific resistivity coefficients based on emulsion sciences calculated in group $1(\rho \mathrm{ECW}$ : \& 169 , $\& 166$, $\rho \mathrm{ICW}$ : 81067 , \& 1256) deviated considerably from the resistivity coefficients provided in the software by the manufacturer ( $\rho \mathrm{ECW}$ : 215. ? 206, $\rho \mathrm{ICW}:$ 824, 9797 ).

The predicted TBW using both the R』 or the software of the BIS was not statistically significant from actual in men (Table 3). Also in women there was not significant difference between predicted TBW using the RI and actual TBW.

ECW in men was best predicted by the software of the BIS, since there was a greater bias in the prediction of ECW using the RI, as shown in table 3. Predicted $\mathrm{ECW}$ in women was not significantly different from actual using both the RI or the software of the BIS and resulted in a comparable bias.

Statistical analysis revealed that the prediction of TBW or ECW using the RI involved a systematic fault (Figure 1). TBW minus predicted TBW correlated significantly to mean TBW in both males $(r=0.68, p<0.001)$ and females $(r=0.88$, $p<0.01$ ). Also ECW minus predicted ECW correlated significantly to mean ECW in 
both males $(r=0.76, p<0.001)$ and females $(r=0.78 p<0.05)$. In the prediction of TBW and ECW based on emulsion sciences there were no such systematic faults (Figure 2 ).

Trable 3: Crossvalidation mean actuat and predicted bodly water compartments.

Data are presented as means \pm SDis: $r$ : correlation between actual and predicted body water compartwent; $B:$ bias $=$ mean difference between actuat and predicted body water compartment: $E_{2}$ error $=S D$ of mean difference; TBW: total body water; ECW: extracellulai" water; RI: predicted volume using the resistivity index (hetght/restistance), enulsion; predicted volume based an emulsion sciences.

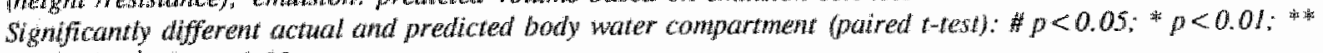
$p<0.001$ ' $^{\prime} N \mathrm{~s}: \mathrm{p}=0.08$.

\begin{tabular}{|c|c|c|c|c|c|c|c|c|}
\hline & Men & & & & Women & & & \\
\hline & & $\mathrm{r}$ & B & $\mathbb{E}$ & & $r$ & B & $E$ \\
\hline Actual TRBW & $35.6 \pm 4.6$ & & & & $29.3 \pm 4.2$ & & & \\
\hline RI & $36.2 \pm 2.8$ & $0.85^{* *}$ & 0.68 & 2.6 & $28.9 \pm 1.8$ & $0.85^{*}$ & 0.30 & 2.9 \\
\hline emulsion & $36.1+4.8$ & $0.88^{* * *}$ & 0.49 & 2.3 & $34.0 \pm 4.2^{3}$ & $0.91 *$ & 4.79 & 1.8 \\
\hline Actual $\mathbb{E C W}$ & $15.8 \pm 1.9$ & & & & $12.6 \pm 1.6$ & & & \\
\hline RI & $13.8 \pm 0.8^{* * k}$ & $0.63 * *$ & 1.93 & 1.6 & $12.2 \pm 0.8$ & $0.73 \mathrm{~A}$ & 0.34 & 1.2 \\
\hline ennulsion & $15.8 \pm 1.9$ & $0.75^{* *}$ & 0.08 & 1.4 & $12.9 \pm 1.8$ & $0.66^{1}$ & 0.33 & 1.4 \\
\hline
\end{tabular}

Actual ECW/TBW was compared to the four ratio's predicted ECW/predicted TBW. This is shown in Figure 3. In men the predicted ratio ECW/TBW based on the $\mathrm{RI}\left(\mathrm{ECW}_{\mathrm{R} /} / \mathrm{TBW}_{\mathrm{Rl}}: 0.38 \pm 0.01\right)$ was significantly different from actual $\mathrm{ECW} / \mathrm{TBW}$ $(0.45 \pm 0.04, p<0.001)$. In fact, the best estimation of ECW/TBW was obtained by $\mathrm{ECW}_{\mathrm{I:M}} / \mathrm{TBW}_{\mathrm{BM}}$ (predicted ECW/TBW based on emulsion sciences: $0.44 \pm 0.03$, bias: -0.004 , error: 0.04 ), but the correlation between actual and predicted $\mathrm{ECW} / \mathrm{TBW}$ was not strong $(r=0.44, \mathrm{p}<0.05) . \mathrm{ECW}_{\mathrm{EM}} / \mathrm{TBW}_{\mathrm{R}}$ were also not significantly different from actual $(0.44 \pm 0.03)$, however, it did not correlate to actual ECW/TBW $(r=0.11$, ns). $\mathrm{ECW}_{\mathrm{R} 1} / \mathrm{TBW}_{\mathrm{tM}}(0.39 \pm 0.04)$ was significantly different from actual ECW/TBW.

In women both $\mathrm{ECW}_{\mathrm{kl}} / \mathrm{TBW}_{\mathrm{EM}}(0.36 \pm 0.03, \mathrm{p}<0.01)$ and $\mathrm{ECW}_{\mathrm{LM}} / \mathrm{TBW}_{\mathrm{IMM}}$ $(0.38 \pm 0.02, \mathrm{p}<0.05)$ were significantly different from actual ECW/TBW $(0.43 \pm$ $0.05)$. $\mathrm{ECW}_{\mathrm{RI}} / \mathrm{TBW}_{\mathrm{Rl}}(0.42 \pm 0.01)$ was not significantly different from actual, but it did not correlate significantly with actual ECW/TBW ( $r=-0.48$, ns). Also 
$\mathrm{ECW}_{\mathrm{EM}} / \mathrm{TBW}_{\mathrm{RI}}(0.44 \pm 0.04$, bias: 0.01 , error: 0.08$)$ was thot significantly different from actual ECW/TBW, however, this predicted ratio only tended to correlate with the actual ratio ECW/TBW $(r=-0.69, p=0.06)$. Moreover, as can be seen in Figure 3 this relationship was reversed.

Figwre 1: Results of crossvalidation based on the resistivity index.

TBWpred: predicted lotal body water; TBW: actual total body water: mean TBW: mean of prediated and actwal total body water; ECWpred: predicted entracellular water; ECW: actual extracellatar water; mean ECW: mean of predicted and actual extracellular water.

$n=32$ men (closed circles), 8 woman (open circles).
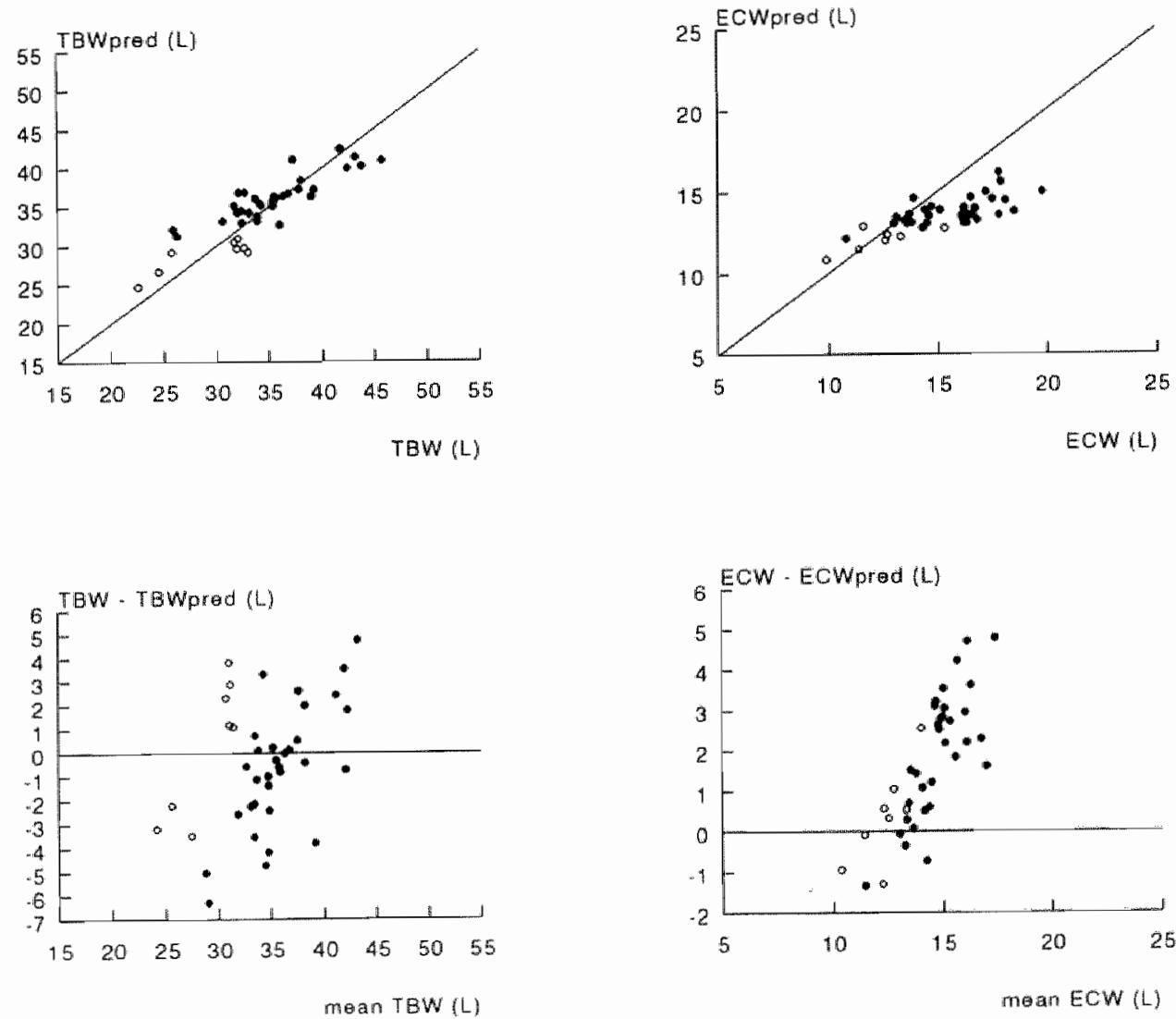
Figure 2 : Results of crossvalidation based on emulsion sciences.

TBWpred: predicted total body water; TBW: actual total body water; mean TBW: mean of predicted and actual total body water; ECWpred: predicted extracellular water; ECW: actual extracellular water; mean ECW: mean of predicted and actual extracellular water.

$n=32$ men (closed circles), 8 woman (open circles).
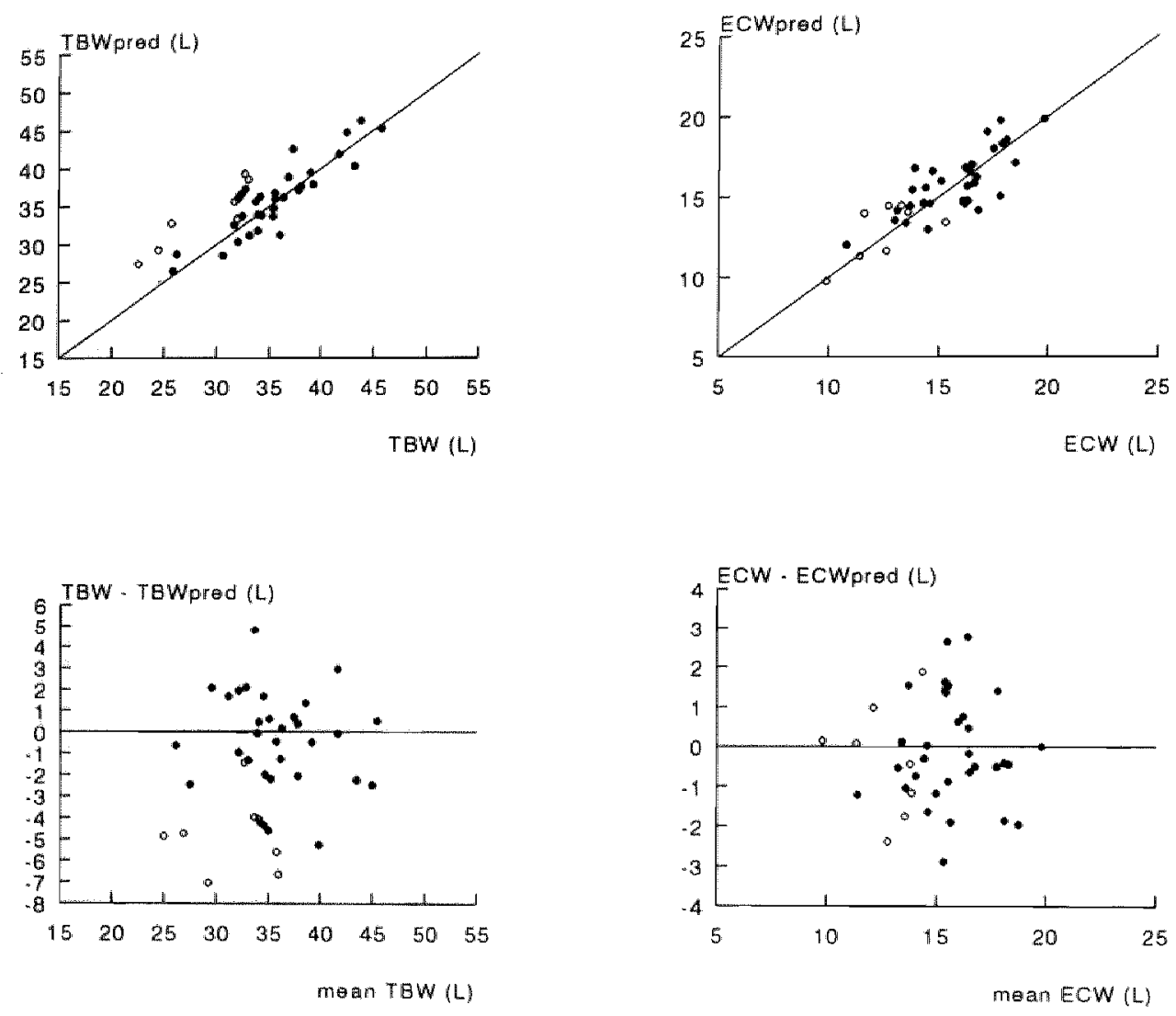
Figure 3: Correlation between actual ECW/TBW and predicted ECW/TBW.

RI: predicted body water compartment based on the nesistivity index; EM: predicted body water compantment based on emulsion sciences; TBW: total body water; ECW: extracellular water.

$n=32$ men (closed circles), 8 woman (open circles).

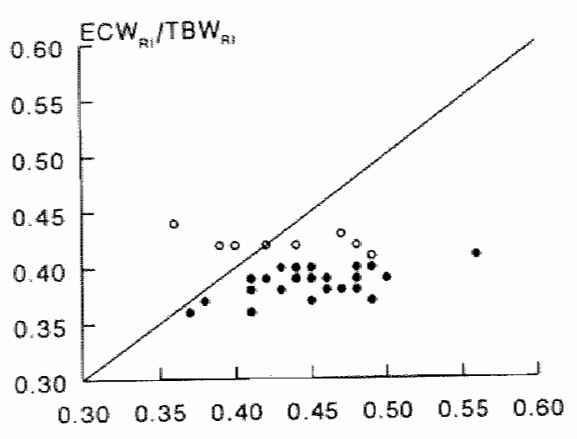

ECW/TBW

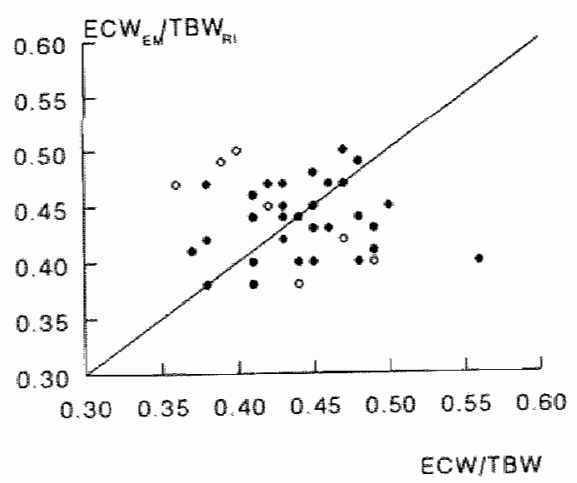

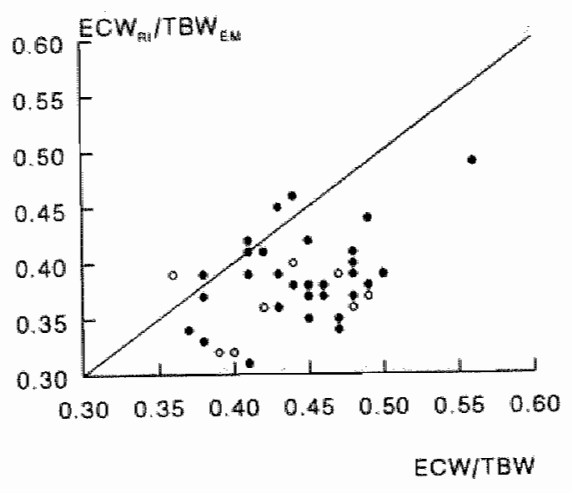

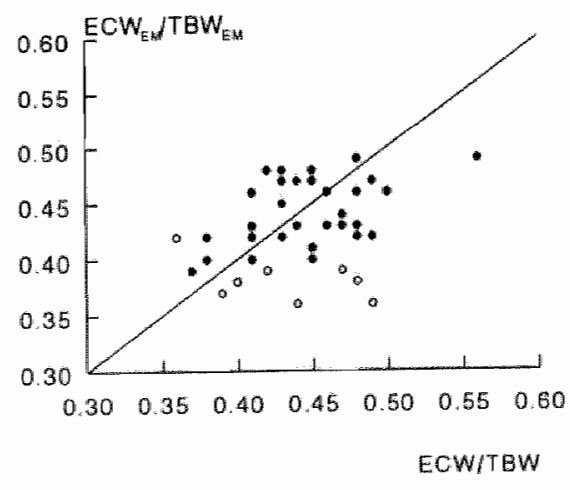




\section{Discussiton}

This study shows that in stable COPD patients, predicted TBW using bioelectrical impedance spectroscopy is not significantly different from actual TBW. The bias and error in the prediction are, however, comparable to that of the prediction of TBW by bio-electrical impedance measurement at $50 \mathrm{kHz}$. Predicted ECW using BISmeasurements was not significantly different from measured $\mathrm{ECW}$, but the error in the prediction was relatively large and the correlation between predicted and actual ECW relatively low compared to most studies in healthy subjects. Therefore, predicted ECW/TBW by BIS was only weakly correlated to actual ECW/TBW. In men ECW and TBW were best predicted (the least bias, error and/or systematic fault) using equations built on emulsion sciences and patient specific resistivity coefficients ${ }^{24.28}$, which incorporate the influence of conductive as well as non-conductive elements in the body. TBW predicted using the formulas based on the emulsion sciences in women resulted in a significant bias, but we recognize that conclusions concerning the female COPD patients in this study must be handled carefully, since the number of women in the crossvalidation was small.

Single frequency measurement studies using the resistance at $50 \mathrm{kHz}$ in healh and disease

Several validation studies in the late 1980 s and early $1990 \mathrm{~s}$ in healthy adults have shown that bioelectrical impedance at $50 \mathrm{kHz}$, using similar measurement conditions as in the present studly, generally results in a good correlation with TBW with standard ertors of estimates (SEE) ranging from 1.4 to $3.5 \mathrm{~L}$. In a previous study ${ }^{2 y}$ it was shown that BIA at $50 \mathrm{kHz}$ was a useful measurement to predict TBW in clinically stable COPD patients with a SEE of only $1.8 \mathrm{~L}$.

In general also in other clinical situations $\mathbb{B l A}$ at $50 \mathrm{kHz}$ was found to produce valid estimates of TBW. In some studies involving patients on dialysis, fluid loss could be reasonably well estimated with $\mathrm{BLA}^{28.29}$, although sometimes TBW was poorly predicted $^{3 n}$. Studies in patients with growth homone deficiency $y^{31}$, patients with cystic fibrosis ${ }^{32,33}$, malnourished or obese subjects ${ }^{3 *}$, patients with acromegally ${ }^{35}$ or anorexia nervosa ${ }^{36}$ showed that the estimation of body composition with BIA was valid. In contrast, in Crohn's disease BIA was found to overestimate TBW significantly by 5.9 
$( \pm 1.1) \%^{37}$. In cancer patients Simons et al found that height $/$ tesistance at $50 \mathrm{kHz}$ was a good predictor of TBW $\left(r^{2}=0.85\right.$, SEE $\left.2.2 \mathrm{~L}\right)$, but that TBW was overesti. mated in malnourished lung cancer patients. In a recent editorial ${ }^{39}$ it was discussed that BIA at $50 \mathrm{kHz}$ seems able to predict TBW in a wide range of conditions.

The use of the resistance or impedance at $50 \mathrm{kHz}$ to measure the resistance of TBW is derived from the work of Nyboer $^{40}$ who determined that this was the critical frequency ( $=$ frequency when the reactance reaches the maximum value) of muscle tissue. With respect to the fact that probably only at frequencies higher than $100 \mathrm{kHz}$ the current flows through all body tissues, the resistance at $50 \mathrm{kHz}$ seems to be suboptimal to measure the resistance of TBW ${ }^{4.5}$. Furthermore although, as summarized above, single frequency BIA measurements at $50 \mathrm{kHz}$ seem to estimate TBW reasonably, information concerming the distribution of water in intra- and extracellular compartments is not provided.

\section{Multifrequency BLA and BIS studies in health and disease: prediction of TBW}

Studies from the 1990s untill now, investigating the prediction of ECW and TBW using multifrequency BIA or BIS in healthy subjects, in general using similar measurement conditions as the present study, demonstrated promising results ${ }^{10-15.24}$. Using prediction equations including multifrequency BIA (resistance $>100 \mathrm{kHz}$ ) or BIS (Rtbw) measurements: height ${ }^{2} /$ resistance (or impedance), and/or other variables in the regression equation, the variance in TBW ranged from $83 \%$ to $98 \%$, with a SEE between $1.2 \mathrm{~L}$ and $3.6 \mathrm{~L}^{\text {(1)-15.24 }}$. In one study ${ }^{15}$, double sided and proximal measurements were used, but these different measurement conditions did not improve the prediction. Furthermore, Rtbw was used in stead of a fixed (high) frequency in the latter study ${ }^{15}$, but this also did not result in a significant improvement of the prediction of body water compartements by BIS. In contrast, in a study by Cornish et a ${ }^{\text {* }}$ in rats it was found that the impedance at the critical frequency resulted in a better prediction of TBW with a lower variation coefficient $(5.9 \%)$ compared to the variation coefficient in studies with a fixed frequency. It can be concluded from the results of all these studies, however, that the SEE of the predicted TBW obtained by multifrequency BLA or BIS is comparable or only slightly an improwement of the prediction of $\mathrm{TBW}$ resulting from the measurement at $50 \mathrm{kHz}$ as summarized earlier. 
In the present study, performed in clinically stable COPD patients, crossvalidation showed that the best predicted TBW (with the least bias, error and/or systematic fault) was obtained by the prediction equations based on emulsion theories in men, and the equation based on hefght ${ }^{2} / \mathrm{Rtbw}$ in women. Predicted TBW correlated significantly to actual TBW $(d: r=0.88, q: r=0.73)$, and there was no significant difference. The error could amount to $2.3 \mathrm{~L}$ in men and $2.9 \mathrm{~L}$ in women. In addition. the prediction of TBW in women and men using the resistivity index involved a systematic error: with a higher TBW the difference between actual and predicted TBW became larger. Compared to the prediction of TBW using the BIS, the correlation coefficient between actual and predicted TBW using BIA at $50 \mathrm{kHz}$ (and a COPDspecific regression equation from Schols et $\left.\mathrm{a}^{2}\right)$ was even better $(r=0.91)$ however, and we error amounted to $2.2 \mathrm{~L}$, with no systematic error. It can therefore be concluded that BIS did not improve the prediction of TBW by BLA at $50 \mathrm{kHz}$ in this study. This is difficult to explain from a theoretical viewpoint, but could be due to the fact that Rtbw is not actually measured, but obtained by calculations (based on a model). As mentioned above, there are no studies clearly demonstrating a lower SEE in the prediction of TBW using Rtbw or the resistance at high frequency compared to SEE of the prediction of TBW at $50 \mathrm{kHz}$ reported in numerous studies.

Multifrequency BIA and BIS studies in health and disease: prediction of ECW

In studies performed in healthy subjects, using in general comparable measurement conditions as in the present study, the prediction equations of $\mathrm{ECW}$ including either multifrequency BIA (resistance at 1 or $5 \mathrm{kHz}$ ) or BIS (Recw) measurements resulted in an $r^{2}$ ranging from 0.74 to $0.96^{10-1524}$ with an $\mathrm{SEE}$ between 0.6-1.75 L. Validation studies of multifrequency BIA or BIS in disease are limited. which is surprising since the accuracy of the prediction of ECW and TBW should particularly be studied in populations in which fluid shifts can occur. In surgical patients Haman et $\mathrm{l}^{42}$ found that predicted ECW was not derived from the resistance measurement at $5 \mathrm{kHz}$, but in stepwise regression analysis the reactance at $50 \mathrm{kHz}$ was chosen as a better predictor of ECW. It was also found in these surgical patients (after crossvalidation) that predicted $\mathrm{ECW}$ declared $86 \%$ of the explained variation in actual ECW. but that SEE was $1.7 \mathrm{~L}$. A study of Sergi et a ${ }^{43}$ showed that in patients with fluid retention states ECW was correlated $\left(\mathrm{r}^{2}\right.$ of 0.74$)$ with height ${ }^{2} /$ resistance at $1 \mathrm{kHz}$. 
whereas in healthy persons $r^{2}$ was 0.85 . Sergi et $\mathrm{al}^{43}$ found a difference between healthy and sick persons in the intercept of the regression line and suggested that there is a difference in body conductivity when water disorders occur.

In the present study the best prediction of ECW resulted in a relatively great error of $1.4 \mathrm{~L}$ in both males and femalles, and there was a low correlation (range $\mathrm{r}$ : 0.63-0.77) between actual and predicted ECW compared with the previously described studies. Particularly in men, ECW seemed better predicted (less bias, error and systematic fault) using the equations based on emulsion sciences (including patientspecific resistivity coefficients). Again, prediction of $\mathrm{ECW}$ using the resistivity index resulted in a significant systematic error (with increasing $\mathrm{ECW}$, the difference between actual and predicted ECW became larger).

It appears that ECW in this study was not predicted very accuratelly, which is not surprising since the partial correlation (correlation between ECW and RI, when the intercorrelation between TBW and ECW is accounted for) was not statistically significant in the group of patients used to derive the prediction equations. In the few other studies in healthy subjects in which the partial correlation between ECW and prediction variables was calculated, significant correlations could be found ${ }^{10.12}$.

\section{Prediction of fluid shifts}

The ratio ECW/TBW ranged from $36 \%$ to $56 \%$ in the studied COPD patients, which is comparable to the study by Hannan in the surgical patients ${ }^{42}$, whereas in the healthy subjects of the study of Marken Lichtenbelt et al ${ }^{15}$ ratio ECW/TBW ranged from $39 \%$ to $48 \%$. The error in the prediction of TBW, accompanied by the error in the prediction of ECW, and the relatively low correlation between actual and predicted ECW, probably caused the poor prediction of the ratio ECW/TBW. Mean predicted ECW/TBW based on emulsion sciences in the studied male COPD patients was not significantly different from actual ECW/TBW, but only a weak correlation between actual ECW/TBW and predicted ECW/TBW was found. To our knowledge no other clinical study has yet tested whether the errors in predicting ECW and TBW are small enough to predict the ratio ECW/TBW.

The reason for the inaccuracies in the prediction of TBW and especially ECW are probably partly due to the underlying assumptions and problems inherent to bio- 
electrical impedance. These are the errors incorporated in the prediction formulas caused by inaccuracies of the reference methods to calculate ECW and TBW' and the not entirely correct assumption that the body is an isotropic conductor with a uniform length and cross-sectional area, as explained in the review by Kushner'. Also possibly the assumptions and constants incorporated in the equations based on the theory of Hanai need reconsideration in order to improve the prediction accuracy. Furthermore, in diseases such as in COPD, physiological processes (variations of ionic concentrations, osmotic pressure, membrane function) may influence resistivity, which are not accounted for by BIS in the presently used theories and/or equations.

In summary, TBW predicted by BIS in COPD patients is comparable to, but no improvement of, the previously published prediction of TBW using BIA at $50 \mathrm{kHz}$. In general, ECW and TBW were best predicted using the theory of Hanai ${ }^{25}$ based on emulsion sciences, which corrects for non-conductive material in the body, but individual differences between actual and predicted ECW could still amount up to $3 \mathrm{~L}$. Because of these errors, the correlation between actual and predicted ratio ECW/TBW was weak, and the prediction demonstrated a relatively large error. It can therefore be concluded that the analysis of BIS needs to be improved in order to predict fluid shifts in COPD patients.

\section{References}

1 Kushner RF. Bioelectrical impedance amalysis: a review of principles and applications. 1. Anil. Col. Nutr. 1992; 11: 199-209.

2 Forbes GB. Simon W. Amatruda JM. Is bioimpedance a good predictor of body composition Change? Am. J. Clin. Nutr. 1992; 56: 4-6.

3 Thgliabue $A$, Cent H. Trentani $C$. Latizola $E$, Sitwa $S$. How reliable is bio-electrical impedance anatlysis for indiwidual patients? Int. J. Obesity 1992: 16: 649-652.

4. National institutes of health technology assessment conference statement. Bioelectrical impedance analysis in hody composition measurement. Am. J. Clin. Nutr. 1994: 64 (suppl): 5245-32s.

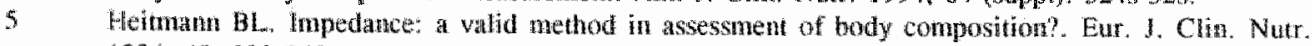
1994: 48: $228 \% 240$.

6 Keys A, Brozelk J. Henschel A. Mickelsen O, Taylor HL. The biology of human starvation. Volune I. Minneapolis, the university of mimesota press, 1950 . pp. $63-78$.

7 Moore FD, Olesen KH, Mcmurrey 1D, Parker HV. Ball MR, Boyden CM. The body cell macs and its supporting cowironment. Philadelphia, London: WB Sannders, 1963

8 Schizgal HM. Bodly composition. In: Fischer JE. ed. Surgicat nutrition. Boston. Toronto: Little, Brown and company, 1983, pp. 3-17

9 Jenin $\mathrm{P}$, Lenoir I, Rouilet $\mathrm{C}$. Thomasset $\mathrm{AL}$. Ducrot is. Determination of body fluid compartatents by electrical inpedance measurements. Aviat. Space environetal med. 1975; 46(2): 152-155.

10 Segal KR, Burastero $S$, Chung $A$, Coronel $P$. Pierson RN, Wang J. Estimation of extracellular and toral body water by multiple frequency bioelectrical-impedance measurement. Am. J. Clin. Nutr. $1991: 54: 26-29$. 
Deurenberg P. Schouten FIM. Loss of total body water and extracellular water assessed by multifrequemcy impedance: Eur. J. Clin. Nutr. 1992; 46: $247-255$.

Deunenberg $\mathbf{P}$, Schouten FIM, Andreoli A. Delorenzo A. Assissment of changes in extracellular water and total body water using multifrequency bioelectrical impedance. Basic life sci. 1993; 60: 129-132.

Van loan MD, Mayclin PL. Use of multi-frequency bioelectrical impedance analysis for the estimation of extracellular fluid. Eur. J. Clin. Nutr. 1992; 46:117-124.

Van loan MD, Withers P, Mattive J, Mayclin PL. Use of multifrequency spectroscopy to deternine extracelluar fluid, intracelluar fluid, total body water, and fat-inee mass. Basic life sci. 1993; 60: 67-132,

Marken Lichtenbelt van W, Westerterp KR. Wouters L, Luijendijk SCM. Validation of bioelectricalimpedance measurements as a method to estimate body-water comparments. Ani. I. Clin. Nutr. 1994: 60: $159-166$.

American thoracic sociely. Standards for the diagnosis and care of patients with chunic obstructive pulmonary disease (copd) and asthma. Am. Rev. Respir. Dis. 1987; 137: 225-228.

Deurenberg $P$, Westrate JA. Seidell JC. Body mass index as a measure of body fatness: age and sex specific prediction formulas. Br. J. Nutr. $1991 ; 65 ; 105-114$.

Lichtenbelt Marken van W, Kester A, Barends EM, Westerterp KR. Bromide dinuion in aduls:

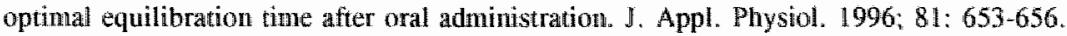

Westerterp KR, Wouters L, Marken Lichtenbelt WD. The Mastricht protocol for the measurement of body composition and energy expenditure with labeled water. Obesity research, 1995; 3: 49-57 (Suppli) 1).

Schoeller DA. Isotope dilution methods. In: Bjontröp P. Brodoft BN, eds. Obesity "Philatelphia: j. B. Lippecott company, 1992, pp, 80 88 . electrical impedance measurements of the human body. Am. J. Clin. Nutr. 1985; 41:810-817.

Quanjer PH, Tammeling GI, Cotes JE, Pedersen OF, Peslin R, Yermanlt J-C. Standardized lung function testing. Eur. Resp. J. 1983; 6 (Suppl 16): 5-40.

Foster KR, Lukaski HC. Whole body impedance-what does it measure? Am. J. Chin. Nutr. 1996 ; 64 (suppl): $388 \mathrm{~s}-96 \mathrm{~s}$.

Lorenzo de A. Andreoli A, Mathie J, Withers P. Predicting body cell mass with bioinpedance by using theoretical methods: a technological review. J, Appl. Physiol. $\llbracket 997 ; 82: 1542-58$.

Hanai T. Electrical properties of emulsions. In: Sherman PH (ed). Emulsion science. London: Acadenic press, 1968, pp. 354-477.

Altman DG, Bland JM. Measurenent in medicine: the analysis of comparison studies. The statistican. 1983:32:207-217.

Schols AMWJ, Wouters EFM, Soeters PB, Westenterp KR. Body compositurn by biomectricalimpedance analysis compared with deuterium dilution and skinfold antlaroponetry an patients whith chronic obstructive pulmonary disease. Ant. J. Clin. Nutr. 1991:53:421-424.

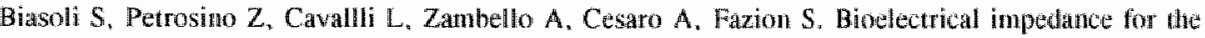
assessment of body composition of dialyzed patients. Clin. Nephrol. 1989: 31: 274-275.

Bohm D, Odaschi M, Beyerlein C. Overbeck W. Total body water: changes during dialysis estimated by bio-electrical impedance andysis. Iufusiontherapie. 1990; 17 (Suppl 3):75-78.

Thompson CM. Kong CH, Lewis CA, Hill PD. Thompson FD. Cam bio-electrical impedance be used to measure total body water in dialysis pacienis? Physiol. Meas. 1993; 14:455-461.

Snel YEM, Bnummer RIM, Bot E, Doerga ME, Zelissen PJM. Dired assessment of extracellular water volume by the bromide-dilution nethod it growth liomonedeficient adults. Eur. J. Clin. Imest. 1995; 25: 708-714.

Lands LC, Gordon C, Bar-Or O, Blinkie Cl, Haning RM, Jones NL. Moss L.A, Webber CE, Wilson WM. Heigenhauser Gif F. Comparisen of thee techniques for body composition analysis in cystic fybrosis. J. Appl. Physiol. 1993: 75: 162-166.

Newby MJ. Keim NL. Brown DL. Body composition of adult cystic fibrossis patients and conmol subjects as determined by densitonetry, bioelectrical impedance, total-body electrical conductivity. skinfold measurements, and deuterium oxide dilution. Am. J. Clin. Nutr. 1990; 52:209-213. 
34. Schizgal MM. Validation of the measurement of body composition fron whole body bio-electrical invedance. Hafusiontherapte. $1990 \% 17$ (Suppl 3): 67-74.

35 Bruminer FU, Bengtsson BA, Bosaleus I. Validation of body composition determination by bioelectrical impedance analysis in acronegaly. Eur. J. Cin. Nutr. 1992; 46: 47-52.

36 Hannan $J$, Cowen $S$, Freeman C. Mackie A. Shapiro CM. Assessment of body composition in anorexic patients. Basic life sci. 1990; 55 : 149-154.

37 Royall D, Greenberg GR, Allard JP, Baker IP, Harrison JE, Jeejeebhoy KN. Critical assessment of body conposition measuremeats in malnourished subjects with crohn's disease: the role of bioellectric impedance analysis. Ann. J. Chn. Nutr. 1994; 59: 325-330.

38. Simons JPFHA, Schols AMWJ, Westerterp KR, Velde ten GPM, Wouters EFM. The use of bicelectrical impedance analysis to predict total body water in patients with cancer cachexia. An. J. Clin. Nutr. 1995; 61: 741-745.

39 Edturial. Bioelectrical impedance and body composition. Lancet. 1992; 340 (8834-8835): 1511 .

40 Nyboer J. Electrical impedance plethysmography. Springfield, il: Charles C Thomas, 1959.

41 Contisfi BH, Thomas B], Ward LC. Improved prediction of extracellular and total body water using impedance loci generated by multiple frequency bioelectrical impedance analysis. Phys. Med. Biol. 1993: $38: 337-346$.

42 Hannan WJ, Cowen SJ, Fearon KCH, Plester CE. Falconer IS. Richardson RA. Evaluation of multifrequency biompedance analysis for the assessment of extracelleular and total body water in surgical patients. Clin. Sci. 1994: 86: 479-485.

43 Sergi G, Bussolotto M. Perini P, Calliari I, Giantin V, Ceccon A. Scanferla F, Bressan M, Moschini G. Enzi G. Accuracy of bioelectrical impedance analysis in estimation of extracellular space in healdry subjects and in fluid retention states. Ann. Nutr. Metab. 1994; 38: 158-165. 


\section{TOTAL FREE LIVING ENERGY EXPENDITURE IN PATIENTS WITH SEVERE CHRONIC OBSTRUCTIVE PULMONARY DISEASE}

Erica M. Buarends', Annemie M.W.J. Schols". Dophne L.E. Pannemans", Kloas R. Wescerterp', Emiel F.M. Wouters". "Deptartments of Pulmonology and" Human Biology", Maastricht University. Madutricht, "Asthma Centre Homerheide. Hom, The Netherlands.

\section{Abstract}

Resting energy expenditure (REE) is often elevated in patients with Chronic Obstructive Pulmonary Disease (COPD), but no data are available regarding total energy expenditure in free living conditions. We compared total daily energy expenditure (TDE) in eight COPD patients (FEV, $36 \pm 13 \%$ ), admitted to a pulmonary rehabilitation center, and eight independently living healthy subjects, matched for sex, age and body mass index (BMI). TDE was measured over a 2-wk interval using doubly labelled water in combination with measurements of REE and body composition. The COPD patients had a significantly higher TDE than the healthy subjects $(2499 \pm 320$ $\mathrm{kcal} / 24 \mathrm{~h}$ and $2107 \pm 88 \mathrm{kcal} / 24 \mathrm{~h}$ respectively, $\mathrm{p}<0.01$ ). The nonresting component of TDE (TDE-REE: physical activity and diet-induced thermogenesis (DIT)) was significantly higher in the COPD patients than in the healthy subjects, resulting in a ratio between TDE and REE of $1.7 \pm 0.2$ and $1.4 \pm 0.1$ respectively $(\mathrm{p}<0.01)$. The results indicate that COPD patients exhibit an increased TDE in comparison with healthy subjects. The difference could be attributed to an increase in the nonresting component of TDE, since REE was comparable between the groups. 


\section{Introduction}

Weight loss is common in Chronic Obstructive Pulmonary Disease (COPD) ${ }^{1.2}$. It involves both a decrease in fat mass and wasting of fat-free mass ${ }^{3}$. The influence of these changes in body composition on several important aspects of the disease is considerable. Weight loss and a low body weight correlate with morbidity and with a poor prognosis ${ }^{2,4}$. In addition, muscle wasting in COPD patients is associated with a decreased diaphragmatic size, a decrease in respiratory muscle strength and endurance $^{3,6}$ and impaired physical fitness ${ }^{7,8}$.

The cause of weight loss in COPD patients is still not fully known, but has been predominantly ascribed to a disturbed energy balance. Because a reduction in energy intake has not been demonstrated in COPD patients ${ }^{910}$, increased attention has been focused on their energy expenditure. Several factors contribute to the amount of energy required by an individual: resting energy expenditure (REE), physical activity, and to a lesser extent the diet-induced thermogenesis (DTT). Because of the methodological difficulties in measuring total daily expenditure (TDE), generally only REE has been measured. Several studies have shown that a substantial percentage of COPD patients exhibit an increased REE ${ }^{11.12}$. Normal as well as increased DIT values have been found in COPD patients ${ }^{13-15}$. However, since DIT accounts only for $10 \%$ of TDE, the influence of a possible increased DIT on TDE seems small. No data are available regarding reliable measured energy requirements of physical activity and TDE in free living conditions in COPD patients.

In this study. TDE was measured by the doubly labelled water technique in COPD patients, and compared with TDE of healthy subjects matched for age, sex, and body mass index (BMI).

\section{Methods}

\section{Parients}

Eight patients with moderate to severe $\mathrm{COPD}^{16}$ in stable clinical condition were studied. The patients were admitted to a pulmonary rehabilitation center. Only men were included in this study, to exclude effects due to sex differences. Patients with an arterial oxygen pressure $\left(\mathrm{PaO}_{2}\right)<7.3 \mathrm{kPa}$, or suffering from cancer, unstable cardiac 
condition (i.e. decompensated cor pulmonale), active gastrointestinal abnormalities, recent surgery, severe endocrine disorders, locomotor disease or obesity (body weight $>120 \%$ of ideal weight) were excluded from the study. The patients were fully informed of the nature and purpose of the study and gave informed consent. The study was approved by the local ethical committee. Procedures followed were in accord with the Helsinki declaration from 1977 as revised in 1983.

\section{Control subjects}

Control subjects were eight healthy men matched for age and BMI with the eight patients studied. They were selected from sixteen free-living healthy elderly men who participated previously in a study of Pannemans and Westerterp ${ }^{17}$. The eight remaining men had a significantly higher BMI $\left(27.6 \pm 1.1 \mathrm{~kg} / \mathrm{m}^{2}\right)$ than the eight subjects selected as matched controls $\left(22.4 \pm 2.5 \mathrm{~kg} / \mathrm{m}^{2}, \mathrm{p}<0.001\right)$.

\section{Total daily energy expenditure}

The premise of the doubly labelled water technique is that after a loading of water labelled with deuterium $\left({ }^{2} \mathrm{H}\right)$ and labelled oxygen $\left({ }^{18} \mathrm{O}\right)$, the ${ }^{2} \mathrm{H}$ is eliminated from the body as water, whereas the ${ }^{18} \mathrm{O}$ is eliminated from the body as water and carbon dioxide $\left(\mathrm{CO}_{2}\right)$. The difference between the elimination rates is therefore proportional to $\mathrm{CO}_{2}$ production and hence energy expenditure ${ }^{18}$.

Energy expenditure was determined following the standard Maastricht protocol as described by Westerterp et $\mathrm{al}^{19}$. In the late evening a baseline urine-sample was collected. Then, a weighted isotope dose was administered at 10.00 p.m., a mixture of 10 atom percentage excess (APE) ${ }^{18} \mathrm{O}$ and 5 APE ${ }^{2} \mathrm{H}$. Subsequently, the isotopes equilibrate with the body water (during equilibration the patient does not consume any food or drink) and the initial urine sample was collected the next morning (Day 1) from the second voiding. Further urine samples were collected in the evening of Day 1 and in the morning and evening of Day 8 and 15. In the evening of Day 15, at 10.00 p.m. after voiding, a (weighed) dose of ${ }^{2} \mathrm{H}_{2} \mathrm{O}$ was administered and the second voiding on Day 16 (after \pm 10 h of equilibration) was sampled for calculation of total body water. Isotope ratios in urine samples were measured by isotope ratio mass spectroscopy (Aqua Sira, VG-Isogas, UK). Calculated carbon dioxide production was convented to 
energy expenditure assuming a respiratory quotient (RQ) of $0.85^{1 /}$.

Resting energy expenditure

REE was measured by an open-circuit indirect calorimetry system using a ventilated hood system (Oxyconbèta, Jaeger, Würzburg, Germany) ${ }^{20}$. The principle of the measurement is that a stream of room air $(40 \mathrm{~L} / \mathrm{min})$ is drawn through the hood, which mixes with the expired air, and is collected in the transparent Plexiglas hood placed over the subject's head. The oxygen consumption and carbon dioxide production are calculated from the difference between incoming and outcoming gases. Energy expenditure was calculated from the abbreviated Weir formula ${ }^{2 !}$. Measurements were done in the early morming after an overnight fast, while the person was comfortable lying on a bed in supine position. The system was callibrated before measurements were taken, and the accuracy of the system was regularly tested with an ethanol combustion test.

Body composition

Anthropometric dlata were collected following standard procedures. BMI was calculated as weight $(\mathrm{kg})$ divided by height ${ }^{2}(\mathrm{~m})$. Total body water (TBW) was determined by deuterium dilution as described previously, and was calculated as the measured deuterium space divided by $1.04^{22}$. Fat free mass (FFM) was calculated assuming a hydration factor of $73 \%$ of TBW.

\section{Pulmonary function}

Lung function measurements included flow wolumes (forced expiratory volume in 1 second: FEV; forced vital capacity: FVC), and diffusing capacity of CO (DL ${ }_{\mathrm{CO}}$ ) measured by the single breath method (Masterlab, Jacger, Würzburg, Germany). The highest value of at least three measurements was used and expressed as a percentage of the reference value ${ }^{23}$. Blood was drawn from the brachial artery at rest while breathing room air. Blood gases were analyzed on a blood gas analyzer (Model ABL 330 ; Radiometer, Copenhagen). 
The healthy subjects completed a standardized activity questionnaire ${ }^{24}$. In this questionnaire (Zutphen physical activity questionnaire, PA-Q) several standard activities are mentioned (walking, cycling, gardening, jobs around the house, household jobs, sport activities, hobbies, and walking stairs), and subjects were asked for how long these activities were performed "last week".

The patients participated in a pulmonary rehabilitation regimen that includes a standard activity programme on weekdays. The patients performed physical activies like gymnastics, cycling and walking, strength training and/or upper extremity training, pulmonary and exercise tests but also several sedentary activities are a part of the programme. These include educational lectures, relaxation sessions, and talks with the physician or other caretakers. In the evening no physical activities were scheduled and most patients performed sedentary leisure activities (reading, puzzlings, playing games, ect.). In Table 1 an example of a weekly activity schedule is presented. The prescribed activities were retrospectively filled in the PA-Q, from which the estimated activity time of the patients was calculated.

\section{Data analysis}

Results are described individually and as mean \pm SD. Differences between the groups were tested with the Mann-Whitney $U$ test; the level of significance was $p<$ 0.05 . 
Table I: Example of mandand activities of the pulmonary rehatititaton programme (weekend not included)

ADL: achivitios of daily liwing

"Moming tess: phwhonary function, body composition, resting exergy expenditure

Miday test: I/wonth incremental cycte ergometry test, $2 /$ month $12 \mathrm{~min}$ walking test

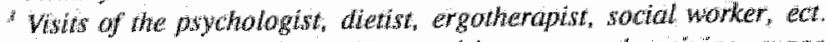

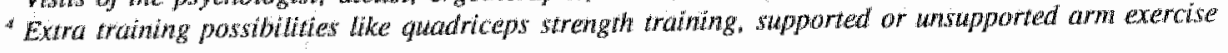

\begin{tabular}{|c|c|c|c|}
\hline : & ADL & Eweryday & Extras \\
\hline \multirow[t]{3}{*}{ Morning } & $\begin{array}{l}6.00 \text { and. awakened } \\
\text { (medicine round) }\end{array}$ & Thorax massage & $\begin{array}{l}\text { Visit of puimonary } \\
\text { pliysician }(1 / \mathrm{wk})\end{array}$ \\
\hline & Washng, dressing (th) & Gymmastics $(1 / 2 h)$ & Test $(1-2 / w k)^{\prime}$ \\
\hline & $8.00 \mathrm{am}$. breakfast $(\mathrm{t} / \mathrm{h})$ & Cycling $(1 / 4 h)$ & \\
\hline \multirow[t]{5}{*}{ Midlday } & Lunch (1 h) & Cycling $(1 / 2 h)$ & $\begin{array}{l}\text { Exercise test } 2 \text { or } \\
4 / \mathrm{moy}\end{array}$ \\
\hline & Sleeping resting $(1 / x h)$ & Relaxation (1 h) & $\begin{array}{l}\text { Educational lectures (1) } \\
\text { h/wh) }\end{array}$ \\
\hline & & Wallking (1 In) & $\begin{array}{l}\text { Visit disciplines }{ }^{3} \\
\left(1 \mathrm{~h} / \mathrm{wk}^{\mathrm{k}}\right)\end{array}$ \\
\hline & & & $\begin{array}{l}\text { Extra training } \\
\left.\text { (3 tines } 1 / 2 \mathrm{~h} / \mathrm{wk}^{4}\right)\end{array}$ \\
\hline & & & $\begin{array}{l}\text { Leisure activities } \\
\text { (1 midday/mo) }\end{array}$ \\
\hline \multirow[t]{3}{*}{ Evenimg } & 22.00 h. Last medicine round & & Watching television \\
\hline & Undressing & & Leisure activities \\
\hline & around 23.00 p.ar. sleeping & & \\
\hline
\end{tabular}

\section{Results}

The characteristics of the study group as well as the results of the pairwise matching are shown in Table 2. The studied COPD patients suffered from a severe airflow obstruction. Except for one patient, all patients had an impaired diffusing capacity adjusted for alveolar volume $\left(\mathrm{K}_{\mathrm{co}}\right)$. Measurements of body composition were not significantly different between patients and control subjects. 
Table 2: Lung function and body composition: individual and mean values ( $\pm \$ D$ ) of patients and conirol subjects.

P; patient: H: healthy subject, FEV : forced expiratory wolume in 1 second, as percentage of predicted $K_{c o:}$ diffusing capacity of carbon monoxide, corrected for alveolar wolume, as pencentage of predicted. $\mathrm{PaO}_{2}$ arterial oxygen pressure; BMI: body mass index (weight/length'2): FFM: fat-free mass: FM: fat mass.

\begin{tabular}{|c|c|c|c|c|c|c|c|c|c|c|}
\hline \multicolumn{2}{|l|}{$\begin{array}{l}\text { Age } \\
\text { (yr) }\end{array}$} & \multicolumn{2}{|c|}{$\begin{array}{l}\mathrm{BMI} \\
\left(\mathrm{kg} / \mathrm{m}^{2}\right)\end{array}$} & \multicolumn{2}{|l|}{$\begin{array}{l}\text { FFM } \\
(\mathrm{kg})\end{array}$} & \multicolumn{2}{|c|}{$\begin{array}{l}\text { FM } \\
\text { (\%weight) }\end{array}$} & \multirow{2}{*}{$\begin{array}{l}\mathrm{FEV}_{1} \\
(\%)\end{array}$} & \multirow{2}{*}{$\begin{array}{l}\mathrm{K}_{\mathrm{co}} \\
(\%)\end{array}$} & \multirow{2}{*}{$\begin{array}{l}\mathrm{PaO}_{2} \\
(\mathrm{kPa})\end{array}$} \\
\hline $\mathrm{P}$ & $\mathbf{H}$ & $\mathrm{P}$ & $\mathrm{H}$ & $P$ & $\mathrm{H}$ & $\mathrm{P}$ & $\mathrm{H}$ & & & \\
\hline 74 & 66 & 19.0 & 18.8 & 41.1 & 52.9 & 18.1 & 18.9 & 37 & 61 & 10.0 \\
\hline 71 & 77 & 24.2 & 24.9 & 46.3 & 50.8 & 29.6 & 35.0 & 49 & 65 & 12.2 \\
\hline 62 & 65 & 18.0 & 18.7 & 45.9 & 46.3 & 16.8 & 18.1 & 27 & 42 & 8.5 \\
\hline 67 & 69 & 25.0 & 25.1 & 53.7 & 47.9 & 29.2 & 25.3 & 25 & 53 & 10.0 \\
\hline 59 & 69 & 20.7 & 22.0 & 47.6 & 45.6 & 22.2 & 22.9 & 30 & 35 & 8.5 \\
\hline 71 & 79 & 22.9 & 22.9 & 46.8 & 52.3 & 24.2 & 22.6 & 61 & 109 & 12.1 \\
\hline 58 & 77 & 20.7 & 23.4 & 47.0 & 43.7 & 18.2 & 27.2 & 21 & 55 & 10.8 \\
\hline 70 & 80 & 23.4 & 23.5 & 40.3 & 48.1 & 33.9 & 25.8 & 37 & 35 & 10.3 \\
\hline 66.5 & 72.8 & 21.8 & 22.4 & 46.1 & 48.5 & 24.0 & 24.5 & 35.8 & 56.9 & 10.3 \\
\hline$\frac{ \pm}{6.1}$ & $\frac{ \pm}{6.1}$ & $\frac{\sharp}{2.5}$ & $\stackrel{ \pm}{2.5}$ & $\begin{array}{l}t \\
4.1\end{array}$ & $\frac{ \pm}{3.3}$ & $\begin{array}{l} \pm \\
6.3\end{array}$ & $\begin{array}{l} \pm \\
5.3\end{array}$ & $\frac{ \pm}{13.4}$ & $\stackrel{t}{23.9}$ & $\pm_{1.4}$ \\
\hline
\end{tabular}

\section{Energy expenditure}

TDE was significantly higher $(p<0.01)$ in the COPD patients $(2499 \pm 320$ kcal/24h) compared to the healthy subjects $(2107 \pm 88 \mathrm{kcal} / 24 \mathrm{~h})$. Figure 1 shows that resting energy expenditure (in absolute terms) was comparable in both groups (COPD: $1471 \pm 174 \mathrm{kcal} / 24 \mathrm{~h}$, healthy: $1474 \pm 138 \mathrm{kcal} / 24 \mathrm{~h})$. The non-resting component of TDE (TDE - REE) was significantly higher in the COPD patients (1028 \pm 236 $\mathrm{kcal} / 24 \mathrm{~h}$, healthy: $633 \pm 90 \mathrm{kcal} / 24 \mathrm{~h}$ ). 
A

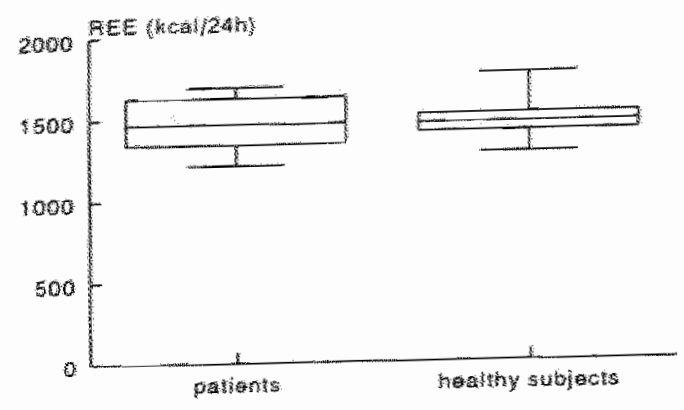

Rigure I: Resting energy expenditwe (6) and the afference between tow daily energy expenditure and rusting energy expenduture (B) in the copo putients and the healthy subjects.

Box plots indicate the $25 \%$, 50 h, and 75 h percentle of the

c

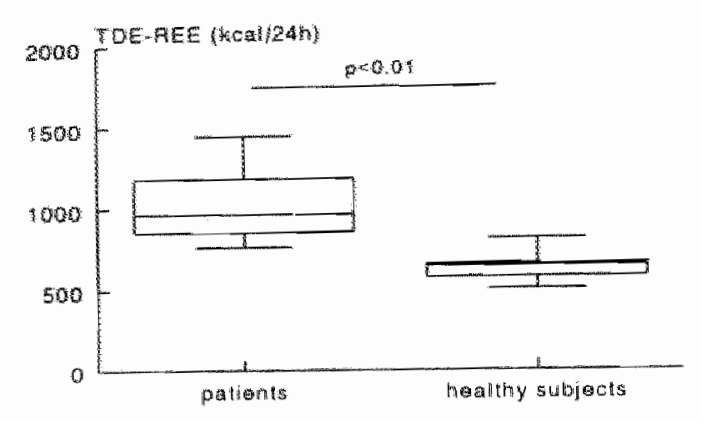
iflustrated data

Furthemore, the ratio TDE/REE was significantly higher in the COPD patients (figure 2) ranging from 1.5 to 2.0 compared to a range from 1.3 to 1.6 in the healthy subjects $(p<0.01)$. According to Carpenter et a ${ }^{25}$ the relationship between TDE and REE is shown for patients and control subjects in Figure 3. This figure also demonstrates that the patients had an increased TDE relative to their REE. 


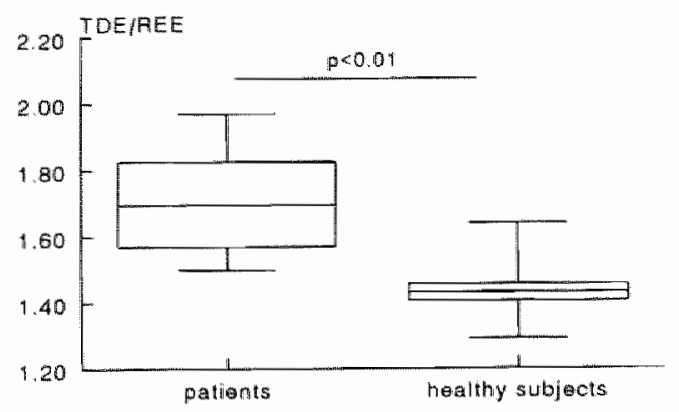

Figure 2: Rario of daily energy

expenditure/resting energy expenditure in COPD patients

and heallhy subjects.

Box plots indicate the $25 \mathrm{~h}$, $50 \mathrm{th}$, and 75 th percentile of the illustrated data.

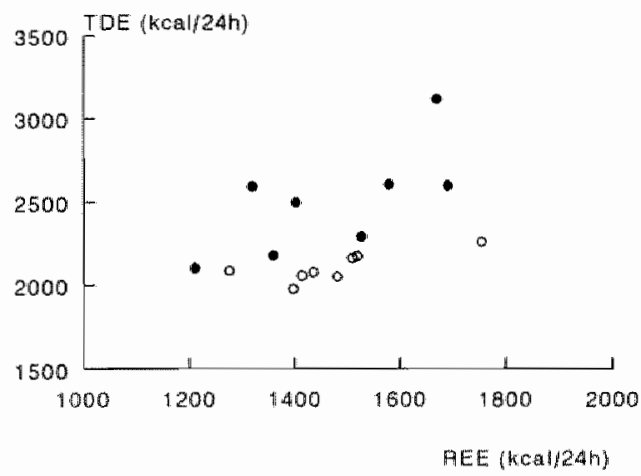

Figure 3: Ratio between TDE and REE fot the patients (closed circles) and matched control subjects (open circles)

Acrivity patern

Most patients rested or slept at $23.00 \mathrm{~h}$. and were awakened at $6.00-6.30 \mathrm{~h}$. which amounted to 7 to 7.5 hours sleep/rest during the night. Most patients however also rested/slept after lunch approximately 0.5 - I hour. Therefore total sleep time was estimated as approximately 7.5 to 8.5 hours for the patients. The results of the PA-Q indicated that mean sleeping time amounted to $9 \pm 2 \mathrm{~h} / 24 \mathrm{~h}$ for the matched control subjects. 
When prescribed activities for the patients were retrospectively filled in the PA-Q. the average estimated activity time amounted to approximately $138 \mathrm{~min} / 24 \mathrm{~h}$. The matched control subjects reported a total physical activity time of $155 \pm 57 \mathrm{~min} / 24 \mathrm{~h}$.

Furthermore, following the PA-Q the eight healthy men not selected as control subjects (from the total of 16 elderly men studied previously ${ }^{17}$ ) had a total daily physical activity time of $121 \pm 88 \mathrm{~min}$, which was not significantly different from the physical activity time of the eight matched control subjects.

Because the TDE/REE of the healthy control subjects might have been lower than typical for this age group, we also compared with the ratio with that of the remaining eight healthy elderly men (with a higher BMI) of the total group of 16 subjects from which the matched controls were selected. The average ratio TDE/REE for the eight subjects not selected as controls was significantly higher $(1.6 \pm 0.3)$ than the TDE/REE of the eight matched controls $(1.4 \pm 0.1, p<0.05)$. However, when adjusted for FFM/height ${ }^{2}$ the ratio TDE/REE was comparable between these groups (rest of healthy subjects: $1.51 \pm 0.2$, eight matched controls: $1.53 \pm 0.2, \mathrm{NS}$ ).

\section{Discussion}

The patients with COPD exhibited a higher TDE in comparison with healthy age matched subjects, when body composition was accounted for. The difference in the ratio TDE/REE between the groups can be attributed to the nonresting component of TDE, since REE was not significantly different.

Until now, no reliable measurements were available of TDE in free living conditions in COPD patients. Hugli et al ${ }^{26}$ studied TDE in a respiration chamber in COPD patients and showed that the TDE corresponded to $1.1-1.4$ of measured REE in these patients. This ratio is much lower than the mean ratio TDE/REE of 1.7 observed in this study. Measurements in the respiratory chamber and the doubly labelled water technique are the only ways available to measure TDE. Values of TDE obtained in the respiratory chamber may be low because the chamber allows only limited activity. Indirect evidence for a high TDE in patients with COPD was provided by several refeeding studies that did not result in a satisfactory weight gain in COPD patients ${ }^{27}$, despite an apparent adequate oral energy supplementation.

The comparable REE between COPD patients and healthy subjects, in this study, may appear differen from previous reports but could also be due to a selection "bias", 
since we deliberately selected normometabolic as well as hypermetabolic COPD patients to participate in this study. Furthermore, the comparable REE could be explained by a good pairwise match of BMI of the control group. It might also be a reflection of the fact that the studied healthy elderly were relatively active. Several studies have suggested that regular physical exercise may attenuate the age-related decline in $\mathrm{REE}^{28.29}$. Nevertheless, since in this study the REE was comparable in both groups, the increased TDE can clearly be attributed to the nonresting component.

The nonresting component of TDE is represented by the DIT, and energy expenditure associated with activities. The mean difference of the ratio TDE/REE between COPD patients and healthy subjects was $30 \%$ of REE. The DIT reported for COPD patients varies around $11 \%$ to $18 \%$ of baseline energy expenditure ${ }^{30}$, and therefore cannot totally explain the high nonresting component. This suggests an increased energy expenditure for activities in COPD patients.

The cause for an elevated energy expenditure for activities is not known. Levison and Cherniack ${ }^{31}$ reported an increased oxygen cost of breathing particularly during exercise in COPD patients, which may partly explain the increased energy expenditure during activities, since during exercise breathing accounts for a substantial part of total energy expenditure ${ }^{3 x}$. However, it could also be hypothesized that the mechanical efficiency of peripheral skeletal muscle is decreased in COPD patients. Recent studies using nuclear magnetic resonance techniques observed an earlier anaerobic energy deliverance during exercise in COPD patients ${ }^{33,34}$. Because the efficiency of anaerobic work is $13 \%$ versus $23 \%$ for aerobic work ${ }^{35}$, this may support the hypothesis of a decreased mechanical efficiency in COPD patients.

It could be argued that the COPD patients had a higher TDE, because they were admitted to a pulmonary rehabilitation center, and therefore performed more activities than the healthy age-matched subjects. The estimated amount of sleep (rest) time for the patients was $8 \mathrm{~h}$, and the healthy subjects reported approximately $9 \mathrm{~h}$ sleep. This suggests that the amount of time awake was comparable between the groups.

The eight matched control subjects completed a $\mathrm{PA}-\mathrm{Q}$ and reported approximately $155 \mathrm{~min} / 24 \mathrm{~h}$ physial activities (including gardening, ect.). We do not have comparable PA-Q data in the COPD patients, but in an earlier study we analyzed the amount of time spent in different activities (by activity diaries) in 11 other patients, participating in the pulmonary rehabilitation programme, and found that the mean duration of the activities requiring physical performance (walking, gymnastics, cycling) was 
approximately $149 \mathrm{~min} / 24 \mathrm{~h}^{36}$. For the eight COPD patients in the present study we estimated the total daily physical activities of $138 \mathrm{~min} / 24 \mathrm{~h}$, based on our interpretation of the clinical treatment programme in the rehabilitation center. Although the difference in the methodology used limits an accurate comparison between the groups, these arguments support the suggestion that the time during which activities were performed was comparable between the groups.

We recognize that the eight matched controls had a relatively lower ratio TDE/REE (1.4 \pm 0.1$)$ compared with other studies ${ }^{37.38}$. However, these men were selected from a group of 16 healthy elderly. The remaining group of men (with a higher BMI) had a significantly higher ratio TDE/REE than the eight matched control subjects. However, when the ratio was adjusted for FFM-index (FFM/height ${ }^{2}$ ), the ratio TDE/REE of the matched controls was simillar to that of the healthy men, who were not selected as control subjects from the total of 16 men studied earlier ${ }^{17}$. This observation confirms an earlier study in which a significant relationship between ratio TDE/REE and FFM-index was reported ${ }^{39}$. Furthermore, the amount of time spent to activities was comparable in all 16 healthy men. This comparison supports our choice to match patients and controls for BMI and shows that a lower ratio TDE/REE does not necessarily means that fewer activities have been performed.

Although the above-stated arguments support the suggestion that the higher TDE of the COPD patients compared with the healthy subjects can at least not be fully explained by a difference in activity pattern between the studied groups, we acknowledge that the COPD patients participating in the rehabilitation programme probably performed more activities than they would have done at home. Nevertheless, the high TDE that was found in this study has an important therapeutic implication. The higher energy needed for activities in the studied COPD patients compared with the healthy subjects despite (most likely) a comparable activity pattern suggests that physical activity represents a relatively high metabolic demand for COPD patients. This may explain partly why several refeeding studies in COPD patients were not able to result in a satisfactory weight gain and improvement of functional performance. In COPD patients, the energy requirements have to be taken into account for repletion of FFM as well as the extra energy needed for activity. Especially considering that we recently showed that in order to achieve a satisfactory increase in metabolic active tissue mass, oral supplementation should be given in combination with exercise $\mathrm{e}^{40}$.

In conclusion, this first study measuring TDE in free living conditions in COPD 
patients demonstrates that TDE is increased, which in this study could primarily be atributed to the nonresting component of TDE. In addition to our earlier reported nutritional intervention study, the results of this study provide important new therapeutic guidelines. In order to maintain or increase FFM in depleted COPD patients, a high metabolic demand of activities should be taken into account and oral supplementation in combination with exercise should be at least 1.7 of measured REE or more.

\section{References}

1 Openbrier DR, Irwin MM, Rogers RM, Gottleib GP, Dauber JH, Vanheil OH. Nutritional status and lung function in patients with emphysema and chronic bronchitis. Chest 1982; 82: 568-571.

2 Wilson DO, Rogers RM, Wright E, Anthonisen NR. Body weight in chronic obstructive pulmonary disease. An. Rev. Resp. Dis. 1989; 139:1435-1438

3 Schols AMWJ, Soeters PB, Dingemans AMC, Mostert R, Frantzen PJ. Wouters EFM. Prevalence and characteristics of nutritional depletion in patients with stable COPD eligible for pulmonary rehabilitation. Am. Rev. Respir. Dis. 1993; 147:1151-1156.


obstnctive lung disease. Am. Rev. Respir. Dis. 1967; 95: 556-566.

5 Rochester DF. Body weight and respiratory muscle function in chronic obstructive pulmonary disease. Am. Rev. Respir. Dis. 1986: 134: 646-648.

6 Morrison NJ, Richardson J, Dunn L, Pardy RL. Respiratory muscle performance in nomal elderly subjects and patients with COPD. Chest 1989; 95:90-94.

7 Schols AMWJ, Mostert R. Soeters PB, Greve LH, Wouters EFM. Nutritional state and exercise performance in patients with chronic obstructive lung disease. Thorax 1989; 44:937-941.

8 Gray-Donald K, Gibbons L, Shapiro SH, Martin JG. Effect of nutritional state on exercise performance in patients with chronic obstructive pulmonary disease. Am. Rev. Respir. Dis. 1989: 140: $1544-11548$.

9 Hunter AMB, Carey MA, Larsh HW. The nutritional status of patients with chronic obstructive pulmonary disease. Am. Rev. Respir. Dis. 1981; 124:376-381.

10 Braun SR. Keim NL. Dixon RM, Clagnaz. P. Anderegg A. Shago ES. The prevalence and determinants of nutritional changes in chronic obstructive pulmonlary disease. Chest 1984; 86:558-563.

11 Goldstein S. Askanazi J, Weissman C, Thomashow B, Kinney JM. Energy expenditure in patients with chronic obstructive pulmonary disease. Chest 1987; 91: 222-224.

12 Schols AMWI, Fredrix EWHM, Soeters PB. Westerterp KR, Wouters EFM. Resting energy expenditure in patients with chronic obstructive pulmonary disease.

Am. J. Clin. Nutr. 1991: 54:983-987.

13 Green JH. Muers MF. The thermic effect of food in underweight patients with emphysematous. chronic obstructiev pulmonary disease. Eur. Respir. J. 1991; 4:813-819.

14 Goldstein SA. Thomashow BM, Kvetan V, Askanazi J, Kimey JM, Elwyn DH. Nitrogen and energy relationship in malnourished patients with emphysema. Ann. Rew. Respir. Dis. 1988; 138: 636-644.

15 Green JH Muers MF. Comparisons between basal nnetabolic rate and diet-induced thermogenesis in different types of clironic obstructive pulmonary disease. Clin. Sci. 1992; 83: 109-116.

16 American Thoracic Society. Standards for the diagnoses and care of patients with chronic obstructive pulmonary disease (COPD) and asthma. Am. Rev. Respir. Dis. 1987: 137:225-228.

17 Pannemans DLE. Westerterp KR. Estimation of energy inake to feed subjects at energy balance as verified with doubly labelled water: a study in the elderly. Eur. J. Clin. Nutr. 1993:47:490-496. 
Schoetfer DA, Rawussin E. Schutz Y. Acheson KJ. Baertschi P. Jequer E. Energy expenditure by double labled water: validation in humans and proposed calculation. Am. I. Physiol. 1986: 250:R82$3-\mathrm{m} 830$.

19 Westerterp KR, Wouters L. Marken Lichtenbelt WD. The Maastricht protocol for the measurement of body composition and energy expenditure with labelled water. Obesity Research 1995; 3:49-57.

Schols AMWJ, Schoffelen PF, Ceulemans H. Wouters EFM, Saris WH. Measurement of REE in patients with COPD in a clinical setting. J. Parenter. Enter. Nutr. 1992; 16: 364-368.

21 Weir JB. New methods for calculating metabolic rate with special reference to protein merabolism. $\mathbb{~}$ Physiol. 1949; 109: 1-9.

Schoeller DA. Isotope dilution methods. In: Bjöntrop P. Brodoff BN, editors. Obesity. J.B. Lippencoth, Philadelphia, 1992: 80-88.

23 Quanjer Ph ed. Standardized lung function testing. Bulletin Europ. Physiopathol. Resp. 1983; 19: 7 44.

24 Caspersen CJ, Bloemberg BPM, Saris WHM, Merrit RK, Kromlnout D. The prevallence of selected physical activity and their relation with coronary heart disease risk factors in elderly men: the Zutphen Study 1985. Am. J. Epidemiol. 1991; 133: 1078-1092.

Carpenter WH, Poehlman ET, O'Connell M. Goran MJ. Influence of body composition and resting metabolic rate on variation in total energy expenditure: a meta-analysis. Am. I. Clin. Nutr. 1995: 61: 4-10.

26 Hugli $O$. Schutz $Y$. Fitting JW. The daily energy expenditure in stable clironic obstructive pulmonary disease. Am. J. Respir. Crit. Care Med. 1996: 153: 294-300.

27 Schols AMWJ. Wouters EFM Wouters. Nutritional considerations in the treatment of chronic abstruc(ive pulmonary disease. Cli. Nutr. 1995; 14:64-73.

28. Fukagawa NK, Bandini LG. Young JB. Eflect of age on body composition and resting metabolic rate. Am. J. Physiol. 1990: 259: E233-E238.

29 Poehlman ET. Berke EM, Gardner AW, Katzman-Rooks SM. Goran MI. Influence of aerobic capacity. body conposition, and thyroid hormones on the age related decline in resting metabolic rate. Metabolism 1992; 41: 915-921.

30 Hugli $O$, Frascarolo $P$. Schutz $Y$, Jequier $\mathbb{E}$, Lenenberger $\mathbb{P}$. Fitting JW. Diet induced thernogensesis in chronic obstructive pulmonary disease. Am. Rev. Respir. Dis. 1993; 48: 1479-1483.

31 Levison H, Cherniack RM. Ventilatory cost of exercise in chronic obstructive pulnonary disease. J. Appll. Physiol 1968; 25: 21-27.

32 Otis AB. The work of breathing. In: Fishman AP, Geiger SR. editors. Handhook of physiology, Respiration. Washington D.C. Am. Physiol. Soc., 1964, sect. 3, vol. 1. chapt. 17. p463-476.

33 Kutsuzawa T, Shioya S, Kurita D, Haida M, Ohta Y, Yambayashi. 31P-NMR study of skeletal muscle metabolism in patients with chronic respirotary impaimtent. Am. Rev. Respir. Dis. 1992:146:1019. 1024


lism in COPD during oxygen supplenentation in patients with clmonic hypoxemia. Am. Rev. Respir. Dis. 1993: 147: $592-598$.

35 Shephard R. Efficiency of muscular work, some clinical implications. Phys. Ther. 1975:55:476-481.

36 Finke $A$. Rens K. Schols AMWI. Wourers EFM. Indirect assessment of 24 hours energy expendiute in COPD (alsstraco). Eur. Respir. J. 1991: 4 (14): 573s.

37 Robers SB, Young VR, Fuss P. Heynan NB, Finatarone M, Dallal GE, Cortiellat I. Evans WJ. Whal are the dietary energy needs of elderly adults? Int. J. Obesiry 1992: 16: 969-976.

38 Reilly JJ, Lord A. Bunker WW, Prentice AM, Coward WA, Thomas All \& Briggs RS. Energy balance in healthy elderly women. Brit. J. Nuir. 1993; 69: 21-27.

39 Pannemans DLE, Westerterp KR. Energy expenditure, pliysical activity, and basal metabolic rate of elderly subjects. Brit. J. Nutr. 1995; 73:571-581.

40 Shtols AMWJ. Soeters PB, Mosteri R. Pluymers RJ, Wouters EFM. Plysiological effects of nutritional support and anabolic steroids in COPD patiens, a placebo controlled randomized trial. An. I. Respir. and Cri. Care Med. 1995; 152: 1268-1274. 


\section{TOTAL DAILY ENERGY EXPENDITURE \\ RELATIVE TO RESTING ENERGY EXPENDITURE \\ IN CIINICALLY STABLE PATIENTS WITH CHRONIC \\ OBSTRUCTIVE PULMONARY DISEASE}

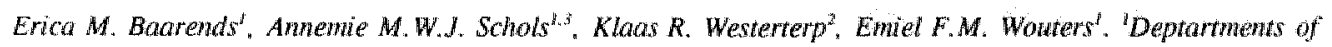
Pulmonology and Human Biology. Maastrich University. Maastricht, Asthma Center Homerheide. Horth, The Netheriands.

\section{Abstract}

An elevated resting energy expenditure (REE) commonly occurs in patients with Chronic Obstructive Pulmonary Disease (COPD). The purpose of this study was to investigate the effect of an increased REE on total daily energy expenditure (TDE) in 20 patients with COPD (190, 19) with a mean (SD) forced expiratory volume in 1 second of 37 (14) \% predicted. TDE was measured over a two week interval using doubly labelled water. Fat-free mass (FFM) was calculated from total body water assessed by deuterium dilution. REE was measured by indirect calorimetry using a ventilated hood system. The patients $(n=100)$ with a significantly higher $\mathrm{REE}$ than those with a normal REE (median difference; $205 \mathrm{kcal} / 24 \mathrm{~h} \mathrm{p}<0.05$ ), had a comparable TDE (median, range, hypermetabolic at rest: $2593 ; 2127-3083 \mathrm{kcal} / 24 \mathrm{~h}$, normometabolic at rest: $2629 ; 2032-3179 \mathrm{kcal} / 24 \mathrm{~h}$ ). There was no difference in mean daily heart rate (HR) between the groups (hypermetabolic at rest: $92 ; 82-98$, normometabolic at rest: $98 ; 75-116 / \mathrm{min}$ ), or the variation of HR during the day. By means of multiple regression analysis it was shown, that REE did not correlate significantly with TDE, when FFM was taken into account. This study shows that there is no significant difference in free-living TDE between clinically stable patients with COPD with an elevated REE and those with a normal REE. Variation in TDE in patients with COPD appears to reflect differences in energy expenditure for activities, but not in REE. 


\section{Introduction}

Weight loss is a common problem in patients with Chronic Obstructive Pulmonary Disease (COPD), which comprises loss of fat mass as well as fat-free mass $^{1-2}$. Nutritional depletion is particularly relevant for the clinical condition of patients with COPD, because it adversely affects functional performance and survival ${ }^{3-}$ 6.

Weight loss occurs when energy expenditure exceeds energy intake, that is, when an individual is in a negative energy balance. In many patients with COPD an increased resting energy expenditure (REE) has been demonstrated ${ }^{7.9}$. REE is the energy needed for the ongoing processes in the body in the resting state, when no food is digested and no renergy is needed for temperature regulation. In sedentary subjects, REE represents the main part of total daily energy expenditure (TDE). The remaining components of TDE are the diet induced thermogenesis (DIT) and the energy expenditure for activities, which is the most variable component.

Data concerning TDE in COPD are very limited. It is, however, difficult to obtain a reliable measurement of TDE. At the moment this is only possible by means of a respiratory chamber, or by using the doubly labelled water method. The disadvantage of the respiratory chamber is that physical activity is limited. To obtain an accurate measure of TDE, including the energy expenditure of usual daily activities, it should be measured in free living conditions, which is only possible by the doubly labelled water method. We have previously reponted that TDE (measured by the doubly labelled water method) is increased in patients with COPD, compared to healthy subjects matched for sex, age and body composition ${ }^{10}$. Since mean REE was comparable between the two groups, conclusions concerning the effect of ann increased REE on TDE could not be made in this study.

Hugli et al" recently measured TDE in patients with COPD and healthy persons in a respiratory chamber. Although REE was increased in the patients with COPD studied, TDE was comparable between the groups. In studies of TDE in other patient groups (cystic fibrosis, human immunodeficiency virus infection (HIV)), it was found that the disease-rellated increase in REE was not reflected in an increased TDE compared to healthy subjects or reference values of TDE ${ }^{12.13}$. To our knowledge, a possible discrepancy in TDE between patients with a normal REE and those with a disease related increased REE has not previously been investigated. 
The aim of the present study was to investigate whether an increased REE in clinically stable patients with COPD is directly related to an increased TDE (in free living conditions).

\section{Methods}

\section{Patients}

Twenty patients $\left(19,190^{\circ}\right)$ with moderate to severe COPD in stable clinical condition were studied. The diagnosis was made following the criteria of the American Thoracic Society ${ }^{14}$ (Table 1).

\section{Table 1: Patient characteristics}

Data are presented as median (range): 1: increased or normal REE for FFM figure 1); BMI: body mass inder (weightheight ${ }^{2}$ ); FFM: fat-free mass; FEV, forced expiratory wolume in I second: FVC: forced wital capacity: TLC: total iung capacity; TTV: intrathoracic gas wolume; $D L_{c o}$ : diffusing capacity of carbon sonoxide: $\mathrm{PaO}_{2}$ : arterial oxygen pressure; 2; cumulative daily dose, only patients asing $\beta_{2}$ angonists $(n=19$ ) were included in the analysis. three patients were excluded becouse they had an incomparable dowage dae wo the we of a nebulizer; group A: $n=6.3:$ only patiens using theophyllines $(n=16)$ were inciuded; group A: $n=8$

\begin{tabular}{|c|c|c|c|c|}
\hline & & $\begin{array}{l}\text { increased REE' } \\
\text { group } A(n=10)\end{array}$ & $\begin{array}{c}\text { normal REE } \\
\text { group } B(n=10)\end{array}$ & p-value \\
\hline $\mathrm{Age}$ & $(\mathrm{yrs})$ & $65(57-74)$ & $69(55-78)$ & NS \\
\hline $\mathrm{BMI}$ & $\left(\mathrm{kg} / \mathrm{m}^{2}\right.$ & $23.9(16.6-32.4)$ & $24.4(17.4-28.9)$ & NS \\
\hline FFM & $(\mathrm{kg})$ & $46.4(41.1-60.8)$ & $48.1(40.3-58.9)$ & $\mathrm{NS}$ \\
\hline $\mathrm{FEV}_{3}$ & (\%pred) & $38(20-72)$ & $31(21-53)$ & NS \\
\hline Fuc & (\%pred) & $86(65-129)$ & $88(64-105)$ & NS \\
\hline TLC & (\%pred) & $1118(86-132)$ & $1.34(92-166)$ & NS \\
\hline mav & (\%pred) & $157(94-193)$ & $187(125-256)$ & NS \\
\hline $\mathrm{DL}_{-0}$ & (spred) & $64(52-91)$ & $60(29-106)$ & NS \\
\hline $\mathrm{PaO}_{2}$ & $(\mathrm{kPa})$ & $10.0(8.5-12.2)$ & $10.2(8.4-11.3)$ & $N S$ \\
\hline$B_{2}$-agonists & $(\mu g / \text { day })^{2}$ & $1600(800-2000)$ & $1600(800-2000)$ & NS \\
\hline Theophyllines & $(\mathrm{mg} / \mathrm{day})^{3}$ & $700(500-900)$ & $600(375-900)$ & NS \\
\hline
\end{tabular}


Lung function measurements included flow volumes (forced vital capacity: FVC, forced expiratory volume in 1 second: $\mathrm{FEV}_{1}$ ) and static lung volumes (total lung capacity (TLC), and intrathoracic gas volume (ITGV)). Diffusing capacity of CO $\left(\mathrm{DL}_{\mathrm{CO}}\right)$ was measured by the single breath method (Masterlab, Jaeger, Würzburg, Germany). The highest value of at least three measurements was used and expressed as a percentage of the reference value ${ }^{13}$. Blood was drawn from the brachial artery at rest while breathing room air. Blood gases were analyzed on a blood gas analyzer (Radiometer, ABL 330, Copenhagen). Data of 8 of the 19 male patients have been reported previously ${ }^{10}$. The patients were admitted to a pulmonary rehabilitation center for a period of 8 to 10 weeks, but were allowed to go home at the weekends. Patients with an arterial oxygen pressure $<7.3 \mathrm{kPa}$, or suffering from cancer, unstable cardiac condition (such as decompensated cor pulmonale), active gastrointestinal abnormalities, recent surgery, severe endocrine disorders or locomotor diseases were excluded. The patients were fully informed about the nature and purpose of the study and gave informed consent. The study was approved by the local ethical committee. Procedures followed were in accord with the Helsinki declaration from 1977 as revised in 1983.

\section{Resting energy expenditure (REE)}

REE was measured at least two times (before and during the doubly labelled water method) by open circuit indirect calorimetry, using a ventilated hood system (Oxyconbèta, Jaeger, Würzburg, Germany) $)^{16}$. A transparent plexiglas hood was placed over the patient's head, and room air was drawn through the hood at a fixed flow (40 I/min). The expired air of the patient mixes with the room air in the hood, from which samples are taken. Oxygen consumption and carbon dioxide production were calculated from the airflow and the difference in the concentration of oxygen and carbon dioxide between the incoming and outcoming air. Energy expenditure was calculated using the abbreviated Weir formula". Measurements were performed in the early morning after an overnight fast, while the subject was comfortable lying on a bed in the supine position. The system was calibrated before measurements were taken, and the accuracy of the system (3-4\%) was regularly tested with an ethanol combustion test. REE was expressed in absolute values, or as percentage of predicted ${ }^{1 x}$. 


\section{Dietary intake}

During the entire 14 days of the doubly labelled water measurement period, dietary intake was obtained by means of dietary records. The dietary records were preprinted, and only the amount of food components had to be completed by the patients. During weekdays, the portion size of the (hot) meal components were weighed by the kitchen staff. During the weekends the patients were encouraged to describe the amount they ate in as much detail as possible. The dietary records were analyzed by an experienced dietician, and the nutrient data base was derived from the Dutch food composition tables ${ }^{19}$.

\section{Total daily energy expenditure}

The premise of the doubly labelled water technique is that after a loading of water labelled with deuterium $\left({ }^{2} \mathrm{H}\right)$ and oxygen ${ }^{18}\left({ }^{18} \mathrm{O}\right)$, the ${ }^{2} \mathrm{H}$ is eliminated from the body as water, whereas the ${ }^{18} \mathrm{O}$ is eliminated from the body as water and carbon dioxide $\left(\mathrm{CO}_{2}\right)$. The difference between the elimination rates is therefore proportional to $\mathrm{CO}_{2}$ production and hence total energy expenditure ${ }^{20}$.

Total daily energy expenditure (TDE) was determined following the standard Maastricht protocol, as described by Westerterp et $\mathrm{a}^{21}$. Late in the evening a baseline urine-sample was collected. A weighted isotope dose was then administered at 10 p.m.consisting of a mixture of 10 atom percentage excess (APE) ${ }^{18} \mathrm{O}$ and 5 APE ${ }^{2} \mathrm{H}$. Subsequently, the isotopes equilibrate with the body water (during equilibration the patient does not consume any food or drink) and the initial urine sample was collected the next morning (day 1) from the second voiding. Further urine samples were collected in the evening of day 1 and in the morning and evening of day 8 and 15 . Isotope ratios in urine samples were measured by Isotope Ratio Mass Spectroscopy (Aqua SIRA, VG-Isogas, UK). Calculated carbon dioxide production was converted to energy expenditure assuming a RQ of $0.85^{20}$.

\section{Physical activity}

The patients participated in a pulmonary rehabilitation program that included a standard activity programme on weekdays. The patients performed physical activities 
such as gymnastics, cycling and walking, strength training and/or upper extremity training. Other components of the programme included sedentary activities such as educational lectures, relaxation sessions, and talks with the physician or other caretakers. In the evening no physical activities were scheduled and most patients performed sedentary leisure activities (reading, puzzling, playing games, etc.).

The energy expenditure for activities was calculated by $(0.9 *$ TDE) - REE, assuming a DIT of $10 \%$ of TDE. Quantification of the activity level was obtained by monitoring heart rate (HR) for 48 (2 weekdays) hours using a sport-tester device (PE 3000 Polar Electro, Finland). This device consists of a transmitter, a battery operated electrocardiographic monitor, a receiver and an electronic watch with an antenna housing, capable of receiving signals from the transmitter. The transmitter was strapped to the patient's anterior chest wall with a rubber belt and bandages. The receiver can store mean heart rate readings of every minute for 16 hours; thereafter the receiver was replaced by another to store the remaining 8 hours of a 24 hour interval.

From these recordings several variables were obtained. Rest-HR was the mean HR during sleeping/resting. The HR of the remaining time was defined as day-HR. The standard deviation from the day-HR illustrates the variation of the HR during the day: VAR-HR. Furthermore, the minutes spent when HR was 15 beats above the day-HR was summarized (TIME-HR ${ }^{+15}$ ), and the mean HR during that time was computed $\left(H R^{+15}\right)$. Finally, the total of minutes spent above twice the standard deviation of dayHR was calculated (TIME $\left.{ }^{2 \mathrm{SD}}\right)$, as well as the mean HR during that time $\left(\mathrm{HR}^{2 \mathrm{SII}}\right)$.

\section{Body composition}

Body height was measured with the subject standing bare foot and was determined to the nearest $0.5 \mathrm{~cm}$ using a stadiometer with head traction and correct posturing (Lameris WM 715, Breukelen). Body weight was measured with a calibrated beam scale with subjects bare footed and in light clothing and was determined to the nearest $0.1 \mathrm{~kg}$ (SECA, FRG). Body mass index (BMI) was calculated as weight (kg) divided by height ${ }^{2}(\mathrm{~m})$. Total body water (TBW) was determined by deuterium dilution obtained on the first day of the doubly labelled water measurement period, and was calculated as the measured deuterium space divided by $1.04^{22}$. Fat-free mass (FFM) was calculated assuming a hydration factor of $73 \%$ of TBW. 
A

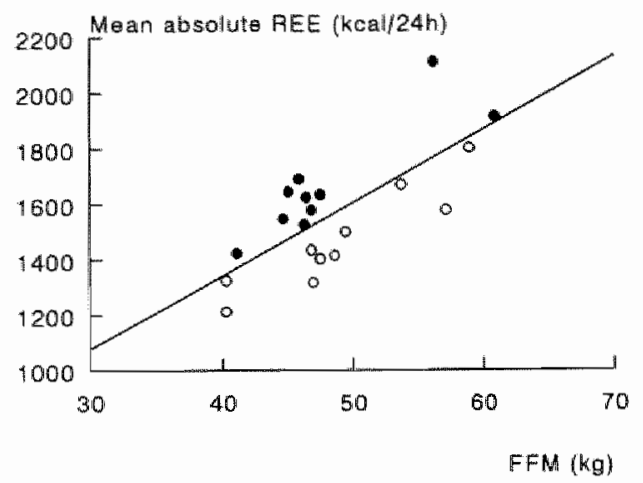

Figure 1A: Resting energy expenditure related to fatsfree mass.

closed $=$ hypermetabolic at rest (group A), open = normometabilic at rest (group B)

B



Figure IB: Total daily energy expenditure related to fat-free mass.

closed $=$ hypermetabolic at rest (growp A), open:= nomnometabolic at rest (growp B)

\section{Statistical analysis and calculations}

There is a significant relationship between both TDE and REE with FFM ${ }^{23}$, because the main part of FFM represents the metabolic active tissue mass which is responsible for energy expenditure. At the moment there is no generally accepted equation to predict REE based on FFM. The Harris and Benedict equations predict 
REE based on weight (and height, age and sex). Considering that, in patients with COPD, depletion of FFM can occur with both a decreased and a normal body weight. it is more accurate to define patients with COPD either hypermetabolic at rest or normometabolic at rest based on metabolic active tissue mass (FFM). In order to define patients with an increased REE (group A) or a normal REE (group B), the linear regression equation between REE and FFM (measured by deuterium dilution) was therefore used in the 20 patients studied (Figure 1). Patients with a REE above or beneath the regression equation as presented in Figure 1 were assigned to group $\mathrm{A}$ and group $\mathrm{B}$ respectively.

The results are presented as median (range). The Mann-Whitney U test was used to compare values between the groups. Correlation coefficients and multiple regression analysis were used to test the linear relationship between variables. The level of significance was $5 \%$ and the Bonferroni correction was used when appropriate.

\section{Results}

As shown in Figure 1A, REE correlated significantly with FFM ( $r=0.73$, $p<0.001), 10$ patients were assigned to group $A$ and 10 to group $B$. There was no significant difference in age, body composition, lung function, or use of medication that might influence energy expenditure ( $B_{2}$-agonists and theophyllines) between group $A$ and $\mathrm{B}$ (Table 1).

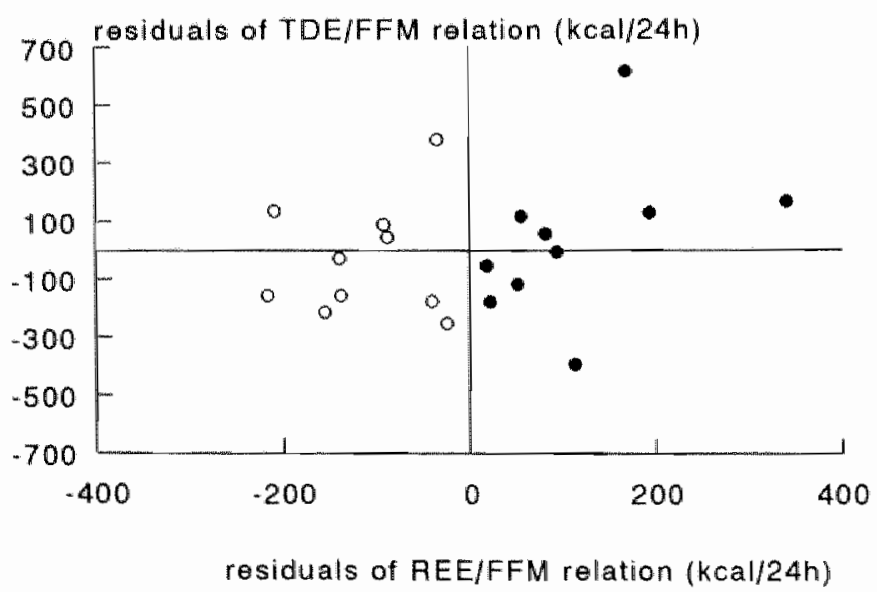

Figure 2: Total daily energy expenditure related to resting energy expenditure, taken into accownt the relation with FFM. closed $=$ hypermetabolic at rest (group A) open = normonetabolic at rest (group B) 
As shown in Figure 1B, TDE also correlated significantly with FFM $(r=0.70$, $p<0.01$ ). In Figure 2 the residuals of figure $1 B$ are plotted against the residuals of figure IA and show that, when the influence of FFM is taken into account, TDE was not rellated to REE in these patients with COPD. Furthermore multiple regression analysis showed that both REE $(p=0.20)$ and FFM $(p=0.08)$ did not independently contribute significantly to the variation in TDE.

As shown in Table 2, TDE did not differ significantly between group A and B. Dietary intake was also not significantly different, although the percentage intake of carbohydrate in group A was increased compared with group B (median difference: $2 \%, \mathrm{p}<0.017)$. It can be seen from Table 2 that dietary intake was lower than TDE. However, the patients were in energy balance at the time of the study, since weight remained stable from the first day of the doubly labelled water method $(63.9 ; 49.1-92.5$ $\mathrm{kg}$ ) until the las! $(63.9,50.2-91.7 \mathrm{~kg})$ in both groups, suggesting that food intake was not fully reported. The estimated energy expenditure for activities $(0.9 *$ TDE -REE) tended to be higher in group B than in group A (median difference: $202 \mathrm{kcal} / \mathrm{day}$, $p=0.028$ ). There was no correlation between pulmonary function (airflow obstruction, diffusing capacity, arterial oxygen pressure), age, body composition, or respiratory muscle strength and energy expenditure for activities. TDE divided by REE was significantly higher in the patients with a normal REE (median difference: $22 \%$, $\mathrm{p}<0.025)$.

17 Patients agreed to wear the HR-recording device during two days. Table 3 summarizes the indices of activity level for group $A\left(n=90^{\circ}\right)$ and group $B\left(n=80^{\circ}\right)$. There was no significant difference in the day-HR, the VAR-HR, HR ${ }^{* 15}$, TIME-HR ${ }^{* 15}$, $T_{T M E^{2 S i}}$ or $H R^{2 S 1}$ between group $A$ and $B$. There was no significant correlation between the energy expenditure for activities and any of these indices of HR monitoring. 
Table 2: Energy explendiure and dietary intake.

Data are presented as median (range). I: Increased or mormal REE for FFM (figure 1); 2: REE as percenage of predicted REE, based on the equations of Harris and Bennedict:3: 3. TDE and REE represent independent measurements, but statistical analysis wsing both these variables should be tested with $p<0.05$ divideat by 2 (Bonferroni correction). 4. Mean taity caloric intake of the 14 doys of the doubly labelled water measurement pertod, percentage proteins, carbohydrate and fat are dependent of each other; these variables should be tested with $p<0.05$ divided by 3 (Bonferroni correction)

\begin{tabular}{|c|c|c|c|}
\hline & $\begin{array}{l}\text { Increased REE } \\
\text { group } A(n=10)\end{array}$ & $\begin{array}{c}\text { Normal REE } \\
\text { group } B(n=10)\end{array}$ & povalue \\
\hline $\begin{array}{l}\text { Resting energy expenditure } \\
(\mathrm{kcd} / 24 \mathrm{H}) \\
\left(\% \mathrm{H} \& \mathrm{~B}^{2}\right)\end{array}$ & $\begin{array}{c}1631(1423-2112) \\
125(104-135)\end{array}$ & $\begin{array}{c}1426(1212-1802) \\
107(90-113)\end{array}$ & $\begin{array}{l}p<0.05 \\
p<0.01\end{array}$ \\
\hline $\begin{array}{l}\text { Total daily energy expenditure } \\
\text { (kcal/24h) } \\
\text { (TDE/REE) }\end{array}$ & $\begin{array}{c}2593(2127-3083) \\
1.56(1.31-1.87)\end{array}$ & $\begin{array}{c}2629(2032-3179) \\
1.78(1.53-2.03)\end{array}$ & $\begin{array}{c}\mathrm{NS} \\
\mathrm{p}<0.025\end{array}$ \\
\hline $\begin{array}{l}\text { Energy expended for activities } \\
0.9^{*} T D E-R E E(\mathrm{kcal} / 24 \mathrm{~h})^{3}\end{array}$ & $680(288-1129)$ & $882(503-1190)$ & $p=0.028$ \\
\hline $\begin{array}{l}\text { Mean daily dietary intakes } \\
\text { Catoric intake (kcal/24h) } \\
\text { \% proteins } \\
\text { \% carbohydrate } \\
\text { \% fat }\end{array}$ & $\begin{array}{c}2070(1761-2602) \\
16(14-21) \\
46(40-50) \\
38(32-45)\end{array}$ & $\begin{array}{c}2123(1604-2423) \\
16(14-20) \\
44(38-45) \\
40(34-47)\end{array}$ & $\begin{array}{c}\text { NS } \\
\text { NS } \\
p<0.017 \\
\text { NS }\end{array}$ \\
\hline
\end{tabular}

Table 3: Indices of activity level.

Data are presented as median (range). 1: increased or normal REE for FFM (figare 1): Rest-HR," mean HR during slepingiresting; doy-HR: the HR of the remoining time; VAR-HR: the standard deviation from the dayHR: TIME-HR : the total of minutes spent when HR was 15 beass above the day-HR and the mean HR

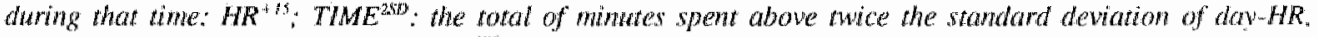
and the mean HR daring that withe: $H R^{250}$

\begin{tabular}{|c|c|c|c|c|}
\hline & & $\begin{array}{l}\text { Increased REE } \\
\text { group } \mathrm{A}(\mathrm{n}=9)\end{array}$ & $\begin{array}{c}\text { normal REE } \\
\text { group B }(n=8)\end{array}$ & p-vallue \\
\hline rest-HR & $(x /$ mino $)$ & $82(59-103)$ & $75(65-76)$ & NS \\
\hline day-HR & $(x / \min )$ & $98(75-116)$ & $92(82-98)$ & $\mathbb{N S}$ \\
\hline$H R: S$ & $(x / \min )$ & $104(83-126)$ & $100(89-102)$ & NS \\
\hline TIME-HR :" & $(\min )$ & $566(254-825)$ & $627(338-872)$ & NS \\
\hline$H R^{2513}$ & (x/min.) & $125(101-143)$ & $117(106-149)$ & NS \\
\hline TIME & (min.) & $33(15-69)$ & $34(10-46)$ & NS \\
\hline VAR-HR & (x/minu) & $9.5(7.8-\| 2.3)$ & $10.0(8.7-15.8)$ & NS \\
\hline
\end{tabular}




\section{Discussion}

This study shows that there is no significant difference in free-living TDE between clinically stable patients with COPD with a raised REE (group A) and those with a normal REE (group B). Moreover, when FFM was taken into account, TDE was not related to REE. In addition, normometabolic patients at rest tended to have a higher energy expenditure for activities (0.9*TDE-REE) than those patients with COPD who were hypermetabolic at rest.

The ratio of TDE to REE was significantly higher for group B (1.78) than group A (1.58). Traditionally, the rate of plyysical activity is obtained from the ratio TDE/REE, according to the current recommendations for energy requirements by the Food and Agriculture Organization/World Health organization/United Nations University $^{24}$. In a recent review it was pointed out that the ratio TDE/REE should be interpreted with care; there is a wide variation in the relationship between TDE and REE in different studies, and the regression equation of TDE with REE has shown significant intercepts in several studies ${ }^{25}$. If the intercept of this relationship is not zero, and is different between studies, this means that the ratio TDE/REE may represent an artiefact. It is therefore more accurate to examine the regression equation between TDE and REE. However, TDE and REE are both also related to FFM. Thus, in the present study it was shown that TDE was not related to REE, when FFM was taken into account. As a result, TDE was similar in groups $A$ and $B$. An estimate of the absolute cost of physical activity can be obtained by subtracting REE from TDE in each individual, adjusting for the DIT. An increased DIT in patients with COPD has been reported once ${ }^{36}$, but the most recent studies suggest a normal DIT in patients with $\mathrm{COPD}^{27.2 \%}$, which is approximately $10 \%$ of TDE. Combined with the comparable dietary intake by patients in groups $A$ and $B$, it appears that the patients of the two groups had a comparable DIT. AS TDE was comparable and REE higher in group A versus group $B$, this resulted in a tendency for an increased energy expenditure for activities in the patients with a normal REE.

The question remains whether this is a consequence of a difference in physical activity level or a difference in energy expenditure for a given activity. By monitoring the HR it was found that there was no significant difference between the resting $H R$, daily $H R$, or variation in $H R$, between the groups of patients with a different $R E E$. We used HR monitoring as an indication of activity level because, as demonstrated in the 
study of Meijer et al ${ }^{29}$, the day-time pattern of HR runs almost parallel to the pattern of body acceleration. This suggests that the level of activity was similar in both groups of patients, although these data should be interpreted with care because of the small number of patients in the study. It should also be remembered however, that all patients were encouraged to participate actively in a standardized pulmonary rehabilitation programme. We recognize that, although the doubly labelled water method measures TDE reliably, the estimate of energy expenditure of activities is indirectly calculated from the measurement of TDE and REE. The estimate of activity level by HRmonitoring is also an indirect method. The energy expenditure for a given activity in patients with COPD should therefore be measured directly in further investigations, in order to investigate whether there is a discrepancy in the energy expenditure for a given activity in palients with COPD and either an increased or normal REE.

TDE was significantly correlated to FFM, but the slope (38.2) of the regression equation of TDE versus FFM was high in our patients compared with healthy subjects (maximum slope: 33.3$)^{23}$. Therefore, this study confirms our earlier observation" that TDE seems to be increased in patients with COPD compared to healthy subjects. Moreover, there was no difference in TDE (or TDE adjusted for FFM) between the 8 patients studied previously ${ }^{10}$ and the 12 other patients of this study (data not shown). Furthermore, it was striking that FFM and REE, did not significantly contribute to the variation in TDE, when they were both included in a multiple regression analysis.

It appears that underlying mechanisms for an increased REE are not involved in stimulating TDE. An increased REE in patients with COPD has been ascribed to three factors: the influence of (chronic) inflammation, the influence of medication, and the oxygen cost of breathing. Evidence for the relationship between infammation and REE has recently been found since, in a subset of patients with COPD who were hypermetabolic at rest enhanced levels of inflammatory mediators were found ${ }^{3 n}$. Obviously, if (chronic) inflammation is the major contributor to the increased REE in patiens with COPD, this does not automatically increase TDE. However, the (chronic) inllammatiom probably interferes with the relationship between REE and FFM, which might explain the disturbing effect of REE on the relationship between TDE and FFM, as found in the present study.

Furthermore, recent studies suggest a possible stimulating effect of, in particular, $\beta_{2}$-agonists and theophyllines on REE and TDE in patients with COPD ${ }^{11.31-32}$. There was no difference between the groups in the intake of either of these 
medications, so it is unlikely that this caused the difference in REE or energy expenditure for activities between the patient groups.

The effect of oxygen cost of breathing (OCB) on REE is probably not large since, in a study by Shridhar et al ${ }^{33}$ there was no correlation between OCB and REE in patients with COPD. This does not exclude the possibility that OCB may have been related to the increased TDE found in the present study, as well as in our previous study $^{10}$. Studies by O'Donnell \& Webb $^{34}$ and Belman et al ${ }^{35}$, have demonstrated the importance of dynamic hyperinflation in COPD. It was demonstrated that acute on chronic hyperinflation can occur during exercise in patients with $\mathrm{COPD}^{34.95}$. Dynamic as well as chronic hyperinflation are important determinants of an increased intrinsic work of breathing ${ }^{34}$, and therefore the energy expenditure of breathing. Both the patients in group A and B suffered from chronic hyperinflation, suggesting that this might have influenced TDE, irrespective of their REE. Further studies are indicated to investigate whether a possible increased energy expenditure for breathing during activities (possibly related to dynamic hyperinflation) substantially increases energy expenditure of activities.

The results of this study as well as of our previous study ${ }^{40}$ suggest that TDE is increased in clinically stable patients with COPD, but that the causes are probablly not directly related to the suggested mechanisms for an increased REE in patients with COPD. The cause for an increased energy expenditure for activities (TDE) in patients with COPD is as yet unknown, but the present study warrants further investigation of the energy expenditure for (standardized) activities.

\section{References}

I Muers MF \& Green JH. Weight loss in chronic obstructive pulmonary disease. Eur. Respir. I. $1993: 6: 729-734$

2 Schols AMWJ \& Wouters EFM. Prevalence and pathophysiology of mutritional deplention in ehromic obstnctive pulmonary disease. Resp. Med. 1993:87 (suppl B): 45-47.

3 Wilson DO, Rogers RM. Wright E. Anthonisen NR. Body weight in Chronic Obstructive Pulmonary Disease. Am. Rev. Resp. Dis. 1989; 139: 1435-1438.

4. Vandienbergh $E$, Van de Woestijne $K_{2}$, Gyselen A. Weight changes in the terminal stages of chronic obstructive lung disease. Am. Rev. Respir. Dis. 1967; 95: 556-566.

5 Selhols AMWJ, Mostert R, Soeters PB, Greve LH, Wouters EFM. Nutritional state and exercise perfornance in pattents with chronic obstructive lung disease. Thorax 1989; 44: $937-941$.

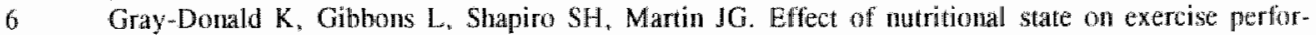
mance in patients with chromic obstructive pumonary disease. Am. Rew. Respir. Dis. 1989; 140: 1544-1548.

7 Goldstem S Askanazi I Wëssnan C Thonnshow B Kinney JM. Eenergy expenditure in patients with chronic obstructive pulmonary disease. Chest 1987: 91: 222-224. 
Schols AMWJ Fredrix EWHM Soters PB Westerterp KR Wouters EFM. REsting energy expendiure in patients with chronic obstructive pulmonary disease. Am, J. Clin. Nutr. 1991: 54: $983-987$. Schols AMWJ. Soeters PB. Saris WHM. Wouters EFM. Energy balance in patients with chromic obsuructive pumonary diseasse. Am. Rew. Respit. Dis. 1991; 143:1248-1252.

Baarends EM. Schols AMWJ, Pannemans DLE, Westerterp KR, Wouters EFM. Tocal daly energy toxpenditure in clinically stable patients with severe COPD and age-matched healthy subjects usitge the doubly labelled water techrique. Am. I. Repir. \& Crit. Care Med. 1997: 155: $549-554$.

Hugli $D$, Schutz $Y$, Fithog IW. The daily energy expenditure in stable Chronic Obstructive Pulmonary Disease. An. J. Respir. Crit. Calte Med. 1996; 153: 294-300.

Spicher $V$, Roulet $M$, Schutz $Y$. Assessment of total energy expenditure in free living panems with cystic fibromis. I. Peadiatr. 1991: $118: 865-872$.

Macallan DC, Noble C, Ballwin C, Jebb SA, Prentice AM, Coward WA, Sawyer MB. McManus TJ, Griffin GE. Energy expenditure and wasting in human immunodeficiency vinu infection. N. Engl. J. Med. 1995; 333: 83-88.

ATS. Standards for the diagnoses and care of patients with chronic obstructive pulmomary disease (COPD) and asthma. Am. Rev. Respir. Dis. 1987; 137:225-228. patients with COPD in a clinicall setting. J. Parenter. Enter. Nutr. 1992: 364-368.

17 Weir JB. New methods for
J. Pliysiol. 1949; 109: 1-9.

Harris $I A$ \& Benedict FG. A bionetric study of basal metabolism in man. Washington DC Carnegie institute of Wastrington. Publication no 279. 1919.

Sichting Nederlands Voedingsstoffenbestand. Newo tabel "s Grawenhage: Voorlichningsbureau woor de Voeding, 1986.

Schoeller DA, Ravussin E, Schutz Y, Acheson KJ, Baertschi P, Jequier E. Energy expenditure by double labelled water: valldatiou in humans and proposed calculation. Am. J'. Physiol. 1986; 250: R823-R830,

Westerterp KR, Wouters L, Marken Lichtenbelt WD. The Mastricht protocol for the measurement of body composition and energy expenditure with labelled water. Obesity Research 1995: 3: 49-57.

Schoeller DA. Isotope dilution methods. In: Bjöntrop P, Brodoff BN, eds. Obesity. Planladelphia: J.B. Lippencott Company, 1992; 80-88.

Cumingham JJ. Body composition as a determinant of energy expenditure: a symthetic review and a proposed general prediction equation. Am. J. Clin. Nutr. 1991; 54: 963-969.

Food and Agriculture Organization/World Health Organization/United Nations University. Energy and protein requirements. Technical Report Series no 724. 1985. Geneva: WHO.

Carpenter WH, Poehlman ET, O'Connell M, Goran MA. Influence of body composition and resting metabolic rate on wariation in total energy expenditure: a meta-analysis. An. J. Clin.. Nutr. 1995; $61: 4-10$.

Goldstein S. Asktnazi J, Weissman C. Thomashow B. Kimey JM. Energy expendinure in patients with Chionic Obstructive Pulmonary Disease. Chest 1987; $91: 222-224$.

Hugli $O$, Frascarolo $P$. Schutz $Y$, Levenberger $P$. Fitting J-W. Diet-indaced fhermogenesic in Chronic Obstructive Pulmonary Diseasc. Ann. Rew. Respir. Dis. 1993; 148: 1479-1483.

Green HH. Muers MF. Conparison between basal netabolic ate and diet-induced themnogenesis in different aypes of chronic obstructive pulmonary disease. Cli. Sci. 1992; 83: 109-116.

Meijer GA, Westerterp KR, Koper H., Ten Hoor F. Assessment of energy expendirure by recording heart rate and body acceleration. Med. Sci. Sports Exerc. 1989:2 $1: 343-347$.

Schols AMWJ, Bunnan WA, Stal-van den Brekel AJ. Dentener MA. Wouters EFM. Evidenae for a relation between metabolic derangements and increased levels of inflammatory naediathors in a subgroup of patients with chronic obstructive pulmonary disease. Thorax 1996; 51: 819-824.

Dash A. Agrawai A. Venkat $N$, Moxhan J, Ponte J. Effect of oral theophyline on resting entrgy expenditure in normal volumteers. Thorax 1994: 49: 1116-1120.

Amoroso P. Wilson SR. Moshlam I. Ponte J. Acute effects of inhaled sallutamol on the metabolic rate of nomal subjects. Thorax 1993: 48:882-885. 
33 Sridhar MK, Carer R, Lean MEJ. Banham SW. Resting energy expenditure and nutritional state of patients with increased oxygen cost of breathing due to emphysema scoliosis and thotacoplasty. Thorax 1994; 49: 781-785.

$34 \quad O^{*}$ Domel DE \& Webb KA. Exertional breathlessness in patients with chronic airflow limitation. "The role of hyperinflation. Am. Rev. Respir. Dis. 1993; 148: 1351-1357.

35 Belnan MJ, Botnick WC, Shin JW. Inhaled bronchodilators reduce dynamic lyperinflation during exercise in patients with chronic obstructive pulmonary disease. Am. J. Respir. Crit. Care Med. 1996; $153: 967-975$. 


\title{
ANALYSIS OF THE METABOLIC AND VENTILATORY \\ RESPONSE TO SELF-PACED 12 MINUTE TREADMILL \\ WALKING IN PATIENTS WITH SEVERE CHRONIC OBSTRUCTIVE PULMONARY DISEASE
}

\begin{abstract}
Enica M. Baarends', Annemic M.W.J. Schols", Rob Mastert" Paul P. Janssen", Emiel F.M. Wouters'. 'Department of Pulmonology, Maasinicht University, Maastrich, "Asthma Center Hornerheide, Horn, The Nesherlands.
\end{abstract}

\begin{abstract}
The 12 minute walking test is frequently used to measure exercise capacity in patients with severe Chronic Obstructive Pulmonary Disease (COPD). The physiological response of this test, however, has been subject of limited investigation. In this study the metabolic and ventilatory consequences of a self-paced 12 minute treadmill walking test (WT) were measured in 17 patients with severe COPD (FEV : $40 \pm 9 \%)$ and evaluated using the physiological response to symptom limited cycle ergometry (CE). During exercise testing heart rate, transcutaneous oxygen saturation and lactate concentration were measured, and oxygen consumption, carbon dioxide production, tidal volume, and breathing frequency were recorded breath by breath. After 4 minutes walking the $\mathrm{V}^{\prime} \mathrm{O}_{2}$ was already $99 \pm 11 \%$ of last-minute walking $\mathrm{V}^{\prime} \mathrm{O}_{2}$. Walking speed was chosen within two minutes and remained stable throughout the test. The WT and CE showed similar (end-)test results for all measurements, except for a higher carbon dioxide production, venous lactate concentration and respiratory quotient after $\mathrm{CE}$. Lactate concentration was however also significantly increased after WT. Severe and prolonged desaturation was demonstrated during walking. The physiological stress evoked during the WT is close to the stress developed at an incremental symptom limited test and the relatively high metabolic and ventilatory stress is sustained from at least 4 to 12 minutes during the WT. This study has shown that anaerobic metabolism not only occurs during incremental cycle ergometry, but also during the WT.
\end{abstract}




\section{Introduction}

Progressive impairment of exercise capacity commonly occurs in patients with Chronic Obstructive Pulmonary Disease (COPD). A disturbed gas exchange, pulmonary hypertension, ventilation/perfusion mismatching, dyspnea, depletion of fatfree mass, a decreased ventilatory muscle strength and psychological dysfunctioning were described to influence factors of physical fitness in these patients ${ }^{1-4}$.

It has generally been adwocated that exercise capacity of patients with COPD has to be assessed not only by a reproducible and valid, but also by a practically applicable test procedure. Therefore, 12 and 6 minute walking tests have been introduced widely in clinical practice in order to assess patient disability. The 12 minute walking test was developed by McGavin et al ${ }^{5}$ to quantify the effects of disease on exercise capacity and daily functional capacity. The authors suggested that, since this test does not take the patients to a symptom limitation such as tests requiring maximum effort, it resembles more everyday activities. Also Morgan et al suggested that a walking test is useful as a simple submaximal test measuring overall disability in COPD patients. On the other hand Swinburn et al stated that the 12 walking test may "take the patients reasonably close to their maximum sustainable oxygen consumption", which would be "exhausting for the patient".

Considering these contradictory opinions concerning the actual quantity of metabolic stress the 12 minute walking test evokes and considering it's wide use in clinical pulmonary rehabilitation, it is suprising that very little is known about the metabolic and ventilatory response to the 12 minute walking test.

The aim of this study was to analyse the physiological response of the self paced 12 minute walking test performed on a treadmill (WT). Besides the 12 minute walking test, the incremental cycle ergometry test (CE) has been used for monitoring functional capacity in $\mathrm{COPD}^{9-16}$. In order to quantify the physiological stress of the WT, metabolic and ventilatory response was compared to the peak response of maximal (symptom limited) $\mathrm{CE}$ as a reference. Furthermore, the minute to minute longitudinal response to WT was analyzed. 
Table 1: Characteristics of the study group

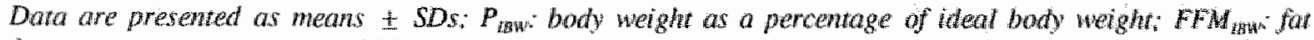
free mass as a percentage of ideal body weigh; $F E V_{1}$ : forced expiratory voluwe in I second; FVC forcad




impiratory mouth pressure; Pe"

\begin{tabular}{|c|c|c|c|}
\hline \multicolumn{2}{|l|}{ Variable } & \multicolumn{2}{|l|}{ Mean sd } \\
\hline Age & $(y r s)$ & $62 \pm 9$ & \\
\hline$P_{\mathrm{IBW}}$ & $(\%)$ & $103 \pm 20$ & \\
\hline FFM $_{1 B W}$ & $(\%)$ & $75 \pm 7$ & \\
\hline FEV & $L$ & $1.4 \pm 0.7$ & $40 \pm 9 \%$ pred \\
\hline FVC & $L$ & $3.5 \pm 0.9$ & $92 \pm 16 \%$ pred \\
\hline TLC & $\mathrm{L}$ & $7.7 \pm 1.9$ & $122 \pm 15 \%$ pred \\
\hline $\mathbb{K}_{60}$ & $\mathrm{mmol} / \mathrm{min} / \mathrm{k} \mathrm{Pa} / \mathrm{I}$ & $1.3 \pm 0.3$ & $74 \pm 16 \%$ pred \\
\hline $\mathrm{PaO}_{2}$ & $(\mathrm{kPa})$ & $9.0 \pm 1.0$ & \\
\hline $\mathrm{PaCO}_{2}$ & $(\mathrm{kPa})$ & $5.3 \pm 0.5$ & \\
\hline $\mathrm{SaO}_{2}$ & $(\%)$ & $93 \pm 2$ & \\
\hline $\mathrm{Pi}_{\mathrm{MAX}}$ & $\left(\mathrm{cmH}_{2} \mathrm{O}\right)$ & $72 \pm 24$ & \\
\hline $\mathrm{Pe}_{\text {Wax }}$ & $\left(\mathrm{cmH}_{2} \mathrm{O}\right)$ & $106 \pm 33$ & \\
\hline
\end{tabular}

\section{Methods}

\section{Patients}

The group consisted of 13 men and 4 women with severe COPD ${ }^{17}$ in a stable clinical condition (Table 1). They were admitted to an inpatient pulmonary rehabilitation program. Prior to entering the program, a careful evaluation of the patient was performed including physical examination, lung function testing and assessment of body composution. During this phase (before actually beginning the rehabilitation program) the present study was conducted. Criteria for inclusion into the study were normal anterial blood gases at rest $(>7.3 \mathrm{kPa}$ ), no cardiovascular, neurological, endocrine or locomotor diseases and a normal body composition. None of the patients was suffering from a respiratory tract infection during the period of exercise testing. Maintenance medication in nearly all patients included theophyllines, B. -agonists, oral and/or inhaled corticosteroids. 


\section{Pulmonary function}

Pulmonary function measurements included the forced vital capacity (FVC) and forced expiratory volume in 1 second $\left(\mathrm{FEV}_{\mathrm{l}}\right)$ (Masterlab, Jaeger, Würzburg, Germany). The best attempt of at least three measurements was taken. All volumes were expressed as a percentage of the reference value ${ }^{i}$. Total lung capacity (TLC) was measured by bodyplethysmography (Masterlab, Jaeger, Würzburg, Germany). The diffusing capacity of carbon monoxide was assessed using the single breath method, and divided by the alveolar space $\left(\mathrm{K}_{\mathrm{co}}\right)$ (Masterlab, Jaeger, Würzburg, Germany).

Respiratory muscle strength was determined by maximal inspiratory and expiratory mouth pressures $\left(\mathrm{Pi}_{-{ }_{\mathrm{MNX}}} / \mathrm{Pe}_{-\mathrm{MAX}}\right)$ as described by Black and Hyat: ${ }^{19}$, although $\mathrm{Pi}_{\mathrm{MAX}}$ is a negative pressure, it is positively expressed in the results. Blood was drawn by puncture of the brachial artery at rest, while breathing room air. Arterial oxygen pressure $\left(\mathrm{PaO}_{2}\right)$, carbon dioxide pressure $\left(\mathrm{PaCO}_{2}\right)$, and oxygen saturation were analysed on a blood gas analyser (Radiometer ABL 330, Copenhagen, Denmark).

\section{Exercise lesting}

The self-paced 12 minute treadmill walking test (WT) was performed on a calibrated horizontal treadmill (Clubtrack 3.0, Quinton, Seattle). The patients could choose their own pace by pushing buttons to start., speed up, slow down, or stop the treadmill. Although it was not allowed to lean on the handgrip, patients were permitted to use one handgrip for stability. Within one week prior to the test, all patients were familiarized with the equipment and practiced for approximately 5 to 10 minutes walking on the treadmill, while the examiner instructed them to experiment with the buttons. In the same week, after this familiarisation with the treadmill, the procedure of the 12 minute walking test was explained and the patients performed one practice walk. The patients were told to walk as far as possible in 12 minutes. They could determine their own pace, even stop if necessary and the examiner instructed them that at the end they should feel like they could not have walked further. The patients were not encouraged during the test.

The incremental cycle ergometry test (CE) was performed on an electromagnetic braked ergometer (Corival 400, Lode, Groningen, The Netherlands). 
every minute by 10 watt. The load cycled was invisible for the patients, and they were encouraged to cycle as long as possible.

During the initial resting period and throughout both exercise tests, heart rate (Sporttester, Pollar Electro cy, Kempele, Finland) and oxygen saturation (Sensor Medics Co, Anaheim, California) were monitored and metabolic and ventilatory parameters (Oxyconbèta, Jaeger, Würzburg, Germany) were measured breath by breath, using a breathing mask. Prior to the test the equipment was calibrated. The patients were asked to estimate the degree of dyspnea on a VAS-scale $(100 \mathrm{~mm})$ before and after both exercise tests.

Peak oxygen consumption $\left(\mathrm{V}^{\prime} \mathrm{O}_{2}\right)$ was predicted using the patient specific prediction equation $\left(53 * \mathrm{DL}_{\mathrm{CO}}+10 * \mathrm{Pi}_{\mathrm{MAX}}+241 * \mathrm{FEV}_{1}-267\right)$ of Dillard ${ }^{20}$, peak $\mathrm{V}^{\prime} \mathrm{O}_{2}$ was also predicted using the formulas for healthy subjects" and peak $V$ 'E was predicted by the formula of Carter $\left(37.5 * \mathrm{FEV}_{1}\right)^{22}$.

The WT and CE were performed in random order in one week. Time between tests was at least 24 hours. Tests were performed at a standardized time (between 13.00 and 14.30 p.m., at least 45 minutes after lunch) and were supervised by the same technician and pulmonary physician.

\section{Lactate measurement}

Immediately before and after the WT a venous blood sample was taken to measure lactate concentration. During CE a little needle (Terumo co., Leuven) was placed in a vein of the fore-arm and the thin rubber tube of the needle was connected with a three-way cock (Codan, Espergaerde, Denmark). The first blood sample of approximately $1 \mathrm{ml}$ was taken at rest and stored on ice. A heparin solution was injected in the tube to avoid coagulation. The first $\mathrm{ml}$ of the blood sample taken two minutes after reaching maximal sustained power was thrown away (blood + heparin), and the following $\mathrm{ml}$ was used for analysis. The blood samples were centrifuged during 5 minutes at 3000 r.p.m. (Sigma 2-15, Lameris, Breukelen, The Netherlands). Plasma lactate concentration was determined by an enzymatic method ${ }^{23}$, using an automated system (Cobas Mira, Roche, Bazel, Switzerland). 


\section{Body composition}

Body composition was assessed by bioelectrical impedance analysis. Resistance (R) was measured in supine position at the right side, as described by Lukaski ${ }^{24}$ (BlA101. RI Systems, Detroit, USA). Measurements were performed between 9.30-10 a.m. after the patients had emptied their bladder, and at least 2 hours after they had received their breakfast. All measurements were performed by the same experienced observer. Fat-free mass (FFM) was calculated from height ${ }^{2} / R$ and body weight, using a patient specific equation ${ }^{2 s}$.

Patients with a FFM lower than $63 \%(\%)$ or $67 \%(0)$ of the ideal body weight were considered to suffer from significant tissue depletion ${ }^{26}$ and were not included in the study. Ideal body weight was determined using the midpoint of the weight range for a given height and frame size (frame size was callculated from wrist circumference) ${ }^{27}$.

\section{Data analysis}

All measured variables are expressed as mean \pm SD rexcept for mean \pm SEM in figures). A paired student t-test was used to test differences. Product moment correlation coefficients were determined by multiple regression analysis. A $p$ value of $<0.05$ was considered significant.

\section{Results}

In Table 2 exercise performance and the metabolic and ventilatory consequences during the last (hall) minute of the WT and peak (=last half minute) response to $\mathrm{CE}$ are summarized. The physiological response during the last minute of WT was close to the peak physiological response achieved at the end of the CE. As a group, the patients reached a higher peak $V^{\prime} O_{2}$ during $\mathrm{CE}$ than the $\mathrm{V}^{\prime} \mathrm{O}_{2}$ during the last minute of $\mathrm{WT}^{\prime}\left(\delta \mathrm{V}^{\prime} \mathrm{O} 2=41 \mathrm{~m} / \mathrm{min}\right)$. In five patients, however, $\mathrm{V}^{\prime} \mathrm{O}_{2}$ during the WT was higher than peak response of the CE. In both tests the average drop in saturation amounted to 4\%. Peak carbon dioxide production ( $\left.\mathrm{V}^{\prime} \mathrm{CO}_{2}\right)$, lactate concentration and respiratory quotient (RQ) after $\mathrm{CE}$, however, were significantly higher than these variables during the last minute of WT. The reported dyspnea was 
comparable after both tests (WT: $70 \pm 28$ vs CE: $80 \pm 24$ ), dyspnea after CE was negatively correlated with the achieved workload $(r=-0.77 \mathrm{p}<0.01)$, whereas the distance walked did not correlate with the reported dyspnea after walking $(r=-0.39$ NS).

Table 2: Metobolic and ventilatory measurements during the last (half minute of the WT and CE

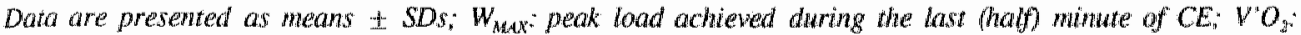
axgen consumption: $V{ }^{\prime} \mathrm{CO}_{2 .}$ carbon diadide production; $\mathrm{RQ}$. respiratory quotien; La: lactate comcentration

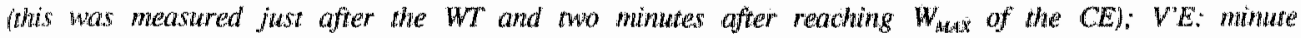

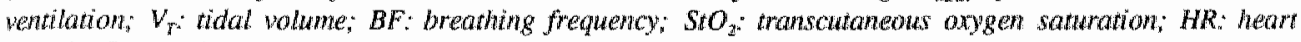
rate: VAS: wisual analogue scale measured just after completing the tests.

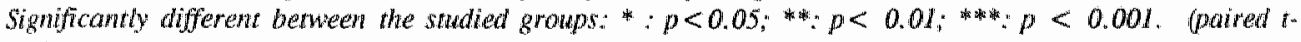
(test)

\begin{tabular}{|c|c|c|c|c|}
\hline Variable & & WT & $\mathrm{CE}$ & p walue \\
\hline Distance/ $W_{\max }$ & $(\mathrm{m}) /($ watt $)$ & $754 \pm 308$ & $67.5 \pm 26$ & \\
\hline $\mathrm{WO}_{2}$ & $(\mathrm{ml} / \mathrm{min})$ & $1003 \pm 420$ & $1044 \pm 271$ & NS \\
\hline $\mathrm{V}^{\prime} \mathrm{CO}_{2}$ & $(\mathrm{ml} / \mathrm{min})$ & $878 \pm 378$ & $1034 \pm 316$ & $* * *$ \\
\hline$R Q$ & & $0.88 \pm 0.05$ & $0.98 \pm 0.08$ & 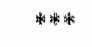 \\
\hline La & $(\mathrm{mmol} / \mathrm{L})$ & $2.8 \pm 1.1$ & $3.8 \pm 1.5$ & $*$ \\
\hline$V^{\prime} E$ & (L/min) & $35 \pm 9$ & $38 \pm 10$ & NS \\
\hline $\mathrm{v}_{\mathrm{r}}$ & $(\mathrm{ml})$ & $1189 \pm 361$ & $1241 \pm 389$ & $\mathrm{NS}$ \\
\hline BF: & $(\mathrm{x} / \mathrm{min})$ & $31 \pm 6$ & $31 \pm 8$ & NS \\
\hline $\mathrm{StO}_{2}$ & $(\%)$ & $89 \pm 4$ & $90 \pm 4$ & $\mathrm{NS}$ \\
\hline $\mathrm{HR}$ & $(\mathrm{x} / \mathrm{min})$ & $129 \pm 19$ & $133 \pm 15$ & $N \$$ \\
\hline VAS & $(\mathrm{mm})$ & $70 \pm 28$ & $80 \pm 24$ & NS \\
\hline
\end{tabular}

The patients of this study had a severly impaired exercise capacity, since peak $\mathrm{V}^{\prime} \mathrm{O}_{2}$ was $39 \pm 8 \%$ of normal ${ }^{21}$. The predicted maximal minute ventilation ( $\mathrm{V}^{\prime} \mathrm{E} ; 41$ $\left.\pm 12 \mathrm{l} / \mathrm{min}^{22}\right)$ was not significantly different from the measured peak $\mathrm{V}^{\prime} \mathrm{E}$ of $\mathrm{CE}$ ( $38 \pm$ $10 \mathrm{l} / \mathrm{min}$ ). Therefore these results indicate that $\mathrm{CE}$ was performed until a ventilatory maximum. Furthermore, peak $\mathrm{V}^{\prime} \mathrm{O}_{2}$ reached during $\mathrm{CE}(1044 \pm 27 \mathrm{l} \mathrm{ml} / \mathrm{min})$ was not significantly different from the patient specific predicted maximal $\mathrm{V}^{\prime} \mathrm{O}_{2}(1112 \pm 332$ $\left.\mathrm{ml} / \mathrm{min}^{20}\right)$. On the contrary, the WT was performed slightly below the ventilatory maximum, since predicted maximal $V^{\prime \prime} E^{22}$ was significantly higher than the $V^{\prime} E$ of the last minute of WT $(35 \pm 9, \mathrm{p}<0.05)$. The measured $\mathrm{V}^{\prime} \mathrm{O}_{2}$ during the last minute of 
the WT (1003 $\pm 420 \mathrm{ml} / \mathrm{min})$ however was not significantly different from the patient specific prediction ${ }^{20}$.

During CE 7 patients reached a RQ greater than or equal to 1 . Furthermore llactate concentration increased significantly during CE (from $1.7 \pm 0.4 \mathrm{mmol} / \mathrm{l}$ to 3.8 $\pm 1.5 \mathrm{mmol} / \mathrm{l}, \mathrm{p}<0.01 \mathrm{)}$, with 12 patients achieving a lactate concentration of 3 mmol/1 or higher. During the WT lactate concentration increased less but still significantly (from $1.7 \pm 0.5 \mathrm{mmol} / 1$ to $2.8 \pm 1.1 \mathrm{mmol} / 1, \mathrm{p}<0.01$ ), with only six patients achieving a lactate concentration of $3 \mathrm{mmol} / \downarrow$ or higher. During walking none of the patients reaching a $\mathrm{RQ}$ greater than or equal to 1 . Lactate concentration achieved after WT correlated significantly with the distance walked $(r=0.65 p<0.01)$, and with last-minute walking $\mathrm{V}^{\prime} \mathrm{O}_{2}(\mathrm{r}=0.72 \mathrm{p}<0.001)$ and $\mathrm{V}^{\prime} \mathrm{CO}_{2}(\mathrm{r}=0.80 \mathrm{p}<0.001)$. Lactate concentration achieved after $\mathrm{CE}$ did not correlate significantly with the cycled workload or peak oxygen consumption achieved.

In Figure 1 the metabolic and ventilatory response during the WT is demonstrated minute by minute. $\mathrm{V}^{\prime} \mathrm{O}_{2}, \mathrm{~V}^{\prime} \mathrm{CO}_{2}, \mathrm{~V}^{\prime} \mathrm{E}$ and heart rate (HR) at 4 minutes walking during WT, was respectively $99 \pm 11 \%, 95 \pm 9 \%, 93 \pm 9 \%$, and $96 \pm$ $5 \%$ of the physiological response during last-minute walking. During $\mathrm{CE}$ the physiological response showed an incremental pattern, as expected (dotted line). Immediately after starting both tests an increase in $V^{\prime} E$ was observed, achieved by both an increased breathing frequency $(\mathrm{BF})$ and tidal volume $\left(\mathrm{V}_{\mathrm{T}}\right)$. In $\mathrm{CE}$ these variables increased gradually, whereas $B F$ and $V_{T}$ increased suddenly during the WT and remained high during the whole test.

After six minutes of CE some patients stopped exercising since they reached their peak performance, therefore the amount of patients representing the data in the figure after six minutes is decreasing. The mean cycled peak response of all patients (as presented in "Table 2) is also shown in the figure as a horizontal line. demonstrating that from 4 minutes until 12 minutes the metabolic and respiratory response of WT was continuously close to the peak physiological response of CE. Figure 1 also demonstrates that saturation decreased quickly during the WT and remained low for a relatively long period, compared to $\mathrm{CE}$. 
Figure I. Mean (SEM) physiological measurements during the course of the WT and CE $W T=$ closed circles; $C E=$ open circles and dotted line; mean peak exercise capacin achieved after $C E$ is shawed by the horizontal line. Mean variables during CE test are calculated for:

at 6 minures $(t=6)$ : all patients $(n=a l l), t=7: n-1, t=8: n-4, t=9: n-8, t=10: n-10, t=11: n-12$.
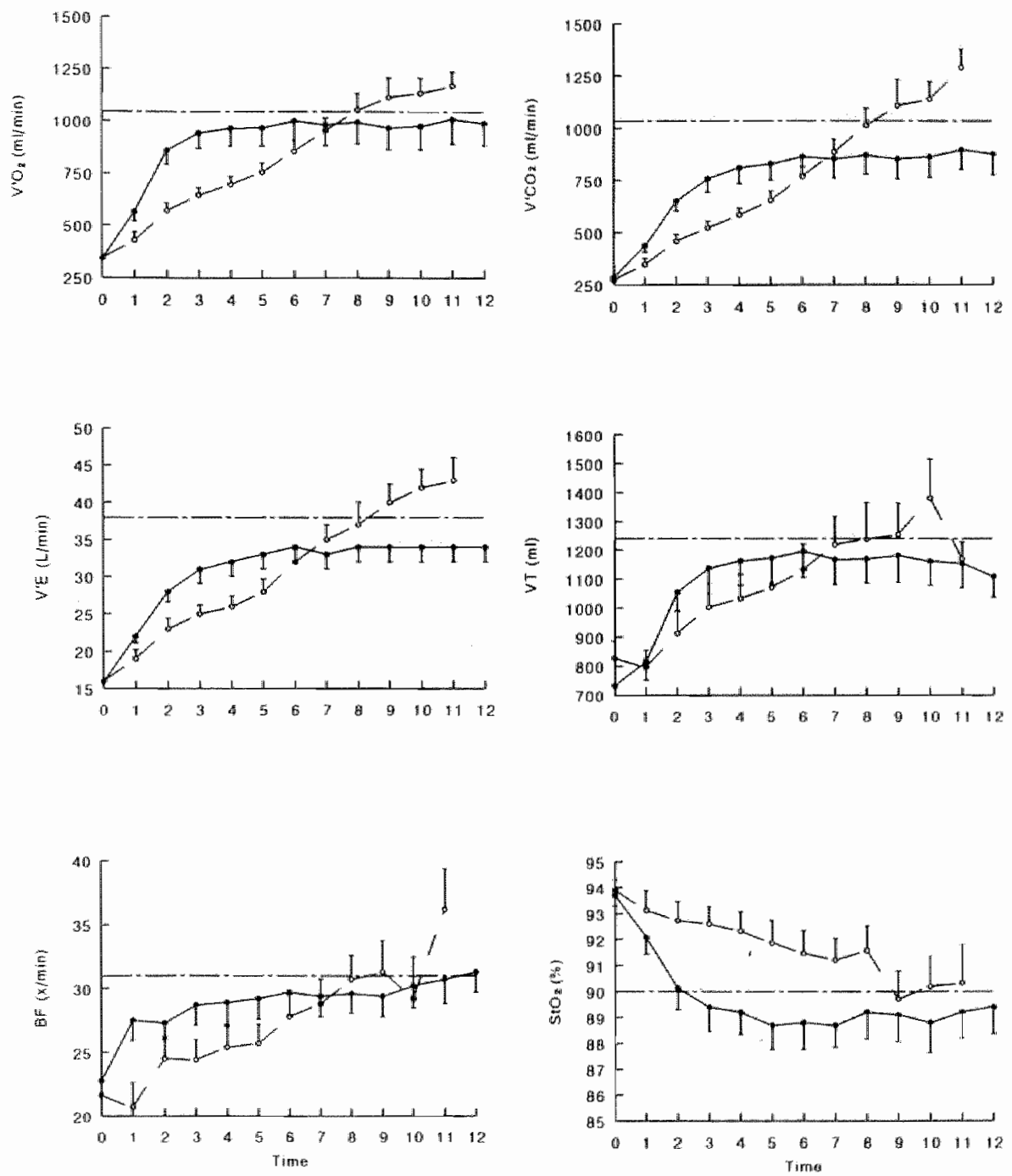
From the measured distances at two, six and twelve minutes it could be computed that walking speed was chosen during the first two minutes $(3.8 \pm 1.5$ $\mathrm{km} / \mathrm{h}$ ) and remained stable throughout the test. 13 patients also performed a 12 mimute walking test in a corridor, approximately 2 weeks after rehabilitation and the treadmill walk. A significantly higher distance was walked in the corridor $(829 \pm 180 \mathrm{~m})$ than or the treadmill $(703 \pm 227 \mathrm{~m}, \mathrm{p}<0.001)$ in this subgroup. In this subgroup the walking speed in the corridor after two minutes was significantly higher $(4.4 \pm 0.7$ $\mathrm{km} / \mathrm{h})$ than after 6 minutes $(4.2 \pm 0.8 \mathrm{~km} / \mathrm{h} \mathrm{p}<0.05)$, but remained stable after that untill 12 minutes $(4.1 \pm 0.9 \mathrm{~km} / \mathrm{h})$.

\section{Discussion}

The 12 minute walking test (WT) has been used very often to evaluate pulmonary rehabilitation. In recent years $\mathrm{CE}$ has been more frequently used, and has been found to be a reproducible test in lung disease ${ }^{2 * 30}$. The reproducibility is a crucial problem of the WT, since often a learning effect has been observed with succesive lests 5.28 .31 .32 . Furthermore it has been found that the most important factor that could predict the increase in distance after rehabilitation was the initial walking distance ${ }^{3.3}$. The WT was developed by McGavin in $1976^{\circ}$ in order to quantify the ability to perform activities of daily living in COPD patients, suggesting that the test requires submaximal effort. Walking is a familiar activity, and during this test the patients can choose their own pace, which all support the idea of submaximal activity. On the other hand, the patients are instructed to walk as far as possible, and other authors have described the 12 minute walking as exhausting*. Obviously, despite the wide use of the WT in pulmonary rehabilitation, there are contradictionary opinions about the actual physiological stress the WT evokes.

In the present study the 12 minute walking test was performed on a treadmill. Allthough we acknowledge that differences between treadmill walking and corridor walking are inevitable, these are probably minor. Two earlier performed studies compared 12 minute walking tests in a corridor and on a treadmill. Swerts et al ${ }^{34}$ found a significantly higher walking distance in the corridor, although this was only appoximately 80 meters. On the other hand, Beaumont et $\mathrm{al}^{35}$ found no differences in walking distance between a treadmill and corridor test.

In our study a subgroup of patients, who received a pulmonary rehabilitation 
exercise programme, also performed a corridor walk two weeks after the 12 mimute treadmill walk. In this subgroup the distance covered in the corridor was significantly higher than on the treadmill, which is most likely predominantly the effect of the pulmonary rehabilitation program, especially considering the small difference in 12 minute corridor and treadmill distance in the other studies ${ }^{34.35}$.

Although the distance covered is probably comparable in treadmill and corridor walking, perhaps a difference in pacing profile would be expected. During the self paced treadmill walking test of the present study the patients chose a rather stable walking speed, which might indicate that the treadmill likely dictates walking speed. There were also however (four) patients in the present study who actually stopped the treadmill during the test, which does implicate that the patients of the present sudy adjusted the walking speed to their ability. Furthermore, in the subgroup of patients who also performed a walking test in the corridor also a relatively stable walking speed was demonstrated. A stable walking speed during the 12 minute corridor walking test was already demonstrated in an earlier study by Schols et al ${ }^{4}$. In addition, Beaumont et al $^{35}$ found a similar correlation between stride length and walking speed in self paced corridor and treadmill walking, which also suggests a similar pacing profile for these two tests. Finally, if patients tend to have a higher walking distance during corridor walking than treadmill walking, this probably represents either a more efficient walk and therefore a comparable metabolic and ventilatory stress, or a better performance which would implicate that during the 12 minute corridor walking test the metabolic and ventilatory stress would be even higher than found in the present study using treadmill walking.

During the last minute of the self paced 12 minute treadmill walking test (WT) in the present study oxygen consumption $\left(\mathrm{V}^{\prime} \mathrm{O}_{2}\right)$, minute ventilation ( $\mathrm{V}^{\prime} \mathrm{E}$ ), tidal volume, breathing frequency. (de)saturation, and heart rate were all close to peak cycled physiological stress. The sensation of dyspnea after both tests was aiso comparable. Finally, last minute- $\mathrm{V}^{\prime} \mathrm{O}_{2}$ of the WT was not significantly different from the patient specific predicted maximal $\mathrm{V}^{\prime} \mathrm{O}_{2}$ according to Dillard ${ }^{2 !}$. Similar results were earlier found in a study of Swinburn et al who measured oxygen consumption and ventilation by a portable device in 8 patients during a 12 minute walking test in a corridor. Swinburn et al found that steady state values were obtained within the first 6 minutes of the test." In this study the "maximum values' recorded during a complete minute of the 12 minute walking test was not significantly different from the maximum 
values of incremental cycle ergometry. It is however unclear from that study ${ }^{7}$ when these maximum values were obtained during the 12 minute walking test, and whether the 'maximum' values of the 12 minute walking test were close to the steady state values, as the present study shows that on the average $V^{\prime} \mathrm{O}_{2}$ and $V^{\prime} E$ remained relatively stable throughout the test.

We used $\mathrm{CE}$ as a reference maximum physiological stress test since this test is also frequently used in clinical practice or research concerning physical performance of COPD patients and it is considered to provoke symptom limited peak performance in COPD. The patients of this study cycled until a ventilatory maximum and achieved a patient specific peak oxygen consumption. In addition a high degree of dyspnea was reached which correlated negatively but significantly to the peak workload achieved. During CE most patients achieved a lactate concentration of $3 \mathrm{mmol} / \mathrm{l}$ or more. These observations provide evidence that the physiological stress evoked by the $\mathrm{CE}$ in this study was indeed maximal for these patients.

In this study the metabolic and respiratory response at 4 minutes of the WT was already comparable to the physiological response during the last minute of walking. It was striking that the minute by minute physiological response during the WT showed that these COPD patients operated at an endurance level close to peak physiological stress. It is questioned if the physiological stress provoked by the WT would also be close to peak physiological stress achieved on a treadmill in stead of a bicycle, since in healthy persons walking exercise usually results in a greater metabolic stress. In COPD patients however a comparable metabolic and ventilatory stress was found in maximal cycle and treadmill exercise ${ }^{36.37}$, supporting the results of the present study that the WT is performed close to maximal ability. This seems contradictorary to the fact that the patients could sustain this performance for several minutes. However, some other studies have shown that patients with COPD are capable to train at relatively large loads of approximately $80-85 \%$ of maximum on a daily basis ${ }^{11.38}$. Still, the fact that dyspnea was not related to the distance walked does not support the suggestion that dyspnea limited the walking distance, and they walked continuously with a V'E slightly below the predicted maximal V'E. As earlier suggested', it could be hypothesised that in order to sustain the WT for twelve minutes and to remain the observed high performance level it was neccesary to walk with a ventilation (just) below the ventilatory maximum.

Peak CE performance in this study resulted in a higher carbon dioxide 
production $\left(\mathrm{V}^{\prime} \mathrm{CO}_{2}\right)$, respiratory quotient and venous lactate concentration compared to the anaerobic physiological response of the last minute of WT. It could be argued that the higher lactate concentration during $C E$ is caused by the fact that $C E$ represents a peak performance and WT does not. However, earlier studies have shown that when submaximal $^{39}$ or maximal $^{36}$ readmill and cycle ergometry was compared in COPD patients, cycling was associated with a higher anaerobic metabolism, although $\mathrm{V}^{\prime} \mathrm{O}_{2}$ was comparable.

Other explanations for an increased lactate concentration during cycling compared to walking is found in healthy subjects ${ }^{40-43}$, which has been ascribed to the use of a smaller muscle mass (and/or blood flow) during cycling compared to walking. Furthermore, Marthur et al ${ }^{36}$ postulated that cycling is a less familiar type of exercise which results in a greater lactate response. Also, it should be considered that arm activity in cycling, supporting and stabilising the upper body, could ellicit a greater lactate response than unsupported walking in COPD. In COPD patients the muscles around the shoulder girdle function both in arm activities and in breathing ${ }^{44.45}$, which can alter the metabolic response to arm activity ${ }^{46}$, so possibly arm activity may also enhamce anaerobic metabolic response during cycling in COPD patients.

During the WT lactate concentration aiso increased significantly. In an individual there is a relation between lactate concentration and the load of exercise, but this relation may differ between persons with a different anaerobic treshold or training stams. The lactate concentration found after the WT was significantly correlated with indices of the load of the WT. This suggests that the patients probably had comparable anaerobic tresholds. However, during $\mathrm{CE}$ there was no correlation between the load and the lactate concentration, suggesting that the heavy load during the CE is sustained too short in order to obtain a correlation with the lactate concentration at the time of the Ioad. Another explanation for the lack of correlation between load and lactate concentration during $\mathrm{CE}$ could be that this test is better capable to differentiate patients with a different anaerobic treshold.

In this study the longitudinal response of metabolic and ventilatory variables during the WT was monitored (Figure 1). Next to the earlier mentioned observation that throughout the test the physiological response of the WT was close to the peak physiological stress, it was striking that almost immediately after starting the WT mean saturation decreased up to approximately $4 \%$, and remained low during the test. In other studies a lower saturation or $\mathrm{PaO}_{2}$ during walking compared to cycling was 
found ${ }^{99.47}$. The observed more severe or more prolonged desaturation during walking than cycling is difficult to explain. The weight bearing character of walking probably provokes a sudden heavy introduction in exercise ${ }^{36}$, compared to the unloaded beginning and slowly increasing load in the CE. Another typical weight bearing test like the steptest has demonstrated to induce an even greater desaturation than walking in COPD patients ${ }^{4 *}$. It could also be postulated that the heavy load of walking and the associated anaerobic metabolism is related to the observed desaturated state during walking. Healthy persons seldomly would produce an increased lactate concentration during walking at the speed the patients of this study walked $( \pm 4 \mathrm{~km} / \mathrm{h})$, because of the relative low load. In COPD an early onset of anaerobic metabolism is confirmed by recent studies (using nuclear magnetic resonance techniques) ${ }^{49.50}$.

The observed immediate increase in $V^{\prime} \mathrm{E}$ and $\mathrm{V}^{\prime} \mathrm{CO}_{2}$ (Figure 1) just after the onset of walking runs allmost parallel to the decrease in saturation. Therefore, the early anaerobic metabolism might have resulted in an adaptive shift of the oxygensaturation curve (Bohr effect) favoring the delivery of oxygen in the tissues. Therefore, the observed low saturation could be the result of a shift of the oxygen-saturation curve. It should be emphasized that saturation $\left(\mathrm{StO}_{2}\right)$ in this study was measured indirectly with pulse oximetry. In a recent review it was stated that in most studies (7 of the ten reviewed) pulse oximetry provided accurate estimates of arterial oxygen saturation ${ }^{5 !}$. Furthermore, in our study $\mathrm{StO}_{2}$ was measured using a finger probe, which was reported to be more accurate than the often used (and studied) ear probe ${ }^{51}$. In addition, pulse oximeters are especially less accurate when saturation levels are extremely low, and due to the inclusion criteria in the present study concerning the blood gases these errors were also minimized.

In summary , analysis of the metabolic and ventilatory response to the self-paced 12 minute treadmill walking test (WT) in patients with severe COPD revealed, that on a group level the WT is performed close to the physiological stress of peak CE exercise. During the WT, a constant level of metabolic and ventilatory response was reached after 4 minutes. Although anaerobic energy deliverance (venous lactate concentration, carbon dioxide production and respiratory quotient) is clearly more evident during $\mathrm{CE}$ in most patients, lactate concentration also increased significantly during the WT. Furthermore, the observed on-going desaturated state during walking is an important feature in these COPD patients. It would be interesting to investigate whether this desaturated state is actually related to anaerobic energy metabolism during 


\section{walking in COPD patients and whether this contributes to a limited walking performance in COPD.}

\section{References}

1 Belman MJ. Exercise in chronic obstructive pulmonary disease. Clin. Clest Med. 1986: 7: 585595.

2 Loke J, Mahler DA, Man PSF, Wiedemann HP, Matthay RA. Exercise impaiment in chronic obstructive pulmonary diseases. Clin. Chest Med. 1984; $5 ; 121-143$.

3 Schols AMWJ, Mostert R, Soeters PB, Greve LH, Wouters EFM. Nutritional state and exercise performance in patients with chronic obstructive lung disease. Thorax 1989; 44: 937-941. Schols AMWJ, Mostert R. Soeters PB, Wouters EFM. Body composition and exercise perfomance in chronic obstructive pulmonary disease. Thorax. 1991; 46: 695-699.

5 McGavin CR, Gupta SP, MCHardy GJR. Twelve-mimure walking test for assessing disability in chronic bronchitis. Brit. Med. J. 1976; 2: 241-243.

6 Morgan AD. Simple exercise testing. Respir. Med. 1989: 83; 383-387 Swinburn CR. Waketield JM. Jones PW. Performance, ventilation, and oxygen consumption in three different types of exercise tests in patients with chronic obstructive lung disease. Thorax 1985 : 40: $581-586$.

Butland RJA, Pang J Gross ER, Woodcock AA, Geddes DM. Two-, six-, and 12-minute walking tests in respiratory disease. Brit. Med. 1. 1982; 284: 1607-1608.

Cox NMJ. Effects of a pulmonary rehabilitation program in patients with chronic obstructive lung diseases (in comparison with a control group). Meppel, Krips Repro, 1990.

10 Belman MJ, Mittman C, Weir R. Ventilatory muscle training improves exercise capacity in chronic: obstructive pulnonary disease patients. Am. Rev. Respir. Dis. 1980; 121: 273-280.

11 Cassaburi R. Patessio A, loli F. Zanaboni S. Donner CF, Wasserman K. Reductions in exercise lactic acidose and ventilation as a result of exercise training in patients with chronic obstnctive lung disease. Am. Rev. Respir. Dis. 1991: 143: 9-18.

Cockroft AE. Saunders MJ, Berry G. Randomised controlled trial of rehabilitation in chronic respiratory disability. Thorax. 1981; 36: 200-203.

13. McGavin CR, Gupta SP, Lloyd El. McHardy JR. Physical reluabilitation for the chronic bronchitis : results of a controlled trial of exercises in the home. Thorax. 1977; 32: 307-311. Pardy RL, Rivington RN, Despas PJ, Macklem PT. Inspiratory muscle training compared with physiodterapy in patients with clnonic airflow limitation. Am. Rev. Resp. Dis. 1981; 123: 421-425. Sinclair DJM. Ingram CG. Controlled trial of supervised exercise training in duronic brondhitis. Brit. Med. J. 1980: i: 256-261.

16 Swerts PMJ. Kretzers LMJ, Terpstra-Lindeman E, Verstappen FTJ, Wouters BFM. Exercise reconditioning in the rehabilitation of patients with chronic obstructive pulnonary disease: a shortand long-term analysis. Arch. Phys. Med. Relab. 1990; 71: $570-573$.

Medical selection of the Anerican Lung Association: Standards for the diagnoses and care of patients with cluronic pulmonary lung disease (COPD) and asthma. An. Rev. of Respir. Dis. 1987: 135: $225-228$. Black LF. Hyatt RE. Maximal respiratory pressures: nomal walues and relationship to age and sex. Am. Rev of Respir. Dis. 1969; 99: 696-702.

20 Dillard TA. Piantadosi S. Rajagopal KR. Determinanis of maximal exercise capacity in patients witly chronic airflow limitation. Chest. 1989: 96: 267-271.

21 Blackie SP. Fairbarn MS, McCelwaney GN, Morrison NJ, Wilco PG. Pardy RL. Prediction of naximal oxygen uptake and power during cycle ergonetry in subjects older than 55 years of age. Am. Rev. Respir. Dis. 1989; 139: 1424-1429. 
23 Noll F. L-C + Mactate. deternination with LDH. GTP and NAD. In: Bergmeytr. ed. Methods of enzymatic andigsis. New York. $1974, \mathrm{pg} 1475$

24 Lukaski HC, Bolunchuk WW, Hall CB. Siders WA, Validation of terapolar bioelectrical impedance method to assess human body composition. 3. Apl. Physiol. 1986; 60: 1327-1332.

Schols AMW, Dingemans ANC. Soeters PB, Wouters EFM. Within day variation of bioclectrical impedance resistance treasurements in patients widh chronic obstructive pulmonary disease. Clin. Nutr. 1990; $9: 266-271$.

Schols AMWJ, Soeters PB, Dingemans ANC. Mostert R, Frantzen PJ . Wouters EFM. Prevalence and characteristics of nutritional depletion in patients with COPD egligble for pulmonary rehabilita. nion. An. Rev. of Resp. Dis. 1993; 147:1151-1156.

Metropolitan Life Insuance Company. New weight standards for men and women. Statistical Bulletin Metropolian Life Foundation 1983: 64: 1-4.

Noseda A. Lung function, maximum and submaximum exercise testing in COPD patients: reproducibility over a long interval. Lung 1989; 167: 247-257.

Cox NMI. Hendriks JCM, Binkhorst RA, Folgering HTHM, van Herwatrden CLA. Reproducibility of incremental maximal cycle ergometer tests in patients with mild to moderate obstrucive lung disease. Lung 1989; 167: 129-133.

Marciniuk DD. Watts RE, Gallegher CG. Reproducibility of incremental oycle ergonetry testing in patients with restrictive lung disease. Thorax 1993: 48: 894-898.

31 Knox AJ. Montison JFJ. Muers MF. Reproducibility of walking test results in chronic onstnctive luntg flisease. Thorax 1988; 43: 388-392.

32 Mungall IPF. Assesment of respiratory function in patients with clmonic obstructive airways disseases. Thorax 1979; 34: 254-258.

33. Zuwallack RL. Patel K, Reardon IZ, Clark BA, Nomandin EA. Predictors of improvement in the 12 minute walking distance following a six week outpatient pulmonary reluabilitation program. Chest 1991: 99: $805-808$.

Swerts PMJ, Mostet R, Wouters EFM. Comparison of corridor and treatmill walking in pathents with severe Chronic Obstructive Pulmonary Disease. Physical Therapy 1990; 70: 40-43.

Beaumont A, Cockcroft A. Guz A. A self paced treadmill walking test for breathless paituts. Thorax 1985; 40: 459-464.

Marthur RS, Revill SM, Vara DD, Walton R, Morgan MDL. Comparison of peak oxygen consumption during cycle and ireadnill excrcise in severe chronic obstructive pulmonary disease. Thorax. 1995; 50: 829-833. Disease I. Appl. Physiol. 1969: 27: 256-261.

Punzal PA. Ries AL. Kaplan RM. Prewitt LM. Maximum intensity exercise training in paticnts with Chronic Ohstructive Pulmomary Disease. Chest 1991 ; 100: 618-23.

Cockroft AE. Beaumont A. Adans L. Guz A. Arterial oxygen desaturation during treadmill athd bicycle exercise in patients with chronic obstructive airways disease. Clin. Sci. 1985; 68: $327-332$.

Miles DS, Critz JB, Knowton RG. Cardiovascular, metabolic, and ventiatory responses of wonen 10 equivaleut cycle ergometer and treadmill exercise. Med. Sci. Sports. Exere. 1980; 12: 14-19.

Koyal SN, Whipp BJ. Huntsman D. Bray GA, Wasserman K. Ventilatory responses th the metatholic acidosis of treadmill and cycle etgometry. I. Appl. Physiol. 1976; 40: 864-867.

Hernansien L. Saltin B.
Physiot. 1969:26:31-37 Senay LC. Rogers G. Jooste P. Changes in blood plasna during progressiwe treadnill and cycle exercise. J. Appl. Physiol. 1980; 49; 59-65.

Dolnage TE, Macstro L. Avendano MA. Goldstein RS. The ventilatory response to arm elevarinon of patients with chronic obstructive pulnonary disease. Chest 1993; 104:109741100.

46 Barends EM. Schonls. AMWJ, Slebos D-. Mostert R. Janssen PP. Wouters EFM. Metabolic and ventilatory response to arm elevation in patients with $C O P D$ and healthy age-matched subjects. Eur. Respir. 1. 1995: 8: 1345.1351. 
47 Spence DPS. Hay JG. Carter J. Pearson MG. Calverley PMA. Oxygen desaturation and breathlessuless during corridor walking in chronic obstructive pulmonary disesse: effect of oxitropium fromide. Thorax. 1993: 48: 1145-1159.

48 Cohn JE, Donoso $H D$. Exercise and intrapulmonary wentilation-perfusion relationships in chronic obstructive pulmonary disease. Am. Rev. Respir. Dis. 1967; 95: 1015-1025.

49 Kutsuzawa T, Shioya S, Kurita D, Haida M, Ohta Y, Yanabayashi H. "s"P-NMR Study of skelefä muscle metabolism in patients with chronic respiratory impairnnent. Am. Rev. Respir. Dis, 1992: \&2146; 1019-1024.

50 Wuyam B, Payen JF, Levy P, Lebas JF, Benabid AL, Paramelle B. Muscular exercise netabolisn in COPD patients with chronic respiratory failure, a ${ }^{31}$ P-NMR study. Am. Rev. Respir. Dis. 1991: 143". A80.

51 Mengelkoch LJ, Martin D. Lawier J. A review of the principles of pulse oximetry and accuracy of pulse oximecer estimates during exercise. Physical therapy 1994: 74: 40-49, 


\section{PEAK EXERCISE RESPONSE IN RELATION TO TISSUE DEPLETION IN PATIENTS WITH CHRONIC OBSTRUCTIVE PULMONARY DISEASE}

Erica M. Baarends", Annemie M.W.J. Schols", Rob Mostert", Ennel F.M. Wouters', "Department of Pulmonology, Maastricht University. Maastrich, "Asthma Center Hornerheide, Horn. The Netheriands

\section{Albstract}

In several studies a correlation between body weight and peak exercise capacity has been found in patients with Chronic Obstructive Pulmonary Disease (COPD). In the present study a thorough analysis of the relationship between body composition and peak exercise performance was executed in 62 patients with clinically stable COPD, based on the hypothesis that particularly muscle mass as largest constituent of fat-free mass and body cell mass is related to exercise capacity. Body composition was assessed using deuterium and bromide dilution techniques, to measure total body water $(\mathrm{TBW})$ and extracellular water $(\mathrm{ECW})$. From these measurements fat-free mass (FFM: $\mathrm{TBW} / 0.73)$, ratio $\mathrm{ECW} / \mathrm{intracellular}$ water $(\mathrm{ICW})$ and $\mathrm{ICW}$-index $\left(\mathrm{ICW} / \mathrm{height}^{2}\right.$ ) were calculated. Peak exercise performance was measured using an incremental cycle ergometry test. Diffusing capacity (DL ${ }_{C O}$ ), intrathoracic gas volume (ITGV), maximal expiratory and inspiratory mouth pressure, forced expiratory volume (FEV $)$, FFMindex (FFM/height ${ }^{2}$ ), body mass index (weight/height ${ }^{2}$ ) and ICW-index correlated strongly $(p<0.01)$ to peak oxygen consumption $\left(\mathrm{V}^{\prime} \mathrm{O}_{2}\right)$. The ratio $\mathrm{ECW} / \mathrm{ICW}$ correlated only weakly, but significantly, with peak $\mathrm{V}^{\prime} \mathrm{O}_{2} \quad(r=0.25, p<0.05)$. Stepwise regression analysis demonstrated that FFM-index and $\mathrm{DL}_{\mathrm{CO}}$ explained $53 \%$ of the variation in peak $\mathrm{V}^{\prime} \mathrm{O}_{2}$. The results of this study furthermore indicate that severe FFM depletion is related to a blunted tidal volume response to peak exercise, a decreased peak oxygen pulse and an early anaerobic metabolism in patients with COPD. Depletion of muscle mass, measurable by assessment of FFM, significantly affects peak oxygen consumption, ventilatory response, the oxygen pulse and anaerobic energy metabolism in patients with COPD. 


\section{Introduction}

Among the overall pattern of functional impairment in patients with Chronic Obstructive Pulmonary Disease (COPD), limitation of peak exercise capacity is an essential feature, which can be accurately determined by incremental cycle ergometry.

The impaired exercise capacity in COPD patients has long been ascribed to an impaired ventilatory capacity due to disturbed pulmonary mechanics, respiratory muscle dysfunctioning, impaired gas exchange and cardiovascular dysfunctioning. Recent publications have drawn attention to peripheral muscle weakness and an altered muscle energy metabolism as contributing factors to impaired exercise capacity ${ }^{2.3}$. Muscle strength and metabolism are closely related to body composition ${ }^{4}$. It could be hypothesized that the association between peripheral muscle weakness and alterations. in muscle metabolism with exercise impairment is partly related to depletion of muscle mass.

Muscle mass is the largest constituent of the body cell mass (BCM), the energy exchanging part of the body. The BCM represents, together with the extracellular fluids and solids of the body, the fat-free mass (FFM). Direct measurement of muscle mass, for instance by magnetic resonance imaging, requires expensive, sophisticated instrumentation, that is not readily accessible ${ }^{5}$. (Isotope) Dilution methods are the next most accurate methods in the hierarchy of body composition methods ${ }^{5}$ that can be applied to estimate muscle mass, by the assessment of FFM. The additional value of measurement of FFM in stead of body weight in the functional characterisation of patients with COPD was demonstrated in an earlier study which showed that FFM correlated stronger with the 12 minute walking distance than body weight ${ }^{6}$. In addition. in this previous study it was found that normal weight patients with a selective loss of FFM expressed a lower walking distance than underweight patients with a relative preservation of $\mathrm{FFM}^{\circ}$.

In a recent study it was shown however that measurement of FFM may mask loss of BCM in some COPD patients? From this study it is hypothesized that subtle changes in the BCM can be estimated by the ECW/intracellular water (ICW) ratio and it was found that an increased ECW/ICW ratio may occur particularly in patients with severe FFM depletion?

Earlier studies have shown a significant relationship between body weight and maximal exercise capacity in patients with $\mathrm{COPD}^{8-10}$. The primary aim of the present 
study was to investigate the relationship between tissue depletion and peak exercise capacity in COPD, thus to study if measurements of FFM or BCM, the latter estimated by ICW, are better predictors of peak exercise capacity than body weight. In addition, the relationship between ECW/ICW ratio and peak exercise capacity was analyzed in order to study the additional effect of a specific, subtle, depletion of ICW $(B C M)$, in case this could not be identified from the difference in correlation between ICW or FFM with peak exercise capacity. The secondary aim of the present study was to analyze the influence of tissue depletion on the ventilatory, cardiac and lactate response to peak exercise in patients with COPD.

\section{Methods}

\section{Patients}

62 patients $\left(44 \delta^{*}, 18 \%\right)$ with moderate to severe COPD (defined by the American Thoracic Society ${ }^{\prime \prime}$ ) were studied (Table 1). They were admitted to a pulmonary rehabilitation center in a stable clinical condition. Patients exhibiting an increase in forced expiratory volume in one second $\left(\mathrm{FEV}_{1}\right)$ greater than $10 \%$ of baseline after inhalation of $B_{2}$-agonists were excluded. None of the patients suffered from a respiratory tract infection or demonstrated clinically visible signs of oedema at the time of the study. The patients did not require supplemental oxygen (resting arterial oxygen tension > $7.3 \mathrm{kPa}$ ), and had no known cardiovascular, neurological, endocrine or locomotor diseases. The patients were fully informed of the nature and purpose of the study and gave informed consent. The study was approved by the ethical committee of the Maastricht University. Procedures followed were in accord with the Helsinki declaration from 1977 as revised in 1983. 
Table 1: Characteristics of the studied group, grouped by gender

Data are presested as means $\pm S D_{s}$. FEV, forced expiratory volume in one second; FVC: forced vital capacity: IVC: inspiratory vitat capacity: $D L_{c o}$ diffusing capacity for carbon monoxide: $K_{c o}$ : $D L_{c o}$ divided by the alwelar space: TLC: total lung capacity: TTGV: intrathoracic gas wolume: RV: residual wolume:

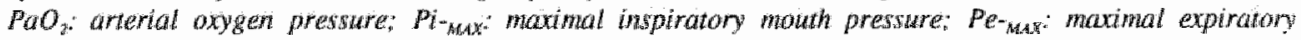
mouth pressure: BMI: body mass index. FFM-index: fat-free mass index: FM: fat mass: ECW: extracelladit: water; TBW: total body water. $\# p<0.05$; $p<0.01$;* $p<0.001$ : differences between men and women (Uipaired trest).

\begin{tabular}{|c|c|c|c|}
\hline & rotal group & $\delta(n=44)$ & $9(n=18)$ \\
\hline Age & $63 \pm 9$ & $65 \pm 7$ & $58 \pm 104$ \\
\hline FEVI (\%pred) & $39 \pm 13$ & $37 \pm 13$ & $45 \pm 13 H$ \\
\hline FVC (\%pred) & $87 \pm 16$ & $84 \pm 16$ & $93 \pm 14$ \\
\hline IVC (\%pred) & $85 \pm 16$ & $82 \pm 16$ & $93 \pm 13^{*}$ \\
\hline $\mathrm{DL}_{\mathrm{co}}(\%$ pred $)$ & $59 \pm 21$ & $57 \pm 22$ & $64 \pm 17$ \\
\hline $\mathrm{K}_{\text {co }}(\%$ pred $)$ & $69 \pm 26$ & $69 \pm 28$ & $72 \pm 20$ \\
\hline TLC (\%pred) & $122 \pm 17$ & $121+18$ & $124 \pm 13$ \\
\hline ITGV (\%pred) & $165 \pm 36$ & $165 \pm 39$ & $163 \pm 27$ \\
\hline RV (\%pred) & $189 \pm 51$ & $189 \pm 52$ & $190 \pm 51$ \\
\hline $\mathrm{PaO}_{2}(\mathrm{kPa})$ & $9.9 \pm 1.1$ & $9.9 \pm 1.0$ & $9.8 \pm 1.3$ \\
\hline $\mathrm{Pi}{ }_{\mathrm{MAN}}\left(\mathrm{cmH}_{2} \mathrm{O}\right)$ & $74 \pm 21$ & $78 \pm 20$ & $65 \pm 20 \%$ \\
\hline $\mathrm{Pe} \mathrm{e}_{\text {MAX }}\left(\mathrm{cmH}_{2} \mathrm{O}\right)$ & $84 \pm 22$ & $87 \pm 21$ & $78.2 \pm 23$ \\
\hline BMI $\left(\mathrm{kg} / \mathrm{m}^{2}\right)$ & $23.2 \pm 4.1$ & $23.3 \pm 3.9$ & $22.9 \pm 4.5$ \\
\hline FFM-index $\left(\mathrm{kg} / \mathrm{m}^{2}\right)$ & $16.1 \pm 1.9$ & $16.6 \pm 1.7$ & $14.9+1.8^{* 4 k}$ \\
\hline FM (然weigho) & $29.2 \pm 9.3$ & $27.5 \pm 8.9$ & $33.5 \pm 9.3 \#$ \\
\hline ECW/TBW (\%) & $44 \pm 5$ & $44 \pm 5$ & $45+4$ \\
\hline
\end{tabular}

Pulmonary function tests

Flow volume measurements included $\mathrm{FEV}_{1}$, forced vital capacity (FVC) and inspiratory vital capacity (IVC). The highest value of at least three measurements was used. Total lung capacity (TLC), intrathoracic gas volume (ITGV) and airways 
resistance $\left(R_{\text {aw }}\right)$ were measured by a bodyplethysmograph (Masterlab, llaeger, Würzburg, Germany). The values were expressed as a percentage of a reference value $^{l:}$. Diffusing capacity of carbon monoxide $(\mathrm{DL} \mathrm{co}$, and adjusted for alveolar volume: $K_{C O}$ ) was measured by a single breath method, and expressed as a percentage of the reference value ${ }^{12}$. Inspiratory $\left(\mathrm{Pi}^{-{ }_{\text {MAX }}}\right)$ and expiratory ( $\mathrm{Pe}_{\mathrm{MAX}}$ ) muscle strength was assessed by maximal inspiratory mouth pressure according to the method described by Black and $\mathrm{Hyatt}^{13}$. $\mathrm{Pi}_{\text {MAX }}$ measurement results in a negative pressure, but in the present study it was expressed and analyzed in positive values. Blood was drawn from the brachial artery at rest while breathing room air. Arterial oxygen pressure $(\mathrm{PaO})$ was anallyzed on a blood gas analyzer (Radiometer, ABL 330 Copenhagen. Denmark).

\section{Body composition}

Body height was determined to the nearest $0.5 \mathrm{~cm}$ (Lameris, WM 715 , Breukelen, The Netherlands) with subjects standing barefoot. Body weight was measured with a beam scale to the nearest $0.1 \mathrm{~kg}$ (SECA, FRG) with subjects barefoot and in light clothing. To adjust body weight for body height, the body mass index (BMI) was calculated as weight/height ${ }^{2}$.

To measure TBW each patient received a weighted $1 \mathrm{~g} / \mathrm{L}$ estimated $\mathrm{TBW}^{14}$ oral dose of deuterium labeled water ( $\mathrm{D}_{2} \mathrm{O}: 99.84$ atom percentage excess) mixed into $\approx$ $50 \mathrm{ml}$ water. For the estimation of extracellular water $60 \mathrm{mg}$ bromide (Br)/L estimated TBW of sodiumbromide was added to the deuterium dose. Patients received this "cocktail" late in the evening around 10 p.m.. Just before and approximately 10 hours later a venous blood sample and urine sample was obtained ${ }^{15.16}$ " Patients were not allowed to eat or drink during equilibration.

Urine was analyzed for deuterium with an isotope ratio mass spectrometer according to the standard Maastricht protocol'15. Deuterium dilution space was calculated from the quantity of administered $D_{2} O$ and the urine $D_{2} O$ concentrations following complete distribution. TBW was calculated from these values by applying a conversion factor of 1.04. This correction accounts for exchange of labile hydrogen which occurs in humans during the equilibrium period ${ }^{17}$. Fat free mass (FFM) was calculated assuming a hydration factor of 0.73 . Analogously to the BMI, FFM was adjusted for body height by calculating the Fl-index (FFM/height'). 
Bromide concentration in serum ultrafiltrate was determined with HPLC (Spectroflow 783: ABI analytical kratos division, Rotterdam, The Netherlands), according to the anion-exchange chromatographic method ${ }^{16.18}$. ECW was estimated by the corrected bromide space (CBS) and calculated according the following formula ${ }^{16.18}$ :

$\mathrm{ECW}(\mathrm{CBS})(\mathrm{L})=\frac{\mathrm{Br}_{\text {ddose }}(\mathrm{mmol})}{\left(\mathrm{Br}_{-\mathrm{f}}-\mathrm{Br}_{\mathrm{b}}\right)(\mathrm{mmol} / \mathrm{L})} \quad * 0.90 * 0.95$

$\mathrm{Br}_{\text {diose }}$ is the exact dosage the patients received, $\mathrm{Br}_{\mathrm{ff}}$ is the final bromide concentration in the serum ultrafiltrate (after 10 hours of equilibrium), $\mathrm{Br}_{\mathrm{b}}$ is the background bromide concentration from the initial blood sample. 0.90 is the correction factor for the $\mathrm{Br}$ in the non-extracellular sites, and 0.95 is the correction factor for the Donnan equilibrium.

Intracellular water (ICW) was the difference between TBW and ECW, and the ICW-index was calculated to adjust for body height (ICW/height ${ }^{2}$ ).

\section{Exercise testing}

The incremental cycle ergometry test (CE) was performed on an electromagnetic braked ergometer (Corival 400, Lode, Groningen, The Netherlands). After a 2 minute baseline resting period and 1 minute unloaded cycling, power was increased every minute by 10 watt. The load cycled was invisible for the patients, and they were encouraged to cycle as long as possible.

During the initial resting period and throughout the CE metabolic and ventilatory parameters (Oxyconbèta, Jaeger, Würzburg. Germany) were measured breath by breath, using a breathing mask. Heart rate was measured with a sporttester (PE3000, Polar Electro cy, Kempele, Finland), and an infrared electrode was placed on the finger to measure oxygen saturation (Fasttrac, Sensor Medics Co, Anaheim, California, USA). Prior to the test the equipment was calibrated.

Two minutes after the peak load was reached, a venous blood sample was obtained and stored at $\pm 4{ }^{\circ} \mathrm{C}$. The blood was centrifuged within 2 hours and lactate concentration in plasma was determined using an enzymatic method ${ }^{19}$ by an automated system (Cobas Mira, Roche, Bazel, Switzerland).

In the analysis, peak $\mathrm{V}^{\prime} \mathrm{O}_{2}$ rather than peak load was used as a measure of 
exercise capacity, because peak $\mathrm{V}^{\prime} \mathrm{O}_{2}$ is related to the actual ability to diffuse oxygen and to the amount of metabolic active tissue mass. Moreover, peak $\mathrm{V}^{\prime} \mathrm{O}_{2}$ is more reproducible than peak load'.

\section{Data analysis}

The characteristics of the patients are given as mean \pm SD. Differences between groups were calculated with an unpaired student T-test. Stepwise regression analysis was performed to define variables which determined exercise capacity. Analysis of covariance was used when appropriate. The level of significance was 0.05 .

In order to test whether patients with a different body composition had a significantly different peak exercise response, the patients were divided into groups of patients with a specific degree of FFM depletion. The cut-off point was determined on the basis of our earlier definition of FFM depletion using FFM adjusted for ideal body weight ${ }^{20}$ ( 9 : FFM $\leq 63 \%$ of ideal body weight, 0 : FFM $\leq 67 \%$ of ideal body weight). To avoid the use of wrist circumference (as a rather abitrary measure of frame size) and reference tables, we adjusted FFM for body height (FFM-index), as suggested by VanItallie et $\mathrm{al}^{21}$. Subsequently, the FFM-index which corresponded to the earlier defined value for FFM/ideal body weight, by means of linear regression analysis, was used in the present study. FFM depletion was thus defined as follows: $q$ : FFM-index $\leq 15 \mathrm{~kg} / \mathrm{m}^{2}$, o: FFM-index $\leq 16 \mathrm{~kg} / \mathrm{m}^{2}$.

\section{Results}

As shown in Table 1, the patients in this study suffered from moderate to severe airflow obstruction $\left(\mathbb{F E V}_{1}: 39 \pm 13 \%\right.$ pred), most patients were characterized by chronic hyperinflation at rest (ITGV: $165 \pm 36 \%$ pred) and had an impaired diffusing capacity ( $\mathrm{DL}_{\mathrm{Co}}: 59 \pm 21 \%$ pred). The women were significantly younger than the men, which could explain why the lung function (IVC and FEV F $_{1}$ in the female group was superior, although respiratory muscle strength was inferior.

Peak-load cycled was $56 \pm 23$ watl, and peak-V'O was $906 \pm 256 \mathrm{~mL} / \mathrm{min}$ which corresponds to $43 \pm 20 \%$ predicted (peak load) and $56 \pm 16 \%$ predicted (peak $\left.\mathrm{V}^{\prime} \mathrm{O}_{2}\right)^{23}$. Mean peak $\mathrm{V}^{\prime} \mathrm{E}$ was $37 \pm 10 \mathrm{~L} / \mathrm{min}$, or $96 \pm 23 \%$ predicted $^{23}$. indicating that during the exercise test most patients reached their predicted maximal 
minute ventilation $\left(=37.5^{*} \mathrm{FEV}_{1}\right)^{23}$.

The body composition of this group varied widely; BMI ranged from 15.3 to $34.4 \mathrm{~kg} / \mathrm{m}^{2}$. As expected, the women had a significantly higher fat-mass than the men, and a significantly lower FFM-index. TBW relative to body weight was close to normal in both men ( $53 \pm 6 \%$ weight) and women ( $49 \pm 7 \%$ weight $)^{24}$. Compared to data in a healthy young population, obtained by the same methods as in the present study $^{25}$, ECW/weight was also normal ( $23 \pm 3 \%$ weight) in the patients of the present study, which together with a normal TBW as percentage of weight implies a normal absolute ECW, but the ECW/TBW ratio was above the highest ECW/TBW ratio in healthy persons ${ }^{25}$ in a substantial part of the patients $(\delta: 21$ patients $>44 \%, q: 3$ patients $>48 \%$ ).

Correlation between lung function, body composition and peak V'O2

In Table 2 the correlation coefficients between peak $\mathrm{V}^{\prime} \mathrm{O}_{2}$ and lung function under resting conditions, and measurements of body composition are shown. Peak $\mathrm{V}^{\prime} \mathrm{O}_{2}$ correlated best with $\mathrm{DL}_{\mathrm{co}}$ (\%pred: $\mathrm{r}=0.55, \mathrm{p}<0.001$ ) and to a lesser degree with $K_{\mathrm{CO}}$ (\%pred: $\left.r=0.49, p<0.001\right)$. Subsequently ITGV $(r=-0.47, p<0.001)$ RV $(-0.45, \mathrm{p}<0.01)$ and $\mathrm{Pe}_{-\mathrm{MAX}}\left(\mathrm{cmH}_{2} \mathrm{O}: \mathrm{r}=0.46, \mathrm{p}<0.001\right)$ correlated best with peak $\mathrm{V}^{\prime} \mathrm{O}_{2}$. Finally, $\mathrm{Pi}_{-{ }_{\mathrm{MAX}}}\left(\mathrm{cmH}_{2} \mathrm{O}: 0.43, \mathrm{p}<0.01\right)$ and $\mathrm{FEV}_{1}(\mathrm{r}=0.35, \mathrm{p}<0.01)$ correlated significantly with peak $\mathrm{V}^{\prime} \mathrm{O}_{2}$. There was no significant correlation between airway resistance and exercise capacity.

With respect to the body composition, peak $\mathrm{V}^{\prime} \mathrm{O}_{2}$ correlated significantly with the BMI $\left(\mathrm{kg} / \mathrm{m}^{2}: \mathrm{r}=0.56, \mathrm{p}<0.001\right)$ and FFM-index $\left(\mathrm{kg} / \mathrm{m}^{2}: \mathrm{r}=0.57, \mathrm{p}<0.001\right)$. ICWindex could not improve the correlation with peak $\mathrm{V}^{\prime} \mathrm{O}_{2}\left(\mathrm{~kg} / \mathrm{m}^{2}: \mathrm{r}=0.54, \mathrm{p}<0.001\right)$ compared to the FFM-index. The ratio ECW/ICW correlated weakly but significantly with peak $\mathrm{V}^{\prime} \mathrm{O}_{2}(\mathrm{r}=-0.25, \mathrm{p}<0.05)$. 
Table 2: Correlation between peak oxygen consumption and lung function or body-composition

lCW: intracelutar water: for further abbreviations see legend to Table 1.

\# $p 0.05 ; \quad p<0.01 ; p<0.001$

\begin{tabular}{|c|c|c|}
\hline \multicolumn{2}{|c|}{ Lung-function } & \multirow{2}{*}{ Peak $V^{\prime} \mathrm{O}_{\mathrm{g}}(\mathrm{mi} / \mathrm{min})$} \\
\hline FEV & (\%pred) & \\
\hline $\mathrm{FVC}$ & (\%pred) & 0.10 \\
\hline INe & (\%pred) & 0.07 \\
\hline $\mathrm{DL}_{\text {ro }}$ & (\%pred) & $0.55^{* *}$ \\
\hline ITGV & (\%pred) & $-0.47 \%$ \\
\hline $\mathrm{PaO}_{2}$ & $(\mathrm{kPa})$ & 0.284 \\
\hline $\mathrm{Pi}_{\mathrm{MANX}}$ & $(\mathrm{cmH} 20)$ & $0.43^{*}$ \\
\hline Pe-Max & $(\mathrm{cmH} 20)$ & $0.46^{* * *}$ \\
\hline \multicolumn{3}{|c|}{ Body composition } \\
\hline BMI & $\left(\mathrm{kg} / \mathrm{m}^{2}\right)$ & $0.56^{* * * 2}$ \\
\hline FFM-index & $\left(\mathrm{kg} / \mathrm{In}^{2}\right)$ & $0.57^{* * ; *}$ \\
\hline ICW-index & $\left(\mathrm{L}^{\prime} \mathrm{m}^{2}\right)$ & 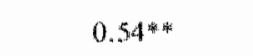 \\
\hline ECW/ICW & & -0.254 \\
\hline
\end{tabular}


Prediction variables for peak $\mathrm{V}^{\prime} \mathrm{O}_{2}$

All parameters of Table 2 which correlated with a $p<0.01$ were entered in a stepwise regression model, with peak $\mathrm{V}^{\prime} \mathrm{O}_{2}$ as the dependent variable. From the variables entered in the regression model, FFM-index $(p<0.001)$ was selected first and accounted for $31 \%$ of the variation of peak $\mathrm{V}^{\prime} \mathrm{O}_{2}$. After FFM-index, $\mathrm{DL}_{\mathrm{CO}}$

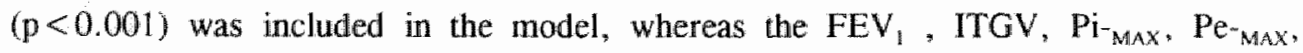
BMI and ICW-index were excluded. FFM-index and DL $\mathrm{DL}_{\mathrm{co}}$ explained together $53 \%$ of the variation of peak $\mathrm{V}^{\prime} \mathrm{O}_{2}$. The relationships between these variables and peak $\mathrm{V}^{\prime} \mathrm{O}_{2}$ are demonstrated in Figure 1.
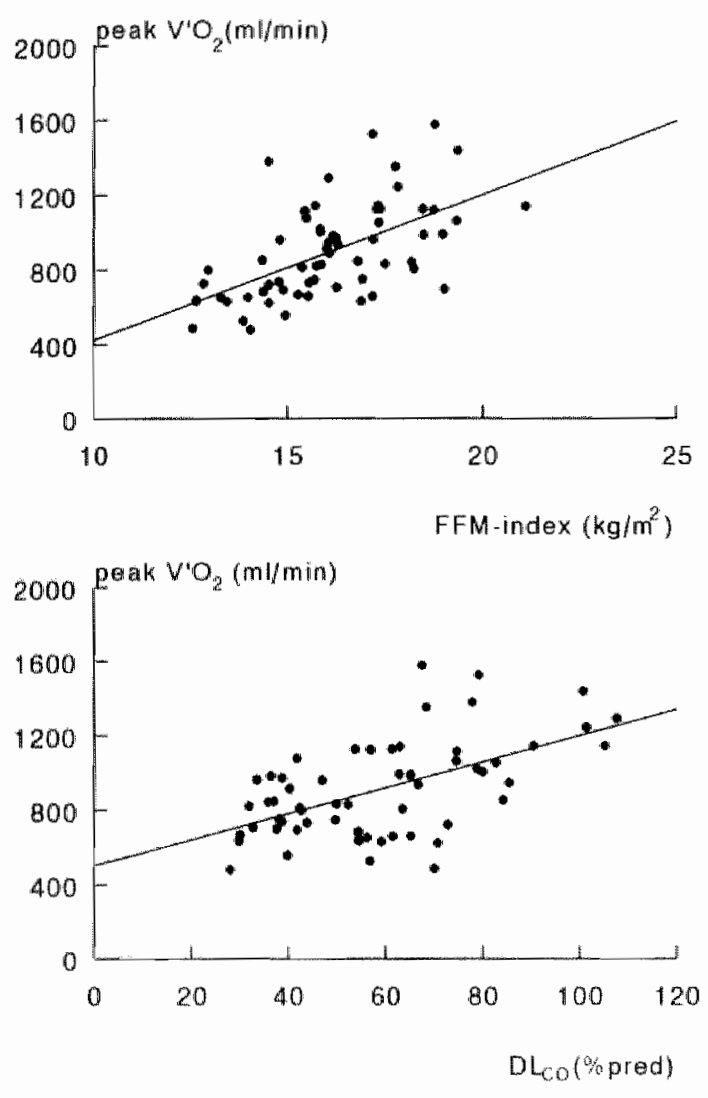

Figure 1: Peak axygen consumption related to FFMindex and diffusing capacity (\%pred) 
To gain more insight into the influence of a disturbed body composition on peak exercise performance, the difference in response to peak exercise between depleted and non-depleted patients was examined.

Table 3: Exercise capacity compared between groups of patients with a different body composition

Data are presented as mean $\pm S D$. V"O $\mathrm{O}_{2}$ : ongen consumption: $F F M$ : fat-free mass: $V$ 'E: misute wentilation. $M W$; predicted moximal voluntary ventilation; $V_{r}$ : tidal wolume: $B F$; breathing frequency; HR: heart rate: Dewal: desaturation. * Unpaired t-"ert

\begin{tabular}{|c|c|c|c|c|}
\hline & & depleted $(n=26)$ & not depleted $(n=36)$ & p value \\
\hline BMI & $\left(\mathrm{kg} / \mathrm{m}^{2}\right)$ & $20.5 \pm 2.6$ & $25.1 \pm 3.8$ & $p<0.001$ \\
\hline FFM-index & $\left(\mathrm{kg} / \mathrm{m}^{2}\right)$ & $14.5 \pm 1.0$ & $17.3 \pm 1.3$ & $p<0.001$ \\
\hline Peak Load & (\%pred) & $40 \pm 21$ & $46 \pm 18$ & NS \\
\hline Peak $V^{\prime} \mathrm{O}_{2}$ & (nll/min) & $755 \pm 205$ & $1015 \pm 235$ & $p<0.001$ \\
\hline Peak V'O & (\%pred) & $55 \pm 13$ & $58 \pm 19$ & NS \\
\hline Peatk $V \cdot O_{2} / F F M$ & $(\mathrm{ml} / \mathrm{min} / \mathrm{kg})$ & $18.8 \pm 4.4$ & $20.4 \pm 4.5$ & NS \\
\hline Peak V'E & $(\mathrm{L} / \mathrm{min})$ & $32.4 \pm 8.6$ & $39.6 \pm 9.8$ & $p<0.01$ \\
\hline Peak V'E/MVV & $(\%)$ & $94 \pm 20$ & $97 \pm 26$ & NS \\
\hline Peak $v_{r}$ & (L) & $1050 \pm 241$ & $1227 \pm 257$ & $\mathrm{p}<0.01$ \\
\hline Peak $V_{\mathrm{p}}$-Rest $V_{\mathrm{T}}$ & (L) & $324 \pm 197$ & $512 \pm 225$ & $p<0,0$ \\
\hline Peak BF & $(x / \min )$ & $31 \pm 7$ & $33 \pm 6$ & NS \\
\hline Peak $H R$ & (x/min $)$ & $127+16$ & $130 \pm 17$ & NS \\
\hline Peak oxygen pulse & $(m L / x)$ & $6.0 \pm 1.6$ & $7.7 \pm 1.7$ & $p<0.001$ \\
\hline $\begin{array}{l}\text { Peak lactated } \\
\text { Puak Work load }\end{array}$ & (mmot/L/wat $)$ & $0.09 \pm 0.06$ & $0.06 \pm 0.03$ & $p<0.05$ \\
\hline Desat & $(\%)$ & $-3.5 \leq 3.3$ & $-3.4 \pm 3.1$ & NS \\
\hline
\end{tabular}


Exercise response in patients with or without FFM depletion

There were $26(10 \%, 16 \%)$ patients with depletion of FEM and $36(89,28$ 3) patients with no depletion of FFM.

Patients with or without FFM wasting had no significantly different FEV, (depleted: $36 \pm 11 \%$ pred, not-depleted: $41 \pm 15 \%$ pred) or DL Co $_{\text {(depleted: } 53 \pm 16}$ $\%$ pred, not depleted: $63 \pm 22 \%$ pred), but significantly different TLC (depleted: 128 $\pm 14 \%$ pred, not-depleted: $117 \pm 17 \%$ pred, $\mathrm{P}<0.05$ ).

As shown in Table 3 , next to the expected significant differences in body composition and peak $V^{\prime} \mathrm{O}_{2}$ between patients with or without depletion of FFM, there was also a significant difference between the two groups in peak $V^{\prime \prime} E$, peak $V_{1}$. increase in $V_{T}$, peak oxygen pulse and the peak lactate/peak load ratio.

Peak V'E and the increase in $V_{\mathrm{T}}$ were still significantly different between the patients with or without FFM depletion $(p<0.05)$ when the relation of FEV (\%pred) with the increase in $V_{\gamma}(p<0.05)$ and $V^{\prime} E(p<0.001)$ was taken into account.

The peak oxygen pulse (peak $\mathrm{V}^{\prime} \mathrm{O}$ /peak HR) was significantly different $(p<0.01)$ between the patients with or without FFM depletion when the contribution of $\mathrm{DL}_{\mathrm{co}}(\%$ pred, $\mathrm{p}<0.01)$ to the variation of the oxygen pulse was taken into account.

The ratio peak lactate/peak load also tended to remain different $(p=0.06)$ between the groups of patients differentiated by FFM depletion, when the contribution of $\mathrm{DL}_{\mathrm{CO}}(\%$ pred, $\mathrm{p}<0.05)$ was taken into account.

\section{Discussion}

This sudy shows that depletion of FFM significantly contributes to a disturbed peak exercise capacity in COPD patients, in addition to diffusing capacity. FFM-index correlated betier with peak exercise capacity than BM】 and ICW-index, as demonstrated on stepwise regression analysis. A weak but significant correlation was found between ECW/ICW ratio and peak exercise capacity. In addition. it was demonstrated that deptetion of FFM contributes to a blunted tidal volume response to peak exercise. Furthermore, a decreased peak oxygen pulse and an earlier anaerobic metabolism during peak exercise appear to be related to FFM depletion in COPD.

A decrease in body weight and FFM in COPD is primarily a consequence of a disturbed energy balance. In a recent study, we demonstrated an increased total daily 
energy expenditure in COPD patients compared to healthy subjects ${ }^{26}$. Furthermore, in an earlier study we found a lower energy intake, in absolute terms as well as expressed as percentage of REE, in weight losing patients compared to weight stable patients ${ }^{27}$. Caloric deprivation generally leads to a selective atrophy of type II or fast twitch (glycolytic) fibers in muscles ${ }^{4}$. This contributes to the decreased respiratory and peripheral $^{29}$ muscle strength in depleted COPD patients, which in turn may affect exercise capacity ${ }^{2}$. In addition, patients with COPD may suffer from a selective depletion of FFM, despite a normal body weight ${ }^{29}$. The reason for a selective FFM depletion is not clear yet, but it probably explains why FFM-index correlated beter with peak $\mathrm{V}^{\prime} \mathrm{O}_{2}$ than $\mathrm{BMI}$, as demonstrated on stepwise regression analysis.

As in our earlier study? , in the present study it was demonstrated that fluid shifts (increased ECW/ICW ratio) can occur in clinically stable COPD patients. Because the TBW and ECW as percentage of body weight of the patients with COPD was similar to healthy persons and the patients showed no signs of peripheral oedema, it is unlikely that the patients suffered from an absolute expansion of ECW. This means that a relative increase of $\mathrm{ECW}$ can be interpreted as a selective depletion of ICW, or $\mathrm{BCM}$. Evidence for a selective decrease in BCM and no absolute ECW expansion in patients with COPD was found earlier in a study by Telfer et al ${ }^{30}$. In that study ${ }^{30}$ a slightly enhanced exchangeable sodium and a pronounced decreased exchangeable potassium was reported, with a normal TBW in patients with $\mathrm{COPD}^{30}$. It is unclear which mechanisms might contribute to a relative increase in ECW in patients with COPD. With respect to a possible explanation of a selective decrease in ICW (or cellular shrinkage), the theories posited by Häussinger are interesting ${ }^{31}$. Following this theory factors such as an inflammatory state, amino acid starvation and stress conditions lead to cellular shrinkage which in turn can act as a catabolic signal ${ }^{31}$. Particularly in depleted patients with COPD, a chronic inflammatory state has been demonstrated ${ }^{32}$, which might support the proposed mechanisms by Häussinger, but underlying causes for a relatively increased $\mathrm{ECW}$ in patients with COPD need further investigation.

Compared to a healthy young population $39 \%$ of the patients had a relatively increased ECW. Nevertheless, the ICW-index did not predict the peak $\mathrm{V}^{\prime} \mathrm{O}$, better than FFM-index. In addition, ratio ECW/ICW correlated only weakly with peak $V$ " $\mathrm{O}_{2}$. Therefore, the results of this study suggest that subtle depletion of BCM masked by FEM measurement is not severe in patients with COPD. since it does not affect exercise capacity to a great extent. However, we cannot exchude the possibility that the 
present study underestimates the effect of muscle mass depletion on exercise performance due to the methodology used, i.e. measurement of BCM by ICW, because it should be remarked that ECW represents also a part of muscles.

The relationship between $\mathrm{DL}_{\mathrm{co}}$ and peak $\mathrm{V}^{\prime} \mathrm{O}_{2}$ is evident, since it represents lung parenchymal damage. Besides, it confirms the significant relation between $\mathrm{DL}_{\mathrm{CO}}$ and peak exercise performance found in many other studies ${ }^{2,33.34,35}$.

The results of this study are similar to those of our earlier study in which it was shown that FFM was an important determinant of the 12 minute walking distance in COPD patients ${ }^{8}$. However, in our previous study we did not measure the influence of FFM depletion on the metabolic, cardial and ventilatory response to exercise. In addition, a drawback of our previous study was that a walking test was used. Walking tests are considered less reliable as a measurement of exercise capacity since they are highly subject to effects of learning and motivation ${ }^{36}$, whereas in the present study an incremental cycle test was used which is usually acknowledged as the "gold standard" for the measurement of aerobic capacity.

The results of the present sudy also correspond to earlier studies in which was shown that a reduced weight is related to a decreased maximal exercise performance ${ }^{2 . \%}$ ${ }^{10}$. but these studies did not involve measurements of body composition. Only in the study of Cotes et $a^{33}{ }^{3}$ it was reported that FFM improved the prediction of peak $\mathrm{V}^{\prime} \mathrm{O}_{2}$ in COPD patients, together with variables concerning pulmonary function (airflow and diffusing) and age. However, the latter study was mainly focussed on the accuracy of predicting exercise capacity by different pulmonary function variables and the potential importance of depletion of FFM with respect to exercise capacity was not discussed.

Analysis of the response to peak exercise between depleted and not-depleted COPD patients demonstrated a different ventilatory response to peak exercise between the groups differentiated by FFM depletion. Although the patients in both groups achieved a comparable peak $V^{\prime} E$ as percentage of predicted, the patients with depletion of FWM specifically had an impaired ability to increase $V_{T}$, even when the contribution of FEV, to $\mathrm{V}_{1}$. was taken into account. Breathing frequency was not significantly different between the groups differentiated by FFM-index. These findings are in agreement with a recent study of Palange et $\mathrm{al}^{7}$, who showed that patients with a lower body weight demonstrate a less efficient breathing pattern (a higher deadspace/ $V_{T}$ ratio). In general, the blunted $\mathrm{V}_{\mathrm{r}}$ response to peak exercise in COPD patients could be explained by dynamic hyperinflation, but this may have been further complicated by 
the respiratory muscle weakness observed in depleted patients with $\mathrm{COPD}^{28}$.

Despite a comparable exercise induced desaturation, the patients with severe depletion of FFM demonstrated a significantly lower oxygen pulse than the patients with no depletion of FFM. In addition, oxygen pulse was still significantly different between patients differentiated by FFM depletion when the influence of $\mathrm{DL}_{\mathrm{Co}}$ to the variation in oxygen pulse was taken into account. It could be hypothesized that depletion of FFM affects the stroke volume, i.e. decreases the pump ability of the heart. This hypothesis is supported by the study of Lands et $\mathrm{al}^{37}$, who found a decreased stroke volume relative to an increased HR during exercise in anorectic patients. Further studies of cardiac output measurement during exercise are needed to confirm this interpretation of a decreased oxygen pulse in depleted COPD patients.

Finally, it should be noted that peak lactate concentration per achieved peak work load was significantly higher in the patients with depletion of FFM than the patients with no depletion of FFM, which tended to persist when the influence of $D L_{c o}$ was taken into account. Evidence for an earlier anaerobic energy metabolism in the patients with excessive tissue wasting in the present study is in agreement with the sudy of Kutsuzwa et $\mathrm{al}^{38}$, who found an early activation of anaerobic glycolysis in patients with COPD, and demonstrated a significant correlation between indices of this early activation and body weight and muscle mass in COPD patients. Furthermore, Palange et al ${ }^{7}$ found an earlier onset of metabolic acidosis in patients with a low body weight.

In conclusion, FFM depletion is an important determinant of exercise capacity in COPD patients. The results of the present study warrant further investigation on the possible role of FFM depletion in the recently found interrelationships between peripheral muscle strength, anaerobic muscle metabolism and a blunted $\mathrm{V}_{\mathrm{T}}$ response and (peak) exercise capacity in COPD.

\section{References}

I Noseda A. Carpiaux JP. Prigogine T, Schmerber I. Lung function, naximan and submaxinam exercise testing in COPD patients. reproducifility over a long interwat. Lung 1989: 167: 247-257.

2 Gosselink R. Tronsters T, Decramer M. Peripherall muscle weakness contributes to exercise limitation. in COPD. An. J, Respir. Crit. Care Med. 1996: 153:976-980.

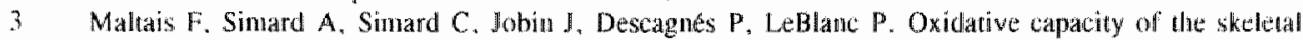
muscle and lactio acid kinetics during exercise in mormal subjects and in patients witl COPD. An. J. Respir. Crit. Care Med. 1996: 153: 288-293. 


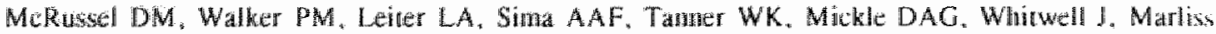
EC. Metabolic and structural changes in sketetal musche during hypocaloric dieting. An. 1. Clin. Nuir. 1984:39:503-513.

5 Batugartmer RN. Body conposition in elderly persons: a critical rewiew of needs and nethods. Progr. Food Nutr. Sci. 1993; 17: 223-260.

6 Schols AMWJ. Moster R, Soeters PB, Wouters EFM. Body composition and exercise perfomance in patients with chronic obstructive pulmonary disease. Thoras 1991: 46: 695-699.

7 Barends EM, Schols AMWJ. Marken-Lichtenbelt WD. Wouters EFM. Analysis of body water comparments in relation to nissue depletion in clinically stable parients with Chronic Obstructive Pulmonary Disease. An. J. Clin. Nutr. 1997; 65: 88.94.

8 Wilson DO, Rogers RM, Wright $\mathbb{E} C$. Anthonisen NR. Body weight in chromic obstnuctive pulmonary disease, Ann. Rew. Respir. Dis. 1989; 139: 1435-1438.

9 Gray-Donild K. Gibbons L, Shapiro SH, Martim JG. Effect of nutritional status on exercise performance in patients with chronic obstmeive pulmonary disease. Am. Rev. Respir. Dis. 1989 ; $140: 1544-1548$.

10 Palange P, Forte S. Feelli A, Galassetti P. Seria P, Carlone S. Nutritional state and exercise tolerance in patients with COPD. CHest 1995; 107: 1206-12.

11. American Thoracic Society. Standards for the diagnoses and care of patients with chronic obstructive pulmonary disease (COPD) and astma. Am. Rew. Respir. Dis. 1987; 137: 225-228.

12 Quanjer Ph, Tammeling GJ, Cotes JE. Pedersen OF, Peslin R, Yernalul J-C. Standardized lung function testing. Eur. Resp. J. 1993; 6 (suppl 16): 5-40.

13 Black $L F$, Hyat $R E$. Maximal respinatory pressures: nomual values and relationship to age and sex. Am. Rev. of Respir. Dis. 1969; 99:696-702.

14 Deurenberg $\mathrm{F}$. Westrate JA. Seidell IC. Body mass index as a meastre of body fatness: age and sex specific prediction formulas. Br. J. Nutr. 1991; 65: 105-114.

15 Westerterp KR. Wouters L, Marken Lichtenbelt WD. The Maastricht Protocol for the nueasurement of body composition and energy expenditure with labeled water. Obesity Research 1995: 3: 49-57 (suppl 1).

16 Marken Lichtenbelt van WD, Kester A. Baarends EM, Westerterp KR. Bromide dillution ün adulis: optimal equilibration tinte after oral administration. J. Appl. Plysiol. 1996:81: 653-656.

17 Schoeller DA. Isotope dilution methods. In: Bjontrop P. Brodoff BN. eds. Obesity. I.B. Lippecunt Company, Philadelphia. 1992; 80-88.

18 Miller ME, Cosgriff JM, Forbes GB. Bromide space determination using anion-exchange chromarograpliy for measurement with bronide. Am. J. Clin. Nutr. 1989; 50: 168-171.

19 Noll F. L-(+)-lactate, detemination with LDH, GTP and NAD. In: Bergneyer, ed, Methods of tonzyutatic atalysis. New York. 1974, ng1475.

20 Schols AMWJ, Soeters PB, Dingemans ANC, Mostert R, Franden PJ. Wouters EFM: Prevaleme

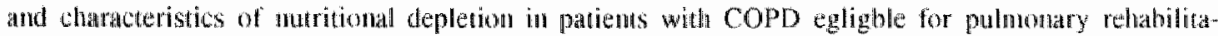
tion. Am. Rev. of Resp. Dis. 1993: 147; 1151-1156.

21 Vanlallie TB, Yan M, Heymsfield SB. Funk RC. Boileau RA. Height-nomalized indices of body" hathe mass and fat mass: potentially useful indicators of nutritionall status. Am. J. Clin. Nutr. 1990 : $52: 953.9$

22 Jomes NL. Clinical exercise testing. Samoters Philadelpha. 3rd ed. 1988. $158-185$.

23 Carter R, Peavler M, Zinkgnaf $S$, Willians J, Fields $S$. Predicting maximal exercise ventilation int Clunic obstmutive pulnonary distase. Chest. $1987: 92: 253-259$.

24 Seloeller DA. Changes in total body water with age. Am. J. Chin. Nuir. 1989: 50: 1176-81.

25 Marken Lichtenbelt van W. Westerterp KR. Wouters L. Luijendijk SCM. Validation of biochectricalintuedanoe measurements as a method to estimate bodyuwater compartments. Ann. I. Clin. Nult. 1994: $60: 159-166$

26 Barends EM, Schols AMWJ, Pannerans DLE, Westerter KR. Wouters EFM. Toral deily energy expenditure in clincally stable patients with severe COPD and age-nateled hesalthy subjects using the doubly labeled water method. Am. I. Repir. Crit. Care Med. (in press)

27 Schols AMWJ, Soeters PB. Saris WHM, Wouters EFM. Energy balance in patients with chromis obstructive pulnomary disease. An. Rav. Respir. Dis. 1991: 143-1248-52. 
Nishinura Y, Tsussmi M, Nakata H. Tsunenari T. Maeda H, Yokoyama M. Relationship bethreen respiratory muscle streagth and lean body mass in men with COPD. Chest 1995: 107: 1232-1236.

29 Engeten MPKJ. Schols AMWJ. Baken WC. Wesseling GI, Wounens EFM. Numinonal deptetion in relation to respiratory and peripheral skeletal muscle funotion in out-patients with COPD. Eur. Respic. J. 1994: 7: 1793-1797.

30 Telfer N. Bauer FK. Mickey MR. Herbst HH. Body composition in chronic obstructive pulmonary disease. An.. Rev. Respir. Dis, 1968: 98: 640-5.

31 Haussinger D, Roth E. Lang F. Gerok W. Cellular hydration state: an important determinant of protein catabolism in health and disease. The Lancet 1993; 34: 1331-1332.

32 Schols AMWJ. Bunrnan WA. Stal-van den Brekel AJ, Dentener MA, Wouters EPM. Evidence for a relation between metabolic derangenents and increased levels of inflammatatory nediators in a subgroup of patients with chronic obstructive pulmonary disease. Thorax, 1996; 51: 819-24.

33 Cotes $ل$ E. Zejda J. King B. Lung functon impaimesut as a guide to exercise limitation in workwared lung disorders. An. Rev. Respir. Dis. 1988; 137; 1089-93.

34 Dillard TA. Piantadosi S, Rajagopal KR. Determinants of maximun exercise capaciey in patients with chronic airflow obstruction. Chest 1989:96:267-271.

35 Wijkstra PJ, Ten Vergert EM, Mark van der Th W, Postma DS, Altena van R, Kraan J, Koeter GH. Relation of lung function, maximal inspiranory pressure, dyspnoea, and quality of life with exercise capaciry in patients with chronic obstructive pulmonary disease. "Thorax 1994: 49:468-472.

36. Steele $\mathbb{B}$. Timed walking tests of exercise capacity in chronic cardiopulmonary illness. J. Cardiopulm. Rehabil. 1996: 16:25-33.

37 Lands $L$. Pavilanis A, Charge TD, Coates Al. Cardiopumanary response to exercise in anovexia nervosa. Peadiatr. Pulnonol. 1992: 13: 101-107.

38 Kutsuzawa T. Shioya S. Kurita D, Haida M. Ohta Y, Yamabayashi H. "P.NMR study of sketetal muscle metabolism in patients with chronic respiratory impaiment. An. Rev. Respir. Dis. 1992; 146: $1019-1024$. 


\section{DECREASED MECHANICAL EFFICIENCY \\ IN CLINICALLY STABLE PATIENTS WITH \\ CHRONIC OBSTRUCTIVE PULMONARY DISEASE}

Erica M. Baarends. Annemie M.W.J. Scholsi, Marco A. Akkernams', Emiel F.M. Wouters. 'Department of Pulmonology. Maastricht University. Maastricht, ${ }^{2}$ Asthma Center Homerheide. Horn. The Netherlands.

\section{Abstract}

Recently we demonstrated that total daily energy expenditure (TDE) is increased in patients with Chronic Obstructive Pulmonary Disease (COPD) and it was hypothesized that these patients may have a decreased mechanical efficiency during activities. The purpose of the present study was to measure the mechanical efficiency of submaximal leg exercise, and to characterize patients with a potentially low efficiency in terms of body conuposition, resting energy expenditure, lung function and symptom limited exercise performance. Metabolic and ventilatory variables were measured breath by breath during submaximal cycle ergometry exercise performed at $50 \%$ of symptom limited achieved maximal load in $33(238,10 \%)$ clinically stable patients with COPD (FEV $: 40 \pm 12 \%$ pred). Net mechanical efficiency was calculated adjusting for REE. Median mechanical efficiency was $15.5 \%$ and ranged from $8.5 \%$ to $22.7 \%$. Patients with an extremely low mechanical efficiency $(<17 \%, \mathrm{n}=21)$ demonstrated an increased $\mathrm{V}^{\prime} \mathrm{O}_{2} / \mathrm{V}^{\prime} \mathrm{E}$ compared to the patients with a normal efficiency (median difference: $4.7 \mathrm{ml} / \mathrm{L}, \mathrm{p}=0.005$ ) during submaximal exercise. There was no difference between the groups differentiated by mechanical efficiency in blood gases at rest, airflow obstruction, respiratory muscle strength, hyperinflation at rest, resting energy expenditure or body composition. There was a significant difference in total airways resistance $(92 \%$ pred, $p=0.03)$ between the groups differentiated by mechanical efficiency. It is concluded that a substantial number of patients with severe COPD have decreased mechanical efficiency. Furthermore, based on the results of this study it is hypothesized that an increased oxygen cost of breathing during exercise contributes to the decreased mechanical efficiency. 


\section{Introduction}

Patilents with Chronic Obstructive Pulmonary Disease (COPD) often suffer from a severely impaired exercise tolerance. Over the years, it has become increasingly clear that the limited exercise capacity in patients with COPD is multifactorially determined. After factors such as an impaired ventilatory capacity, respiratory muscle dysfunction, impaired gas exchange and cardiovascular problems", recent studies have focussed on peripheral muscle weakness and impaired muscle metabolism as factors contributing to the decreased exercise capacity in $\mathrm{COPD}^{2.3}$. Muscle strength and muscle metabolism are closely related to body composition ${ }^{4}$. In patients with COPD a disturbed body composition is frequendy present $^{5}$ due to loss of body weight as well as to a selective depletion of fat-free mass (FFM). In particular, loss of FFM negatively influences the exercise capacity in patients with $\mathrm{COPD}^{6,7}$, independently of lung function impairment.

The reason for the observed disturbances in body composition is not completely understood, but body weight loss implies a negative energy balance. Recently we demonstrated that total daily energy expenditure is increased in patients with COPD compared to healthy subjects". Furthermore, it was demonstrated that especially the nonresting component (predominantly the energy expenditure for activity) contributes to the increased total dailly energy expenditure. In a subsequent study it was shown that the variation in total daily energy expenditure in patients with COPD was not strongly related to $\mathrm{REE}$ but mainly a reflection of the energy expenditure for activities. Based on the results of these two studies it was hypothesized that patients with COPD could have a reduced mechanical efficiency during exercise.

To test this hypothesis. we measured the mechanical efficiency of submaximal leg exercise in a group of patients with COPD. Furthermore, we examined if mechanical efficiency was related to patients' characteristics such as body composition, resting energy expenditure, lung function and symptom limited exercise performance. 


\section{Methods}

\section{Paitents}

33 Patients $(23 \%, 10 \%)$ with moderate to severe COPD according to the criteria of the American Thoracic Society ${ }^{10}$ were studied (Table 1). Patients exhibiting an increase in forced expiratory volume in one second $\left(\mathrm{FEV}_{1}\right)>10 \%$ after inhalation of $\beta_{2}$-agonists, or requiring oxygen supplementation $\left(\mathrm{PaO}_{2}\right.$ at rest $\left.<7.3 \mathrm{kPa}\right)$ were not included. All patients were admitted to a pulmonary rehabilitation center in a stable clinical condition. None of the patients had a respiratory tract infection or clinically visible signs of oedema at the time of the study and no known cardiovascular, neurological, endocrine or locomotor diseases. The patients were fully informed of the nature and purpose of the study and gave informed consent. The study was approved by the ethical committee of the Maastricht University. Procedures followed were in accord with the Helsinki declaration from 1977 as revised in 1983.

\section{Pulmonary function tests}

Flow volume measurements included $\mathrm{FEV}_{1}$, and forced vital capacity (FVC); the highest value of at least three measurements was used. Total lung capacity (TLC), intrathoracic gasvolume (ITGV) and airways resistance $\left(R_{\mathrm{aw}}\right)$ were measured by bodyplethysmography (Masterlab, Jaeger, Würzburg. Germany). The values were expressed as a percentage of reference values ${ }^{\prime \prime}$. The upper limit of normal $R_{a w}$ was considered 0.3 $\mathrm{kPa}^{*} \mathrm{~s} / \mathrm{L}^{12}$. Diffusing capacity of carbon monoxide $\left(\mathrm{DL}_{\mathrm{CO}}\right)$ was measured by a single breath method (Masterlab, Jaeger, Würzburg, Germany), and expressed as a percentage of the reference value". Inspiratory muscle strength was assessed by maximal inspiratory mouth pressure ( $\mathrm{Pi}_{\text {MAX }}$ ) according to the method described by Black and Hyatt, and expressed in positive values ${ }^{13}$. Blood was drawn from the brachial artery at rest while breathing room air. Arterial pressures of oxygen and carbon dioxide $\left(\mathrm{PaO}_{2}\right.$ and $\left.\mathrm{PaCO}_{2}\right)$ were analyzed on a blood gas analyzer (Radiometer, ABL 330 Copenhagen, Denmark). 
Table 1: Charocheristics and maxinal exercise capacity of the studied group

Data dore presented as medion (range). BMT body mass index; REE (F HB): resting evergy expenditure as

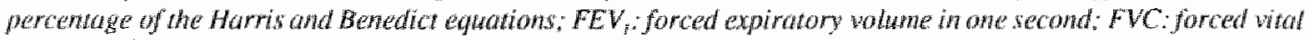

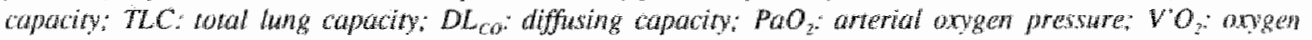
consamption: VE: minuté wentilation; HR: heart rate.

\begin{tabular}{|c|c|c|c|}
\hline Characteristics & & median (range) & \\
\hline age & (yr) & $61(38-82)$ & \\
\hline BMI & $\left(\mathrm{kg} / \mathrm{w}^{2}\right)$ & $22.8(18-44)$ & \\
\hline REE $(\% H B)$ & $(\% \mathrm{HB})$ & $112.6(76 \sim 166)$ & \\
\hline FEV, & (\%pred) & $36.7(17-69)$ & \\
\hline FVC & (\%pred) & $84.2(64-110)$ & \\
\hline TLC & (\%pred) & $125.3(87.7-144.6)$ & \\
\hline $\mathrm{DL}_{\mathrm{L}: 0}$ & (\%pred) & $50.9(36-112)$ & \\
\hline $\mathrm{PaO}_{2}$ & (kPa) & $9.3(7.7 .12 .5)$ & \\
\hline Exercise capacily & & & \%pred \\
\hline Peak load & (watt) & $58(24-145)$ & $36(16-77)$ \\
\hline peratk $V^{\prime} \mathrm{O}_{2}$ & (L/min) & $0.96(0.59-2.14)$ & $36(21-81)$ \\
\hline Peak V'E & (L/min) & $38(24-72)$ & $95(56.185)$ \\
\hline Peak HR & $(x /$ min $)$ & $128(85-176)$ & $83(56-108)$ \\
\hline
\end{tabular}

\section{Metabolic profile}

Body height was determined to the nearest $0.5 \mathrm{~cm}$ (Lameris, WM 715. Breukelen, The Netherlands) with subjects standing barefoot. Body weight was measured with a beam scale to the nearest $0.1 \mathrm{~kg}$ (SECA, FRG) with subjects barefoot and in light clothing. To adjust body weight for body surface area the body mass index (BMI) was calculated as weight/height .

Fat-free mass (FFM) was assessed by bioelectrical resistance measurements at 50 kHz (Xitron 4000b, Xitron technologies, San Diego, California, USA). Resistance (R) was measured in supine position at the right side as described by Lukaskil4. FFM was calculated from height $* / R$ and body weight using a patient specific regression equation ${ }^{15}$, and also adjusted for body height (FFM-index: FFM/height').

Resting energy expenditure (REE) was measured by indirect calorimetry using a ventilated hood system (Oxyconbèta, Jaeger, Würzburg. Germany). Measurements were 
done in the early morning after an overnight fast, while the person was comfortably lying on a bed in supine position ${ }^{16}$. The system was calibrated before measurements were taken, and the accuracy of the system (3-4\%) was regularly tested with an ethanol combustion test.

\section{Exercise tests}

During exercise tests heart rate (HR) (Sporttester, Polar Electro cy, Kempele, Finland) and transcutaneous oxygen saturation $\left(\mathrm{StO}_{2}\right)$ (Sensor Medics $\mathrm{Co}$, Anaheim, California, USA) were monitored. Oxygen consumption $\left(\mathrm{V}^{\prime} \mathrm{O}_{2}\right)$, carbon dioxide production $\left(\mathrm{V}^{\prime} \mathrm{CO}_{2}\right)$, minute ventillation (V'E), breathing frequency $(\mathrm{BF})$ and tidal volume $\left(\mathrm{V}_{\uparrow}\right)$ (Oxyconbèta, Jaeger, Würzburg, Germany) were measured and calculated from breath by breath analysis, using a breathing mask. The equipment was calibrated before the tests, which were performed in the two weeks before the patients entered the rehabilitation exercise programme.

Incremental cycle ergometry test

The incremental cycle ergometry test. (CE) was performed on an electromagnetic braked ergometer (Coriwal 400, Lode, Groningen, The Netherlands). After a 2 minute resting period and 1 minute unloaded cycling, power was increased every minute by 10 Watts. The load cycled was invisible for the patients, and they were encouraged to cycle as long as possible. Immediately before and 2 minutes after reaching the peak workload of the CE a venous blood sample was taken to measure lactate concentration. The blood samples were stored on ice $\left(4^{\circ} \mathrm{C}\right)$ and were centrifuged during 5 minutes at $3000 \mathrm{r} . \mathrm{p} . \mathrm{m}$. (Sigma 2-15. Lameris, Breukelen, The Netherlands). Plasma lactate concentration was determined by an enzymatic method ${ }^{i 7}$, using an automated system (Cobas Mira, Roche, Bazel, Switzerland). Peak $\mathrm{V}^{\prime} \mathrm{O}_{2}$ was predicted using formulas for healthy elderly subjects ${ }^{\prime 8}$ and peak $V^{\prime} \mathrm{E}$ was predicted by the formula of Carter $(37.5 * \mathrm{FEV})^{14}$. Maximal HR was calculated using the equation 220 minus age (yrs).

\section{Submaximal leg exercise tests}

The patients performed a submaximal leg exercise test at $50 \%$ of individually 
measured peak load for 7 minutes, at a fixed pedal rate of 60 rates per minute. The mean values of the last 3 minutes of the metabolic and ventilatory variables were used for analysis. Net efficiency was calculated by the following equation:

$$
\text { Net efficiency }^{20}=\frac{\text { load (watt) of exercise * } * 0.01433(\mathrm{kcal} / \mathrm{min})}{(\text { energy expenditure during exercise }-\mathrm{REE})(\mathrm{kcal} / \mathrm{min})} \quad \text { * Wo\% }
$$

Energy expenditure during exercise was calculated from the steady state values of $\mathrm{V}^{\prime} \mathrm{O}_{2}$, and $\mathrm{V}^{\prime} \mathrm{CO}_{2}$ using the abbreviated Weir formula".

The steady state values of the metabolic and ventilatory variables during submaximal exercise were expressed as percentage of the peak value.

Reproducibility of the test

In a pilot study the reproducibility of a submaximal cycle ergometry test was determined in 11 patients with COPD ( $\mathrm{FEV}_{1}: 49.8 \pm 10.5 \%$ pred). There was no signilicant difference between the first and the second test in all measured metabolic and ventilatory variables as well as net efficiency. The mean difference between in $\mathrm{V}^{\prime} \mathrm{O}_{2}$ and $V^{\prime} \mathrm{CO}_{2}$ between the first and the second test was respectively $26.7 \mathrm{ml} / \mathrm{min}$ ( $95 \%$ confidence interval of mean difference: -9.9 to $63.3 \mathrm{ml} / \mathrm{min})$, and $22.4 \mathrm{ml} / \mathrm{min}(-11.6$ to 56.6 $\mathrm{ml} / \mathrm{min})$, resulting in a mean difference of $0.6 \%$ in net efficiency $(-1.6$ to $0.4 \%)$. For the other variables ( $\mathrm{V}^{\prime} \mathrm{E}, \mathrm{BF}, \mathrm{V}_{\mathrm{T}}$, and $\mathrm{HR}$ ) the mean difference was also between $0-3 \%$.

Data analysis

Characteristics of the study group are given as median (range). The wilcoxon rank test was used to test within-group differences.

In order to identify characteristics of patients with a decreased efficiency, the group was split into those patients with a low and those with a normal efficiency. In healthy persons the net mechanicall efficiency of cycle ergometry is $23 \%{ }^{22}$. Efficiency can be lower (approximately $19 \pm 1 \%$ ) at low work rates ${ }^{20}$, comparable to the load of the submaximal exercise tests in the present study. We therefore considered an efficiency of $17 \%$ on lower ( 2 times the standard-deviation below the lowest mean mechanical efficiency reported in healthy subjects) as low. 
The Mann-Whitney $U$ test was used to compare groups. A value $<0.05$ was considered statistically significant. The Bonferroni correction was applied when nessecary.

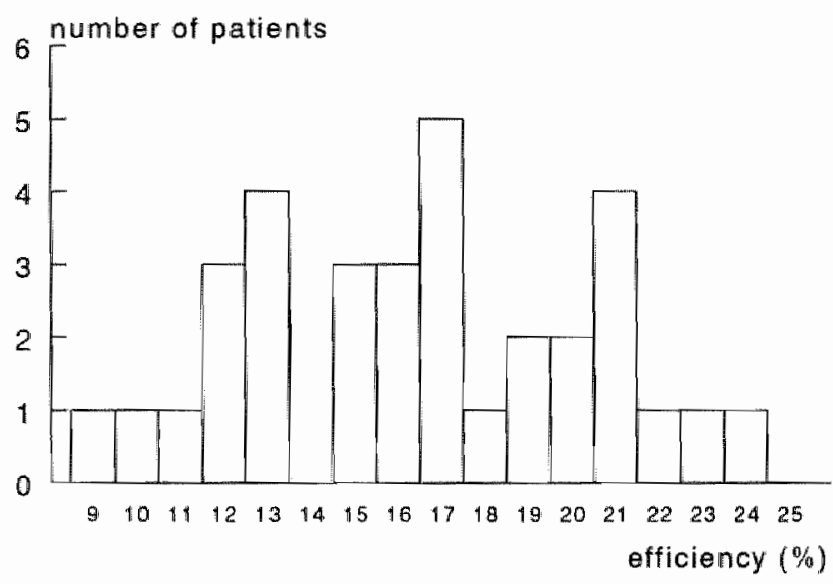

Figure 1: Frequency distribution for mechanical efficiency.

\section{Results}

The median net mechanical efficiency was $15.5 \%$ and ranged widely from 8.510 $22.7 \%$. The frequency distribution for the mechanical efficiency is shown in Figure 1. There were $21(130,89)$ patients with a low mechanical efficiency $(14.0,8.5-16.7 \%)$ and only $12(10 \%, 2 \%)$ patients with a normal mechanical efficiency $(19.3,17.2-22.7 \%$, $\mathrm{p}<0.001)$. 
Table 2 Submatinal ererise response in potients differentated by mechanical efficiency.

Data are presented as median (ronge). $R Q$ : respiratory quotient: $V_{7}$ : thdal wolume; $B F$ : breathing frequency; StO. wawculaneous oxygen saturation; for further abbreviations see legend to Tabie $I$.

* $\Delta V^{\prime} O_{2} /$ load: steady state $V^{\prime \prime} O_{2}$ during submaximal exercise minus resting oxygen consumption fobained from REE mecsurement) divided by submaximal cycled toad. Mann-Whitrey U-test

\begin{tabular}{|c|c|c|c|c|}
\hline & & $\begin{array}{c}\text { efficiency } \\
<17 \% \\
(n=21,89,138)\end{array}$ & $\begin{array}{c}\text { efficiency } \\
>17 \% \\
(n=12,2 \%, 108)\end{array}$ & p-value* \\
\hline$v^{\prime} \mathrm{O}_{2}$ & (\%peak) & $85.1(74.4-104.5)$ & $73.6(60.8 .95 .8)$ & $p<0.01$ \\
\hline $\mathrm{RQ}$ & (\%peak) & $93.0(60.9-120.2)$ & $91.1(86.8-101.9)$ & NS \\
\hline$V^{\prime} E$ & (\%pak) & $89.2(72.9-110.0)$ & $75.8(64.5-100.6)$ & $p<0.05$ \\
\hline$V^{\prime} \mathrm{O}_{2} / V^{*} \mathrm{E}$ & $(\mathrm{ml} / \mathrm{L})$ & $25.6(17.5-36.8)$ & $20.9(16.1-28.9)$ & $p<0.01$ \\
\hline$\Delta V^{\prime} \mathrm{O}_{2} / \operatorname{load}^{*}$ & (ml/watt) & $20.6(17.6-33.7)$ & $14.6(12.8-17.1)$ & $p<0.001$ \\
\hline$v_{\mathrm{r}}$ & (Wpeak) & $102.3(80.6-131.5)$ & $89.6(77.0-115.0)$ & NS \\
\hline$B F$ & (\%peak) & $90.0(67.0-1.00 .6)$ & $86.1(70.6-100.9)$ & NS \\
\hline $\mathrm{HR}$ & (\%peak) & $88.7(77.6-103.6)$ & $87.4(64.3-105.9)$ & NS \\
\hline $\mathrm{StO}_{3}$ & (\%peak) & $101.1(93.2 \mathrm{~m} 108.4)$ & $101.5(98.9-104.9)$ & NS \\
\hline $\mathrm{V}^{\prime} \mathrm{O}_{2} / \mathrm{HR}$ & $(\mathrm{ml} / \mathrm{x})$ & $7.1(4.6-12.4)$ & $6.2(5.0-11.8)$ & NS \\
\hline
\end{tabular}

As demonstrated in Table 2, patients with a low mechanical efficiency had a significantly higher $\mathrm{V}^{\prime} \mathrm{O}_{2}$ (\% peak), $\mathrm{V}^{\prime} \mathrm{E}$ (\% \%eak), a higher $\mathrm{V}^{\prime} \mathrm{O}_{2} /$ load relationship, and a higher $\mathrm{V}^{\prime} \mathrm{O}_{2} / \mathrm{V}^{\prime} \mathrm{E}(\mathrm{ml} / \mathrm{L})$, and tended to achieve a higher $\mathrm{V}_{\mathrm{T}}$ (\%peak: $\left.\mathrm{p}=0.03\right)$ than the patients with a normal mechanical efficiency during submaximal exercise. BF (\%peak). $\mathrm{StO}_{2}$ (\% peak), HR (\% peak) and oxygen pulse $\left(\mathrm{V}^{\prime} \mathrm{O}_{2} / \mathrm{HR}\right)$ were comparable between the two groups.

No significant differences in body composition, REE, flow-volume measurements, static lung volumes, diffusing capacity or blood gases at rest were found between the patients with a low or normal mechanical efficiency (Table 3 ). $R_{\text {aw }}$ was significantly higher $(p<0.05)$ in the patients with a low mechanical efficiency. 
Table 3: Characteristics of patients differentiated by mechanical efficiency

Dato are presented as median (range). BMI: body mass index. FFM-inder: fat-free mass index; REE: resting energy expenditure; FEV $V_{j}$ forced expiratory volume in one second; FVC: forced vital capacity: TLC: total lung

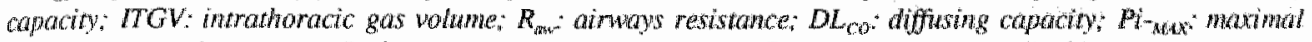
inspiratory mouth pressure; $\mathrm{PaO}_{3}$ : arterial axyen pressure, $\mathrm{PaCO}_{2}$ anterial carbon dionide pressure.

* also not significanily different corrected for FFM (ANOVA);" Mann-Whitmey U-test"

\begin{tabular}{|c|c|c|c|c|}
\hline & & $\begin{array}{c}\text { efficiency } \\
<17 \% \\
(n=21,89,130)\end{array}$ & $\begin{array}{c}\text { efficiency } \\
>17 \% \\
(n=12,29,100)\end{array}$ & p-walue? \\
\hline age & $(\mathrm{yr})$ & $60(38-82)$ & $67(43-74)$ & NS \\
\hline $\mathrm{BMI}$ & $\left(\mathrm{kg} / \mathrm{m}^{2}\right)$ & $24.1(17.9-44.1)$ & $22.3(18.1-27.9)$ & NS \\
\hline FFM-index & $\left(\mathrm{kg} / \mathrm{m}^{3}\right)$ & $17.5(13.1-21.9)$ & $16.9(13.0-21.2)$ & NS \\
\hline REE & $(\mathrm{keal} / 24 \mathrm{~h})$ & $1524(1174.2148)$ & $1522(1168-2121)$ & $N S^{*}$ \\
\hline $\mathrm{FEV}$ & (\%pred) & $36.1(17.4-67.9)$ & $44.0(30.1-62.7)$ & NS \\
\hline FVC & (\%pred) & $82.9(63.9-107.0)$ & $86.8(75.2-109.8)$ & $N S$ \\
\hline TLC & (\%pred) & $126.5(87.7-142.4)$ & $121.6(92.9-144.6)$ & NS \\
\hline ITGV & (\%pred) & $169.8(105.5-225.7)$ & $166.7(120.8-205.9)$ & NS \\
\hline $\mathrm{R}_{\mathrm{aw}}$ & (\%ored) & $250.0(113.3-373.3)$ & $158.3(103.3-273.3)$ & $p<0.05$ \\
\hline $\mathrm{DL}_{\sim} \%$ & (\%pred) & $58.9(36.4-111.6)$ & $45.9(36.5-80.4)$ & $\mathrm{NS}$ \\
\hline$P \mathrm{Pi}$ - & $\left(\mathrm{cmH}_{2} \mathrm{O}\right)$ & $79(35-137)$ & $62(44-117)$ & NS \\
\hline $\mathrm{PaO}_{2}$ & (kPa) & $9.3(8.3-12.5)$ & $9.6(7.7-11.4)$ & NS \\
\hline $\mathrm{PaCO}_{2}$ & $(\mathrm{kPa})$ & $5.7(4.4-7.1)$ & $5.3(4.0-8.2)$ & NS \\
\hline
\end{tabular}

Patients with a low mechanical efficiency achieved a lower peak load during the $\mathrm{CE}$ test, a lower peak respiratory quotient (RQ) and a higher peak $\mathrm{V}^{\prime} \mathrm{O}_{2} / \mathrm{V}^{\prime} \mathrm{E}$, as shown in Figure 2. Peak $\mathrm{V}^{\prime} \mathrm{O}_{2}$, peak $\mathrm{V}^{\prime} \mathrm{E}$, peak plasma lactate concentration, peak $\mathrm{HR}$ and peak $\mathrm{StO}_{2}$ were not significantly different between the groups differentiated by mechanical efficiency (data not shown). 



Figure 2: Peak exercise response in patients with a low or normal mechanical efficiency. Boxplots indicate the $5 t h, 25 t h, 50 t h, 75 t h$ and 95th percentile of the data. $V$ ' $\mathrm{O}_{2}$ : oxygen consumption; $V ' E$ : minute ventilation; $R Q$ : respiratory quotient; FFM: fatfree mass.

\section{Discussion}

In this study it was shown that a considerable number of patients with COPD have a severely impaired mechanical efficiency during exercise. The results of the present study suggest that a decreased efficiency is related to an increased oxygen cost of breathing. The patients with a severely impaired efficiency were characterized by an enhanced ventilatory response to exercise and demonstrated a higher airways resistance at rest. Peak exercise capacity was slightly reduced in the patients with a low efficiency, and the peak oxygen consumption per liter ventilation was increased. 
Until now, only limited data of mechanical efficiency in patients with COPD are available. This study confirms the recent findings by Palange $\mathrm{et}^{\mathrm{l}^{23}}{ }^{23}$, who reported a significantly decreased (net) efficiency of $16 \%$ in patients with COPD (which corresponds to the median mechanical efficiency in the present study) compared to $25 \%$ in healthy subjects during submaximal cycling.

Due to limited investigations, it is not totally clear how a decreased mechanical efficiency can be explained, but several mechanisms might be considered including an increased oxygen cost of ventilation. Levison and $\mathrm{Cherniack}^{24}$ showed that during exercise the oxygen consumption per liter ventilation was significantly higher in patients with COPD compared to healthy subjects. Also Spiro et $\mathrm{al}^{25}$ reported that the physiological strain of ventilation during submaximal exercise was much higher in patients with COPD compared to healthy subjects.

In patients with COPD the increased oxygen cost of breathing is assumed to be related to an increased inspiratory work of breathing. In clinically stable patients with COPD, both the resistive and elastic components of inspiratory work are increased due to high airways resistance and hyperinflation ${ }^{26}$. Recent studies have focussed attention on the importance of acute- on chronic hyperinflation during exercise in patients with $\mathrm{COPD}^{27,2 \%}$. The dynamic hyperinflation results in a substantial increased elastic load, since $V_{7}$ is forced to oscillate on a stiffer portion of the pressure-volume relationship of the respiratory system. Furthermore, dynamic hyperinflation increases the inspiratory threshold loading caused by the inward elastic recoil of the respiratory system. In addition, the ability of the respiratory muscles to generate pressure is decreased during dynamic hyperinflation due to length-tension inappropriateness ${ }^{28}$. However, the exact effects of dynamic hyperinflation on the oxygen cost of breathing during exercise and mechanical efficiency of exercise in patients with COPD needs further study.

Other factors may have influenced mechanical efficiency in the present study, including test conditions, the age of the patients, and the familiarization with exercise. Firstly, in a study of Gaesser et a $\mathrm{l}^{20}$ it was shown that at low loads the net efficiency is decreased to approximately $19 \%$. In the present study the cycled load was relatively low, thus this could have resulted in a slighly lower efficiency than the assumed $23 \%$ efficiency $y^{22}$. Secondly, age is probably no confounder in the present study, since it has been demonstrated by deVries et al that age has no influence on mechanical efficiency ${ }^{29}$. Thirdly, in the Netherlands cycling is a very familiar activity, making it unlikely that the 
studied patients had never cycled before in their life. Moreover, it was demonstrated in the present study that the submaximal exercise test was highly reproducible.

Furthermore, it could be suggested that maintenance medication influences metabolism during exercise. Unfortunately only little attention has been paid to the metabolic effects of drugs (during exercise) in patients with COPD. Recently it was suggested that inhalation of $B_{2}$-sympathicomimetics could be related to an increased total daily energy expenditure in patients with $\mathrm{COPD}^{30}$, but potential stimulating effects of medication on exercise induced metabolism needs further investigation.

In the present study a comprehensive analysis of potential factors contributing to a variation in mechanical efficiency in patients with COPD was performed. However, measurements performed at rest including pulmonary function, body composition, resting energy expenditure, or information obtained by incremental exercise testing could not characterize patients with a normal or increased mechanical efficiency. Therefore, we analyzed the response to the submaximal exercise test in detail. Patients with a decreased mechanical efficiency had a significantly higher oxygen consumption per liter ventilation during submaximal exercise than the patients with a normal efficiency. With respect to the earlier mentioned possible important role of dynamic hyperinflation to an increased oxygen cost of breathing in patients with COPD, it could be hypothesized that a more pronounced level of dynamic hyperinflation is supposed in the group of patients with decreased mechanical efficiency, as suggested from the observed enhanced ventilatory response and maximal $V_{1}$ response during submaximal exercise. Furthermore, under resting conditions the patients with a decreased mechanical efficiency demonstrated a higher airways resistance which also could have contributed to a higher oxygen cost of breathing compared to the patients with a normal mechanical efficiency.

An enhanced oxygen cost of breathing for the patients with decreased mechanical efficiency was also suggested by the significantly increased $\mathrm{V}^{\prime} \mathrm{O}_{2}$ /load relationship compared to the patients with a normal mechanical efficiency, since the $\mathrm{V}^{\prime} \mathrm{O}_{2}$ /load relationship can be interpreted as a reflection of the oxygen cost of breathing ${ }^{31}$. In earlier studies it was reported that patients with COPD demonstrate a normal $V$ ' O./oad relationship during incremental exercise ${ }^{24.32 .33}$. However, considering the $\mathrm{V}^{\prime} \mathrm{O}_{2} /$ /oad relationship reported for healthy subjects during incremental as well as submaximal exercise $( \pm 10 \mathrm{ml} / \mathrm{min} / \mathrm{watt})^{34}$, it should be remarked that in the present study, an enhanced $\mathrm{V}^{\prime} \mathrm{O}_{2}$ /load relationship was found not only in the group of patients with a 
decreased mechanical efficiency, but also in the group with a normal efficiency, suggesting also an increased oxygen cost of breathing in the latter group.

There are several important clinical implications of a decreased mechanical efficiency as found in the present study. Although the patients with a decreased mechanical efficiency were characterized by a slightly lower $C E$ performance and a higher peak $V^{\prime} \mathrm{O}_{2} / \mathrm{V}^{\prime} \mathrm{E}$, presence of decreased efficiency cannot be determined from an incremental cycle ergometry test.

Furthermore, as shown in this study, cycling at $50 \%$ of symptom-limited maximum workload results for a lot of patients with COPD in a metabolic response which is close to peak physiological response. Already in an earlier study we showed that supposed submaximal exercise like 12 minute walking results in a ventilatory and metabolic response close to peak physiological response ${ }^{35}$. Training load should induce a certain metabolic response in order to result in a physiological training effect. The results of the present study may therefore explain why training at relatively low loads could have resulted in a significant physiological training effect in patients with severe COPD, as demonstrated by Maltais et $\mathrm{al}^{36}$. Therefore, a submaximal exercise test should be performed in order to choose an adequate training load and the metabolic and ventilatory response it evokes. Although in patients with less severe $\mathrm{COPD}^{37}$ it was demonstrated that high intensity training should be performed in order to achieve a training effect, the results of the present study suggest that, from a metabolic point of view, particularly for patients with severe COPD, a lower intensity training program can also be successful.

In conclusion, the results of the present study suggest that a substantial number of patients with COPD demonstrate decrcased mechanical efficiency, which is not related to body composition, REE, chronic hyperinflation, airflow obstruction and respiratory muscle strength. The results of this study suggest that the decreased efficiency is related to an increased oxygen cost of breathing during exercise. Dynamic hyperinflation in patients with COPD is probably an important contributing factor to the increased oxygen cost of breathing during exercise, but this needs further investigation.

\section{References}

Loke I. Malher DA, Man P. Wiedenann HP. Mathay RA. Exencise impairment in chronic obstructive putmonary disease. Clin. in Chesi Med. 1984; $5: 121-142$.

2 Hamiton AL, Killian KJ. Summers E, Jones NL. Muscle strength, symptom intensity, and exercise wapacity in patients with cardiorespiratory disorders. Am. J. Respir. Crit. Cara Med. 1995: 152: $2021-31$. 



and lactic acid kinetics during exercise in normal subjects and in patients with COPD. Am. I. Respi Crit. Care Med. 1996: 153: 288-93.

MoRussel DM, Walker PM, Leiter LA, Sima AAF, Tanner WK, Mickle DAG. Whitwell J, Marliss EC Metabolic and structural changes in skeletal muscle during hypocaloric dietïng. Am. J. C; in. Nutr. 198 39: $503-513$.

Schols AMWJ, Soeters PB, Dingemans ANC, Mostert R, Frantzen PJ, Wouters EFM. Prevalence at characteristics of nutritional depletion in patients with COPD egligble for pulmonary rehabilitation. Ar Rev. of Resp. Dis. 1993: 147: 1151-1156.

Scluols AMWI, Mostert R, Soeters PB. Wouters EFM. Body composition and exercise performance patients with chronic obstructive pulmonary disease. Thorax 1991; 46: 695-699.

Cotes JE. Zejda J, King B. Lung function impairment as a guide to exercise limitation in work-relat lung disorders. Am. Rev. Respir. Dis. 1988; 137; 1089.93.

Baarends EM, Schols AMWJ, Pannemans DLE, Westerterp KR, Wouters EFM. Total dailly ener expenditure in clinically stable patients with severe COPD and age-matched healthy subjects using doubly labelled water technique. Am. I. Repir \& Crit. Care Med. 1997; 155: 549-554.

Baarends EM, Schols AMWJ, Westerterp KR, Wouters EFM. Total daily energy expenditure in clinical stable COPD patients with a normal or increased resting energy expenditure. Cli. Nutr. 1996: 15 (sup 1): 45

10 American Thoracic Society. Standards for the diagnoses and care of patients with chronic obstructi pulmonary disease (COPD) and asthma. Am. Rev. Respir. Dis. 1987; 137:225-228.

11 Quanjer Ph ed. Standardized lung function testing. Eur. Resp. J. 1993;6 (suppl. 16): 5-40.

12 Pestin R. Lung mechanics II: Resistance measurements. Bull. Europ. Physiopath. Resp. 1983. 19 (supl 5): $33-38$,

Black LF, Hyat RE. Maximal respiratory pressures: nomal values and relationship to age and sex. As Rev. of Respir. Dis. 1969; 99: 696-702.

Lukaski HC, Bolunchuk WW, Hall CB. Siders WA. Validation of tetrapolar bioelectrical impedan method to assess human body composition. J. Apl. Pliysiol. 1986; 60: 1327-1332.

Schols AMWJ, Dingentans ANC. Soeters PB, Wouters EFM. Within day variation of bioelectri impedance resistance measurements in patients with chronic obstructive pulmonary disease. Clin. Nu 1990: 9: 266-271.

Schols AMWJ, Schoffelen PF, Ceulemans H, Wouters EFM, Saris WH. Measurement of REE in patiei with COPD in a clinical setting. J. Parenter. Enter. Nutr. 1992; 16:364-368.

Noll F. L- $(+)$-lactate, detemination with LDH, GTP and NAD. In: Bergmeyer, ed. Methods enzymatic anallysis. New York, 1974, pg1475

Blackie SP, Fairbarn MS. McCelwaney GN. Morrison NI, Wilco PG. Pardy RL. Prediction of maxin oxygen uptake and power during cycle ergometry in subjects older than 55 years of age. Am. Re Respir. Dis. 1989; 1.39; 1424-1429.

19 Canfer $\mathbb{R}$, Peavler M. Zinkgraf S, Williams J, Fields S. Predicting maximal exercise ventilation in Chrot obstructive pulnomary disease. Chest. 1987: 92: 253-259:

20 Gaesser GA, Brooks GA, Muscular efliciency during steady-rate exercise; effects of speed and work rat J. Appl. Physiol. 1975: 38: 1132-39.

21 Weir JB. New methods for calculating metabolic tate with special reference to protein metabolisn. Pliysiol. 1949; 109: 1.9.

22 Shephard RJ. Efficiency of muscular work. Sone clinical implicarions. Plyysical Therapy 1975; 55: 47 481.

23 Palange P, Galassetti P, Mannix ET, Farber MO, Manfredi F, Serra P. Carlone S. Oxygen effect on deficit and $\mathrm{V}^{\prime} \mathrm{O}$, kineties during exercise in obstructive pulmonary disease. J. Appl. Physiol. 1995: (6): $2228-2234$.

24 Levison H, Cherniack RM. Veutilatory cost of exercise in chronic obstructive pulmonary disease. J. App Plysinol 1968; 25:21-27. 
25 Spiro SG, Hathn HL, Edwards HT, Pride NB. An analysis of the physiological strain of submaximal exercise in patients with chronic obstructive bronchitis. Thorax. $1975 ; 30: 415-425$.

26 Similowski T, Dereme J, Millic Emili 1. Respiratory nnechanics during acute respiratory failure in Chronic Obstructive Pulmonary Disease. In: Acute respiratory failure in Chronic Obstructive Pulmonary Disease. Ed: Dereme J, Whitelaw WA, Similowski T, Lung Biology in Health and Disease, vol 92. 1996. pp: $23-46$.

27 Belman MJ, Botnick WC, Shin JW. Inhaled bronchodilators reduce dynamic hyperinflation during exercise in patients with chronic obstructive pulmonary disease. Am. I. Respir. Crit. Care Med. 1996; 153: $967-975$.

28 ODonnel DE, Webb KA. Exentional breathlessness in patients with Chronic Obstructive Pulmonary Disease. The role of lung luyperinflation. Am. Rev. Respir. Dis. 1993; 148: 1351-7.

29 deVries HA, Wiswell RA, Romero G. Moritani T. Bulbulian R. Comparison of oxygen kinetics in young. and old subjects. Eur. J. Appl. Physiol. 1982; 49:277-286.

30 Hugli $O$, Schutz Y. Fitting JW. The daily energy expenditure in stable Chronic Obstructive Pulmonary Disease. Am. J. Respir. Crit. Care Med. 1996: 153: 294-300.

31 Younes M. Interpretation of clinical exercise testing in respiratory disease. Cli. Chest Med. 1984: 5: 189. 206.

32 Filley GF. Pulmonary ventilation and the oxygen cost of exercise in emphysema. Trans, Am. Clin. Climat. Assoc. 1958: 70: 193-203.

33 Shuey $\mathrm{CB}$. Pierce AK, Johnson RL. An evaluation of exercise tests in chronic obstructive lung disease. J. Appl. Physiol. 1969; 27: 256-261.

34 Wasserman K. Hansen JE, Shue DY, Whipp BJ. Principles of exercise testing and interpretation. Lea and Febiger, Philadelphia, 1987: pp $27-46$.

35 Baarends EM. Schols AMWJ, Mostert R, Janssen PP, Wouters EFM. A conparison berween the 12 minute walking test and incremental cycle ergonnetry in patients with severe COPD. Am. Rev. Respir. Dis. 1993; 147(4): A742.

36 Maltais F, LeBlane $P$. Simard $C$, Jobin J, Bérubé C, Bruneau J, Carrier L, Belleau R. Skeletal muscle adaptation to endurance training in patients wh Chronic Obstructive Pulmonary Disease. Am. I. Respir. Crit. Care Med. 1996: 154: 442-7.

37 Cassaburi R, Patessio A. Ioli F, Zanaboni S, Donner CF, Wasserman K. Reductions in exercise lactic acidose and ventilation as a result of exercise training in patients with chronic obstructive lung disease. Am. Rev. Respir. Dis. 1991; 143: 9-18 


\section{METABOLIC AND VENTILATORY RESPONSE PATTERN \\ TO ARM ELEVATION IN PATIENTS WITH CHRONIC OBSTRUCTIVE PULMONARY DISEASE AND HEALTHY AGE-MATCHED SUBJECTS}

Erica M. Baarends', Annemie M.W.I. Schols', Dirk-Jan Sllebas', Rob Mostert? Paul P. Janssen", Emiel F.M. Wouters". "Department of Pulmonology, Macstrich University, Maastricht. ${ }^{2}$ Astma Center Hornerheide, Homs. The Netherlands

\section{Abstract}

Many patients with chronic obstructive pulmonary disease (COPD) experience problems in activities of daily living, which often consist of so called unsupported arm elevations (AE). In this study possible differences in the metabolic and ventilatory response pattern to three types of arm elevation were compared between $13 \mathrm{COPD}$ patients (FEV 1 (mean (SD)) 38 (13) \% of predicted) and 13 age-matched healthy subjects. Each subject consecutively performed three types of arm elevation for $2 \mathrm{~min}$, with 3 min. rest in between. Breath-by-breath metabolic and ventilatory parameters and heart rate (HR) were registered during a $3 \mathrm{~min}$. baseline period and throughout the measurement period. Adjusted for significantly greater baseline test results in COPD patients, it was found that AE (arm elevation including recovery) tended to be more demanding with respect to metabolic and ventilatory response for patients with COPD than for the age-matched healthy subjects. Arm elevation resulted in an increase in oxygen consumption ( $\mathrm{V}^{\prime} \mathrm{O}_{2}$ ) (COPD: $12 \%$, healthy: $6 \%$ ), carbon dioxide elimination $\left(\mathrm{V}^{\prime} \mathrm{CO}_{2}\right)(\mathrm{COPD}: 15 \%$, healthy: 10\%), minute ventilation (V'E) (COPD: $13 \%$, healthy: $7 \%$ ) and heart rate (COPD: $2 \%$, healthy: $5 \%$ ). A pronounced difference was found in the pattern of metabolic and ventilatory response to arm elevation, i.e. there was an earlier but sluggish $\mathrm{V}^{\prime} \mathrm{O}_{2}$ onset in COPD patients, whereas the healthy subjects demonstrated a sudden peak approximately $30 \mathrm{~s}$ after AE. Mutual comparison of the three different types of arm elevation demonstrated a comparable response pattern. Knowledge of the specific response to $\mathrm{AE}$ in COPD patients seems essentiall for interpretation of arm elevation tests in upper extremity rehabilitation programs. 


\section{Introduction}

Patients with severe chronic obstructive pulmonary disease (COPD) often complain of dyspnoea during activities of daily living, such as combing their hair, brushing their teeth or shaving ${ }^{12.3}$. These activities mainly involve (unsupported) movements of arm and shoulder museles.

Several factors may contribute to impairment of unsupported arm activities in COPD patients such as a dual activity of shoulder muscles in breathing as well as movement $t^{4.5}$, and peripheral ${ }^{6}$ and respiratory ${ }^{7}$ skeletal muscle weakness.

In order to examine the possible limitations of (unsupponted) arm activities in patients with COPD, other investigators have studied the metabolic and ventilatory requirements of simple arm elevation. In all studies arm elevation resulted in a significant increase in metabolic and ventilatory requirements ${ }^{3,4.5 . *}$. Possible differences in metabolic and ventilatory response pattern following arm elevation between COPD patients and healthy persons, however, have not yet been specified. Furthermore, it may be hypothesized that the response pattern depends on the type of arm elevation due to different muscle recruitment.

In this study the metabolic and ventilatory requirements of three basic arm elevations were compared between COPD patients and healthy age-matched control subjects.

\section{Methods}

Patients and control subjects

Thirteen male patients with severe COPD participating in an in-patient pulmonary rehabilitation program were studied (characteristics are given in Table 1). The diagnosis of COPD was made by history, physical examination, and pulmonary function tests according to the criteria of the American Thoracic Society". All patients had severe airflow obstruction (forced expiratory volume in $\mathbb{s e c}$ (FEV 1 ) $<50 \%$ of predicted values) ${ }^{9}$. The patients were in a stable clinical condition.

Thirteen age-matched healthy male control subjects were recruited (Table 1 ), and were tested under the same conditions. 
Table 1: Physiological and metabolic characteristics of the groups studied.

Data are presented as mean \pm SD. BMI: body mass index. FFM: fal free mas : FRM-index: fat free mass



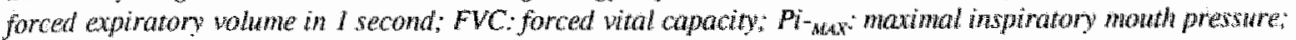
o pred.: percentage of predicted value; COPD: chronic obstmotive pulmonary disease:

Signficanty different between de sudied groups: $p<0.05, \quad p<0.01$, * $p<0.001$. WS not signiflont. Manm Whithey U lest)

\begin{tabular}{lllll}
\hline Variables & & COPD $(\mathrm{n}=13)$ & Control $(\mathrm{n}=13)$ & p value \\
\hline Age & $(\mathrm{yrs})$ & $64 \pm 6$ & $65 \pm 7$ & NS \\
FEV & $(\% \mathrm{pred})$ & $38 \pm 13$ & $101 \pm 1.3$ & $* * *$ \\
FVC & (\%pred) & $90 \pm 15$ & $113 \pm 10$ & $* * *$ \\
Pi-MAX & $(\mathrm{kPa})$ & $7.4 \pm 1.4$ & $9.7 \pm 2.1$ & $* *$ \\
Weight & $(\mathrm{kg})$ & $66.8 \pm 9.9$ & $81.5 \pm 9.8$ & $* *$ \\
BMI & $\left(\mathrm{kg} / \mathrm{m}^{2}\right)$ & $21.7 \pm 2.9$ & $27.6 \pm 5.8$ & $* *$ \\
FFMI & $\left(\mathrm{kg} / \mathrm{m}^{2}\right)$ & $16.5 \pm 1.7$ & $20.2 \pm 3.3$ & $* * *$ \\
REE-act & $(\mathrm{kcal} / 24 \mathrm{~h})$ & $1614 \pm 238$ & $1643 \pm 140$ & $\mathrm{NS}$ \\
ADJ-REE & $(\mathrm{kcal} / 24 \mathrm{~h})$ & $1744 \pm 243$ & $1529 \pm 116$ & $* *$ \\
\hline
\end{tabular}

Pulmonary function and metabolic profile.

Forced expiratory volume $\left(\mathrm{FEV}_{1}\right)$ and forced vital capacity $(\mathrm{FVC})$ were measured (Masterlab, Jaeger, Wurzburg, Germany). The highest value of at least three spirometric manouures was used and expressed as percentage of the reference value ${ }^{10}$. Inspiratory muscle strength was measured in patients and controls by determining maximal inspiratory mouth pressures ( $\mathrm{Pi}_{\text {MAX }}$ ) according to the technique described by Black \& Hyatt".

Resting energy expenditure (REE) was measured by indirect calorimetry using a ventilated hood system (Oxyconbèta, Jaeger, Würzburg, Germany). Measurements were performed in the early morning (between 8.00 and $9.30 \mathrm{a} . \mathrm{m}$. ) in the fasting state ${ }^{12}$.

Fat-free mass (FFM) was assessed by bioelectrical resistance measurements (BIA 101 , RJL Systems, Detroit, USA) at the right side in the supine position as described by Lukaski et $\mathrm{al}^{13}$. FFM was calculated using a patient specific regression equation, as described by Schols et al ${ }^{14}$. 
Three basic static arm elevations, i.e. static position held for 2 min., were compared (Figure 1): 90 degrees elevation of extended arms in the frontal plane (AE1); 180 degrees elevation of extended arms in the frontal plane (AE2); and 90 degrees abduction with extended arms (AE3). The test procedure was as following: firstly the subject sat quietly on a chair for a $3 \mathrm{~min}$. baseline measurement with his arms down on the knees. This was followed by $2 \mathrm{~min}$. of AE1, AE2, and then AE3 with $3 \mathrm{~min}$. restperiods in between, and $2 \mathrm{~min}$. rest after AE3. During the AEs and resting periods heart rate was continuously measured with a sporttester (PE 3000, Polar Electro cy, Kempele, Finland). Oxygen consumption, carbon dioxide production, tidal volume, and breathing frequency were measured breath-by-breath with an automated system (Oxyconbèta, Jaeger, Würzburg, Germany).

The following calculations were performed in order to interpret the test results:

1) the metabolic and ventilatory requirements during each $\mathrm{AE}$ and the following recovery period,

2) percentage increase of metabolic and ventilatory parameters for each $\mathrm{AE}$. To adjust for differences between healthy subjects and COPD patients at baseline (i.e. the first 3 min. of the test) the mean baseline test-result was subtracted from the mean metabolic and ventilatory requirement of each $\mathrm{AE}$.

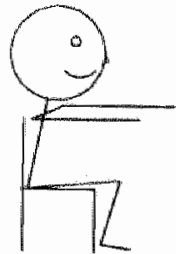

$\mathrm{AE}_{1}$

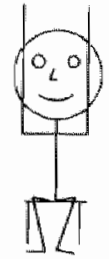

$A E_{2}$

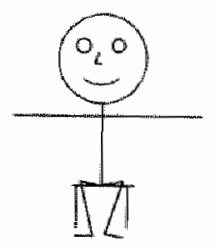

$\mathrm{AE}_{3}$
Figure 1: Types of arm elevation studied. AEl: 90 degrees elevation of extended arms in the frontal plane; AE2: 180 degrees elevation of extended arms in the frontal plane; AE3: 90 degrees abduction with extended arms. 


\section{Data analysis}

The characteristics of the two groups are given as mean \pm SD, whereas figures show mean \pm SEM. Differences between groups were tested by the Mann-Whitney U test. Differences within groups were tested by Wilcoxon (for comparisons of two variables) or Friedman (for comparison between more than two variables). The level of significance was determined at $5 \%$.

\section{Results}

Baseline characteristics of the patients and control subjects

The patients studied suffered from severe airflow obstruction as shown in Table 1. FFM and body mass were significantly lower in COPD patients compared to the healthy subjects. In COPD patients REE adjusted for $\mathrm{FFM}^{10}$ was significantly elevated, and maximal inspiratory mouth pressure $\left(\mathrm{Pi}_{-\mathrm{MAX}}\right)$ was decreased.

Baseline results (the mean value of the first $3 \mathrm{~min}$. of the test) were significantly higher in COPD patients compared to healthy subjects for oxygen consumption $\left(\mathrm{V}^{\prime} \mathrm{O}_{2}\right.$ : COPD $5.8 \pm 1.1$; healthy: $4.4 \pm 0.9 \mathrm{~mL} / \mathrm{min} / \mathrm{kg}$ FFM $\mathrm{p}<0.01$ ), carbon dioxide production ( $\mathrm{V}^{\prime} \mathrm{CO}_{2}$ : COPD $5.0 \pm 1.0$, healthy: $3.7 \pm 0.8 \mathrm{~mL} / \mathrm{min} / \mathrm{kg}$ FFM $\mathrm{p}<0.01$ ), minute ventilation ( $V^{\prime} E$ : COPD $14.4 \pm 2.5$, healthy: $10.7 \pm 2 \mathrm{~L} / \mathrm{min} \mathrm{p}<0.00 \|$ ), breathing frequency (BF: COPD $20.1 \pm 5.5$, healthy: $15.0 \pm 3.2 \mathrm{x} / \mathrm{min} p<0.05$ ) and heart rate (HR: COPD 95.4 \pm 13.2 , healthy: $68.8 \pm 26.1 \times / \mathrm{min} p<0.001$ ). 
Table 2: Percentoge increase in metabolic and ventilatory requirements following the three types of arm elevation $(A B)$

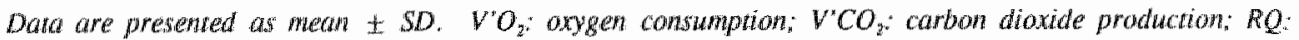

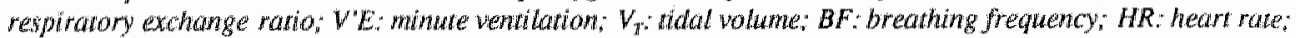
COPD: chronic obstuctive pulmonary diseate; AE 1. 90 degrees alewation of extended arms in the fromal plane; AE2: 180 degrees elewation of extended arms in the frontal plane: AE3: 90 degrees abduction with exterded armis.

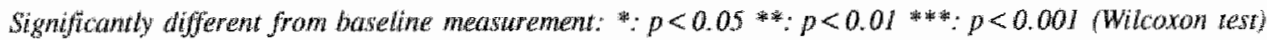

\begin{tabular}{lcccccc}
\hline & \multicolumn{2}{c}{$\% \mathrm{AE}$} & \multicolumn{2}{c}{$\% \mathrm{AE2}$} & \multicolumn{2}{c}{$\% \mathrm{AE3}$} \\
& $\mathrm{COPD}$ & control & $\mathrm{COPD}$ & control & COPD & conirol \\
\hline $\mathrm{V}^{\prime} \mathrm{O}_{2}$ & $11.6 \pm 4.8^{*}$ & $6.1 \pm 2.5^{*}$ & $14.2 \pm 5.9$ & $5.1 \pm 4.6$ & $13.7 \pm 6.2$ & $5.4 \pm 5.3$ \\
$\mathrm{~V}^{\prime} \mathrm{CO}_{2}$ & $15.4 \pm 17.7^{* *}$ & $9.7 \pm 2.9^{*}$ & $21.1 \pm 21.8$ & $11.3 \pm 5.2$ & $21.1 \pm 22.6$ & $11.1 \pm 5.9$ \\
$\mathrm{RQ}$ & $3.3 \pm 0.5^{* *}$ & $4.2 \pm 1.2^{*}$ & $6.3 \pm 0.9$ & $6.6 \pm 1.4$ & $6.9 \pm 1.2$ & $6.3 \pm 1.8$ \\
$\mathrm{~V} \mathrm{E}$ & $12.8 \pm 5.8^{*}$ & $7.4 \pm 2.4^{*}$ & $18.1 \pm 5.8$ & $7.2 \pm 4.1$ & $19.6 \pm 6.6$ & $7.2 \pm 4.1$ \\
$\mathrm{~V}_{\mathrm{T}}$ & $4.4 \pm 4.1$ & $2.9 \pm 3.8$ & $8.8 \pm 5.8$ & $2.1 \pm 4$ & $6.8 \pm 5.2$ & $5.6 \pm 5.6$ \\
$\mathrm{BF}$ & $8.4 \pm 5.8$ & $4.6 \pm 3.3$ & $10.0 \pm 6.5$ & $5.0 \pm 3.3$ & $12.9 \pm 6.3$ & $1.6 \pm 3.8$ \\
$\mathrm{HR}$ & $1.9 \pm 2.2^{*}$ & $5.0 \pm 6.5^{*}$ & $2.0 \pm 2.1$ & $7.0 \pm 8.7$ & $1.4 \pm 3.9$ & $6.1 \pm 5.6$ \\
\hline
\end{tabular}

Results of arm elevation testing

As the recovery periods after $\mathrm{AE} 1$, (and/or) $\mathrm{AE} 2$ and (or) AE3 showed significantly higher than baseline values of V'E, respiratory quotient (RQ), and HR in COPD patients, and of RQ in healthy subjects, only AEl (Table 2) was used to compare the effect of arm elevation in patients and controls. In COPD patients as well as in healthy subjects $\mathrm{V}^{\prime} \mathrm{O}_{2}, \mathrm{~V}^{\prime} \mathrm{CO}_{2}, \mathrm{RQ}, \mathrm{HR}$ and $\mathrm{V}^{\prime} \mathrm{E}$ were significantly higher than baseline during AEI. There were no statistically significant differences between the groups in the percentages increase of any metabolic or ventilatory parameter.

Figure 2 and 3 show the response patterns during the time course of arm elevation. In COPD patients $\mathrm{V}^{\prime} \mathrm{O}_{2}, \mathrm{~V}^{\prime} \mathrm{CO}_{2}, \mathrm{~V}^{\prime} \mathrm{E}$, tidal volume $\left(\mathrm{V}_{\mathrm{T}}\right)$ and $\mathrm{HR}$ gradually increased and decreased, whereas in the healthy control subjects a sudden peak was demonstrated (except for HR). In both groups, RQ increased after each arm elevation, and did not return to resting $\mathrm{RQ}$. 
Figure 2: Changes in $\mathrm{V}^{\prime} \mathrm{O}_{2}, \mathrm{~V}^{\prime} \mathrm{CO}_{2}$, and $\mathrm{HR}$ during arm elewation testing in healthy subjects (on the left side of the page) and COPD patients (on the right side)

Data are presented as mean $\pm S E M$. Each black bar on the $x$-axis indicates a 2 min. period of elewation; 0 - 3 min. baseline measurements; $3-8 \mathrm{~min}$ : AEI and recover; $8-13$ min. AE2 and recovery: $13-17$ min.: $A E 3$ and recovery. $V^{\prime} O_{2}$ axygen consumption; $V^{\prime} \mathrm{CO}_{2}$ carbon doxide production; HR: heart rate.

Healthy
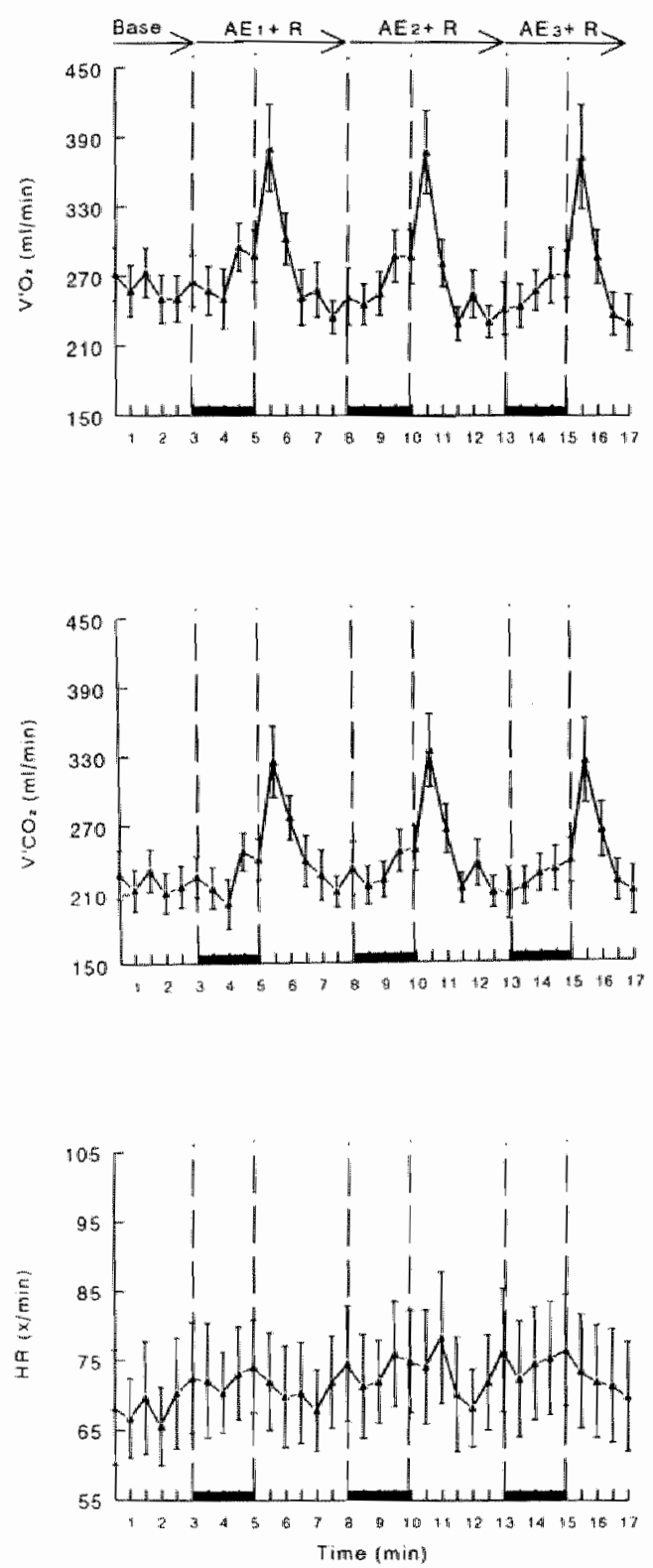

COPD
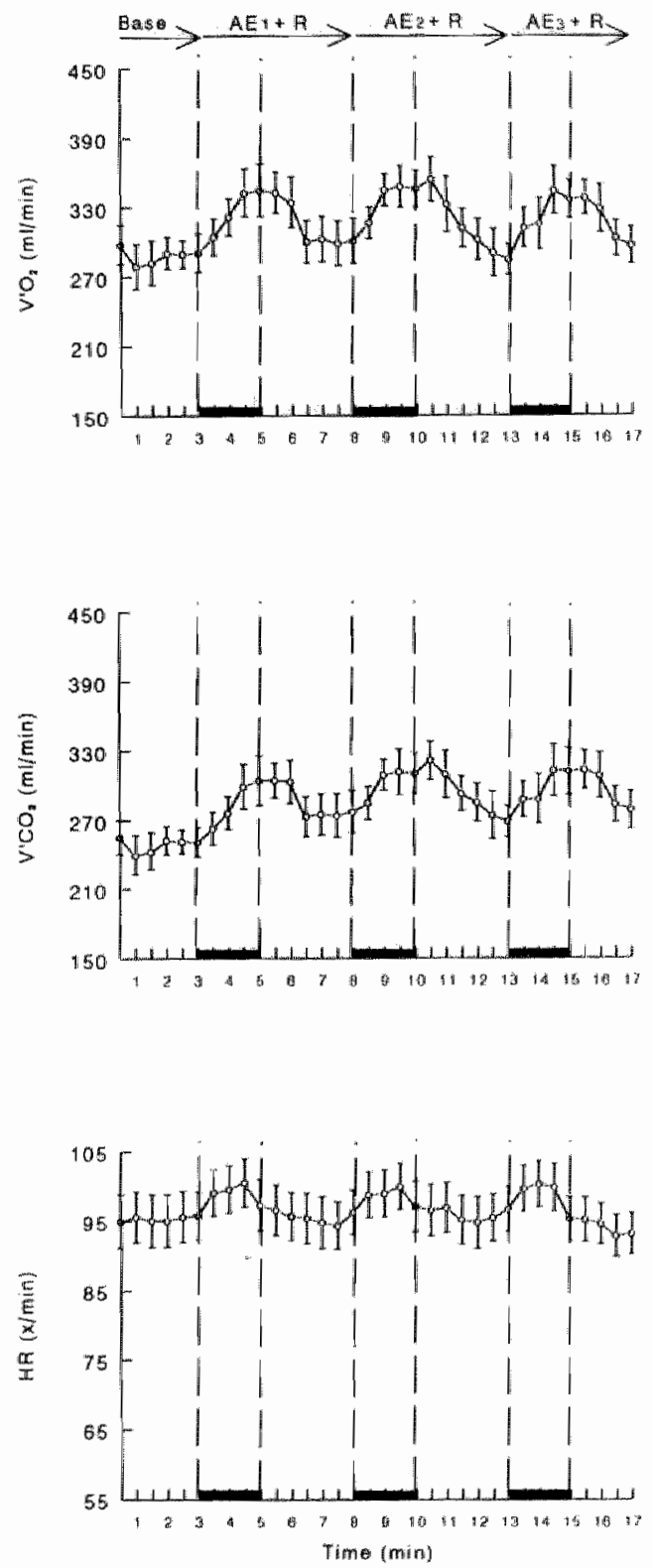
Figure 3: Changes in $V^{\prime} E_{3}, V_{T}$ and $B F$ during arm elevation in healthy subjects (on the lefi side of the page) and in COPD patients.

Data are presented as mean $\pm S D$. Each black box on the $x$-axis indicates a 2 min. period of elevation; 0 . 3 min. baseline measurements; $3-8$ min.: AEI and recowery; $8-13$ min: AE2 and recovery; $13-17$ min: AE3 and recovery. V'E: minute ventilation; $\mathbb{V}_{r}$ tidal volume; $B F_{*}^{\prime}$ breathing frequency.

Healthy
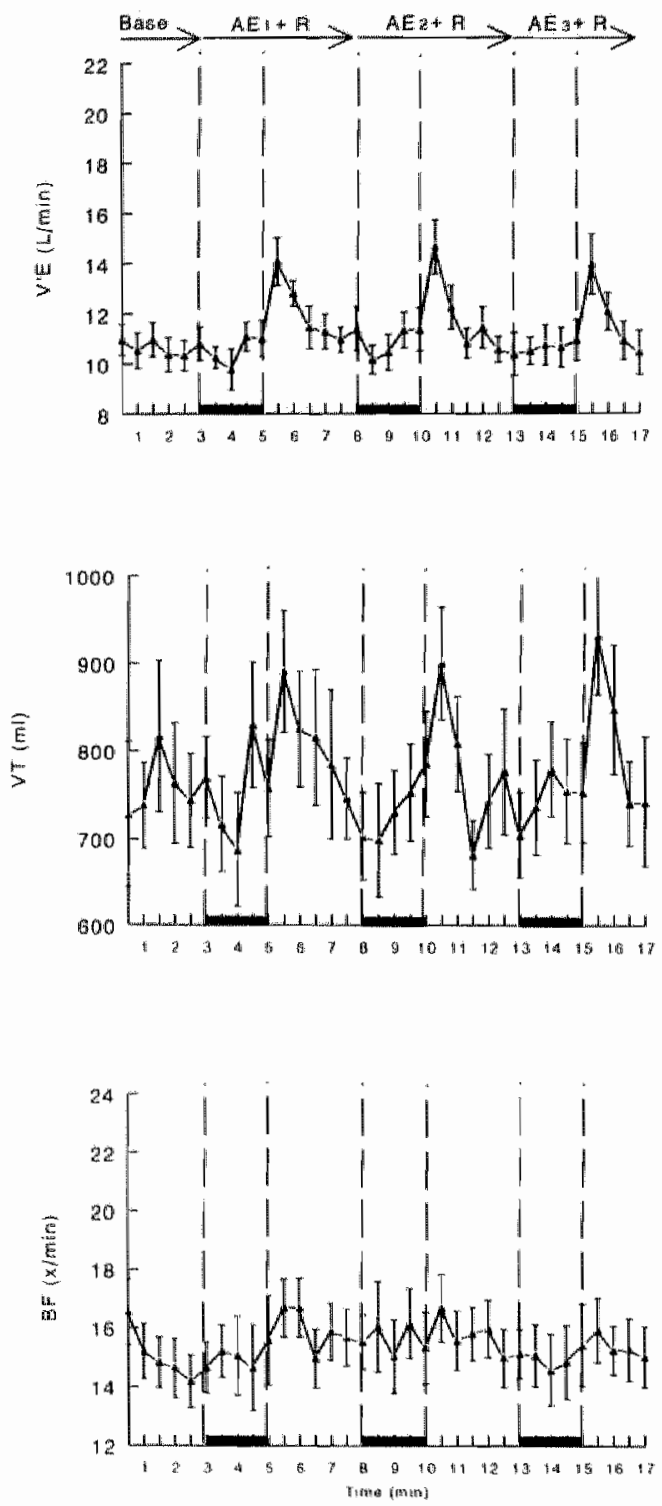

COPD
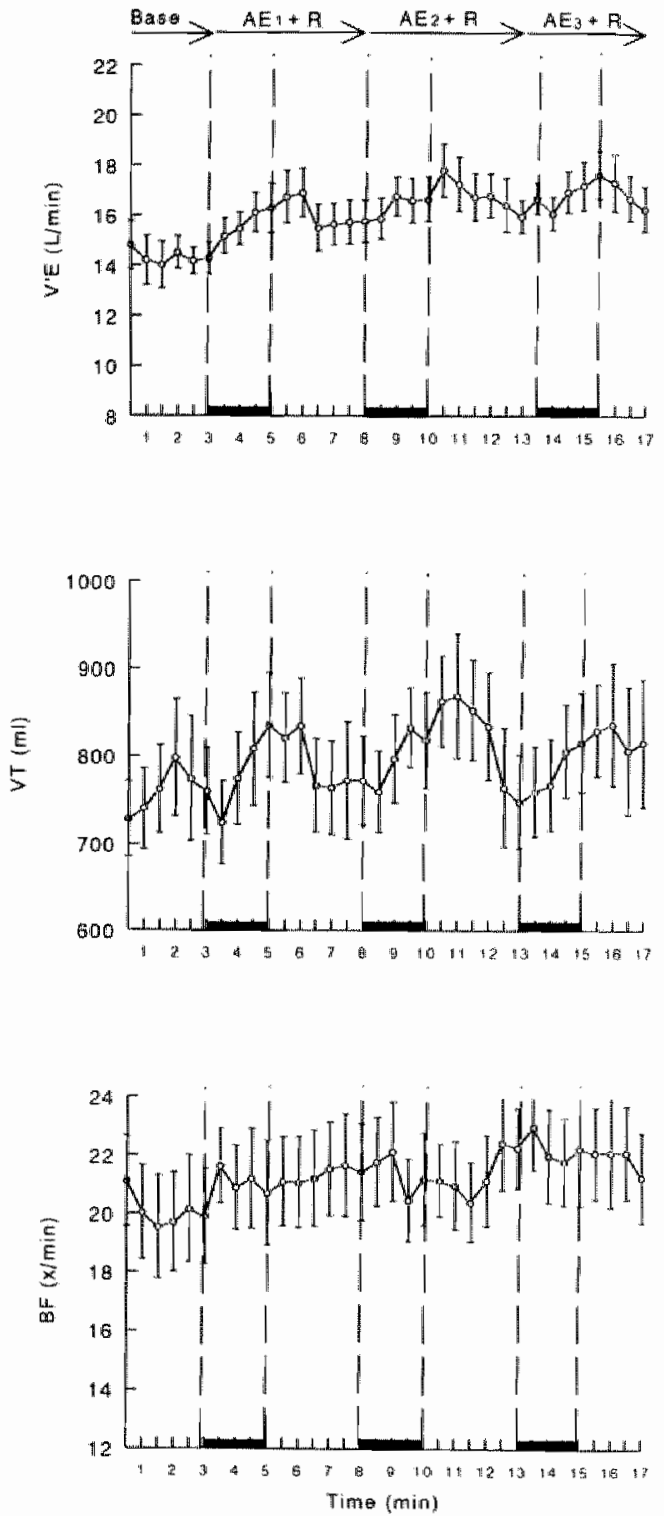
Difference between the three types of arm elevation

There were some minor differences between the three types of arm elevation which were due to an incomplete recovery between AE1 and AE2 and berween AE2 and AE3. Although, in absolute terms, these differences were not large, they did reach statistical significance for $V^{\prime} \mathrm{CO}_{2}, \mathrm{RQ}$ and $\mathrm{V}^{\prime} \mathrm{E}$ in the COPD patients, and for $\mathrm{RQ}$ in the healthy subjects. These results were all mearly in parallel with the differences between recovery periods and baseline test results.

\section{Discussion}

In this study the metabolic and ventilatory requirements of three types of arm elevation were compared between COPD patients and age-matched, healthy subjects. Adjusted for significantly greater baseline values in COPD patients, it was found that $\mathrm{AE}$ (arm elevation including recovery) tended to be more demanding with respect to metabolic and ventilatory response for patients with COPD than for the age-matched liealthy subjects.

A pronounced difference was found in the pattern of metabolic and ventilatory response to arm elevation between the two groups. Mutual comparison of the three different types of armelevation demonstrated a comparable response pattern, although due to an incomplete recovery (especially in COPD patients) $\mathrm{V}^{\prime} \mathrm{CO}_{2}, \mathrm{~V}^{\prime} \mathrm{E}$ and $\mathrm{RQ}$ at $\mathrm{AE} 1$ were lower than AE2 and (or) AE3.

It is known that in healthy persons arm exercise is relatively more demanding than leg exercise, since, at a given work output, heart rate, systolic and diastolic pressure, minute ventilation, oxygen uptake, respiratory exchange ratio and blood lactate concentration are higher, whilst stroke volume, anaerobic treshold ${ }^{15}$ and mechanical efficiency $y^{16.17 .18}$ are lower. Furthermore, a disproportionate increase in the diaphragmatic contribution to the generation of ventilatory pressures has been observed during arm elevation by Couser et $a^{5}$. Another study showed increases in electromyographic amplitudes of trapezius and supraspinatus muscles during arm elevation, and a rapid decrease in the median frequency, suggesting that arm elevation is a fatiguing task for the muscles involved ${ }^{19}$.

The arms are needed for many activities of daily living such as lifting, bathing, dressing, combing hair, hanging out the washing, or gardening ${ }^{20}$. Tangri and Woolf ${ }^{1}$ 
found that patients with COPD manifest a marked dyspnoea after simple arm movements. Furthermore, Celli at al have shown that unsupported arm exercise (UAE) is more difficult to sustain than leg exercise. In several studies UAE and arm elevation resulted in alterations in breathing patterm ${ }^{25.21}$. This was confirmed in a study by Dolmage et $\mathrm{al}^{4}$, who found that even arm positioning only (arms elevated but supported by a sling) changed breathing pattern in COPD patients (decrease in $\mathrm{V}_{\mathrm{T}}$, increase in BF). In addition Martinez et al found that except for an increased diaphragmatic recruitment, COPD patients probably also recruite expiratory muscles during arm elevation.

In this study, arm elevation resulted in a significant increase in $\mathrm{V}^{\prime} \mathrm{O}_{2}, \mathrm{~V}^{\prime} \mathrm{CO}, \mathrm{RQ}$, $H R$ and $V^{\prime} E$ compared to baseline. This is in accordance with earlier studies ${ }^{5.8}$ although the percentage increases in $\mathrm{V}^{\prime} \mathrm{O}_{2}, \mathrm{~V}^{\prime} \mathrm{CO}_{2}, \mathrm{~V}^{\prime} \mathrm{E}$, and $\mathrm{HR}$ in these studies were much higher than reported here. In stead of callculating peak metabolic and ventilatory response in these earlier studies, we calculated the mean increase of the total period of arm elevation and recovery. We chose to calculate the mean increase because (peak) response to $\mathrm{AE}$ was individually different within each group, and clearly between the groups. We could not confirm the data of Martinez et al ${ }^{8}$ who reported that an increase in $V ' E$ was caused predominantly by an increase in $\mathrm{BF}$, In our study, $\mathrm{V}_{\mathrm{T}}$ and $\mathrm{BF}$ did not significantly increase compared to baseline values in patients or healthy subjects, suggesting that both are determining factors of mirute ventilation, as was also reported by Dolmage et al".

The pattern of metabolic and ventilatory response to $\mathrm{AE}$ was clearly different between the groups. The healthy subjects demonstrated a sudden peak in $\mathrm{V}^{\prime} \mathrm{O}_{2}, \mathrm{~V}^{\prime} \mathrm{CO}_{2}$ and $V^{\prime} E$ after $A E$, but, in contrast to the COPD patients, the onset of the increase was relatively late. In $\mathrm{AE}$ a later adjustment of $\mathrm{V}^{\prime} \mathrm{O}_{2}$ would be expected, since $\mathrm{AE}$ represents a relatively low "workload" and the rate of $\mathrm{V}^{\prime} \mathrm{O}_{2}$ response is lower to a smaller workload than to a great workload ${ }^{2}$. Furthermore, arm exercise usually shows a sluggish $\mathrm{V}^{\prime} \mathrm{O}$. adaptation compared to leg exercise ${ }^{23}$. The quicker response to $\mathrm{AE}$ in the COPD patients is, therefore, suprising. Several explanations are possible for this earlier but more sluggish response patten seen in COPD patients.

Many studies have shown, that in untrained subjects, the kinetics of adjustment of $\mathrm{V}^{\prime} \mathrm{O}_{2}$ are markedly delayed ${ }^{24}$ and can increase by training ${ }^{-5}$. In a study of Cerretelli et al ${ }^{25}$ it was concluded that this was due to factors involved in $\mathrm{O}_{2}$ conductance from the capillary to the muscle (such as an increased capillary to fibre exchange surface, an increased myoglobin concentration, and a greater enzymatic oxydative potential associated with mitochondrial changes), change in fibre type (reducing glycolisis) ${ }^{26}$. COPD patients 
use accessory breathing muscles almost constantly to breathe, and this may cause such a training effect. In animal studies, malnutrition has shown a relative increase of type I fibers ${ }^{27.28}$. Since, in this study, the COPD patients suffered from tissue depletion compared to the healthy subjects, differences in fiber composition may have been a contributing factor to an earlier metabolic adaptation in the patients. On the other hand, the COPD patients also showed a slower recovery, which is more difficult to interpret.

Another possible explanation for the different response pattern is derived from the fact that pre-existing moderate work by a given muscle group has been demonstrated to accelerate its $\mathrm{V}^{\prime} \mathrm{O}_{2}$-onset response ${ }^{29.30}$, especially at lower workloads ${ }^{24}$. Because COPD patients could use shoulder girdle muscles in breathing (already at rest) as well as in armpositioning, this could have enlanced an earlier onset of the metabolic response.

Thirdly, the earlier $\mathrm{V}^{\prime} \mathrm{O}_{2}$-onset in COPD patients could be the result of different V'E-kinetics compared to healthy subjects. It has been shown in a study of Celli et al' that arm exercise leads to dyssynchronous breathing in COPD patients. Therefore, problems in co-ordinating breathing could have resulted in an earlier rise in $V^{\prime} E$ and $\mathrm{V}^{\prime} \mathrm{O}_{2}$ in the COPD patients.

There were differences in baseline metabolism and ventilation between COPD patients and healthy subjects prior to the arm elevation testing, despite comparable test conditions. In several studies ${ }^{12.31 .32}$, it was found that COPD patients demonstrate a significantly higher resting energy expenditure than healthy subjects. Although it is clear that a $15-20 \mathrm{~min}$. REE-measurement under strict conditions is not the same as a baseline test measurement (of $3 \mathrm{~min}$.), it can be hypothesized that the significantly increased baseline test results in the COPD patients were a reflection of the increased REE.

In addition, percentage increase during $\mathrm{AEI}$ also tended to be higher for metabolic variables in patients with COPD compared to healthy subjects. It has been demonstrated in several studies ${ }^{33.34}$ that COPD patients have a reduced respiratory mechanical efficiency. This, logether with the dual demand of the shoulder girdle muscle in ventilation and postural activities, may result in an increased metabolism during arm elevation. A disporportionate increase in V'E may have been the result of the dual demand of shoulder girdle muscle (difficulties in co-ordinating breathing), but may also be explained by an increased dead space ventilation in the COPD patients.

In conclusion, when adjusted for the increased baseline test results in the COPD patients, arm elevation in COPD patients tended to result in a greater metabolic and ventilatory response than healthy persons. This could be explained by a reduced 
respiratory mechanical eficiency, a dual activity of shoulder girdle muscle in COPD and an increased dead space ventilation. The response pattern was clearly different between the groups. The healthy subjects demonstrated a peak approximately $30 \mathrm{~s}$ after $\mathrm{AE}$. In the $\mathrm{COPD}$ patients, an earlier response of $\mathrm{V}^{\prime} \mathrm{O}_{2}$ was obsersed following arm elevation, which could be explained by tissue depletion, the dual activity of shoulder girdle muscle and a difference in $V$ 'E kinetics in COPD patients. Knowledge of the specific response to $\mathrm{AE}$ in COPD patients seems essential for interpretation of arm elevation tests in upper extremity rehabilitation programs.

\section{References}

1. Tangri $S$, Woolf $C R$. The breathing pattern in chronic obstructive lung disease during performance of some common daily actiwities. Chest 1973; 63: 126-127.

2. Celli BR, Rassulo J, Make BJ. Dyssynchroneous breathing during arm but not leg exercise in patients with chronic airflow obstruction. New. Eng. J. Med. 1986: 314:1485-1490.

3. Criner GJ. Celli BR. Effect of unsupported arm exercise on ventilatory muscle tecruitment in patients witll severe airflow obstruction. Am. Rev. Respir. Dis. 1988; 138:856-861.

4. Dolmage TE, Maestro L, Avendano MA, Goldstein RS. The ventilatory response to arm elevarion of patients with chronic obstructive pulmonary disease. Chest 1993: 104: 1097-1100.

5. Couser JI, Maryinez FJ, Celli BR. Respiratory response and ventitlatory muscle recruitment during arm elevarion in normal subjects. Chest $\mathbb{1 9 9 2 : 1 0 1 : 3 3 6 - 3 4 0 .}$

6. Kilian KJ, LeBlanc P. Martin DH. Summers E, Jones. NL. Campbell EJM. Exercise capacicy and ventilatory, circulatory, and symptom limitation in patients with chronic airflow limitation. An. Rew. Respir. Dis. 1992; 146: 935-940.

7. Janssens $\mathrm{S}$. Decramer $\mathrm{M}$. Corticortsteroid induced myopathy and the respiratory muscle. Chest. 1989: 95: $1160-1162$.

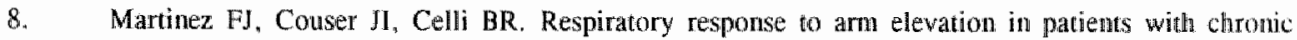
airflow obstruction. Am. Rev. Respir. Dis. 1991; 143:476-480.

9. Medical selection of the American Lung Association. Standards for the diagnosis and care of patients with chronic obstructive pulmonary disease (COPD) and asthma. Am. Rev. Respir. Dis. 1987: 134:239-243.

10. Quanjer PH, ed Standardised lung function testing. Bull. Eur. Physiopathol. respir. 1983; 19: 7-44.

11. Black LF, Hyatt RE. Maximal respiratory pressures: nomal values and relation to age and sex. Am. Rev. Respir. Dis. 1969; 99:696-702.

12. Scholls AMWJ, Fredrix EWHM, Soeters PB. Westerterp KR. Wouters EFM. Resting energy expenditure in patients with chronic obstructive pulmonary disease. Am. J. Clin. Nutr. 1991: 54:983-987.

13. Lukaski $\mathrm{HC}$. Bolonchuk WW, Hall $\mathrm{CB}$. Siders WA. Validation of tertapolar bioelectrical impedance method to assess human body composition. J. Appl. Physiol. 1986; 60: 1327-1332.

14. Schols AMWJ, Wouters EFM. Soeters PB. Westerterp KR. Body composition by bioelectricalimpedance anklysis compared with deuteriun dilution and skinfold anthropometry in patients with chronic obstructive pulmonary disease. Am. J. Clin. Nutr. 199\#; 53:42》-424.

15. Franklin BA. Exercise testing, training and arm ergometry. Sports Medicine 1985; 2:100-119.

16. Jensen $M$. Ahlborg $G$. Is the high lactate release during arm exercise due to a low training status. Clin. Plyysiol. 1992; 12:487-496.

17. Jensen-Urstad M. Hallback I, Sahlin K. High anaerobic energy release during submaxumal arm exercise. Clin. Pliysiol. 1993; 13:81-87.

18. Bevergand S. Preyschuss U. Strandell T. Circulatory adaptation to arm and leg exercise in supine and sitting position. J. Appl. Plyysiol. 1966: 21:37-46. 
19. Harberg M. Electromyographic signs of shoulder muscle facigue in two elevated anm positions. Am. J. Phys. Med. 1981; 69:111-121.

20. Lake FR, Henderson K, Briffa T, Openshaw J, Musk W. Upper tumb and lower limb exercise training in patients with chronic airflow limitation. Chest 1990; 97:1077-82.

21. Maestro L, Dolmage $T$, Avendano M, Goldstein R. Inffuence of arm position in ventilation during incremental exercise in healthy individuals. Chest 1990;98:113s.

22. Whipp BJ. Wasserman $\mathrm{K}$. Oxygen uptake kinetics for various intensities of constant-load work. J. Appl. Physiol. 1972: 28:452-456.

23. Cerretelli P, Shindell D, Pendergast DP, Prampero PE, Remie DW. Oxygen uptake transients at the onset and offset of arm and leg work. Resp. Physiol. 1977; 30:81-97.

24 Pendergast DR. Cardiovascular, respiratory, and metabolic responses to upper body exercise. Med. Sci. Sports Exerc. 1989: 21 (Suppli. 5):S121-S125.

25. Cerretelli P, Pendergast D, Paganelli WC, Renuie DW. Effects of specitic muscle training on $V^{\circ} \mathrm{O} 2$ on-response and early blood lactate. I. Appl. Physiol. 1979: 47:761-769.

26. Andersen P. Hendriksson J. Capillary supply of the quadriceps fenoris muscle in man: adaptive response to exercise. J. Physiol. Londen 1977: 270: 677-690.

27. Sieck GC, Lewis MI, Blanco CE. Effects of undernutrition on diaphragm fiber size, SDH activity, and faiigue resistance. J. Appl. Physiol. 1989; 66:2196-2205.

28. Kelsen SG, Ference M. Kapoor S. Effects of prolonged undernutrition on structure and function of the diaphragm. J. Appl. Physiol. 1985; 58:1354-1359.

29. di Prampero PE. Davies $M$. Cerretell $P$. Margaria $R$. An analysis of $O_{2}$ debi contraction in submaximal exercise. J. Appl. Physiol. 1970; 29:547-551.

30. Karlsson J, Bonde-Peterson F, Hendrikssoon Jr. J., Knottgen HJ. Effects of previous exercise with ams or legs on metabolism and performance in exhaustive exercise. J. Appl. Physiol. 1970; 28: 397406.

31. Goldstein SA, Askanazi J, Weissman C. Thomashow B, Kinney J. Energy expenditure in patients with chronic obstructive pulmonary disease. Chest 1987; 91:222-224.

32. Fitting JW. Frascarolo Pla. Jéquier E. Leuenberger Ph. Energy expenditure and rib cage abdominal motion in chronic obstructive pulmonary disease. Eur. Respir. J. 1989: 2:840-845.

33. Cherniack RM. The oxygen consumption and efficiency of the respiratory muscles in healdh and emphysena. J. Clin. Unvest. 1959: 38:494-499.

34. Levison $\mathrm{H}$, Cherwiack RM. Ventilatory cost of exercise in chronic obstructive pulnonary disease. J. Appl. Physiol. 1968; 25:21-27. 


\section{BREATHING EFFICIENCY DURING INSPIRATORY \\ THRESHOLD LOADING IN PATIENTS WITH CHRONIC OBSTRUCTIVE PULMONARY DISEASE}

Erica M. Baarends, Annemie M. W.J. Schols, Christa M. Nusmeier, Chris P.M. van der Grinten, Eniel F, M. Wouters. Deptarment of Putmonology, Maastricht Uniwersity, Maastricht, The Netherlands

\section{Abstract}

Patients with Chronic Obstructive Pulmonary Disease (COPD) demonstrate an increased oxygen cost of breathing (OCB). It is yet unclear whether this is related to an inefficient respiratory muscle energy metabolism. The aim of the present study was to compare breathing efficiency between 16 patients with $\operatorname{COPD}(11 \delta, 59)$ and 16 healthy elderly subjects $(7 \%, 99)$, and to investigate a possible relationship between breathing efficiency and resting energy expenditure (REE). REE was measured using a ventilated hood system. Breathing efficiency was assessed by measuring oxygen consumption $\left(\mathrm{V}^{\prime} \mathrm{O}_{2}\right)$, mean inspiratory mouth pressure (MIP) and flow during breathing at rest and subsequently during breathing against an inspiratory threshold $(40 \%$ of maximal inspiratory pressure). During the test, patients as well as healthy subjects were encouraged not to increase their ventilation. During loaded breathing there was a significant increase in $\mathrm{V}^{\prime} \mathrm{O}_{2}, \mathrm{MIP}$, and external work of breathing compared to unloaded breathing in both groups. As intended, ventilation did not increase significantly during the breathing efficiency test in the patients with COPD. Breathing efficiency (median, range) of the patients with COPD was comparable (3.7, $1.4-8.7 \%)$ with those of the healthy elderly subjects $(3.2,1.7-8.3 \%)$. There was no significant correlation between breathing efficiency and REE in both groups. In the present study, in which dynamic hyperinflation was likely prevented, no difference in breathing efficiency was found between healthy elderly subjects and COPD patients when breathing against an external inspiratory threshold. Furthermore, breathing efficiency was not related to REE in both groups. 


\section{Introduction}

The force-generating capacity of the respiratory muscles as a whole is reduced in COPD patients ${ }^{12}$. Hyperinflation is one of the major contributors to respiratory muscle weakness, resulting from the inadequate length-tension proportion and altered rib cage and diaphragm geometry ${ }^{3}$. However, the strength of the diaphragm in patients with COPD is as good as normal, when taking lung volume into account ${ }^{4}$. It has been shown by Morrison et al that the endurance for loaded breathing in patients with COPD was decreased compared to healthy elderly, matched for sex and body weight ${ }^{5}$. It was further demonstrated that respiratory muscle endurance was decreased to a much greater extent than respiratory muscle strength ${ }^{5}$.

Besides investigations on changes in respiratory muscle function in COPD, already in the sixties several studies examined the oxygen cost of breathing (OCB) during stimulated ventilation. It was found that $\mathrm{OCB}$ could be 2 to 10 times higher in COPD patients than healthy subjects ${ }^{6-12}$. The variation is probably related to the different methods used to stimulate ventilation. In addition, it remains unclear whether the increased $O C B$ is related to the increased work of breathing in patients with COPD, or to an inefficient energy metabolism of the respiratory muscles.

In some investigations, estimates of internal or external work of breathing were made in combination with measurements of the energy requirements of stimulated breathing, and it was suggested that COPD patients (and asthma patients) might suffer from a decreased efficiency of breathing ${ }^{6.7 .13 .14}$. Unfortunately, reference values for breathing efficiency in these studies were derived from much younger control subjects than the COPD patients, although it has been demonstrated that the oxygen cost of breathing increases with age ${ }^{1.5}$. In addition. Field et al showed that the calculated internal work of breathing in most earlier studies probably does not represent a good estimate of the breathing work performed, since it correlated only weakly with $\mathrm{OCB}^{\text {th }}$.

The aim of the present study was to investigate the efficiency of breathing in patients with COPD, compared with the breathing efficiency of healthy elderly. In addition to earlier studies investigating breathing efficiency, it was the intention to prevent a confounding effect of a disproportionate increase in the internal work of breathing during the breathing efficiency test, due to dynamic hyperinflation. Therefore, ventilation was not supposed to increase during the breathing efficiency test. An inspiratory threshold was used, because the work of breathing with this device is 
merely dependent on generated pressure and minute ventilation, and only slightly affected by changes in breathing pattern.

There is renewed interest in the $O C B$, since it has been postulated that an increased $\mathrm{OCB}$ at rest may contribute to the increased REE commonly observed in COPD patients ${ }^{1 \%}$. Until now, however, only one study actually investigated the relationship between REE and OCB in a very small group of COPD patients ${ }^{11}$. A side issue of the present study was to measure REE in order to analyze whether the efficiency of inspiratory threshold loaded breathing was decreased in subjects with an increased REE.

\section{Methods}

\section{Patients}

16 patients $(110,5 \%$ ) with moderate to severe COPD (defined by the American Thoracic Society) ${ }^{19}$ were studied (Table 1). Patients exhibiting an increase in forced expiratory volume in one second $\left(\mathrm{FEV}_{1}\right)>10 \%$ after inhalation of a $\mathrm{B}_{2}$-agonist, or requiring supplemental oxygen (arterial oxygen pressure $<7.3 \mathrm{kPa}$ ) were not included. The patients were admitted to a pulmonary rehabilitation center in a stable clinical condition. The breathing efficiency test was performed in the first week of admission, before the rehabilitation programme actually started. None of the patients had a respiratory tract infection or clinically visible signs of oedema at the time of the study and they had no known cardiovascular, neurological, or endocrine diseases. The patients were fully informed of the nature and purpose of the study and gave informed consent. The study was approved by the ethical committee of the Maastricht University. Procedures followed were in accord with the Helsinki declaration from 1977 as revised in 1983.

\section{Control subjects}

16 Healthy elderly ( $>50$ years) persons $(78,99)$ were recruited from clubs for elderly (Table 1). During recruitment all persons were interviewed to make sure that they had no pulmonary complaints, used no medication, and were not suffering from any of the above mentioned exclusion criteria. 
Table 1: Characteristics of the siudied group

Data are presented as median (rongel. BMI: body mass index; FFM-index fat-free mass index: FEV;: forced expiratory wolume in one second, FVC forced wital capacity; TLC: total lumg capacity; TTGV: intrathoracic


\% HBB: as percentage of predicted REE based an the Harris \& Benedict formulas." "n=15: I women Had chustrophobia; she did not want to by under the ventilated hood nor to be in the narrow body box for these measuremenus $=15$ : I measurement is missing (I women not measured) 'also not significantly different whon FFM is taken into account by analysis of covariance.

\begin{tabular}{|c|c|c|c|c|}
\hline & & $\begin{array}{c}\text { Heal thy } \\
\mathrm{n}=16(72,99)\end{array}$ & $\begin{array}{c}\text { Patients } \\
\mathrm{n}=16(113,59)\end{array}$ & p-value \\
\hline Age & $(y r)$ & $64(52-76)$ & $66(38-72)$ & NS \\
\hline BMI & $\left(\mathrm{kg} / \mathrm{m}^{2}\right)$ & $25.2(21.1-34.1)$ & $24.7(17.9 .27 .9)$ & NS \\
\hline FFMI & $\left(\mathrm{kg} / \mathrm{m}^{2}\right)$ & $18.3(15.7-21.4)$ & $17.9(13.8 \cdot 20.3)$ & NS \\
\hline$F E V_{1}$ & (\%pred.) & $115(72-132)$ & $39(117-69)$ & $p<0.001$ \\
\hline FVC & (opred.) & $1.19(77-155)$ & $84(72-133)$ & $p<0.001$ \\
\hline TLC & (\%pred.) & $110(74-134)$ & $120(94-137) \%$ & NS \\
\hline ITGV & (\%pred.) & $104(68-153)$ & $134(104-197)^{*}$ & $p<0.001$ \\
\hline$R_{\text {qux }}$ & (\%pred.) & $88(40-197)$ & $233(117-373)^{*}$ & $p<0.001$ \\
\hline Pi- ${ }_{\text {MAX }}$ & $\left(\mathrm{kPa}^{\mathrm{Pa}}\right)$ & $9.8(7.6-13.6)$ & $8.4(5.8-11.2)$ & $p<0.01$ \\
\hline REE & (kcal/24h) & $1562(1124-1829)$ & $1508(1056-1658)^{*}$ & NS! \\
\hline REE & $(\% \mathrm{HB})$ & $103(85-115) A$ & $103(73-114) *$ & NS \\
\hline
\end{tabular}

Pulmonary function tests

Flow volume measurements included $\mathrm{FEV}_{1}$, and forced vital capacity (FVC). The highest value of at least three measurements was used. Total lung capacity (TLC), intrathoracic gas volume (ITGV) and airways resistance $\left(\mathrm{R}_{\mathrm{aw}}\right)$ were measured by bodyplethysmography (Masterlab, Jaeger, Wurzburg, Germany). The values were expressed as a percentage of a reference value $e^{20}$. The upper limit for normality of $R_{a w}$ was considered to be $0.3 \mathrm{kPa} \mathrm{Ps}^{*} \mathrm{~L}^{21}$. Inspiratory muscle strength was assessed by maximal inspiratory mouth pressure ( $\mathrm{Pi}$ - $_{\text {MAX }}$ ) according to the method described by Black and Hyatt ${ }^{22}$, and it was expressed in positive values. Only in the patients, blood was drawn from the brachial artery at rest while breathing room air and immediately analyzed for arterial oxygen and carbon dioxide pressures $\left(\mathrm{PaO}_{2}\right.$ and $\mathrm{PaCO}_{2}$ ) (Radiometer, ABL 330 Copenhagen, Danmark). 


\section{Metabolic profile}

Body height was determined to the nearest $0.5 \mathrm{~cm}$ (Lameris, WM 715, Breukelen, The Netherlands) with subjects standing barefoot. Body weight was measured with a beam scale to the nearest $0.1 \mathrm{~kg}$ (SECA, FRG) with subjects barefoot and in light clothing. To adjust body weight for body surface area, the body mass index (BMI) was calculated as weight/height ${ }^{2}$.

Fat-free mass (FFM) was assessed by bioelectrical impedance measurements at $50 \mathrm{kHz}$ (Xitron 4000b, Xitron technologies, San Diego, California). Resistance (R) was measured in supine position at the right side as described by Lukaski ${ }^{23}$ (BLA-101, RJL Systems, Detroit, USA). FFM was calculated from height ${ }^{2} / \mathrm{R}$ and body weight using a patient specific equation ${ }^{24}$ for the patients and the formula of Lukaski ${ }^{23}$ for the healthy elderly subjects. FFM was also adjusted for body surface area (FFM-index: FFM/height ${ }^{2}$ ).

Resting energy expenditure (REE) was measured by indirect calorimetry using a ventilated hood system (Oxycon B, Jaeger, Wurzburg, Germany). Measurements were done in the early morning after an overnight fast, while the person was comfortably lying on a bed in supine position ${ }^{25}$. The system was calibrated before measurements were taken, and the accuracy of the system (3-4\%) was regularly tested with an ethanol combustion test. REE was expressed as percentage of predicted ${ }^{26}$.

\section{Breathing efficiency testing}

The experimental setup is schematically demonstrated in Figure 1. Subjects breathed through a mouthpiece. The inhaled and expired air was separated using a valve system. Inspiratory minute ventilation (V'I) was measured using a Fleisch Head connected to a pressure transducer (Validyne). Mouth pressure (Uniflow 43-600F, Baxter BV, Uden, The Netherlands) was measured between the mouth piece and the valve system, the precision of the pressure transducer was within $99.9 \%$. Expired air and a bias flow were drawn through a mixing chamber, from which mixed expiratory air was sampled and oxygen consumption $\left(\mathrm{V}^{\prime \prime} \mathrm{O}_{2}\right)$ and carbon dioxide production ( $\mathrm{V}^{\prime} \mathrm{CO}_{3}$ ) were measured (Oxycon B, Jaeger, Wurzburg, Germany). V'I and mouth pressure were sampled by a computer system at $100 \mathrm{~Hz}$, and stored on hard disk for off-line analysis. 


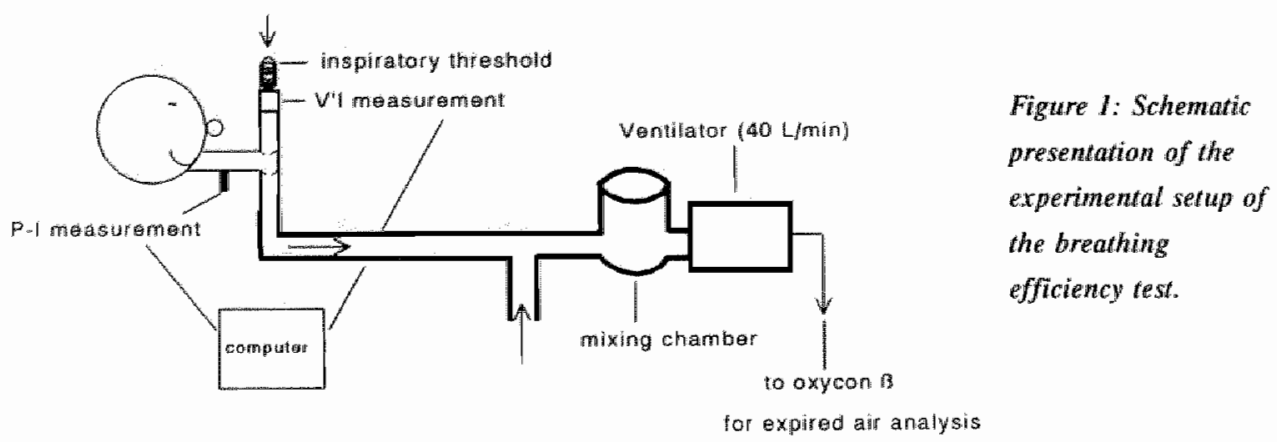

Before the tests the equipment was calibrated. Subjects fasted for at least 4 hours, and rested for at least half an hour prior to the test. Before starting the test the subjects first practiced to breathe against the inspiratory load of $40 \%$ of $\mathrm{Pi}_{\text {MAX }}$ (Threshold, Health Scan Prod, Mecomfa). They were encouraged to sit as quietly as possible, to "breathe as normally as possible", and to breathe only with more strength. Then the subjects would start to breathe quietly through the system and a 10 minutes rest-measurement was started as soon as stable $\mathrm{V}^{\prime} \mathrm{O}_{2}$ and $\mathrm{V}^{\prime} \mathrm{CO}_{2}$ measurements were obtained. The next 10 minutes the threshold load was attached to the inspiratory inlet. During the first minutes of inspiratory loaded breathing, the load was again checked with a manometer, to make sure that a peak inspiratory load of $40 \%$ of $\mathrm{Pi}_{\text {-MAX }}$ was reached. Otherwise the pressure was adjusted. Furthermore, the subjects were continuously encouraged to breathe as normally possible, in order to prevent hyper- or hypoventilation. Only the last 5 minutes of each 10 minutes period was used for analysis.

Accuracy of the measurement

In 8 healthy young persons, the accuracy of the mechanical efriciency test was determined on three occasions. Mean $( \pm$ SD) mechanical efficiency was $4.3 \pm 1.7 \%$ on the first occasion, $4.5 \pm 1.6 \%$ on the second occasion (5 higher, 3 lower), and 4.2 $\pm 1.2 \%$ on the third occasion ( 4 higher, 4 lower compared to the second occasion). 
This was not significantly different. The difference in breathing efficiency between tests averaged $1.4 \pm 0.8 \%$.

Data analysis

The added inspiratory mechanical work per minute (work) was calculated by multiplying the inspiratory llow ( $\mathrm{V}^{*} \mathrm{I}, \mathrm{L} / \mathrm{s}$ ) by the added mouth pressure (P, KPa), and was expressed in joule per minute:

$$
\text { work }=\left\{\int_{[=0}^{t=300} V^{\prime} I(t) * P(t)\right\} / 5[\Pi / \mathrm{min}]
$$

Mechanical efficiency was then calculated as follows:

added inspiratory mechanicall work (J/min)

efficiency $^{27}=\overline{\text { extra energy expenditure }(\mathrm{J} / \mathrm{min})} \quad * 100 \%$

Extra energy expenditure was computed as the difference in energy expenditure during loaded and unloaded breathing. Energy expenditure was calculated from the steady state values of $\mathrm{V}^{\prime} \mathrm{O}_{2}$ and $\mathrm{V}^{\prime} \mathrm{CO}_{2}$ using the abbreviated Weir formula ${ }^{28}$.

Characteristics of the study group are given as the median (range). The MannWhitney- $U$ test was used to test differences between the healthy elderly subjects and the COPD patients. The Wilcoxon rank test was used to test differences within a group. Analysis of variance (ANOVA) was performed when appropriale. A p-value < 0.05 was considered statistically significant.

\section{Results}

The patients as well as the healthy subjects were elderly persons (Table 1). The healthy subjects had a normal pulmonary function and a significantly higher Pi-max than the COPD patients. REE ranged from $73 \%$ to $115 \%$, but was not significantly different between the groups. Furthermore, the patients had moderate to severe airflow obstruction, had increased airways resistance, demonstrated chronic hyperinflation, and had a nomal oxygenation at rest $\left(\mathrm{PaO}_{2}: 9.9,7.8-12.5 \mathrm{kPa}\right)$. 
Table 2: Response to the mechanical efficiency test

Data are presented as median (range). ${ }^{\prime} O_{2}$ axygen consumption. $V ' I$ : minute ventilation. Work: extemat brearling work: MIP: mean inspiratory pressure: TilTtot: inspiration time divided by the toul chcle sime.

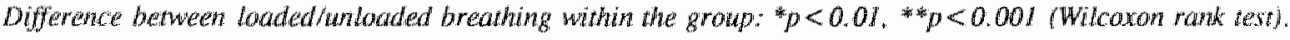

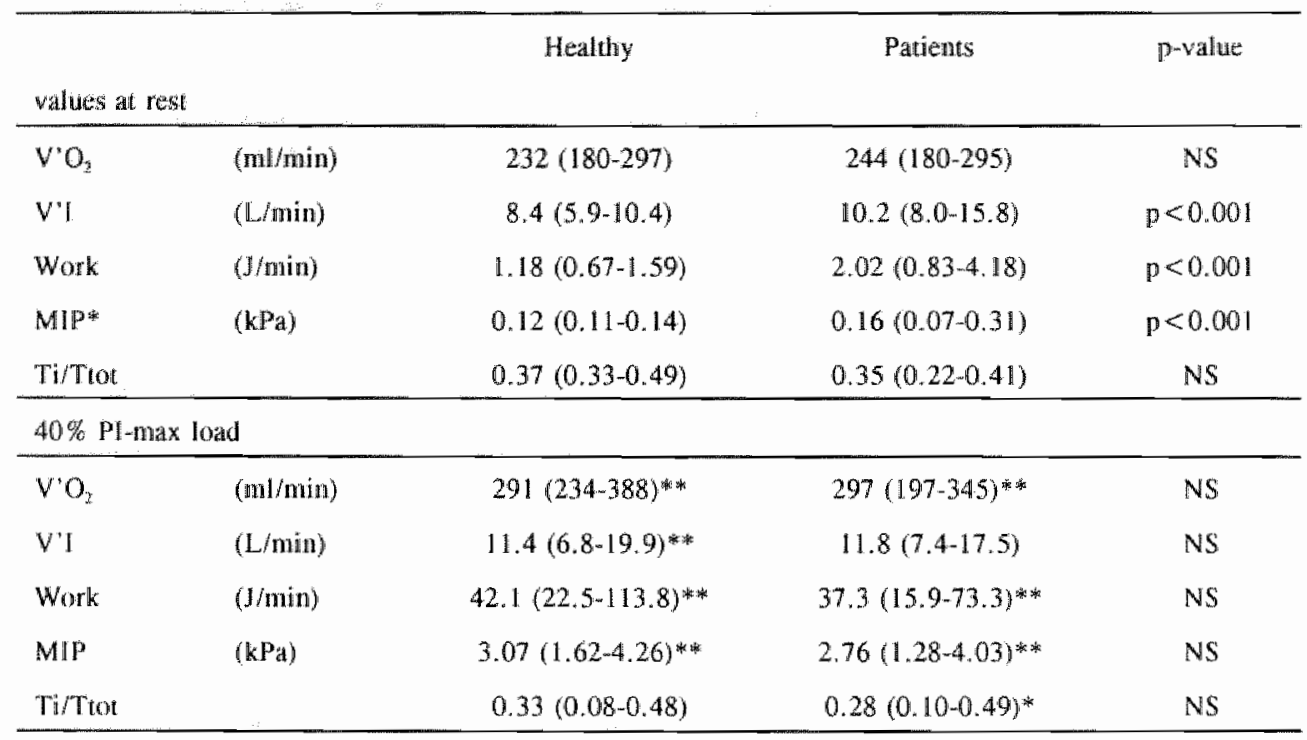

In Table 2 the results of the breathing efficiency test are shown. The COPD patients had a significantly greater V'I, mean inspiratory pressure (MIP), and external breathing work at rest than the healthy subjects.

In both groups there was a significant increase in $\mathrm{V}^{\prime} \mathrm{O}_{2}$, external work of breathing and MIP during inspiratory threshold loading, compared to these measurements during breathing at rest. The healthy persons also demonstrated an increased V'I, whereas in the COPD patients V'I did not change. However, the COPD patients had a significant decrease in Ti/Ttot, which was not the case in the healthy persons. During loaded breathing there were no differences in the measured variables between COPD patients and healthy subjects.

The difference in Pi- MAX between the studied groups was obviously too small to result in a difference in MIP. Furthermore, although peak inspiratory pressure was held at $40 \%$ of $\mathrm{Pi}_{\text {MAX }}$, both in the COPD patients and in the healthy subjects, MIP was lower than $40 \%$ of $\mathrm{Pi}_{-\mathrm{MAx}}$. 
Table 3 : Measures of breathing efficiency

Dara are presented as median (range). For abbreviations, see legend to Table 2

\begin{tabular}{lcccc}
\hline & & Healthy & Patients & p-value \\
Increase (loaded - rest) & $(\mathrm{ml} / \mathrm{min})$ & $58.6(18.4-1.41 .4)$ & $47.3(17.2-98.3)$ & $\mathrm{NS}$ \\
\hline $\mathrm{VO}_{2}$ & $(\mathrm{~L} / \mathrm{min})$ & $2.8(-0.3-10.8)$ & $-0.1(-2.2-8.3)$ & $\mathrm{p}<0.05$ \\
$\mathrm{VI}$ & $(\mathrm{J} / \mathrm{min})$ & $40.9(21.3-112.6)$ & $31.9(13.5-71.6)$ & $\mathrm{NS}$ \\
Work & $(\mathrm{kPaj})$ & $2.96(1.51-4.1 .5)$ & $2.55(1.08-3.86)$ & $\mathrm{NS}$ \\
$\mathrm{MIP}$ & & $-0.06(-0.28-0.15)$ & $-0.05(-0.25-0.12)$ & $\mathrm{NS}$ \\
Ti/Ttot & $(\%)$ & $\mathbf{3 . 2 ( 1 . 7 - 8 . 3 )}$ & $\mathbf{3 . 7}(\mathbf{1 . 4 - 8 . 7 )}$ & $\mathrm{NS}$ \\
Efficiency & & & & \\
\hline
\end{tabular}

Table 3 demonstrates the difference between loaded and unloaded breathing in the measured variables. For the COPD patients and healthy subjects a similar change was found between loaded and unloaded breathing in $\mathrm{V}^{\prime} \mathrm{O}_{2}$, external breathing work, MIP and Ti/Ttot. Only the change in V'I between loaded and unloaded breathing was significantly different. The COPD patients were more succesful in maintaining normal ventilation than the healthy elderly subjects. In addition, there was no difference in breathing efficiency between both groups.

As shown in Figure 2, there was no significant correlation between the difference in loaded/unloaded $V^{\prime} I$ and breathing efficiency $(r=-0.11)$ in both groups. The difference in loaded/unloaded external work was also not related to breathing efficiency $(r=0.04)$.

In the COPD patients, breathing efficiency did not correlate to airflow obstruction, airways resistance, measures of chronic hyperinflation, $\mathrm{Pi}_{r_{\operatorname{MAX}}}$, blood gases at rest, age, body composition or REE $(r=-0.19, p=0.49)$. Breathing efficiency correlated moderately but significantly to FVC $(r=0.53, p<0.05)$ in the patients.

In the healthy elderly subjects, breathing efficiency did not correlate to airflow obstruction, airways resistance, measures of chronic hyperinflation, $\mathrm{Pi}_{-\mathrm{MAX}}$, age, body composition, or $\operatorname{REE}(r=0.13, p=0.65)$. The lack of correlation, for patients and control subjects, between breathing efficiency and REE is demonstrated in Figure 3. 


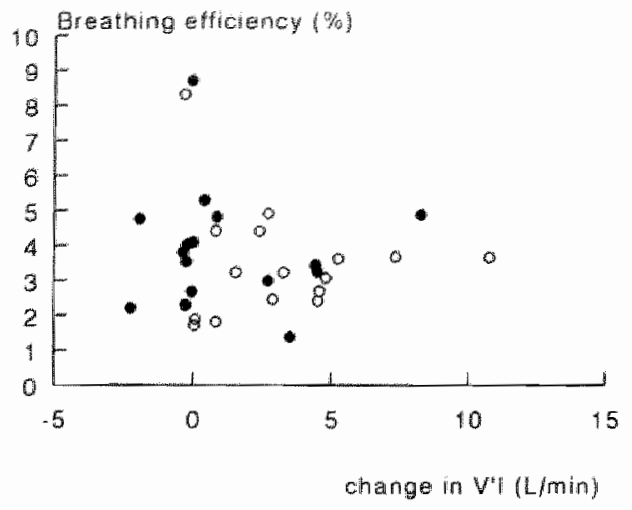

Figure 2: Relationship between the change (loadedunloaded breathing) in minute ventilation and breathing efficiency.

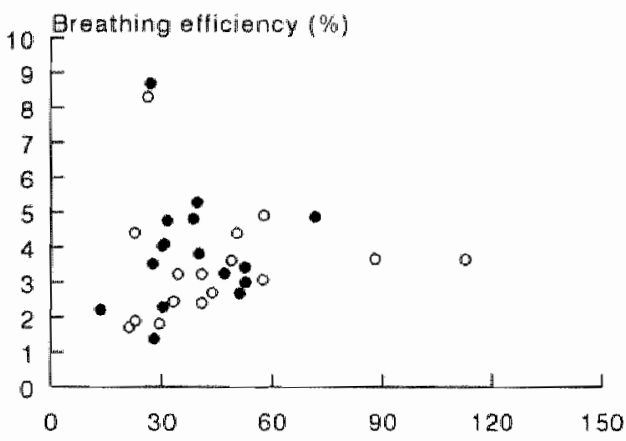

Relation between the change (loaded-unloaded breathing) in external work and breathing efficiency.

change in work (J/min)



Figure 3: Relationship between resting energy expenditure (as percentage of predicted) and breathing efficiency.

Closed circles $=$ parients with COPD

Open circles $=$ healthy elderly subjects 


\section{Discussion}

From the results of the present study it is concluded that there is no difference in breathing efficiency between healthy elderly subjects and COPD patients when breathing against an external inspiratory threshold load. Furthermore, in the present sudy breathing effictency was not related to REE expressed as percentage of predicred.

These findings are in contrast with several other studies in which breathing efficiency was significantly different between COPD patients and healthy subjects. In most studies this difference was only one or two percent ${ }^{7.13}$, is, except for the sudy by Cherniack $^{6}$, in which a large difference in efficiency between patients with emphysema and healthy subjects was found. In that study, however, mean efficiency in healthy subjects $(8.6 \%)$ was much higher than the reported breathing efficiency for healthy subjects $(3$ to $5 \%$ ) in several other studies $7.13,14.16 .29-32$

There can be several reasons why, in contrast to the above mentioned previous studies, in the present study no difference in breathing efficiency between patients with COPD and healthy subjects was found. First of all, in the other studies ${ }^{6.7 .13 .14}$ the breathing efficiencies of patients with COPD were compared with those of a younger control group. Takishima et $\mathrm{a}^{1.5}$ showed that the OCB was significantly increased in older subjects. This is in line with the observed lower efficiency $(\rho=0,07)$ of the healthy elderly subjects in the present study, compared with the healthy young subjects, who were measured to test the accuracy of the breathing efficiency test.

Secondly, in other studies ${ }^{7.13}$ internal work of breathing was callculated by means of (internal) pressure-volume calculations. Later Field et al ${ }^{16}$ demonstrated. that the calculated internal work of breathing correlated only weakly to the OCB. suggesting that these calculations may not cover the actual work performed. In the study by Chemiack ${ }^{6}$ and Weiner ${ }^{14}$, external work of breathing was calculated, ignoring the increase in internal work of breathing. It was not reported if and to what extent ventilation increased during the efficiency tests of the latter studies, in which ventilation was not controlled.

This might be very inportant, since in general the compliance of the respiratory system is reduced in patients with COPD particularly during increased ventilation ${ }^{\text {k3. }}$. Expiratory flow limitation causes inspiration to begin before the respiratory system has had the time to return to passive FRC, promoting dynamic hyperinflation. This means 
that tidal volume then oscillates at a stiffer range of the pressure-volume curve ${ }^{33.34}$. Also, the patient must first generate enough inspiratory pressure to overcome the elastic recoil pressure near end-expiration, before inspiration can begin ${ }^{33.3}$. OCB may be further increased by the extra energy needed by the inspiratory muscles, to operate at a more disadvantaged length-tension proportion and for the diaphragm, with a decreased zone of apposition ${ }^{34}$. In addition, activation of expiratory muscles, which also cost energy, has been reported during breathing in patients with $\mathrm{COPD}^{35}$. Unfortunately, this activation of the expiratory muscles probably fails to reduce endexpiratory lung volumes below passive FRC, due to flow limitation ${ }^{33}$.

In shont, it could be hypothesized that in the earlier studies which assessed breathing efficiency in COPD patients and healthy persons $s^{6,5.13 .4}$, increases in ventilation have resulted in dynamic hyperinflation in the patients, which was not incorporated accurately in the calculations of internal and/or external work of breathing. Therefore, the decreased efficiency of breathing found in these earlier studies, may have resulted from an underestimated work of breathing.

The effect of (dynamic) hyperinflation on breathing efficiency has been clemonstrated in two studies in healthy subjects ${ }^{30,32}$. It was shown that breathing at high lung volumes resulted in a significantly lower breathing efficiency, than breathing at lower lung volumes. Furthermore, Weiner et al ${ }^{14}$ showed that efficiency increased in asthmatic patients after inhalation of a $B_{2}$-agonist. The increase in efficiency correlated significantly with the decrease in intrathoracic gas volume after medication ${ }^{14}$.

In the present study, minute ventilation hardly changed during the breathing efficiency test, especially in the patients with COPD. This suggests, although we did not actually measure FRC during the test, that there was no dynamic hyperinflation in the patients of the present study. This is underlined by the finding that breathing efficiency was not related to the difference between loaded/unloaded minute ventilation (Fügure 2), both in the healthy elderly subjects and in the COPD patients.

In the present study there was no correlation found between REE and breathing efficiency in both groups. This confinms the results from the study by Shridhar et al". who also did not find a correlation between OCB and REE in patients with COPD. A drawback of the present study was that the patients (as a group) did not have an increased REE. There was, however, a wide range in REE, suggesting that a relation between breathing efficiency and REE should have been found, if it would have existed. 
The lack of a relation between REE and OCB may be explained by the fact that at rest, the work of breathing is probably low in clinically stable patients with COPD. Although many patients with COPD (as in the present study) demonstrate a chronic hyperinflation at rest, this does not, per se, produce an increase in elastic work of breathing at rest. This was shown in a study by Sharp et al ${ }^{36}$, who demonstrated when patients with COPD breathe near their passive FRC, their elastic work of breathing is normal. In addition, increased static work of breathing at rest in patients with COPD could be caused by intrinsic positive end-expiratory pressure (PEEP-i), but it has been found that in stable patients PEEP-i is low at rest (approximately $\left.2-3 \mathrm{cmH}_{2} \mathrm{O}\right)^{37}$.

In patients with COPD, REE can be increased by approximately 15-20\% 17.18 . which is roughly 200 to $300 \mathrm{kcal} /$ day, or approximately 30 to $40 \mathrm{ml} / \mathrm{min}^{\prime} \mathrm{V}_{2}$. In the present study, a considerable threshold load of $40 \%$ of $\mathrm{Pi}_{-\mathrm{MAX}}$, resulted in an increase of $50 \mathrm{ml} / \mathrm{min} \mathrm{V}^{\prime} \mathrm{O}_{2}$. Therefore, it seems unlikely that the breathing work during a REE measurement is comparable to such a load, even in patients with severe COPD.

Measurement of breathing efficiency is inevitably complicated by a limited accuracy. This is due to the fact that small differences in $\mathrm{V}^{\prime} \mathrm{O}_{2}$ have to be detected. Resting $\mathrm{V}^{\prime} \mathrm{O}_{2}$ can be measured very accurately ${ }^{25}$, but variations of 3 to $5 \%$ are inevitable. If a difference around 40 to $50 \mathrm{ml} / \mathrm{min}$ is to be measured, a variation of 3 $5 \%$ of resting $\mathrm{V}^{\prime} \mathrm{O}_{2}$, suddenly seems very large. This is illustrated by the relationship between breathing efficiency and the difference in loaded/unloaded external work (Figure 2). Although there was no significant correlation, it can be observed that the variation in breathing efficiency is more pronounced at a lower increase in work, than at a greater increase in work. Although this means that the breathing efficiency test camot be used to differentiate between individuals, or to measure subtie changes after an intervention, we believe that comparisons can be made on a group level.

In summary, in this study in which dynamic hyperinflation was likely prevented, patients with clinically stable COPD have a similar breathing efficiency compared with healthy elderly subjects. Breathing efficiency was not related to REE. From the presented calculations, it seems very unlikely that an increased work of breathing at rest is responsible for the increased REE observed in many COPD patients. With respect to the functional performance of patients with COPD, the effect of dynamic hyperinflation on the oxygen cost of breathing is interesting, and remains to be studied. 


\section{References}

1 Decramer M. Demedts M, Rochette F, Billiet L. Maximal transrespiratory pressures in obstnective hung disease. Bull. Eur. Physiopathol. Respir. 1980: 16: 479-90.

2 Tohin MJ. Respiratory muscles in disease. Clin. Chest Med. $1988: 9: 63-86$.

3 Decramer $M$, Gosselink $R$, Derom E. Respiratory muscle mechanics in Chronic Obstructive Pulmonary Disease and acute respiratory failure, In: Lung Biology in health and disease. Ed.: Dereme I, Whitelaw WA, Similowski T. 1996; 92: 47-64.

Similowski T, Yan S, Gauthier AP, Macklem PT, Bellemare Fi. Contractile properties of the human diaphragm during chronic hyperinflation. N. Engl. J. Med. 1991; 325:917-23.

Morrison NJ, Richardson J. Dunn L. Pardy RL. Respiratory muscle performance in normal elderly subjects and patients with COPD. Chest 1989; 95: 90-94.

Cherniack RM. The oxygen consumption and efficiency of the respiratory muscles in health and emphysema. J. Clin. Invest. 1959; 38:494-499.

McGregor M. Becklake MR. The relationship of oxygen cost of breating to respiratory mechanical work and respiratory force. J. Clin. Invest. 1961; 40:971-80.

Levison $H$. Cherniack RM. Ventilatory cost of exercise in chronic obstructive pulmonary disease. J. Appl. Physiol 1968; 25: 21-27.

Donahoe M. Rogers RM. Wilson DO, Pennock BE. Oxygen consunuption of the respiratory muscles in normal and malnourished patients with chronic obstructive pulmonary disease. Am. Rev. Respre. Dis. $1989 ; 140: 385-391$.

10 Mannix ET, Manfredi F, Palange $P$, Dowdeswell JRG. Fraber MO. Oxygen nay lower the oxygen cost of ventilation in Cluronic Obstuctive Lung Disease. Chest 1992: 101: 910-915.

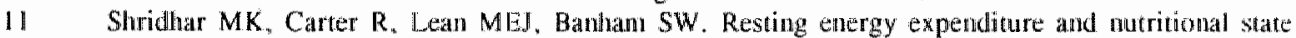
of patients with increased oxygen cost of breathing due to enphysema, scoliosis and thoracoplasty. Thorax 1994: 49: 781-785.

Shindon C. Hida W, Kikuchi $Y$, Taguchi O, Miki H, Takishima T, Shirato K, Oxygen consumption of respiratory muscles in patients with COPD. Chest 1994; 105: 790-797.

Fritts HW, Filler J, Fishman AP, Cournand A. The efficiency of ventilation during volumary hyperpnea: studies in normal subjects and in dyspneic patients with either chronic pulmonary emphysema or obesity. J. Clin, Invest. 1959: 38: 1339-1348. Weiner P. Suo J, Fernandez E. Cherniack RM. The effect of hyperinflation on respiratory muscle strength and efficiency in healthy subjects and patients with Asthma. Am. Rev. Respir. Dis. 1990: 114: $1501-1505$.

Takishima T. Shindoh C. Kikuchi $Y$. Hida W. Inoue $H$. Aging effect on oxygen consumption of respiratory muscles in hunnans. J. Appl. Physiol. 1990; 60: 14-20.

favedd $S$. Danci $S$. Grassino. Respiratory thuscle oxygen consumption estinated by the diaphragm pressure-time index. J. Appl. Pliysiol: Respirat. Emviron. Exercise Plyysiol. 1984: 57: 44-51

Schols AMWJ Fredrix EWHM Soeters PB Westerterp KR Wouters EFM. Resting energy expenditure in patients with chronic obstructive pultnonary disease. An. 1. Clin. Nuir. 1991: $54: 983-987$.

Goldstein S Askanazi J Weissman C Thomashow B Kimey JM. Energy expenditure in patients with chromic obstructive pulmonary disease. Chest 1987: 91: 222-224.

(COPD) intal asthma. Ann. Rev. Respir. Dis. 1987: 137:225-228.

20 Quanjer Ph ed. Standardized lung function testing. Eur. Resp. J. 1993; 6 (suppl. 16): 5-40.

21 Peslin R. Lung nechanics II: Resistance measurements. Bull. Europ. Plysiopath. Resp. 1983. 19 (suppl. 5): 33-38.

22 Black LF, Hyat RE. Maximal respiratory pressures: normal values and relationship uo age and sex. Am. Rev, of Respir. Dis. 1969: 99: 696-702.

23 Lukaski HC, Bonlunchuk WW. Hall CB, Siders WA: Validation of tetrapolar bioclectrical innpedance method to assess hunan hody composition. J. Apl. Plyysiol. 1986; 60: 1327-1332. 
Schols AMWJ, Dingemans ANC, Soeters PB. Wouters EFM: Within day variation of bioulectrica! impedance resistance measurements in patients with chronic obstructive pulmonary disease. Clin. Nurr. 1990; 9, $266-271$.

Sehols AMWJ, Schoffelen PF. Cenlemans H, Wouters EFM, Saris WH. Measurement of REE in patients with COPD in a clinical setting. 1. Parenter. Enter. Nutr. 1992; 16: 364-368. Harris IA \& Benedict FG. A biometric study of basal metabolism hit man. Washington DC: Carnegie institute of Washington, Publication no $279,1919$.

27 Gaesser GA. Brooks GA. Muscular afficiency during steady-nate exercise: effects of speed and work rate. J. Appl. Physiol. 1975: 38: 1132-39.

28 Weir JB. New methods for calculating metabolic rate with special reference to protein metabolism. J. Physiol. 1949: 109: 1-9.

29 Collet PW. Perry C. Engel LA. Pressure-time product, flow, and oxygen cost of breathing of resistive breathing in humans. 1. Appl. Physiol. 1985; 58:1263-72.

30 Collet PW. Engel LA. Influence of hung volume on oxygen cost of resistive breathing. J. Appl. Physiol. 1986: 61: 16-24.

31 Weiner P. Suo J. Fernandez E. Cheniack RM. Efficiency of respiratory nuscles in healthy individuals. Am, Rev. Respir. Dis. 1989; 140: 392-96.

MoCool DF, Tzelepis GE, Leith DE. Hoppin FG. Oxygen cost of breathing during fatiguing inspiratory loads. J. Appl. Physiol. 1989; 66: 2045-55.

33 Younes $M$. Determinants of thoracic excursions during exercise. In: Whipp BJ "Wassemm $K$, eds. Lung biology in healkh and disease. Vol 52: Exercise pulnonary physiology and pathophysiology. New York: Marcel Dekker. 1991: 1-65. ODonnell DE. Webb KA. Exertional breathessness in patients with chronic airflow limitation. The role of lisng liyperinfation. Am. Rev. Respir. Dis. 1993; 148: 1351-7.

Ninane V, Rypens F, Yermalt $\mathbb{J}-\mathrm{C}$, DeTroyer A. Abdonninal muscle use during breathing in patients with chronic obstructive pulmonary disease. Am. Rev. Respir. Dis. 1992: 146:16-21.

Sharp IT, Lith PV. Nucliprayoon CV. Brinev R, Johnson FN. The thotax in chronic obstructive lung disease. An. J. Med. 1968: 44:39-46.

Dal Vechio L. Polese G. Poggi R. Rossi A. "Intrinsic" positive end-expiratory pressure in stable patients with cluronic obstructive pulmonary disewse. Eur. Respir. J. 1990; 3: 74-80. 
CHAPTER 11

\section{GENERAL DISCUSSION}




\section{Introduction}

The research reported in this thesis was directed to body compositional disturbances and effort related energy expenditure in patients with COPD. A disturbed body composition occurs in a substantial proportion of clinically stable patients with COPD $^{12}$. Marked depletion of fat-free mass (FFM) can occur even despite a relatively spared fat mass (FM) ${ }^{1,2}$ (chapter 2). Furthermore, it has been demonstrated that depletion of PFM has important consequences for the clinical condition of patients with COPD. Loss of body weight and/or FFM adversely effects survival ${ }^{3-6}$, and functional performance ${ }^{4 \% 10}$, independently of pulmonary related impairments. In addition, in this thesis it was demonstrated that FFM significantly correlates with maximal, symptom limited, oxygen consumption in patients with COPD, independently of diffusing capacity (chapter 7 ).

The above mentioned relationships clearly imply that measurement of body composition is an indispensable part in the characterization of patients with COPD. The research reported in this thesis suggest that a two compartment model of body composition is generally justified in patients with COPD, since only a selective group of predominantly severely depleted patients expresses a relative expansion of extracellular water (chapter 2). Moreover, the expression of fluid shifts has a negligible influence on peak exercise performance (chapter 7).

Earlier it was demonstrated that, in order to measure FFM or total body water (TBW), bio-electrical impedance analysis (BIA) at $50 \mathrm{kHz}$ represents a non-invasive, practical and valid method in patients with COPD" ${ }^{\prime \prime}$. Theoretically, only at low frequencies an altemating current flows only through the extracellular compartment of TBW, because of the capacitance aspects of cell membranes, and through the intracellular and extracellular component of TBW at higher frequencies. It is generally assumed that the critical frequency at which the current flows through TBW is $50 \mathrm{kHz}$, but it is known now that the current flows predominantly through ECW at $50 \mathrm{kHz}$. Therefore, as a potential improvement of BIA, bio-electrical impedance spectroscopy (BIS) was developed, providing the opportunity to measure total body resistance at a spectrum of frequencies. Subsequently, it should be possible to obtain the resistance of TBW and extracellular water for each individual, using a theoretical model of the electrical properties of the human body. In this thesis it was found that BIS does not (yet) provide a more precise estimation of FFM compared to the estimation of FFM 
using BlA (chapter 3).

\section{Mechanisms associated with a disturbed body composition in patients with COPD}

In general, changes in body composition are explained by a disturbed balance between energy intake and energy expenditure. In COPD, the attention is especially focused on energy expenditure, since earlier studies demonstrated an increased resting energy expenditure (REE) in a substantial part of these patients in clinically stable condition $^{[2-17}$. Three mechanisms have been proposed to explain this increased rate of metabolism at rest.

Firstly, it has been suggested that an increased oxygen cost of breathing (OCB) at rest contributes significantly to an increase in whole-body oxygen consumption at rest. However, as discussed in this thesis (chapter 10), it is unlikely that the work of breathing at rest is increased to such extent, even in patients with severe COPD, that it can explain the relatively large increase in $\mathbb{R E E}$ reported. Moreover, a recent study of Hugli et al. ${ }^{18}$ indicated that at rest the OCB is generally not severely increased in clinically stable patients with COPD.

Secondly, it has been suggested that the rate of metabolism can be enhanced by pharmacological treatment such as theophyllines and $B_{2}$-sympathicomimetics, commonly used by patients with COPD ${ }^{19}$. The thermogenic effect of $B_{2}$-sympathicomimetics reaches a peak after 30 minutes, but declines an stabilizes into an increase of only $5 \%$ of REE after 2 hours ${ }^{19}$. In addition, recently it was observed that theophylline did not induce an acute elevating effect on $\mathrm{REE}^{20}$. Therefore, themogenic effects of bronchodilators cannot be the only explanation for an increased REE in patients with COPD.

A recent study by Schols et al. indicates that the rate of metabolism at rest can be influenced by systemic inflammation. It was shown that an acute phase response was presen in $50 \%$ of patients with an increased REE, as demonstrated by increased Creactive protein (CRP) levels, whereas patients with a normal $R E E$ did not express increased CRP levels in peripheral blood". Increased levels of CRP were in turn associated with elevated levels of inflammatory mediators in peripheral blood such as the soluble Tumor Necrosis Factor (TNF) receptors 55 and $75^{2}$. It is yet unclear whether the increased REE is induced by an increased oxygen consumption of energy metabolizing mass in the whole body, resulting from circulating levels of cytokines in 
the serum, or if the effects of systemic inflammation on REE is mainly due to an enhanced liver metabolism, considering that liver metabolism covers $20 \%$ of REE ${ }^{32}$ and that it represents the organ which is responsible for acute phase protein symhesis.

In this thesis it was observed that total daily energy expenditure (TDE) was increased in patients with COPD, compared to healthy subjects matched for age, sex and body composition (chapter 4). The reported increased energy expenditure implies that, although in general patients with COPD have a comparable dietary intake to healthy subjects ${ }^{23,24}$, weight-losing patients can suffer from relative undernutrition, predominantly caused by an increased TDE.

As discussed in detail earlier (chapter 2), relative undernutrition, or chronic partial starvation, results in a decreased $F M$, combined with a relatively preserved FFM. The fact that patients with COPD can suffer from marked depletion of FFM despite a normal body weight, suggests that next to a relative undernutrition, other mechanisms must be present which cause depletion of FFM.

FFM includes the viscera (liver, kidneys, lungs, gastrointestinal tract), the central nerwous system, peripheral connective tissue (bone, tendon, ect.), extracellular fluids, but the main part consists of muscles. A selective depletion of FFM can therefore involve an enhanced catabolisn of muscle mass, a disturbed synthesis of muscle mass, or a combination of these mechanisms.

Evidence for an increased catabolism in muscle is indirectly indicated by the presence of systemic inflammation in patients with $\mathrm{COPD}^{21}$. In a recent study in animals it was demonstrated that disturbances in muscle structure, a decreased expression of muscle protein (myosin) and a decreased expression of an important modulator of skeletal muscle structure and function (myosin creatinine phosphokinase), were related to TNF $\alpha$ through the presence of oxidative stress ${ }^{25}$. In addition, evidence has been found for a decreased protein synthesis in patients with $\mathrm{COPD}^{26}$, which might be associated with increased catecholamine levels ${ }^{27}$, since these can induce a decreased insulin secretion and therefore suppress protein synthesis.

A recent study indicates that also loss of FM might be only partly the result of an impaired energy balance. In particular hypoxemic patients with COPD demonstrated an increased free fatty acid (FFA) and glycerol concentration after an overnight fast compared to healthy subjects, and also an increased turn over rate of FFA, which suggests an enhanced lipolysis in part of the patients with COPD ${ }^{28}$.

These potential underlying metabolic mechanisms for a decrease in muscle mass 
or FFM indicate that, although the reported increased TDE in patients with COPD (chapter 4) might contribute to a disturbed energy balance, mechanisms such as an altered substrate metabolism, oxidative stress and systemic inflammatory processes are probably important mediators contributing to a disturbed body composition in patients with COPD.

\section{Mechanisms for an increased effort related energy expenditure in COPD}

The observed increased TDE represents an important feature in patients with COPD, although it does not necessarily lead to a disturbed body composition, since the data reported in this thesis indicate that supposed submaximal (daily) activities induce an on-going, relatively high metabolic and ventilatory stress.

It was demonstrated that TDE was increased in patients with COPD compared to healthy subjects, matched for age, sex and body weight. In addition, since REE was comparable between patients and control subjects and activity level also seemed similar, it was discussed that especially activity related energy expenditure might be increased in the patients with COPD (chapter 4). Furthermore, it was demonstrated that the variation in TDE is not related to REE in patients with COPD when the relationship between FFM with both REE and TDE is taken into account, providing additional evidence that especially the energy expenditure for activities determines the variation of TDE in patients with COPD (chapter 5). In addition, it was demonstrated that supposed submaximal activities like the 12 minute walking test (chapter 6) and cycle ergometry exercise at $50 \%$ of the achieved peak load (chapter 8), represent a high metabolic and ventilatory stress in patients with COPD. An inefficient metabolic response to exercise is confirmed by a recent study of Palange et al ${ }^{29}$, that also demonstrated a decreased work efficiency during submaximal exercise in patients with COPD. In the latter study ${ }^{29}$, analysis of the kinetics of the metabolic response to exercise revealed that patients with COPD demonstrated a greater oxygen deficit during exercise, resulting from a sluggish $\mathrm{V}^{\prime} \mathrm{O}_{2}$-onset. In this thesis similar results were found with respect to the kinetics of metabolism during static arm exercise (chapter 9),

It is difficult to explain the increased effort related energy expenditure in patients with COPD, since limited studies investigated disturbances in metabolism during exercise in these patients. Part of an increase in oxygen consumption could be related to an inefficient ventilation. In this thesis it was found that at rest, patients with COPD 
express a comparable breathing efficiency to healthy elderly subjects, under the circumstance that dynamic hyperinflation is likely prevented (chapter 10). However "in the case of increased ventilatory demand, such as during exercise, dynamic hyperinflation often occurs in patients with COPD (chapter 1). It could therefore be suggested that an increased oxygen cost of breathing during exercise contributes to an increased energy expenditure during exercise (chapter 8). On the other hand, it is unllikely that the oxygen cost of breathing is the only explanation for the observed relatively high metabolic stress during exercise.

Energy derived from nutrients is harvested and funneled through the energy-rich compound adenosine triphosphate (ATP). The potential energy within the ATP molecuIe is utilized for all the energy-requiring processes of the cell. Several studies indicate that patients with COPD demonstrate disturbances in the metabolism of high energy phosphate compounds at rest. In two studies, patients with COPD demonstrated lower concentrations of ATP and creatine phosphate (CrP) at rest compared to healthy subjects, as measured in quadriceps femoris muscle biopsies ${ }^{30.31}$. Recently, it was found that patients with COPD expressed decreased ATP/adenosine diphosphate and $\mathrm{CrP} / \mathrm{cre}$ atine ratios in a tibialis anterior muscle biopsy taken at rest compared to healthy elderly subjects $^{32}$. Furthermore, in the latter study, inosine monophosphate could be detected in the resting muscle of a substantial part of patients with COPD, which indicates an imbalance between utilization and resynthesis of ATP in the resting muscle of these patients $^{32}$. In addition to evidence for disturbances in the metabolism of high energy phosphate compounds, recent studies have demonstrated a decreased oxidative enzyme activity and enhanced glycolytic enzyme activity in muscle biopsies taken at rest in patients with $\mathrm{COPD}^{33.34}$. Taken together, these studies indicate a shift from aerobic to an enhanced anatrobic ATP production in the muscle metabolism of patients with COPD.

Limited investigations have related metabolic characteristics measured at rest or changes in metabolism to functional performance or metabolism during exercise. In a study of Maltais et al. ${ }^{34}$, it was shown that a steep increase in lactic acid during incremental exercise in patients with COPD was associated with decreased activity of oxidative enzymes, measured in the resting muscle ${ }^{34}$. Furthermore, it was demonstrated that exercise training did not only result in an increased functional performance, but also in an increase in the activity of oxidative enzymes measured in the resting muscle ${ }^{35}$. In the present thesis it was suggested that severe depletion of FFM might be 
related to a relatively early anaerobic metabolism during peak exercise (chapter 7).

It seems inevitable, however, that altered metabolic pathways for the production of ATP at rest in patients with COPD, result in changes in metabolic pathways for the production of ATP under the circumstance of an increased energy demand, such as exercise. This is confirmed by recent studies, demonstrating a disturbed metabolism of high energy phosphate compounds during exercise in patients with COPD, using "1Pmagnetic resonance (MRS) techniques. In particular hypoxemic patients with COPD demonstrated a decreased aerobic ATP production during exercise, associated with an increased anaerobic ATP production ${ }^{36}$. In addition, several investigations demonstrated that patients with COPD express intracellular acidosis during (light) exercise, likely resulting from an increased glycolytic ATP production ${ }^{37.38}$. Furthermore, it was shown that patients with COPD demonstrate a decreased ratio $\mathrm{PCr} / \mathrm{PCr}+$ inorganic phosphate during light exercise, whereas this is not the case in healthy controls. Finally, it was suggested in these studies that anaerobic ATP production is switched on early in exercise in patients with COPD compared to healthy controls ${ }^{37.38}$. In a recent study of Evans et al. ${ }^{39}$, the considerable impact of these metabolic disturbances was demonstrated. After lung transplantation, patients with pulmonary diseases, including COPD, still suffered from a marked decreased peak exercise performance. This could not be totally explained by a lack of ventilatory improvement, suggesting a persistence of a reduced potential for oxidative utilization in peripheral muscles. This suggestion was based upon the observation of an early intracellular acidosis during exercise in the patients after transplantation.

In summary, these studies indicate a severely impaired oxidative phosphorylation during exercise in COPD, accompanied by an increased and early anaerobic metabolism involving both the energy release from high energy phosphate compounds, as well as an enhanced glycolysis. It is generally known that anaerobic metabolism is inefficient compared to aerobic metabolism ${ }^{40}$. Assuming that a human being requires approximately its own body weight ATP a day. which is exclusively provided by the complete oxidation of glucose, than $650 \mathrm{~g}$ glucose would be sufficient for the production of $70 \mathrm{~kg} \mathrm{ATP}$, whereas if giucose was catabolized anaerobically, $13 \mathrm{~kg}$ glucose would have been needed for the same ATP production. The enhanced glycolysis results in production of lactate, which is not only responsible for the receival of hydrogen ions in order to facilitate further glycolysis, but represents also a metabolite which can be oxidized further by means of gluconeogenesis (Cori cycle) or by the Krebs cycle. 
Furthermore, it is generally considered that an imbalance between ATP production and ATP utilization represents an extra stimulus for the mitochondrial production of ATP ${ }^{4}$. Hypothetically, oxidation of lactate as well as an enhanced mitochondrial ATP production (possibly in non-exercising muscle or the liver), or maybe a waste of energy resulting from disturbances in metabolic pathways, could be explanations for the relatively high oxygen uptake during submaximal activities, such as reponted in this thesis.

The underlying mechanisms for a disturbed metabolism during exercise are not clear yet, however. Many factors such as an increased ventilatory demand, hypoxia, catecholamines, medication, inactivity, systemic inflammation, changes in the muscle structure, or depletion of FFM might contribute to changes in metabolism during exercise. In clinical investigations it is difficult to unravel which factors are most important, because often most elements co-exist. In this thesis a decreased efficiency of submaximal exercise was unrelated to REE or other measurements performed at rest such as pulmonary function or FFM (chapter 8).

\section{Implications for future treatment and future investigations}

It can be expected that patients with different rates of metabolism during exercise, will respond in different ways to exercise training or other anabolic stimuli. When these characteristics are not assessed and training is not adjusted to the metabolic stress of exercise, it is not surprising that some exercise training regimens have resulted in only limited functional improvements ${ }^{42.43}$

In order to further adjust treatment to the metabolic disturbance in patients with COPD, much unsolved issues need to be investigated. In particular, possible changes in substrate metabolism in the muscle at rest, as well as during exercise, need to be studied further, in relation to underlying pathophysiological mechanisms. It should be elucidated which factors, like the use of metabolically interfering drugs, ventilatory requirements, hypoxia and quality or quantity of muscle influence ATP and substrate metabolism. These investigations might provide a foundation for treatment strategies and for the characterization of patients who respond differently to exercise.

Furthermore, it should be examined how and if these specific changes in muscle metabolism are related to (a selective) depletion of FFM.

These investigations may provide tools to adapt intervening strategies directed to 
different aspects of the metabolic disturbance in COPD. With respect to FFM depletion, intervention should not only be focused on improving energy balance, but also on influencing systemic inflammation and/or the possibly accompanying oxidative stress. In addition, protein synthesis might be influenced by anabolic agents.

With respect to a decreased mechanical efficiency of activities, or an increased effort related energy expenditure, intervention should be focused on underlying mechanisms. Current research suggests intervening strategies aimed to decrease dynamic hyperinflation, as well as strategies to influence muscle metabolism.

\section{References}

Schols AMWJ. Soeters PB. Dingemans ANC. Mostert R, Frantzen PJ, Wouters EFM: Prevalence and characteristics of mutritiomal depletion in patients with COPD egligble for pulmonary rehabilitation. Am. Rev. of Resp. Dis. 1993; 147; 1151-1156.

2 Engelen MPKJ, Schols AMWJ. Baken WC. Wesseling GI, Wouters EFM. Nutritional depletion in relation to respiratory and peripheral skeletal muscle function in out-patients with COPD. Eur. Respir. J. $1994 ; 7 ; 1793-1797$.

3 Vandenhergh $E$, Van de Woestijne $K$, Gyselen $A$. Weight changes in the terminal stages of chronic obstructive lung disease. An. Rev. Respir. Dis. 1967; 95:556-66. Wilson DO, Rogers RM, Wright E, Anthonisen NR. Body weight in chronic obstructive pulmonary disease. Am. Rev. Respir. Diss. 1989: 139: 1435 8.

5 Gray-donald K, Gibbons L. Shapiro SH, Macklem. PT, Martin lG. Nutritionall status and morkality in chronic obstructive pulnonary disease. Am. J. Respir. Crit. Care Med. 1996; 153: 1961-6.

6 Schols AMWJ, Slangen J, Volovics A, Wouters EFM. Body weight and survival in COPD. Am. J. Respir. Crit. Care Med. 1996; 153: A 452 (abstract).

7 Gray-Donald K, Gibbons L. Shapiro SH, Martin JG. Effect of nutritional status on exereise performance in parients with chronic obstrucive pulmonary disease. Am. Rew. Respir. Dis. 1989; 140: 1544 1548 .

Palange P. Forte S, Felli A. Galassetti P. Serra P, Carlone S. Nutritional state and exercise tolerance in patients with COPD. Chest 1995; 107: 1206-12.

9 Gosselink R. Troosters T. Decraner M. Peripheral musele weakness contributes to exemeise linitation in COPD. An. J. Respir. Cril Care Med. 1996:153:976-980.

Schols AMWJ. Mostert R. Soeters PB. Wouters EFM. Body composition and exercise perfommance int pothents with chrondic obstructive pulmonary disease. Thorax 1991: 46: 695-699.

11 Schols AMWJ, Wouters ERM, Soeters PB. Westerterp KR. Body composition by bioelectrical inmedance analysis compared with devterium dilution and skinfold anthropometry in patients with chronic obstructive pulmonary disease. AM. J. Clin. Nutr. 1991: 53:421-4.

Schols AMWJ. Soeters PB, Saris WHM, Wouters EFM. Energy balance in patients with chronic obstructive pulmonary disease. Am. Rev. Respir. Dis. 1991: 143: 1248 - 1252 .

13 Schols AMWJ. Fredrix WWHM, Soeters PB. Westerterp KR, Wouters EFM. Resting wergy expenditure in patients with chronic obstructive pulmonary disedse. Am. $\$$. Clin. Nuttr. 1991; 54: $983-7$.

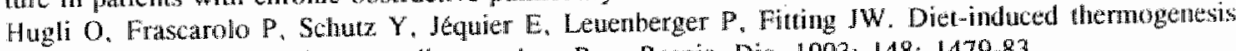
in chronic obstructive pulmonary disease. An. Rev. Respir. Diss, 1993; 148: 1479-83. Fining IW. Fiacarolo $P$. Jequier E, Leuenberger $P$. Energy expendiure and rib cage abdominal nonion in chronic obstructive pulmonary disease. Eur. Respir. 11. 1989; $2 ; 840-45$. Donalioe M, Rogers RM, Wilson DO, Pennock BE. Oxygen consumption of the respiratory muscles in mormal and in malnourished patients with chronic obstructive pulmonary disease. Au. Rev. Respir. Dis. 1989: 140: $385-91$. 
17 Gren $J H$. Muers MF. The thermic effects of food in underweight patients with emphysematous chronic obstructive pulmonary disease. Eur. Respir. I. 1991: 4: 813-9.

18 Hugli $O$, Schutz $Y$. Fitting JW. The cost of breathing in stable chronic obstructive pulmonary disease. Clinical science. 1995; 89:625-632.

19 Burdet L, Muralt de B, Schutz Y. Fitting JW. Thermogenic effects of bronchodilators in patients witl chronic obstructive pulmonary disease. Thorax $1997: 52: 130-5$.

20 Mosier K. Renvall MJ. Ramsdell JW, Spindler AA. The effect of theophylline on metabolic rate in chronic obstructive lung disease pattients. J. Am. Coll. Nutr. 1996; 15: 403-407.

21 Schơls AMWJ, Buuman WA, Staal-van den Brekel AJ, Dentener MA. Wouters EFM. Evidence for a relation between merabolic derangements and increased levels of inflammatory nuediators in a subgroup of patients with chronic obstructive pulmonary disease. Thorax 1996: $51: 819-824$.

22 Elia $M$. Organ and tissue contribution to metabolic rate. In: Energy metabolism. Tissue determinants and cellular corollaries. Eds. Kinney JM and Tucker HN. Raven Press. New York. 1992.

23 Hunter AMB, Carey MA, Larsh HW. The nutritional status of patients with chronic obstructive pulmonary disease. Am. Rev. Respir. Dis. 1981: 124: 376-81.

24 Schols AMWJ, Soeters PB. Saris WHM, Wouters EFM. Energy balance in patients with chronic obstructive pulmonary disease. Am. Rev. Respir. Dis. 1991: 143: 1248-1252.

25 Buck $M$, Chojkier $M$. Muscle wasting and dedifferentiation induced by oxidative stress in a murine model of cachexia is prevented by inhubitors of nitric oxide synthesis and antioxidants. The EMBO journal. 1996; 15: 1753 65.

26 Morrison WL, Gibson JNA, Scrimgeour C. Rennie MJ. Musele wasting in emphysena. Clinical Science 1988: 75: 415-20.

27 Hofford JM. Milakofiky L. Vogel WH. Sacher RS. Savage GI, Pell S. The nutritional status in advanced enphysema associated with chronic bronchitis. A study of annino acid and catecholanine levels. Am. Rev. Respir. Dis. 1990; 141: 902-8.

28 Jacobbson $P$, Jorfeldt $L$. Schenk won $H$. Fat metabolism and its response to infusion of insulin and glucose in patients with advanced chronic obstructive pulmonary disease. Clin. Phissiol. 1995: 15: 310 29.

29 Palange P. Galassetti P. Mannix ET. Farber MO, Manfredi F. Serra P. Carlone S. Oxygen effect on $\mathrm{O}_{2}$-deficit and $\mathrm{V}^{\prime} \mathrm{O}_{2}$-kinetics during exercise in obstructive pulmonary disease. J. Appl. Physiol. 1995; 78: 2228-2234.

30 Gertz I, Hedenstierna $G$, Hellers $G$. Walhren $J$. Muscle netabolism in patients with chronic obstructive lung disease and acute respiratory failure. Cli. Sci.\& Mol. Med. 1977; 52: 395-403.

31 Fiaccadori E. Canale Del S, Vitali P. Coffrini E. Ronda N, Guariglia A. Skeletal muscle energetics, acid-base equilibrium and lactae metabolism in patients with severe thypercapnia and hypoxemia. Chest 1987; $92: 883-887$.

32 Pouw EM, Schols AMWJ, Vusse van der GJ. Wouters EFM. Muscle adenine nucleoride status in COPD. Am, J. Respir, Crit. Care Med. 1996, 153: A 453 (abstraci).

33 Jakobsson P. Jorfeldt L. Henriksson J. Metabolic enzyme activity in the quadriceps fenoris nuscle in patients with severe chronic obstructive pulmonary disease. Am. J. Respir. Crit. Care Med. 1995: I51: 374-377.

34 Mattais F, Simard A, Simard C, Jobin $\int$, Descagnés P. LeBlanc P. Oxidative capacity of the skeletal muscle and lactic acid kinetics during exercise in normal subjects and in patients with COPD. Am. I. Respir. Crit. Care Med. 1996: 153: 288-293.

35 Maltais F. Leblanc P. Simard C. Jobin J. Bérubé C, Bruneau J, Carrier L. Belleau R. Skeletal muscle addaptation to endurance training in patienss with chronic obstructive pulnonary disease. Am. I. Respir. Crit. Care Med. 1996; 154: 442-7.

Mannix ET. Boska MD, Galasseti P. Burton $G$, Manfredi F. Farher MO. Modulationl of ATP production by oxygen in obstructive lung disease as assessed by ${ }^{31}$ P-MRS. J. Appl. Physiol. 1995; 78 : 2218-27.

Kutsuzawa T, Shioya S. Kurita D, Haida M, Ohta $Y$, Yamabayashi H. "sp-MRS study of sketetal muscle metaholism in patienis with chronic respiratory impairment. Am. Rev. Respir. Dis. 1992; 146: 1019-24.

38 Thompson CH. Davies RJO, Kemp GJ. Taylor DJ, Radda GK, Rajagopalan B. Skelletal nuscle netabolism during exercise and recovery in patients with respiratory failure. Thorax 1993; 48: 486-90. 
39 Exans AB, Al-Himyary AJ. Hrovat MI, Pappagianopoulos P, Wain JC. Gims LC, Systrom DM. Abnormal skeletal oxidative capacity after lung transplantation by " ${ }^{3}$.MRS. Am. I. Respir. Crit. Car: Med. 1997; 155: 615-21.

40 Shephard RJ. Efficiency of muscular work. Some elinical implications. Physical Therapy 1975: 55: 476-48I.

41 Brown GC. Control of respiration and ATP synthesis in mammaliam mitochondria and cells. Biochem. I. $1992 ; 284: 1-13$.

42 Lacasse Y, Wong E, Guyatt GH, King D, Cook DJ. Goldstein RS. Meta-anallysis of respiratory rehabilitation in chronic obstructive pulmonary disease. The Lancet 1996; 348: 1115-9.

43 Albert RK. Is pulmonary rehabilitation an effective treatment for chronic obstructive pulmonary disease? No. An. J Respir. Crit. Care Med. 1997; 135: 784-785. 


\begin{tabular}{|c|c|c|c|}
\hline $\mathrm{ADL}$ & Activities of daily living & ${ }^{8} \mathrm{O}$ & "Oxygen ion \\
\hline $\mathrm{AE}$ & Arm ellevation & OCB & Oxygen cost of breathing \\
\hline ATP & Adenosine tri phosphate & $\rho$ & Resistivity of water \\
\hline $\mathrm{BCM}$ & Body cell mass & $P i_{\text {MAX }}$ & Maximal inspiratory pressure \\
\hline $\mathrm{BF}$ & Breathing frequency & $P \mathrm{e}_{\operatorname{MAX}}$ & Maximal expiratory pressure \\
\hline BIA & Bio-electrical impedance analysis & $\mathrm{PaCO}_{2}$ & Arterial pressure of carbon \\
\hline \multirow[t]{2}{*}{ BIS } & Bio-electrical impedance & & dioxide \\
\hline & spectroscopy & $\mathrm{PaO}_{2}$ & Arterial pressure of oxygen \\
\hline BMI & Body mass index & $\mathrm{PA}-\mathrm{Q}$ & Zutphen physical activity \\
\hline $\mathrm{Br}$ & Bromide & & questionnaire \\
\hline CBS & Corrected bromide space & $\mathbf{R}$ & Resistance \\
\hline $\mathrm{CE}$ & Incremental cyele ergometry test & $\mathrm{R}_{\mathrm{aw}}$ & Airways resistance \\
\hline \multirow[t]{2}{*}{ COPD } & Chronic Obstructive Pulmonary & Recw & Resistance of $\mathbb{E C W}$ \\
\hline & Disease & REE & Resting energy expenditure \\
\hline $\mathrm{CO}_{2}$ & Carbon dioxide & RI & Resistivity index \\
\hline CRP & C-reactive protein & Ricw & Resistance of ICW \\
\hline DIT & Diet induced thermogenesis & RQ & Respiratory quotient \\
\hline \multirow[t]{2}{*}{$\mathrm{DL}_{\mathrm{C}}$} & Diffusing capacity for carbon & Rtbw & Resistance of TBW \\
\hline & monoxide & $\mathrm{SaO}_{2}$ & Arterial oxygen saturation \\
\hline $\mathrm{D}_{2} \mathrm{O}$ & Deuterium labeled water & $\mathrm{StO}_{2}$ & Transcutaneous oxygen \\
\hline ECW & Extracellular water & & saturation \\
\hline \multirow[t]{2}{*}{$\mathrm{FEV}_{1}$} & Forced expiratory volume in I & TBW & Total body water \\
\hline & second & TDE & Total daily energy expenditure \\
\hline FFM & Fat-free mass & Ti/Ttot & Inspiratory time divided by the \\
\hline$F M$ & Fat mass & & iotal cycle time \\
\hline $\mathrm{FRC}$ & Functional residual capacity & TLC & Total lung capacity \\
\hline $\mathrm{FVC}$ & Forced vital capacity & TNF & Tumor necrosis factor \\
\hline $2 \mathrm{H}$ & "Hydrogen ion & VAS & $V$ isual analogue scale \\
\hline$H R$ & Heart rate & $\mathrm{V}^{\prime} \mathrm{CO}_{2}$ & Carbon dioxide production \\
\hline$\sqrt{C W}$ & Intracellular water & $V^{\prime} E$ & Minute ventilation \\
\hline ITGV & Intrathoracic gas volume & $V^{\prime \prime}$ & Inspiratory minute ventilation \\
\hline IVC & Inspiratory vital capacity & $\mathrm{V}^{\circ} \mathrm{O}_{2}$ & Oxygen consumption \\
\hline \multirow[t]{3}{*}{$\mathbb{K}_{i \cdots,}$} & Ditfusing capacity for carbon & $\mathrm{v}_{\mathrm{r}}$ & Tidal volume \\
\hline & monoxide corrected for the & WT & 12 Minute walking test \\
\hline & alverilar space & $x$ & Reactance \\
\hline Liat & Lactate & $Z$ & Impedance \\
\hline$M \| P$ & Mean inspiratory pressure & & \\
\hline $\mathrm{NaBr}$ & Sodium-bromide & & \\
\hline NS & Not significant & & \\
\hline
\end{tabular}


This thesis describes derangements in body composition and energy expenditure in relation to exercise impairment in patients with Chronic Obstructive Pulmonary Disease (COPD).

Body composition can be presented by a two-compartment model: fat mass (FM) and fat-free mass (FFM). Previously it was shown that patients with COPD can suffer from FFM depletion, even despite a normal body weight. FFM can be further subdivided into the intracellular compartment and the extracellular compartment. It is generally assumed that $73 \%$ of FFM consists of water: Total body water (TBW), which can be similarly divided into intracellular water (ICW) and extracellular water (ECW).

In chronic diseases associated with weight loss, there is limited information concerning the changes in the intracellular and extracellular compartments. In order to analyse possible changes in body-water compartments in relation to tissue depletion in patients with COPD, TBW and ECW were measured using respectively deuterium and bromide dilution methods in chapter 2. It was shown that fluid shifts (an altered ratio ECW/ICW) were not related to a decreased body weight. In contrast, when patients were differentiated by FFM, it was demonstrated that fluid shifts particularly occured in patients with COPD and extreme depletion of FFM. From this study it was concluded that, on the one hand, patients with COPD demonstrate alterations in bodycomposition comparable to those after chronic partial starvation, since there was only a relative expansion of $\mathrm{ECW}$. On the other hand, this study confirmed the earlier observation that patients with COPD can suffer from FFM depletion, without a decrease in FM, which suggests that other factors than a decreased energy intake must contribute to FFM depletion in COPD.

The measurement of TBW and ECW by dilution techniques such as used in chapter 2 requires sophisticated equipment, which is therefore not readily applicable in clinical practice. Earlier it was shown that bio-electrical impedance analysis (BIA) at $50 \mathrm{kHz}$ represents a simple, practical, convenient and valid method to predict TBW, or FFM, in patients with COPD. The impedance (reactance and resistance) of an altemating current applied to the body is dependent on the frequency of the current. The current will flow only through ECW at low frequencies because the capacitant effect of cell membrames is thought to be bypassed, and at high frequencies the current will flow through TBW, because the capacitant effects are diminished to insignificant values resulting from the speed of charge and discharge of the 
capacitants. Using a theoretical model concerning the electrical propenies of the human body, the resistance of TBW and ECW can be calculated for each individual when the impedance of alternating currents at a range of frequencies (from low to high) is measured: bio-electrical spectroscopy (BIS). The measurement of the resistance at $50 \mathrm{kHL}$ is theoretically suboptimal for the prediction of TBW, because the current does not flow completely through TBW. In chapter 3 it was demonstrated that BIS prowided an accurate estimate of TBW, but it was also found that it: represented no improvement of the prediction of TBW using BLA at $50 \mathrm{kHz}$. Predicted $\mathbb{E C W}$, using BIS, was not significantly different from measured $\mathbb{E} C W$, but the individual differences between measured and actual ECW were relatively llarge, and also the correlation between predicted and actual ECW was low. In addition, it was not possible to obtain a reliable estimate of fluid shifts (ratio ECW/TBW). It was therefore concluded that the underlying theories and/or calculations involved in BIS, need to be improved in order to obtain a reliable estimate of fluid shifts by BIS in patients with COPD.

The observed changes in body weight or FFM in patients with COPD appear to be related with changes in energy expenditure. In earlier studies it was found that many patients with COPD demonstrate an increased resting energy expenditure (REE). In sedentary subjects, REE represents the main part of total daily energy expenditure (TDE). The remaining components of TDE are the diet induced therrmogenesis (DIT) and the energy expenditure for activities, which is the most variable component. Untill now, no information was availlable concerning the TDE of patients with COPD in free living conditions. In chapter $\mathbf{4}$ it was shown that the TDE of clinically stable patients with severe COPD was significantly higher than the TDE of independently living healthy subjects. Since REE was comparable between the groups of this sudy, the difference in TDE could be attributed to an increase in the non-resting component of TDE, which mainly represents the energy expenditure for activities.

In chapter 5 the influence of an increased REE on TDE was investigated in 20 clinically stable patients with COPD. It was shown that, when the influence of FFM on both REE and TDE was accounted for, REE was not related to TDE in patients with COPD. Combining the results of these two studies, it can be concluded that TDE is increased in patients with COPD, independently of REE. Therefore, probably predominantly the energy expenditure for activities is enhanced. Possible factors contributing to an increased TDE are the use of metabolic stimulating medication. allered muscle metabolism, a (chronic) inflammatory state, and an increased oxygen cost of breathing. Although in both studies energy expenditure for activities and 
activity level were measured indirectly; these studies lead to the Iypothesis that patients with COPD might express a decreased efficiency of energy expenditure during activities.

In chapter 6 the physiological consequences of the 12 minute walking test was comprehensively analyzed. The 12 minute walking test is developed to quantify the effects of disease on exercise capacity and daily functional capacity, and has since been used extensively in pulmonary rehabilitation. However, contradictory opinions were reported about the physiological load this test evokes in COPD, i. e. whether this test is submaximal. Therefore, the metabolic and ventilatory consequences during the 12 minute walking test in patients with COPD were compared with their physiological response of an incremental cycle ergometry test. There was no significant difference between these tests, except for an increased carbon dioxide production, lactate concentration and respiratory quotient during cycle ergometry. The results of this study suggested that the 12 minute walking test represent a relatively high, continual (from 4 to 12 minutes), metabolic and ventilatory stress in COPD, associated with anaerobic metabolism and marked desaturation.

In the next study (chapter 7) the relationship between maximal, symptom limited, metabolic response during cycle ergometry exercise in patients with COPD and measurements of pulmonary function and body composition was examined. It was demonstrated that FFM-index (= FFM adjusted for body height) correlated best with the peak oxygen consumption. The relationship between FFM-index and peak oxygen consumption was independent of diffusion capacity. In addition, the results of this study suggested that patients with FFM depletion express a different response to peak exercise than patients without FFM depletion with respect to the tidal volume, anaerobic metabolism and the cardiac response to peak exercise.

In the final part three studies investigating the physiological response to activities are described, in order to examine the efficiency of converting energy into activities in patients with COPD. In chapter 8 the mechanical efficiency of a submaximal cycle exercise is examined. Mechanical efficiency represents the proportion between delivered work, and the energy needed to conduct this work. It can be calculated by measuring energy expenditure during submaximal cycle ergometry. It was demonstrated that the efficiency of cycle ergometry was considerably lower in patients with COPD than theoretically expected. When the patients were differentiated into two groups with a low or normal mechanical efficiency, it was demonstrated that there was no difference in pulmonary function (except for airway resistance), body composition, peak exercise capacity or REE 
between the patients of those two groups. It was concluded that an enhanced ventilatory response and increased oxygen consumption for ventilation probably contributed to the disproportionate energy expenditure for the submaximal load, but that other possible causes, such as for instance metabolic stimulating medication, remain to be studied.

In a subsequent study, indirect evidence was found for a decreased efficiency of unsupported arm exercise (which resembles arm movement during average daily activities). In chapter 9 it was demonstrated that a simple arm elevation resulted in a clearly different (inefficient) metabolic and ventilatory response pattern in COPD patients compared to healthy elderly subjects. Patients with COPD expressed a sluggish onset of metabolism and ventilation and a slow recovery after 2 minutes of arm elevation, whereas the healthy subjects demonstrated a sudden short peak after arm elevation. In addition, when adjusted for the increased baseline test results in the patients with COPD, arm elevation in COPD tended to result in a greater metabolic and ventilatory response than the response of healthy elderly subjects. Factors contributing to the inefficient response are the clual demand on the shoulder girdle muscles for breathing as well as arm-activity in COPD, and/or a decreased breathing efficiency. It is known that patients with COPD specifically complain of dyspnea during daily arm-activities, which might be partly explained by the observed inefficient metabolic response pattern to arm-activity.

Fimally, in chapter 10 the potential role of breathing efficiency in the observed enhanced energy expenditure in patients with COPD was discussed. Breathing efficiency was calculated as the proportional increase in energy expenditure for an increase in external work of breathing. External work of breathing was increased using an inspiratory threshold. The patients were instructed not to increase minute ventilation during the test, in order to prevent dynamic hyperinflacion. Dynamic hyperinflation leads to an increased work of breathing, and in turn to a disproportionate oxygen cost of breathing. The fact that breathing efficiency was comparable between patients with COPD and healthy elderly, could therefore possibly predominantly be explained by the prevention of dynamic hyperinflation in this study. In addition. breathing efficiency did not correlate significantly to REE.

In conclusion, the summarized studies suggest that total daily energy expenditure is enhanced in patients with COPD, particularly the energy expenditure during activities. Hypermetabolism contributes to a negative energy balance in patients with COPD, which can result in weight loss and ultimately in depletion of FFM. Depletion of FFM is negatively related to functional performance, independently of 
pulmonary function impairment. Therelore, a combined treatinem approach consisting of training and nutrition is important in patients with COPD and weight loss or depletion of FFM. 
In dit proefschrift worden stoornissen beschreven in het energieverbruik en de lichaamssamenstelling bij patiënten met chronisch obstructieve longziekten (COPD), alsmede de relatie tussen deze stoornissen en de beperkte mogelijkheden tor inspanning.

Het lichaamsgewicht kan onderverdeeld worden in twee componenten: de vetmassa (FM) en de vet-vrije massa (FFM). In eerder onderzoek is aangetoond dat bij patiënten met COPD depletie van FFM kan optreden, ondanks een normaal lichaamsgewicht. De FFM kan verder worden onderverdeeld in een intracellulaire en een extracellulaire component. Algemeen wordt aangenomen dat de FFM voor $73 \%$ uit water bestaat: het totale lichaamswater (TBW), dat op vergelijkbare wijze kan worden onderverdeeld in intracellulair water (ICW), en extracellulair water (ECW).

$\mathrm{Er}$ is slechts beperkt onderzoek verricht naar de veranderingen in de intracellulaire en extracellulaire componenten bij chronische ziekten, die gepaard gaan met gewichtsverlies. In hoofdstuk 2 zijn het TBW en ECW gemeten met behulp van verdunnings-technieken om mogelijke veranderingen in de lichaamswater-componenten ten opzichte van de depletie van weefsel te bestuderen bij patiënten met COPD. Er werd aangetoond dat vocht-verschuivingen (veranderingen in de verhouding tussen ECW en ICW) niet samenhangen met de factor gewicht. Wanneer de patiënten daarentegen onderverdeeld werden op basis van FFM-depletie, werd duidelijk dat vocht-verschuivingen met name optraden bij patiènten met een ernstige FFM-depletie. De conclusie van deze studie was enerzijds dat de verandering in lichaamssamenstelling bij patiënten met COPD vergelijkbaar was met de verandering die optreedt na gedeeltelijke ondervoeding, ondat er alleen een relatieve toename in ECW gevonden werd. Anderzijds bevestigde zij de eerdere bevinding dat patiënten met COPD depletie van FFM kunnen hebben, zonder een afname in FM, wat betekent dat het onwaarschijnlijk is dat een afgenomen energie-inname de enige oorzaak is van FFM-depletie.

Voor het meten van het TBW en ECW door middel van verdunnings-technieken, als genoemd in hoofdstuk 2 , is speciale apparatuur nodig. waardoor de meting klinisch niet uitvoerbaar is. In eerder onderzoek werd aangetoond dat bio-elektrische impedantie-analyse (BIA) bij $50 \mathrm{kHz}$ een eenvoudige, practische, geschikte en valide methode is om het TBW, of de FFM, te bepalen bij patiënten met COPD. De mate van impedantie (weerstand en reactantie) van een wisselstroom die door het lichaam wordt gevoerd, is afhankelijk van de frequentie van de wisselstroom. Bij lage 
frequenties zal de stroom alleen door het ECW gaan, omdat er van uitgegaan wordt dat dan aain de isolerende effecten van celmembranen voorbij gegaan wordt. Bij hoge frequenties zal de stroom door het TBW gaan, omdat de isolerende effecten afgenomen zijn vanwege de snelheid van opladen en ontladen. De weerstand van het ECW en TBW kan voor ieder individu worden uitgerekend nadat de impedantie van wisselstromen met variërende frequenties (van laag naar hoog: bio-electrische impedantie spectroscopie (BIS)) gemeten is. Hiervoor wordt gebruik gemaakt van een theoretisch model met betrekking tot de electrische eigenschappen van het lichaam. Het meten van de weerstand bij $50 \mathrm{kHz}$ zou uit theoretisch oogpunt minder optimaal zijn om het TBW te voorspellen, omdat de stroom dan niet volledig door het TBW gaat.

In hoofdstuk 3 is beschreven dat de BIS een nauwkeurige voorspelling van het TBW oplevert, maar dat deze voorspelde TBW niet beter is dan de voorspelde TBW door middel van de BIA. Er was geen significant verschil tussen het voorspelde ECW door middel van de BIS en het werkellijke ECW, maar de individuele verschillen tussen het voorspelde en het werkelijke ECW waren relatief groot. Er was tevens een zwakke correlatie tussen beide. Daarbij was het niet mogelijk om vocht-verschuivingen (verhouding ECW/TBW) nauwkeurig te voorspellen. De conclusie was dan ook dat de onderliggende theoriëen en/of berekeningen die nodig zijn voor de BIS, verbeterd moeten worden om een betrouwbare schatting te kunnen maken van vochtverschuivingen bij patiënten met COPD.

De veranderingen in het lichaamsgewicht en de FFM die optreden bij patiënten met COPD blijken samen te hangen met veranderingen in het energieverbruik. In eerder onderzoek is aangetoond dat het energieverbruik tijdens rust (REE) bij veel COPD-patiënten verhoogd is. Bij inactieve mensen bestaat het totale dagelijkse energieverbruik (TDE) voornamelijk uit het REE. De andere componenten van het TDE zijn de dieetgeïnduceerde thermogenese (DIT) en het energieverbruik tijlens activiteiten. Laatstgenoemde component is het meest variabel. Tot nu toe is er geen onderzoek verricht naar het TDE bij patiènten met COPD in de normale dagelijkse omgeving.

In hoofdstuk 4 is beschreven dat klinisch stabiele patiënten met COPD een significant hoger TDE hebben dan gezonde proefpersonen. Omdat het REE vergelijkbaar was tussen de bestudeerde groepen, kon het verschil in TDE toegeschreven worden aan het niet-REE gedeelte van het TDE, dat voornamelijk uit het energieverbruik tijdens activiteiten bestaat.

De invloed van een verhoogd REE op het TDE werd bestudeerd bij 20 klinisch stabiele COPD-patiënten (hoofdstuk 5). Er werd aangetoond dat het REE niet 
gerelateerd was aan het TDE bij patiẻnten met COPD, wammeer rekening gehouden werd met de invloed van de FFM op zowel het REE als het TDE. De resultaten wan deze twee onderzoeken tezamen gaven te zien dat het TDE toegenomen was bij patiënten met COPD, onathankelijk van het $\mathbb{R E E}$. Kennelijk was dus met name het energieverbruik tijdens activiteiten verhoogd. Mogelijke factoren die hebben kunnen bijdragen tot een toegenomen TDE zijn het gebruik van metabool-stimulerende medicatie, een veranderd spiermetabolisme, een (chronisch) inflammatoire status en een toegenomen zuurstofconsumptie bij het ademen. Hoewell in beide studies het energieverbruik voor activiteiten en het activiteiten-niveau indirect zijn gemeten, leidden $z i j$ tot de hypothese dat het energieverbruik voor een bepaalde activiteit verhoogd is bij patiënten met COPD.

Een uitgebreide analyse van de fysiologische consequenties van de 12 -minutenlooptest is beschreven in hoofdstuk 6. De 12-minuten-looptest is ontwikkeld on de effecten van de ziekte op het inspanningsvermogen en het dagelijks functioneren te kunnen $\mathrm{kwantificeren.} \mathrm{In} \mathrm{de} \mathrm{longrevalidatie} \mathrm{wordt} \mathrm{deze} \mathrm{test} \mathrm{veel} \mathrm{gebruikt,} \mathrm{maar} \mathrm{er} \mathrm{is}$ geen eenduidigheid over de fysiologische belasting die de 12 -minuten-looptest weroorzaakt bij COPD: met andere woorden, of deze test een submaximale inspanning is. In deze studie werden de metabole en de ventilatoire respons op de 12 -mimutenlooptest van patiënten met COPD vergeleken met die op een symptoom-gelimiteerde maximale fiets-ergometertest. Er was geen significant verschil aantoonbaar tussen beide testen, behalve dat een verhoogde koolstof-dioxide productie, lactaat-concentratie en respiratoir quotient tijdens fiets-ergometrie werden gevonden. De resultaten van deze studie doen sterk vermoeden dat de 12 minuten-looptest continu een relatief hoge metabole en ventilatoire belasting vormt voor patiënten met COPD, hetgeen gepaard gaat met an-äeroob metabolisme en een belangrijke afname in zuurstofsaturatic.

In het volgende onderzoek (hoofdstuk 7) werd de maximaal haalbare metabole respons gedurende inspanning op een fietsergoneter bij patiënten met COPD gerelateerd aan parameters van longfunctie en lichaamssamenstelling. Er werd gevonden dat de FFM-index (=FFM gecorrigeerd voor lichaamslengte) het meest correleerde met de symptoom-gelimiteerde maximale zuurstofconsumptie. De relatie cussen FFM-index en maximale zuurstofconsumptie was onafhankelijk van de diffusiecapaciteit. Er waren daarnaast aanwijzingen dat er een andere respons op maximale inspanning was bij patiënten met FFM-depletie als bij patiënten zonder FFM-depletie; dit ten aanzien van het teug-volume, het an-äerobe metabolisme en de cardiale respons op maximale inspanning.

In het laaste deel van dit proefschrift zijn drie studies beschreven aangaande de 
fysiologische respons op activiteiten bij patiênten met COPD: met andere woorden er is onderzocht wat de efficientie is waarmee energie in activiteiten wordt omgezet. In hoofdstuk 8 werd de mechanische efficiëntie onderzocht van een submaximale fietsinspanning. Mechanische efficientie is de verhouding tussen de geleverde arbeid en de energie die nodig is om die arbeid te verrichten. Deze kan berekend worden door het meten van het energieverbruik gedurende een submaximale fiets-ergometrie-test. In deze studie werd aangetoond dat een groot deel van de patiënten met COPD een aanzienlijk lagere efficiéntie had gedurende fiets-ergometrie dan theoretisch zou mogen worden verwacht. Wanneer de patiënten verdeeld werden in groepen met een lage en met een normale efficiëntie werd gevonden dat er tussen deze twee groepen met uitzondering van de luchtwegweerstand, geen verschillen waren in longfunctie, lichaamssamenstelling, symptoom-gelimiteerde maximale inspanningscapaciteit en rustmetabolisme. De conclusie van deze studie is dat een toegenomen ventilatoire respons en een grotere zuurstofconsumptie bij ademen waarschijnlijk bijdroegen tot een onevenredig hoog energieverbruik gedurende deze submaximale belasting. Andere mogelijke oorzaken, zoals bijvoorbeeld metabool stimulerende medicatie, moeten nog bestudeerd worden.

In een volgende studie werden indirecte aanwijzingen gevonden voor een afgenomen efficiëntie bij arm-inspanning waarbij de armen niet ondersteund werden (zoals arm-bewegingen bij de algemene dagelijkse activiteiten). In hoofdstuk 9 is beschreven dat een eenvoudige armelevatie bij patiënten met COPD tot een duidelijk andere (inefficiënte) metabole en ventilatoire respons leidde als bij gezonde proefpersonen. De patiënten met COPD hadden een tragere respons van het metabolisme en de ventilatie bij aanvang en bij herstel na 2 -minuten armelevatie. terwijl gezonde ouderen een korte piek vertoonden na armelevatie. Na correctie voor de hogere basale metabole en ventilatoire test-resultaten van de COPD-patiënten. tendeerde armelevatie bij patiènten met COPD naar een hogere metabole en ventilatoire respons dan die bij gezonde, oudere proefpersonen. Factoren die mogelijk zouden kunnen bijdragen aan deze inefficiëntere respons zijn het gebruik wan de schoudergordell-spieren voor zowell het ademen als voor de armbeweging, en/of een verminderde ademhalingsefficièntie. Het is bekend dat patiënten met COPD met name klagen over kortademigheid tijdens gebruikelijke arm-activiteiten, wat gedeeltelijk wellicht verklaard kan worden door de geobserveerde, inefficiënte metabole respons op arm-activiteiten.

Tenslotte werd in hoofdstuk 10 de rol besproken van de ademhalingsefficiëntie tijdens het in eerder onderzoek aangetoonde toegenomen energie-verbruik bij patiënten 
met COPD. De ademhalingsefficièntie werd berekend als zijnde de verhouding tussen de toename in energieverbruik en de toename in externe ademarbeid. De externe ademarbeid werd geeffectueerd door een inspiratoire drempelbelasting. De patiënten werd geinstrueerd hun ademminuutvolume gedurende de test niet te verhogen om het optreden van dynamische hyperinflatie te voorkomen. Deze leidt immers to een belangrijke verhoging van de ademarbeid, en dus tot een onevenredig grote zuurstofconsumptie bij ademen. Het feit dat in deze studie een vergelijkbare ademhalingsefficiëntie werd gevonden tussen patiënten met COPD en gezonde ouderen kan daarom mogelijk veroorzaakt zijn door de preventie van dynamische hyperinflatie. Daarnaast correleerde de ademhalingsefficiëntie niet significant met het $\mathbb{R E E}$.

Concluderend wordt gesteld dat de opgesomde resultaten van de studies in dit proefschrift er op wijzen dat het totale dagelijkse energieverbruik verhoogd is bij patiënten met COPD, met name gedurende lichamelijke inspanning. Hypermetabolisme draagt bij tot een negatieve energiebalans die leidt tot gewichtsverlies en uiteindelijk tot depletie van FFM. Depletie van FFM correleert negatief met inspanningstolerantie, onafhankelijk van de longfunctiestoornis. Een gecombineerde aanpak van zowel voeding als training is daarom van belang bij de behandeling van patiënten met COPD met gewichtsverlies of depletie van FFM. 
Tenslotte het dankwoord. Dat valt nog niet mee, want hoe pak je zoiets aan? Veel mensen hebben een steentje of steen bijgedragen aan de totstandkoming van dit proefschrift. Inmiddels zijn er bijna vijf jaren voorbij en het is merkwaardig hoe alles in die tijd op de een of andere manier verweven is met zo"n werk. Een puur formeel dankwoord lijkt niet toereikend om deze periode passend af te sluiten. Daarom heb ik besloten dit te schrijven zonder omwegen, zowel vanuit mijn herinnering, mijn verstand als mijn gevoel.

Er zijn twee mensen die ik als eersten wil noemen: Professor Wouters en Annemie Schols. Professor Wouters, uw bijjrage aan dit proefscluift, met name het bewaken van de lijn van het onderzoek en de hulp bij het schrijven van artikelen, was evident. Minder direct zichtbaar misschien, maar voortdurend voelbaar voor mij als AIO, was uw rol op de achtergrond. De vervulling van uw rol als promotor en uw zo nu en dan poëtische wijze van spreken, kunnen toepasselijk worden gelardeeerd met de woorden van de Libanese dichter Kahlil Gibran: "Zo hij inderdaad wijs is, nodigt hij je niet uit het huis van zijn wijsheid binnen te treden, maar leidt hij je naar de drempel van je eigen geest". Ook al heb ik mij weleens pijnlijk gestoten aan die drempel, uw wijsheid dwingt veel respect af en ik dank $U$ van harte voor uw gedreven begeleiding.

Annemie, zonder te overdrijven moet ik zeggen dat je een groot compliment verdient en dat ik je veel dank verschuldigd ben! Je hebt een groot wetenschappelijk inzicht en ik heb veel van je geleerd. Je geeft een enorm voorbeeld met je zelfdiscipline en betrokkenheid en je wekt als begeleider veel respect op omdat je heel consequent en zorgvuldig handelt. Ik wil je bedanken voor je persoonlijke en motiverende begeleiding, maar ook (heel belangrijk) voor de gezelligheid en het meeleven met ups en downs.

Natuurlijk wil ik alle proefpersonen en patiënten bedanken die mee hebben gewerkt, ondanks de moeheid of kortademigheid die met name de extra inspanningstesten met zich meebrachten. Zonder dleze mensen was dit onderzoek onmogelijk geweest.

Ik wil ook alle leden van de beoordelingscommissie bedanken voor de bereidheid om het proefschrift te lezen en te beoordelen.

Met veel plezier heb ik samengewerkt met iedereen wan de Stichting Homerheide, de vakgroep Humane Biologie en de vakgroep Pulmonologie: bedankı allemaal voor de hulp en leuke werksfeer! Enkele mensen wil ik graag met naam 
noemen: Paul (Janssen) van de afdeling fysiotherapie, bedankt voor je hulp en betrokkenheid de afgelopen jaren, jij bent één van de eerste mensen die ik leerde kennen op Hornerheide, en die me daar ook echt thuis heeft laten voelen. Ook alle andere mensen van deze afdeling, inclusief de bewegingsagogen en stagiaires bedanki voor het plezier, de samenwerking (met name Lucie) en het relativeren (Gerda...). Marco, dat jij ến van mijn paranimfen bent stond eigenlijk al lang voor mij vast: wanaf het begin was je altijd bereid te helpen, mee te denken en het werk een stuk aangenamer te maken: bedankt!

Het onderzoek op Hornerheide werd in belangrijke mate ondersteund door Rob (Mostert): bedankt voor je interesse, alle hulp en het meedenken. Natuurlijk ook Annelies, Peggy, Monique en Gonnie bedankt voor de gezelligheid, het plezier (!) en jullie hulp (of opvang). Ik heb ook de hulp van de verpleging, de centrale keuken en de voedingsassistenten (Truus en Alda) enorm gewaardeerd: allemaal bedankt!

In het bijzonder wil ik jou, Clarie bedanken woor je vriendschap, je enthousiasme, je optimisme, en alle practische oplossingen en hulp. Je hebt met me meegeleefd deze afgelopen jaren. Op de weg naar Hornerheide ligt inmiddels meer dan wat asfalt, nietwaar?

Esther en Tim, met jullie heb ik de eerste twee jaar een kamer gedeeld, dat schept een band: zeker de start met jou, Esther! Ook de andere AIO's: Solange, Veerle, Mariëlle, Jeske en Mieke bedankt voor de fijne werksfeer en de uitjes.

Voor de ademhalingsefficiëntie-opstelling moeten veel mensen worclen bedankt. Op de eerste plaats natuurlijk Chris (van der Grinten): bedankt voor al je hulp, ondanks mijn groeiende wanhoop. Professor Luijendijk: ook u wil ik bedanken voor uw adviezen ten aanzien van deze opstelling. Paul (Schoffelen), Loek (Wouters) maar vooral ook Ger (Stassen) en Alex (van der Hulst): bedankt voor de technische adviezen en de hulp. Francine (Bothmer-Quadvlieg) en Christa (Nusmeier) wil ik bedanken voor het meten van veel proefpersonen en patiënten en de gezellige samenwerking.

Wouter (Lichtenbelt) en Nel (Cox), leuk dat we af en toe onze hoofden bij elkaar hebben gestoken ten behoeve van het begrijpen van de achterliggende theorie van de bio-electrische impedantie: bedankt voor alle hulp! Klaas (Westerterp), ik heb het enorm gewaardeerd dat ik altijd even kon binnenlopen om weer een beetje wijzer naar buiten te gaan; bedankt voor de bijzonder prettige en efficiënte samenwerking. Mijnheer Kester, $u$ wil ik van harte bedanken voor de statistische hulp, waarvoor ik altijd zomaar langs mocht komen.

Ik wil een speciaal woord van dank richten tot mijn ouders. Pa en Ma, bedankt 
voor jullie onvoorwaardelijke steun; niet alleen als jullie jongste dochter, maar ook als (jongste) onderzoeker. Jullie staan altijd voor me klaar, zelfs als het gaat om het produceren van onderzoeksdata, of een proefschrift-layout. Ik ben een trotse en gelukkige dochter van zulke ouders!

Bedankt Willy en Alex, voor het delen van jullie ervaringen als promovendi: jullie goede raad en hulp waren onmisbaar. Agnes, Michel, Bart, Janneke, Loes, Ida, Max, vrienden en vriendimnen, de familie Meulensteen, Bastiaens c.s. allemaal bedankt voor jullie interesse en ontspanning gedurende deze (spannende) tijd.

Hendrikje, ik ben hardstikke blij met het ontwerp van de voorkant, dat je tussen al je eigen drukte en werk moest maken, bedankt! Eva, een extra bedankje voor jou natuurlijk: voor alle hulp, zorgzaamheid (eten..!) en vriendschap deze periode. Lieve Rob, in tijden van stress weet je altijd alles (heel rustig) in het juiste perspectief te plaatsen; jij staat ook altijd klaar om me te helpen, om vervelende dingen met me te delen, of om leuke dingen nog een beetje leuker te maken: veel dankbaarheid voor en geluk door jou. 
Baarends EM, Schols AMWJ, Slebos D, Mostert R, Janssen PP, Wouters EFM. Metabolic and ventilatory response pattern to arm elevation in patients with Chronic Obstructive Pulmonary Disease and healthy age-matched subjects. Eur. Repir. J. 1995; 8: $1345-1351$.

Baarends EM, Schols AMWJ, Pannemans DLE, Westerterp KR, Wouters EFM. Total free living energy expenditure in severe Chronic Obstructive Pulmonary Disease. Am. J. Repir. Crit. Care Med. 1997; 155: 549-554.

Baarends EM, Schols AMWJ, Marken-Lichtenbelt WD, Wouters EFM. Analysis of body water compartments in relation to tissue depletion in clinically stable patients with Chronic Obstructive Pulmonary Disease. Am. J. Clin. Nutr. 1997; 65: 88-94.

Marken Lichtenbelt van W, Kester A, Baarends EM, Westerterp KR. Bromide dilution in adults: optimal equilibration time after oral administration. J. Appl. Physiol. 1996; $81: 653-656$.

Baarends EM, Schols AMWJ, Westerterp KR, Wouters EFM. Total daily energy expenditure relative to resting energy expenditure in clinically stable patients with Chronic Obstructive Pulmonary Disease. Thorax, in press.

Baarends EM, Schols AMWJ, Mostert R, Janssen PP, Wouters EFM. Analysis of the metabolic and ventilatory response to 12 minute walking in patients with severe Chronic Obstructive Pulmonary Disease. J. Cardiopulm. Rehab., in press.

Baarends EM. Schols AMWJ, Mostert R, Wouters EFM. Peak exercise response in relation to tissue depletion in patients with severe Chronic Obstructive Pulmonary Disease. Eur. Respir. J., in press

Baarends EM, Schols AMWJ, Akkermans MA, Wouters EFM. Decreased mechanical efficiency in clinically stable patients with Chronic Obstructive Pulmonary Disease. Thorax, in press. 
Erica Baarends werd geboren op 9 maart 1970 te Steenbergen (Noord-Brabant). In 1988 behaalde zij het VWO diploma aan het Dukenburg College in Nijmegen. In datzelfde jaar begon zij met de studie Gezondheidswetenschappen aan de Universiteit Maastricht, met als afstudeerrichting Bewegingswetenschappen. Het doctoraalexamen werd behaald in oktober 1992 a een stage op het Astmacentrum Hornerheide (Hom). Op november 1992 begon zij als assistent in opleiding (AIO) bij de vakgroep Pulmonologie (Prof. dr, E.F.M. Wouters) van de Universiteit Maastricht. Het in dit proefschrift beschreven AIO project, gesubsidieerd door het Nederlands Astma Fonds, werd uitgevoerd in nauwe samenwerking met het Astmacentrum Homerheide en de vakgroep Humane Biologie van de Universiteit Maastricht. Momenteel is zij als postdoc aangesteld bij vakgroep Pulmonologie van de Universiteit Maastricht. 
